\title{
DEVELOPMENT OF GREEN GEOPOLYMER BINDERS BASED ON CONSTRUCTION AND DEMOLITON WASTES
}

By

\section{Obaid U Rahman Mahmoodi}

B.Sc., Nangarhar University, 2008

\author{
A thesis \\ presented to Ryerson University \\ in partial fulfillment of the requirements for the degree of \\ Master of Applied Science \\ in the program of \\ Civil Engineering
}

Toronto, Ontario, Canada, 2019

CObaid Mahmoodi, 2019 


\section{AUTHOR'S DECLARATOIN}

I hereby declare that I am the sole author of this thesis. This is a true copy of the thesis including my required final revisions, as accepted by examiners.

I authorize Ryerson University to lend this thesis to other institutions or individuals for the purpose of scholarly research.

I further authorize Ryerson University to reproduce this thesis by photocopying or by other means, in total or in part, at the request of other institutions or individuals for the purpose of scholarly research.

I understand that my thesis may be made electronically available to the public. 


\title{
DEVELOPMENT OF GREEN GEOPOLYMER BINDERS BASED ON \\ CONSTRUCTION AND DEMOLITON WASTES
}

\author{
Obaid U Rahman Mahmoodi \\ Master of Applied Science, 2019 \\ Department of Civil Engineering, Ryerson University
}

\begin{abstract}
This research focuses on the complete recycling of construction and demolition wastes (CDWs) to develop new green geopolymeric binders. An innovative mix design method based on $\left(\mathrm{SiO}_{2} / \mathrm{Al}_{2} \mathrm{O}_{3}\right)$ and $\left(\mathrm{Na}_{2} \mathrm{O} / \mathrm{SiO}_{2}\right)$ chemical factors and liquids/solids (L/S) ratio was developed. The main focus was to optimize the compressive strengths of mixes incorporating mono, binary and ternary geopolymer systems of concrete waste $(\mathrm{CW})$, red clay brick waste $(\mathrm{RCBW})$ and ceramic tile waste $(\mathrm{CTW})$. The effects of high temperature curing and the addition of supplementary cementitious materials (SCMs) were also investigated. Fresh properties comprising slump flow and setting time and mechanical characteristics including compressive strengths were investigated. Microstructural study was performed utilizing scanning electron microscopy (SEM), energy-dispersive X-Ray spectroscopy (EDS) and X-Ray Diffraction (XRD). This research proved the efficiency of the new mix design method in reaching high compressive strengths of mono-system of RCBW and CTW and all binary and ternary systems of geopolymer binders.
\end{abstract}




\section{ACKNOWLEDGEMENTS}

I would like to express my deepest gratitude to my supervisor Dr. Mohamed Lachemi for providing support, inspiration, motivation and continued encouragement during my MASc studies and this research program.

I wish to express sincere gratitude to Dr. Hocine Siad as my co-supervisor for this research study. He has been instrumental in the development and implementation of this research. Without his motivation, countless proof readings, corrections and support this document would not have been possible.

I would like to thank Dr. Medhat Shehata and Dr. Anwar Hossain for accepting to be part of the examination committee of my MASc defense and for their valuable time and insights.

I would also like to thank my friend Sina Dadsetan for his continuous support, guidance and countless hours together spent on the development of mix design methodology for geopolymers.

In addition, I am grateful to all my teachers who have taught me and provided me with a wealth of knowledge.

Finally, I wish to express my gratitude to my mother and to Uncle Shamel Mahmoodi who have always nurtured and supported me. 


\section{TABLE OF CONTENTS}

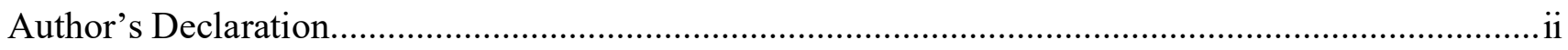

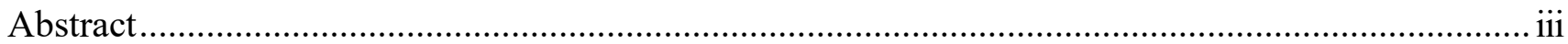

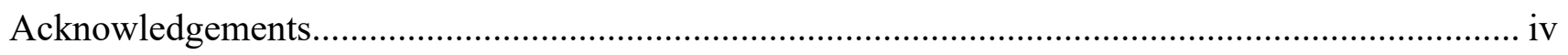

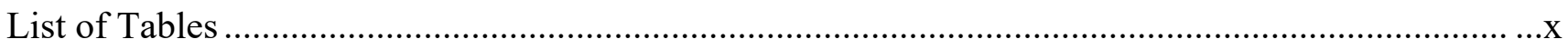

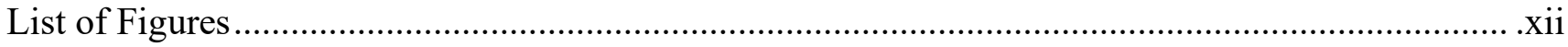

Symbols and Abbreviations................................................................

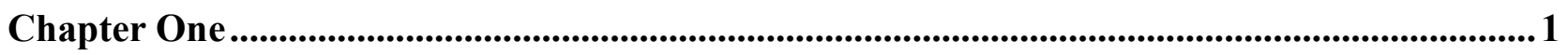

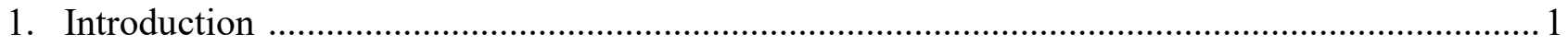

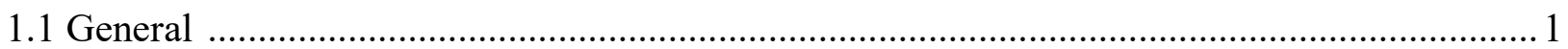

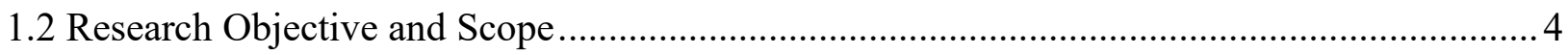

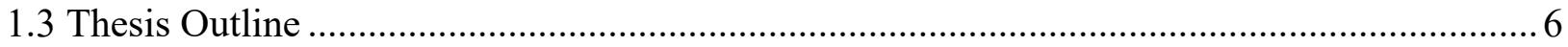

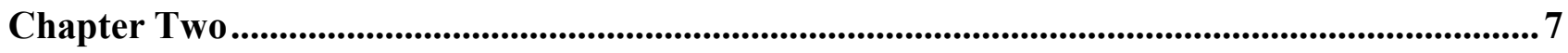

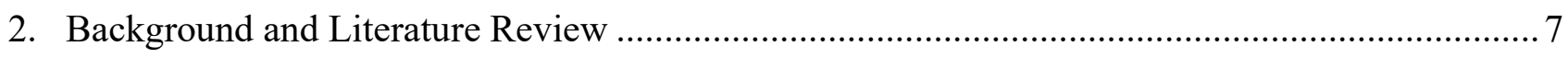

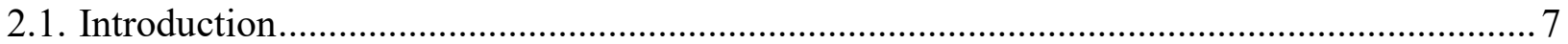

2.2. Overview and Historical Development of Geopolymers and Alkali-Activated Materials ...... 7

2.3. Geopolymer and Alkali-activated Binders, Synthesis, Process and Mechanism .................. 9

2.4. Reaction Products of Geopolymer and Alkali-Activated Materials .................................. 15

2.5. Factors Influencing the Geopolymerisation Process .................................................... 16

2.6. Classification and Characteristics of Alkali-Activated Binders ........................................20

2.6.1. Alkali-activated Slag Based Cement ................................................................... 20

2.6.2. Alakli-activated Pozzolan Cements ........................................................................... 21

2.6.3. Alakli-activated Lime-Pozzolan/slag Cements ..................................................... 22

2.6.4. Alakli-Activated Calcium Aluminate Blended Cements ...........................................22

2.6.5. Alakli-Activated Potland Blended Cements: Hybrid Cements................................. 23

2.7. Construction and Demolition Wastes (CDWs) Based Geopolymers .................................23

2.7.1. Literature Review on the Use of CDWs in Geopolymer Systems ..............................24

2.7.2. Effect of Particle Size of CDW Powders .....................................................................2

2.7.3. Effects of $\mathrm{NaOH}$ Concentration of CDW-based Geopolymers ...................................28

2.7.4. Influence of $\mathrm{SiO}_{2} / \mathrm{Na}_{2} \mathrm{O}$ Molar Ratio of the Geopolymer System ..............................31 
2.7.5. Influence of Water/Binder (w/b) Ratio of Geopolymer Binders

2.7.6. Effect of High Temperature Curing .................................................................... 34

2.7.7. Effect of Other Parameters....................................................................................... 36

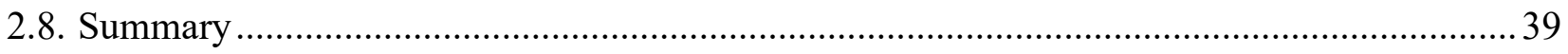

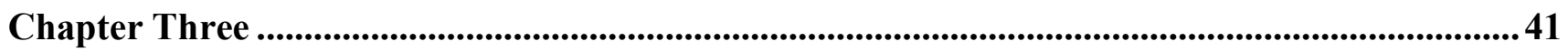

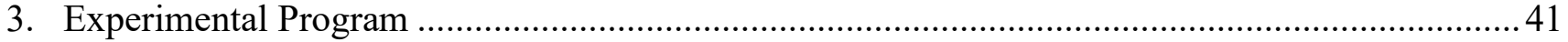

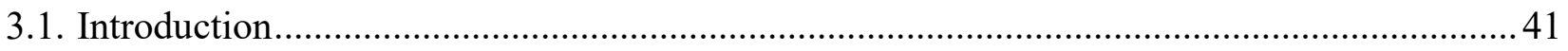

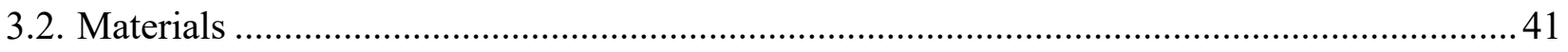

3.2.1. Selection and Preparation of CDW Materials........................................................ 41

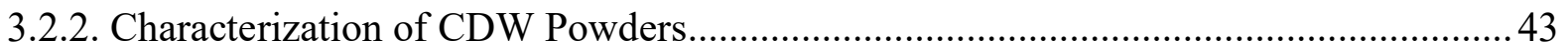

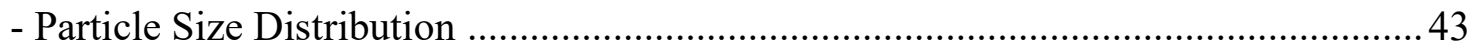

- Chemical Composition and Physical Properties of CDW Powders .......................... 44

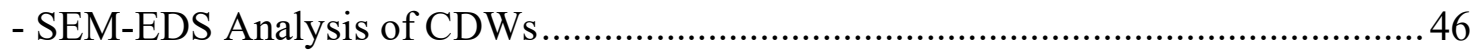

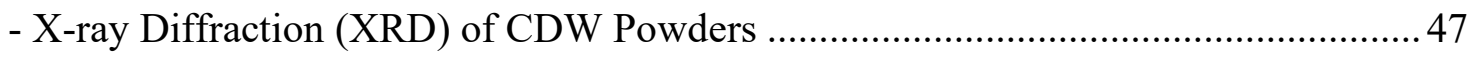

3.2.3. Characterization of Supplementary Cementitious Materials (SCMs) ........................47

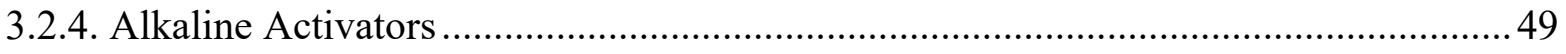

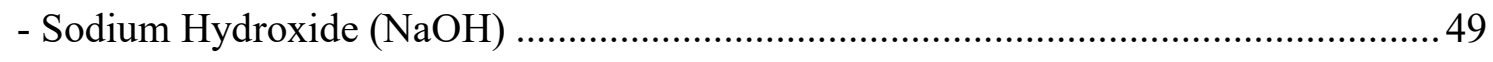

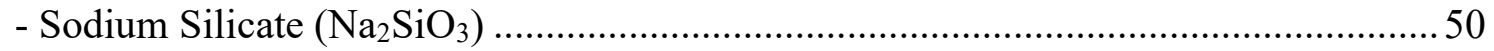

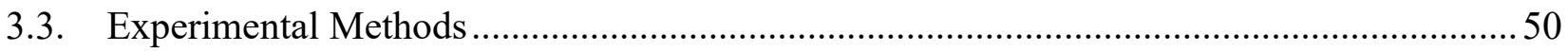

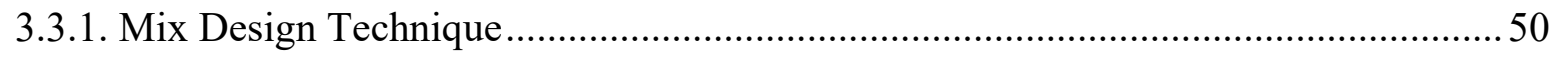

3.3.2. Preparation of Sodium Hydroxide $(\mathrm{NaOH})$ Solution............................................52

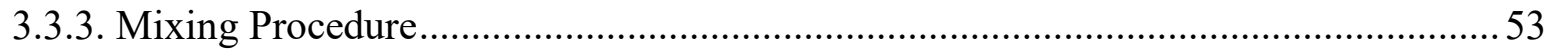

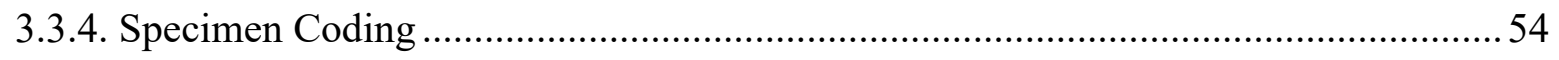

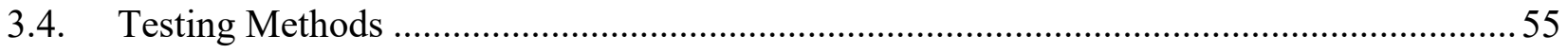

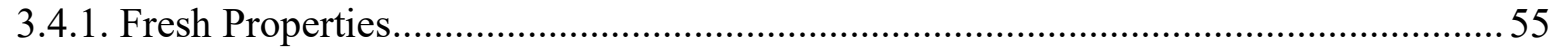

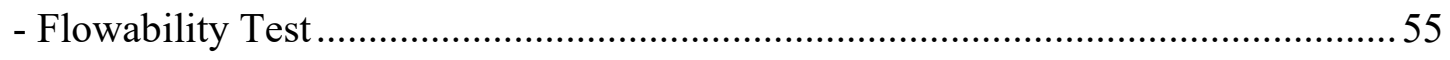

- Time of Setting of Geopolymer Binders ..................................................... 55

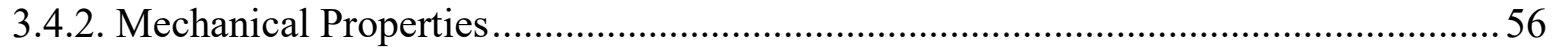

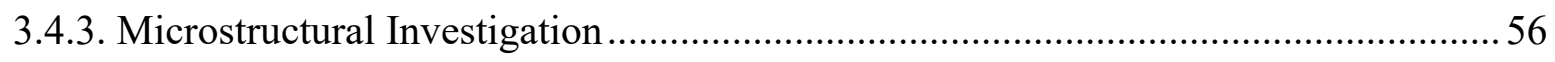

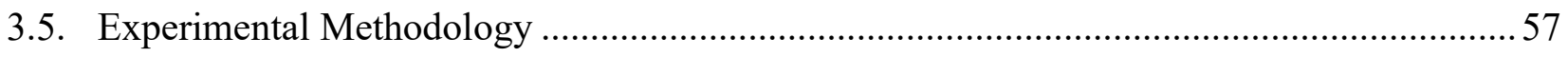

Chapter Four ............................................................................................................................................59

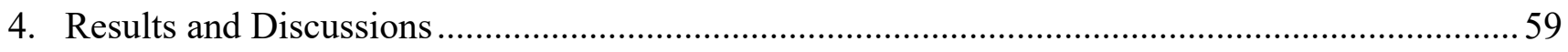


4.1. Introduction

4.2. Determination of Different Mix Compositions …................................................................59

4.2.1. Mono-system Geopolymer Composition.............................................................5

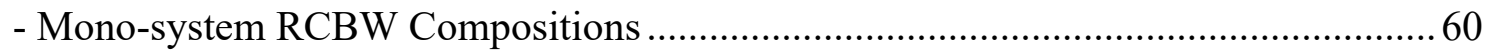

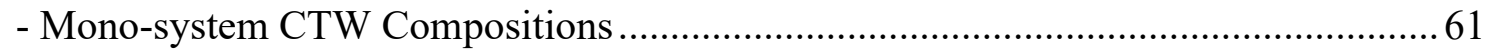

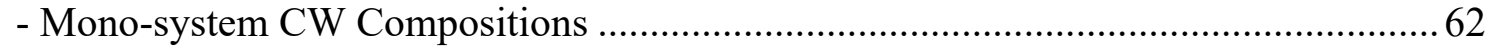

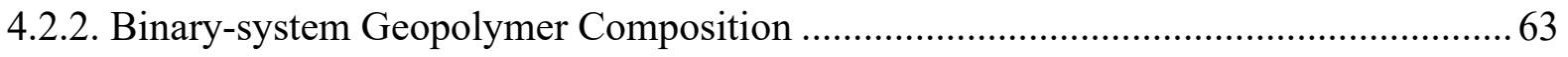

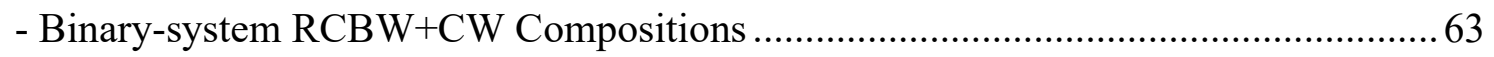

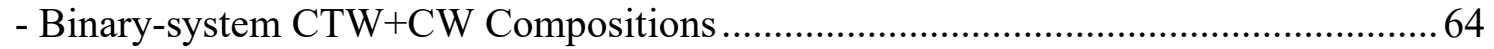

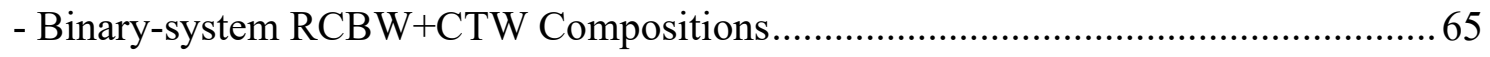

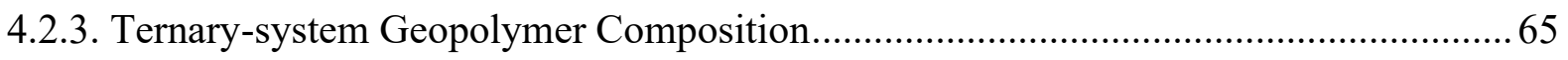

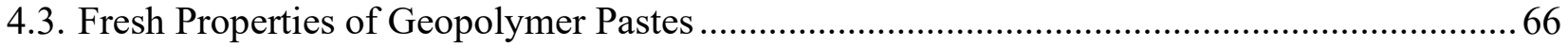

4.3.1. Fresh Properties of Mono-system Compositions ................................................. 66

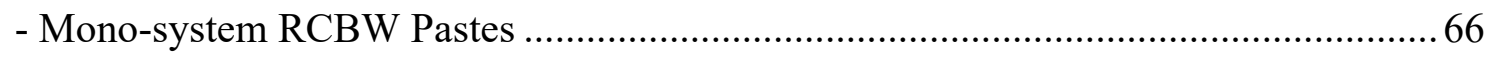

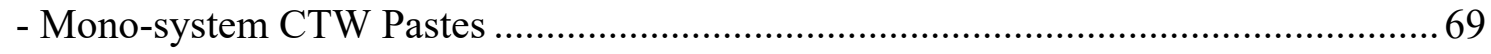

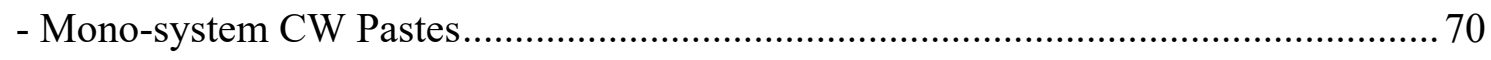

4.3.2. Fresh Properties of Binary-system Compositions.................................................. 72

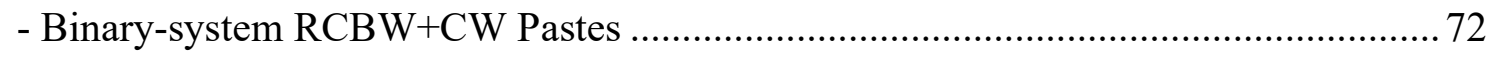

- Binary-system CTW+CW Pastes ..................................................................... 74

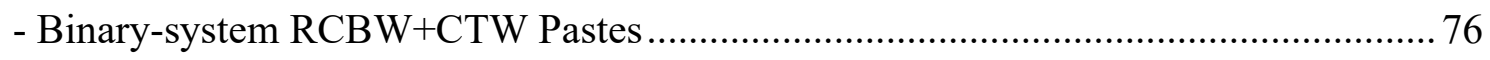

4.3.3. Fresh Properties of Ternary-system Compositions................................................ 77

4.4. Mechanical Strengths at Ambient Temperature Curing ................................................. 81

4.4.1. Mechanical Strengths of Mono-system Compositions .......................................... 81

- Mechanical Strengths of Mono-system RCBW Geopolymers .................................81

- Mechanical Strengths of Mono-system CTW Geopolymers.................................... 83

- Mechanical Strengths of Mono-system CW Geopolymers ..................................... 85

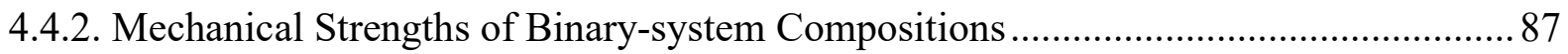

- Mechanical Strengths of Binary-system RCBW+CW Geopolymers......................... 87

- Mechanical Strengths of Binary-system CTW+CW Geopolymers........................... 88

- Mechanical Strengths of Binary-system RCBW+CTW Geopolymers ......................89

4.4.3. Mechanical Strengths of Ternary-system Compositions ........................................ 91

4.5. Effect of High Temperature Curing on Mechanical Strengths ........................................... 94 
4.5.1. Effect of High Temperature Curing on Mono-system Geopolymers 94

- Effect of High Temperature Curing on Mono-system RCBW Geopolymers .............94

- Effect of High Temperature Curing on Mono-system CTW Geopolymers .................95

- Effect of High Temperature Curing on Mono-system CW Geopolymers...................96

4.5.2. Effect of High Temperature Curing on Binary-system Geopolymers .........................97

- Effect of High Temperature Curing on Binary-system RCBW+CW Geopolymers ...97

- Effect of High Temperature Curing on Binary-system CTW+CW Geopolymers ...... 98

- Effect of High Temperature Curing on Binary-system RCBW+CTW Geopolymers.99

4.5.2. Effect of High Temperature Curing on Ternary-system Geopolymers

4.6. Effect of Adding Supplementary Cementitious Materials (SCMs) into CDW-based

Geopolymers

4.6.1. Effect of the Addition of SCMs on the Strengths of Mono-system Geopolymers

- Effect of the Addition of SCMs on the Strengths of Mono-system RCBW

Geopolymers.

- Effect of the Addition of SCMs on the Strengths of Mono-system CTW

Geopolymers.

- Effect of the Addition of SCMs on the Strengths of Mono-system CW

Geopolymers....

4.6.2. Effect of the Addition of SCMs on the Strengths of Binary-system Geopolymers 108

- Effect of the Addition of SCMs on the Strengths of Binary-system RCBW+CW

Geopolymers

- Effect of the Addition of SCMs on the Strengths of Binary-system CTW+CW

Geopolymers.

- Effect of the Addition of SCMs on the Strengths of Binary-system RCBW + CTW

Geopolymers

4.6.3. Effect of the Addition of SCMs on the Strengths of Ternary-system RCBW+CTW+CW geopolymers

4.7. Microstructural Characterization and Discussions

4.7.1. X-Ray Diffraction Analysis

- XRD Analysis of Mono-system CDW Pastes

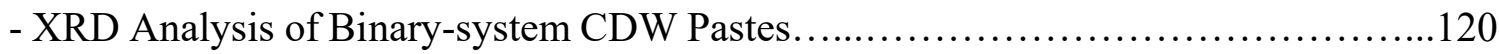

- XRD Analysis of Ternary-system CDW Pastes 
- XRD Analysis of Mono-system CDW Pastes Incorporating Different SCMs.........123

- XRD Analysis of Binary-system CDW Pastes Incorporating Different SCMs.........125

4.7.2. Scanning Electron Microscopy (SEM) and EDS Analysis....................................... 127

- SEM-EDS Analysis of Mono-system CDW Pastes........................... 128

- SEM-EDS Analysis of Binary-system CDW Pastes............................ 130

- SEM-EDS Analysis of Ternary-system CDW Pastes...........................133

- SEM-EDS Analysis of Mono-system CDW Pastes Incorporating Different SCMs....134

- SEM-EDS Analysis of Mono-system CDW Pastes Incorporating Different SCMs....137

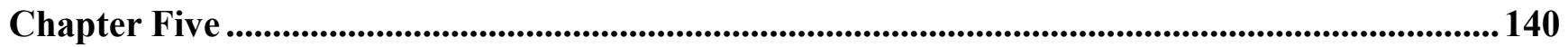

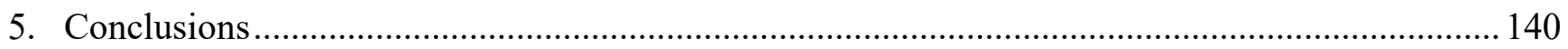

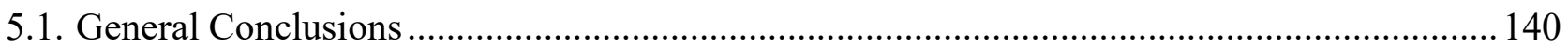

5.2. Recommendations for Future Research...................................................................... 144

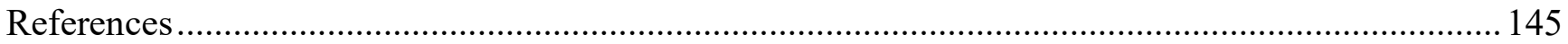




\section{LIST OF TABLES}

Table 2-1: Products precipitating in different types of binders (Garcia-Lodeiro et al., 2014)............19

Table 2-2: Summary of Research Papers studied the use of CDWs in geopolymer systems.............25

Table 3-1: Mean particle size, D10, D50 and D90 of CDWs and SCMs Utilized in this research.......44

Table 3-2: Chemical composition of CDWs and SCMs by XRF analysis.........................45

Table 3-3: Chemical composition and physical properties of SCMs $\ldots \ldots \ldots \ldots \ldots \ldots \ldots \ldots \ldots \ldots \ldots \ldots . \ldots \ldots$

Table 3-4: Properties of sodium hydroxide pellets........................................49

Table 3-5: Properties of sodium silicate solution.........................................50

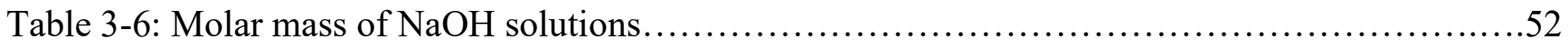

Table 3-7: Amount of solid $\mathrm{NaOH}$ and water content in one-liter $\mathrm{NaOH}$ solution....................53

Table 3-8: Coding examples of geopolymer specimens...................................5

Table 4-1: Mix proportions of mono RCBW Geopolymers......................................

Table 4-2: Mix Proportions of mono-system CTW Geopolymers...............................62

Table 4-3: Mix Proportions of mono-system CW Geopolymers................................63

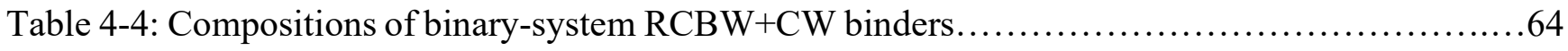

Table 4-5: Compositions of binary-system CTW+CW binders...............................64

Table 4-6: Compositions of binary-system RCBW+CTW binders ..............................65

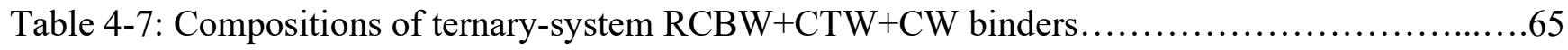

Table 4-8: Compressive strengths of mono-system RCBW binders $\ldots \ldots \ldots \ldots \ldots \ldots \ldots \ldots \ldots \ldots \ldots \ldots . \ldots 2$

Table 4-9: Compressive strengths of mono-system CTW binders..............................84

Table 4-10: Compressive strengths of mono-system CW binders............................. 85

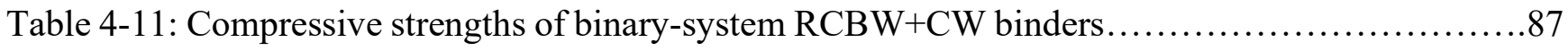

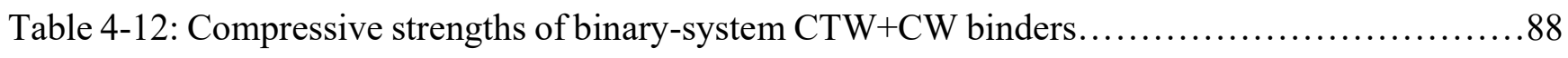


Table 4-13: Compressive strengths of binary-system RCBW+CTW binders......................89

Table 4-14: Compressive strengths of ternary-system RCBW+CTW+CW binders..................92

Table 4-15: Compressive strengths of mono-system RCBW binders $\ldots \ldots \ldots \ldots \ldots \ldots \ldots \ldots \ldots \ldots \ldots \ldots$

Table 4-16: Compressive strengths of mono-system CTW binders............................. 105

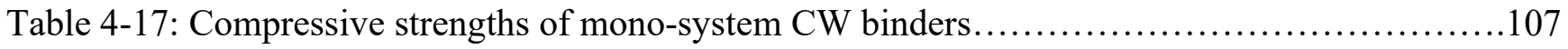

Table 4-18: Compressive strengths of binary-system RCBW+CW binders......................... 109

Table 4-19: Compressive strengths of binary-system CTW+CW binders.........................111

Table 4-20: Compressive strengths of binary-system RCBW+CTW binders ......................113

Table 4-21: Compressive strengths of ternary-system RCBW+CTW $+\mathrm{CW}$ binders.................115 


\section{LIST OF FIGURES}

Figure 2-1: Schematic diagram of conceptual model of alkali-activation of aluminosilicate precursor (J.

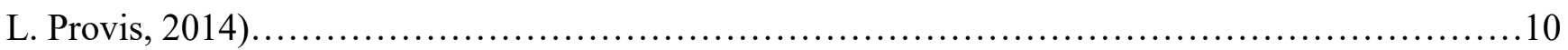

Figure 2-2: Schematic diagram of tobermorite-like structure of Calcium based aluminosilicate gel (Richardson, 2004).

Figure 2-3: Model proposed for N-A-S-H gel formation (Shi et al., 2011).

Figure 2-4: Descriptive model for alkali-activation of aluminosilicates (Fernandez-Jiminez and Palomo, 2005; Shi et al., 2011)........................................................... 13

Figure 2-5: Poly(sialate) geopolymeric structure according to Davidovits ( Davidovits, 1991; PachecoTorgal et al., 2008) ............................................................... 14

Figure 2-6: Conceptual model for geopolymerization (Duxson et al. 2007).......................15

Figure 2-7: Plan view projection of the three-dimensional structure of a N-A-S-H gel (Garcia-Lodeiro et

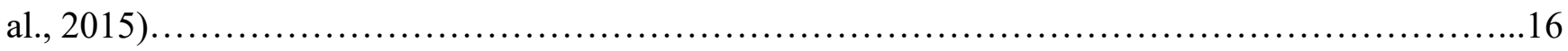

Figure 2-8: Theoretical model for the reaction mechanism in alkali activated slag (Glasser. 1990; Garcia-

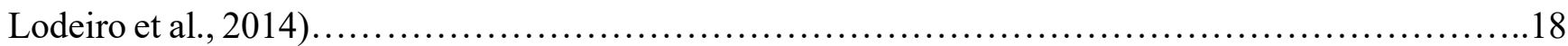

Figure 2-9: Strength development of alkali-activated slag and Portland cement mortars (Shi et al.,

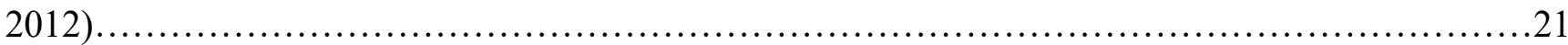

Figure 2-10: The positions of most concrete waste (CW), red clay brick waste (RCBW), tile, class F Fly ash (FAF), ground granulated blast furnace slag (GGBS), silica fume (SF), and Metakaolin (MK) in the triangular chemical compounds (Dadsetan et al. 2019).

Figure 2-11: Effect of particle size of raw materials on the compressive strength of geopolymers produced from (a) tiles (b) bricks and (c) concrete waste (Komnitsas et al. 2015) ...........................28

Figure 2-12: Effect of $\mathrm{NaOH}$ molarity on the compressive strengths of alkali-activated CDW materials (RT: room temperature, 60 and 80: curing at $60^{\circ} \mathrm{C}$ and $80^{\circ} \mathrm{C}$ ) (Dadsetan et al. 2019).................29

Figure 2-13: Influence of $\mathrm{NaOH}$ solution on compressive strength of alkali activated RCBW mortars cured 3 and 7 days at $65 \mathrm{C}$ (Reig et al. 2013b). 30

Figure 2-14: Development of the compressive strength of geopolymers produced from (a) tiles,

(b) bricks and (c) concrete vs. $\mathrm{NaOH}$ concentration and curing temperature (Komnitsas et al., 
Figure 2-15:The effect of $\mathrm{SiO} 2 / \mathrm{Al} 2 \mathrm{O} 3$ molar ratio on the compressive strengths of CDW materials (Dadsetan et al. 2019)...... .32

Figure 2-16: Influence of $\mathrm{SiO} / \mathrm{Na} 2 \mathrm{O}$ molar ratio on the compressive strength, for a constant 5 molal $\mathrm{Na}+$ concentration (Reig et al. 2013b)..... .33

Figure 2-17: Influence of w/b ratio on compressive strength of alkali activated RCBW (Reig et al., 2013b). 34

Figure 2-18: Effect of curing temperature and $\mathrm{Na} 2 \mathrm{O}(\mathrm{NaOH}$ sole activator) concentration on the compressive strength of RCBW geopolymers (Robayo et al. 2016). .35

Figure 2-19: Compressive strengths of RCBW, $\mathrm{CW}$ and $\mathrm{GW}$ activated with $\mathrm{NaOH}$ and/or Sodium silicate and cured at 25 and $70 \mathrm{oC}$ temperature (Robayo-Salazar et al., 2017) ........................

Figure 2-20: Effect of $\mathrm{SiO} 2 / \mathrm{Al} 2 \mathrm{O} 3$ and $\mathrm{Na} 2 \mathrm{O} / \mathrm{SiO} 2$ ratios on the compressive strength of $100 \% \mathrm{RCBW}$ at $25 \mathrm{C}$ at 28 days (sodium silicate + sodium hydroxide as activators) (Robayo et al. 2016) ..............37

Figure 2-21: (a) Effect of $\mathrm{Na} 2 \mathrm{O}$ concentration on final setting time (b) Effect of $\mathrm{Na} 2 \mathrm{O}$ concentration on

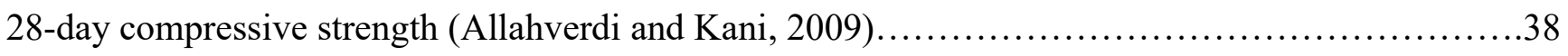

Figure 2-22: Compressive strength of lkali-activated pastes with different RCBW/GBFS ratios and

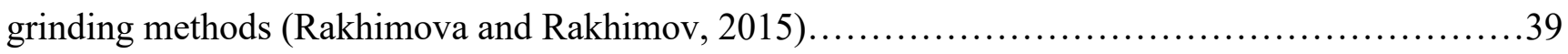

Figure 3-1: (a) Construction and Demolition Wastes (CDWs) classified into (b) Red Clay Brick Waste (RCBW), (c) Concrete Waste (CW) and (d) Ceramic Tile Waste (CTW) .........................42

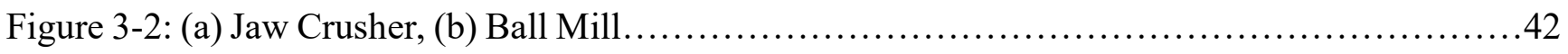

Figure 3-3: Crushed RCBW (a.1) powdered RCBW (b) crushed CTW (b.1) powdered CTW (c) crushed

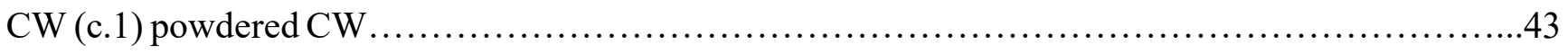

Figure 3-4: Particle size distribution of CW, RCBW and CTW powders..........................44

Figure 3-5: The position of $\mathrm{CW}, \mathrm{RCBW}$ and $\mathrm{CTW}$ powders compared to those studied in the

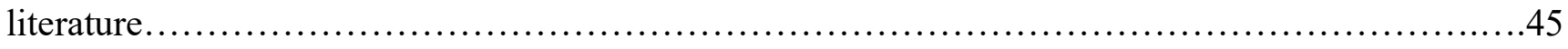

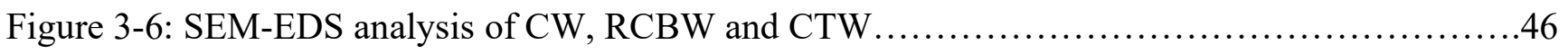

Figure 3-7: XRD patterns of concrete, red clay brick and ceramic tile wastes (Q: Quartz; Mt: Montmorillonite, Ms: Muscovite; Al: Albite).............................................. 47

Figure 3-8: Particle size distribution of FA-F, GBBS, MK and Fly Ash-C .........................48 
Figure 3-9: Sodium hydroxide pellets.

Figure 3-10: Flowchart of sequential mix design method 51

Figure 3-11: Mixing procedures of geopolymer binders Mixing procedures of geopolymer binders...54

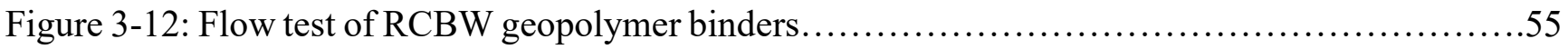

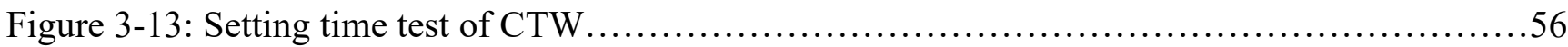

Figure 3-14: Curing of CDW geopolymer specimens.....................................56

Figure 3-15: JEOL JSM-6380LV Scanning Electron Microscope and EDS.......................57

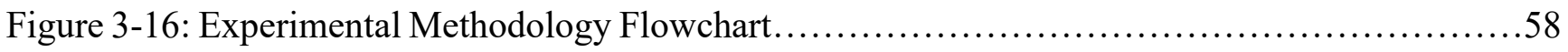

Figure 4-1: Flow diameter of mono-system RCBW geopolymers $\ldots \ldots \ldots \ldots \ldots \ldots \ldots \ldots \ldots \ldots \ldots \ldots \ldots 7$

Figure 4-2: Initial and final setting times of mono-system RCBW geopolymers...................68

Figure 4-3: Flow diameter of mono-system CTW geopolymers...............................69

Figure 4-4: Initial and final setting times of mono-system CTW geopolymers $\ldots \ldots \ldots \ldots \ldots \ldots \ldots \ldots . \ldots 70$

Figure 4-5: Flow diameter of mono-system $\mathrm{CW}$ geopolymers............................... 71

Figure 4-6: Initial and final setting times of mono-system CW geopolymers.......................72

Figure 4-7: Flow diameter of binary-system RCBW+CW geopolymers.........................73

Figure 4-8: Initial and final setting times of binary-system RCBW $+\mathrm{CW}$ geopolymers................74

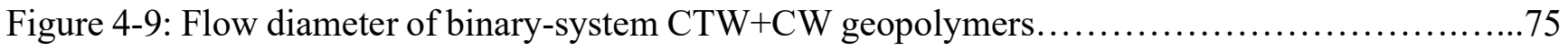

Figure 4-10: Initial and final setting times of binary-system CTW $+\mathrm{CW}$ geopolymers................75

Figure 4-11: Flow diameter of binary-system RCBW+CTW geopolymers $\ldots \ldots \ldots \ldots \ldots \ldots \ldots \ldots \ldots \ldots 77$

Figure 4-12: Initial and final setting times of binary-system RCBW+CTW geopolymers............77

Figure 4-13: Flow diameter of ternary-system RCBW+CTW+CW geopolymers...................79

Figure 4-14: Initial and final setting times of ternary-system $\mathrm{RCBW}+\mathrm{CTW}+\mathrm{CW}$ geopolymers........80

Figure 4-15: Effect of $\mathrm{SiO} 2 / \mathrm{A} 12 \mathrm{O} 3$ and $\mathrm{Na} 2 \mathrm{O} / \mathrm{SiO} 2$ ratios on the strengths of mono-system $\mathrm{RCBW}$

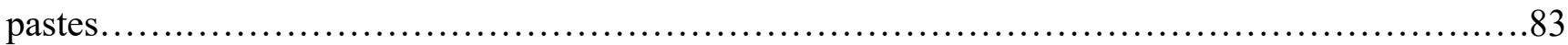


Figure 4-16: Effect of $\mathrm{SiO} 2 / \mathrm{A} 12 \mathrm{O} 3$ and $\mathrm{Na} 2 \mathrm{O} / \mathrm{SiO} 2$ ratios on the strengths of mono-system CTW pastes. 84

Figure 4-17: Effect of $\mathrm{SiO} 2 / \mathrm{A} 12 \mathrm{O} 3$ and $\mathrm{Na} 2 \mathrm{O} / \mathrm{SiO} 2$ ratios on the strengths of mono-system $\mathrm{CW}$ pastes. .86

Figure 4-18: Effect of $\mathrm{SiO}_{2} / \mathrm{Al}_{2} \mathrm{O}_{3}$ and $\mathrm{Na}_{2} \mathrm{O} / \mathrm{SiO}_{2}$ ratios on the strengths of binary $\mathrm{RCBW}+\mathrm{CW}$ pastes. 87

Figure 4-19: Effect of $\mathrm{SiO}_{2} / \mathrm{Al}_{2} \mathrm{O}_{3}$ and $\mathrm{Na}_{2} \mathrm{O} / \mathrm{SiO}_{2}$ ratios on the strengths of binary $\mathrm{CTW}+\mathrm{CW}$ pastes.

Figure 4-20: Effect of $\mathrm{SiO}_{2} / \mathrm{Al}_{2} \mathrm{O}_{3}$ and $\mathrm{Na}_{2} \mathrm{O} / \mathrm{SiO}_{2}$ ratios on the strengths of binary $\mathrm{RCBW}+\mathrm{CTW}$ pastes. .90

Figure 4-21: Effect of $\mathrm{SiO}_{2} / \mathrm{Al}_{2} \mathrm{O}_{3}$ and $\mathrm{Na}_{2} \mathrm{O} / \mathrm{SiO}_{2}$ on the strengths of ternary $\mathrm{RCBW}+\mathrm{CTW}+\mathrm{CW}$ pastes.

Figure 4-22: Effect of high temperature curing on compressive strengths of mono RCBW geopolymers.

Figure 4-23: Effect of high temperature curing on compressive strengths of mono CTW geopolymers. .96

Figure 4-24: Effect of high temperature curing on compressive strengths of mono CW geopolymers.

Figure 4-25: Effect of high temperature curing on strengths of binary RCBW+CW geopolymers......98

Figure 4-26: Effect of high temperature curing on strengths of binary $\mathrm{CTW}+\mathrm{CW}$ geopolymers 99

Figure 4-27: Effect of high temperature curing on strengths of binary RCBW+CTW geopolymers....100

Figure 4-28: Effect of high temperature curing on strengths of ternary $\mathrm{RCBW}+\mathrm{CTW}+\mathrm{CW}$ geopolymers

Figure 4-29: Effect of SCMs on strength development of mon RCBW geopolymers.................104

Figure 4-30: Effect of SCMs on strength development of mono CTW geopolymers 106

Figure 4-31: Effect of SCMs on strength development of mono CW geopolymers..................108

Figure 4-32:Effect of SCMs on strength development of binary RCBW+CW geopolymers 110

Figure 4-33: Effect of SCMs on strength development of binary CTW+CW geopolymers.... 112 
Figure 4-34: Effect of SCMs on strength development of binary RCBW+CTW geopolymers

Figure 4-35: Effect of SCMs on strength development of ternary RCBW+CTW+CW geopolymers...116

Figure 4-36: XRD patterns of RCBW powder, RCBW at high temp, highest strength RCBW, lowest strength RCBW.

Figure 4-37: XRD patterns of RCBW powder, RCBW at high temp, highest strength RCBW, lowest strength RCBW.

Figure 4-38: XRD patterns of $\mathrm{CW}$ powder, $\mathrm{CW}$ at high temp, highest strength $\mathrm{CW}$ and lowest strength $\mathrm{CW}$ geopolymer binder.

Figure 4-39: XRD patterns of binary $\mathrm{RCBW}+\mathrm{CW}$ geopolymer binders 121

Figure 4-40: XRD patterns of binary CTW+CW geopolymer binders. 121

Figure 4-41: XRD patterns of binary $\mathrm{RCBW}+\mathrm{CTW}$ geopolymer binders. 122

Figure 4-42: $\mathrm{XRD}$ patterns of ternary $\mathrm{RCBW}+\mathrm{CTW}+\mathrm{CW}$ geopolymers. 123

Figure 4-43: XRD patterns of mono RCBW+SCMs 124

Figure 4-44: XRD patterns of mono CTW+SCMs .124

Figure 4-45: XRD patterns of mono CW+SCMs. 125

Figure 4-46: XRD patterns of binary $(\mathrm{RCBW}+\mathrm{CW})+\mathrm{SCMs}$ 126

Figure 4-47: XRD patterns of binary $(\mathrm{CTW}+\mathrm{CW})+\mathrm{SCMs}$ 126

Figure 4-48: XRD patterns of binary $(\mathrm{RCBW}+\mathrm{CTW})+\mathrm{SCMs}$ 127

Figure 4-49: SEM micrograph of mono RCBW geopolymers (a) B-7.1-0.24-0.30 (highest) (b) B-7.70.16-0.3 (lowest). 128

Figure 4-50: SEM micrograph of mono CTW geopolymers (a) T-11.1-0.20-0.30 (highest) (b) T-11.50.14-0.30 (lowest).

Figure 4-51: SEM micrograph of mono CW geopolymers (a) CW-12.9-0.23-0.30 (highest) (b) CW-13.20.35-0.30 (lowest). .130

Figure 4-52: SEM micrograph of binary RCBW+CW geopolymers (a) BC-8.4-0.18-0.30 (highest) (b) BC-7.7-0.24-0.30 (lowest).

Figure 4-53: SEM micrograph of binary $\mathrm{CTW}+\mathrm{CW}$ geopolymers (a) TC-12.3-0.18-0.30 (highest) (b) xvi 
Figure 4-54: SEM and EDS micrograph of binary RCBW+CTW geopolymers (a) BT-10-0.24-0.30 (highest) (b) TC-8.4-0.18-0.30 (lowest).....

Figure 4-55: SEM and EDS micrograph of ternary RCBW+CTW+CW geopolymers (a) BCT-102-0.180.30 (highest) (b) BCT-7.6-0.24-0.30 (lowest).

Figure 4-56: SEM and EDS micrograph of mono RCBW with SCMs (a) RCBW+FAC (b) RCBW+FAF (c) $\mathrm{RCBW}+\mathrm{MK}$ and (d) RCBW+GBFS. 135

Figure 4-57: SEM and EDS micrograph of mono CTW with SCMs (a) CTW+FAC (b) CTW+FAF (c) $\mathrm{CTW}+\mathrm{MK}$ and (d) $\mathrm{CTW}+\mathrm{GBFS}$. 136

Figure 4-58: SEM and EDS micrograph of mono $\mathrm{CW}$ with SCMs (a) CW+FAC (b) CW+FAF (c) $\mathrm{CW}+\mathrm{MK}$ and (d) $\mathrm{CW}+\mathrm{GBFS}$.

Figure 4-59: SEM and EDS micrograph of binary RCBW with SCMs (a) RCBW+MK (b) RCBW + Slag. .... 138

Figure 4-60: SEM and EDS micrograph of binary CTW+CW with SCMs (a) CTW+FAF (b) CTW+MK and (c) CTW+ Slag. 139

Figure 4-61: SEM and EDS micrograph of binary CTW with SCMs (a) CTW+FAF (b) CTW+MK and (c) CTW+ Slag. 140 


\section{SYMBOLS AND ABBREVAITIONS}

\begin{tabular}{|c|c|}
\hline CDW & Construction and Demolition Wastes \\
\hline RCBW & Red Clay Brick Waste \\
\hline TW & Tile Waste \\
\hline $\mathrm{CW}$ & Concrete Waste \\
\hline SCMs & Supplementary Cementitious Materials \\
\hline FA-C & Fly Ash Type C \\
\hline FA-F & Fly Ash Type F \\
\hline GBFS & Granulated Blast Furnace Slag \\
\hline MK & Metakaolin \\
\hline GP & Glass Powder \\
\hline OPC & Ordinary Portland Cements \\
\hline AAs & Alternative Aggregates \\
\hline $\mathrm{RAC}$ & Recycled Aggregates Concrete \\
\hline AACs & Alkali-Activated Cements \\
\hline HYCs & Hybrid Cements \\
\hline $\mathrm{C}-\mathrm{S}-\mathrm{H}$ & Calcium Silicate Hydrate \\
\hline N-A-S-H & Sodium Alumino Silicate Hydrate \\
\hline C-A-S-H & Calcium Alumino Silicate Hydrate \\
\hline $\mathrm{SiO}_{2}(\mathrm{Si})$ & Silica \\
\hline $\mathrm{Al}_{2} \mathrm{O}_{3}(\mathrm{Al})$ & Alumina \\
\hline $\mathrm{Na}_{2} \mathrm{O}$ & Sodium Oxide \\
\hline
\end{tabular}

xviii 

$\mathrm{L} / \mathrm{S}$
Liquids/Solids

$\mathrm{Si} / \mathrm{Al}$

$\mathrm{R}_{2} \mathrm{O} / \mathrm{Al}_{2} \mathrm{O}_{3}$

$\mathrm{R}_{2} \mathrm{O} / \mathrm{SiO}_{2}$

$\mathrm{SiO}_{2} / \mathrm{Na}_{2} \mathrm{O}$

$\mathrm{R}$ or $\mathrm{M}$

RH

XRF

XRD

SEM

EDS

TGA

CAC

NMR

MAS-NMR

FTIR
Silica/Alumina Molar Ratio

$\mathrm{Na}_{2} \mathrm{O}$ or $\mathrm{K}_{2} \mathrm{O}$ /Alumina Molar Ratio

$\mathrm{Na}_{2} \mathrm{O}$ or $\mathrm{K}_{2} \mathrm{O} /$ Silica Molar Ratio

Silica/Sodium Oxide Molar Ratio

Alkali Cation $\left(\mathrm{Na}^{+}\right.$or $\left.\mathrm{K}^{+}\right)$

Relative Humidity

X-Ray Fluorescence

X-Ray Diffraction

Scanning Electron Microscopy

Energy-Dispersive X-Ray

Thermogravimetric Analysis

Calcium Aluminosilicate Cements

Nuclear Magnetic Resonance

Magic Angle Spinning-Nuclear Magnetic Resonance

Fourier-transform Infrared Spectroscopy 


\section{CHAPTER ONE:}

\section{INTRODUCTION}

\subsection{General}

Concrete is a versatile construction material and is used more than any other building material in the world. Concrete contains water, cement, fine and coarse aggregates. Among these materials, the manufacturing of Portland cement (PC) consumes a large amount of energy and releases a vast volume of greenhouse gases such as $\mathrm{CO}_{2}$ (Bondar et al., 2011). For instance, around $4 \mathrm{GJ}$ of energy is consumed and 1.5 tons of raw materials are needed in order to produce a ton of PC which in turn releases almost one ton of $\mathrm{CO}_{2}$ (Tokyay, 2016). This caused cement production to be currently responsible for around $8 \%$, and concrete industry for $8-10 \%$, of global $\mathrm{CO}_{2}$ emissions (Robayo-Salazar et al., 2017).

One of the sustainable and green ingredients that can replace the use of Portland cement is geopolymer or inorganic polymer material, a term coined by Joseph Davidovits in 1979. Researchers also call this novel material a low-calcium alkali-activated system. Geopolymer is defined as a man-made rock that is synthesized from inorganic polymeric materials possessing amorphous structure. The aluminosilicates from solid sources can react with alkali hydroxide and silicates (Sodium and Potassium Hydroxide and Sodium or Potassium Silicate) to form a 3-D alkali aluminosilicate network. This involves three main processes that include dissolution of aluminosilicates in alkaline solutions, development of temporary gel or gelation, and finally hardening (poly-condensation) and polymerization. First, the solid aluminosilicates source dissolves by alkaline hydrolysis to produce aluminate and silicates. These elements take up aqueous phase shape resulting in the formation of a complex mix of silicate, aluminate and aluminosilicates. The amorphous aluminosilicates dissolve quickly at alkaline environments, generating a supersaturated aluminosilicate solution. This leads to the formation of gel in the process of gelation, reorganization of gels and finally the polymerization and hardening take place and the 
aluminosilicate binder takes shape.

Various supplementary cementitious materials (SCMs) such as fly ash (FA) type C and F, granulated blast furnace slag (GBFS) and metakaolin (MK) have largely been studied and utilized as precursor materials to produce geopolymers. The type of the abovementioned SCMs was presented as a significant aspect in the formation of the final geopolymer product. Allahverdi and Kani (2013) explained that the mechanism of reaction and binder development depend on the chemical properties of the precursor materials (SCMs and/or recycled materials) and the alkali-activators, specifically on the calcium (Ca) content available for geopolymerization. N-A-S-H based geopolymers are formed with the presence of a low amount of $\mathrm{Ca}$ in the system. A high level of calcium may result in the formation of C-A-S-H gel, which does not have the same long-range order as N-A-S-H. For many years geopolymers have been synthesized using conventional physical methods of mix combination of specific percentages of aluminosilicate source materials and alkali-activator solutions. However, many researchers have recently pointed out the importance of chemical factors, such as silica/alumina $\left(\mathrm{SiO}_{2}\right.$ to $\left.\mathrm{Al}_{2} \mathrm{O}_{3}\right), \mathrm{R}_{2} \mathrm{O} /$ alumina, $\mathrm{R}_{2} \mathrm{O} /$ silica $\left(\mathrm{R}_{\text {is }} \mathrm{Na}^{+}\right.$or $\mathrm{K}^{+}$), and liquid/solid ( $\mathrm{L} / \mathrm{S}$ ) ratios on the mechanical, microstructural and fresh properties of geopolymers. Lahoti et al. (2017) investigated the effect of four mix design parameters namely $\mathrm{Si} / \mathrm{Al}$, water/solids, $\mathrm{Al} / \mathrm{Na}$ and $\mathrm{H}_{2} \mathrm{O} / \mathrm{Na}_{2} \mathrm{O}$ on the mechanical properties of metakaolin based geopolymers. They found that $\mathrm{Si} / \mathrm{Al}$ ratio is the most significant factor, followed by $\mathrm{Al} / \mathrm{Na}$ molar ratio, while water/solid ratio was presented to be not as important as the other parameters in view of the strength results of metakaolin-based geopolymer. The curing method plays an important role in the geopolymerization process. Kani and Allahverdi (2009) confirmed that strength development was significant at $85^{\circ} \mathrm{C}$ curing and the lowest curing temperature resulted in the least compressive strength. Many researchers have explained that ambient temperature is not appropriate for geopolymer binders, especially those prepared by kaolin and fly ash (Somna et al. 2011; Heah et al. 2011). Furthermore, 
relative humidity was showed to influence the quality of geopolymer products. According to Criado et al. (2011), at lower humidity the aluminosilicate materials dissolved slowly delaying the formation of gel and resulting in lower mechanical properties of geopolymer binders. However, Perera et al. (2007) found that curing at lower relative humidity results in better mechanical properties compared to higher RH.

In recent decades, construction and demolition waste (CDW) has become a major portion of total global solid waste production which goes to landfills and causes severe environmental and ecological problems (Patel et al. 2015). The CDW is regarded to be responsible for more than $30 \%$ of universal production of solid wastes and more than one-third of solid waste stream generated in Canada (Habert et al. 2011). Among major CDW components, concrete and masonry units, including bricks and ceramics, are of greater importance given the fact that these materials account for more than $50 \%$ of total waste from construction and demolition activities (Schneider et al. 2011). Moreover, many existing structures built in the second half of the last century are already approaching the end of their service lives, which may intensify the CDW generation. Thus, handling CDW in a proper manner that consider the environmental, the financial and the health issues is a growing concern in whole the world.

Recycling and reutilization of CDWs in geopolymeric materials may provide a sustainable and technological solution to reduce the ecological burdens of CDWs and growing cement production. Compared to SCMs, the integration of different CDWs, yet rich in silica, calcium and alumina, in geopolymer materials is not well established in the literature. Recent studies on the utilization of brick, tile, ceramic and concrete wastes demonstrated that CDWs can be successfully used in geopolymeric binder production, particularly when using initial high temperature curing of $65^{\circ} \mathrm{C}$ and higher (Komintsas et al, 2015). The potential of using CDWs to produce appropriate geopolymeric binders at ambient temperature is still a challenge that needs to be considered, though some authors recommended adding GBFS, fly ash and metakaolin to form stronger CDW-binders prepared with and without high 
temperature curing, (Rakhimova and Rakhimov, 2015), Ahmari et al., 2012 and Vásquez et al., 2016). Interestingly, to date, very limited studies have been published about the combining use of two CDW materials in geopolymer binders (Allahverdi and Najafi Kani, 2009). Also, there has been no useful method followed in the development of different CDWs incorporated geopolymer binders, especially if taking under account the different chemical properties of CDWs in the world.

This thesis encompasses the utilization of red clay brick waste (RCBW), ceramic tile waste (CTW) and concrete waste $(\mathrm{CW})$ as aluminosilicate precursor sources in a mono, binary and ternary system of geopolymer binders cured at ambient temperature. Sodium hydroxide $(\mathrm{NaOH})$ and sodium silicate $\left(\mathrm{Na}_{2}\right.$ $\mathrm{SiO}_{3}$ ) were used as alkali-activators. A new mix design method is used in this study relying on targeted chemical and physical ratios of silica to alumina $\left(\mathrm{SiO}_{2} / \mathrm{Al}_{2} \mathrm{O}_{3}\right)$, sodium to silica $\left(\mathrm{Na}_{2} \mathrm{O} / \mathrm{SiO}_{2}\right)$ and liquid/solid (L/S) ratios. Fresh (slump flow and setting time), mechanical (compressive strength) and microstructural (SEM-EDS and XRD) properties of the developed CDWs-based geopolymer binders were assessed. The effect of high temperature curing on the properties of the optimized compositions was considered by testing an initial $24 \mathrm{~h}$ curing at $50^{\circ} \mathrm{C}, 75^{\circ} \mathrm{C}$ and $100^{\circ} \mathrm{C}$. Furthermore, the effect of adding GBFS, FA-C, FA-F and MK into the highest compressive strength-compositions of mono, binary and ternary blended binders was studied.

\subsection{Research Objectives and Scope}

Demolition, renovation and construction processes produce high amount of waste materials such as concrete, wood, asphalt, gypsum, metals, bricks, glass and salvaged building components. Brick, tile and concrete wastes are known with their important volumes compared to other construction and demolition wastes (CDWs). On the other hand, these components are characterized with high amounts of silica and alumina. These make them good candidates to be used as precursors in OPC free geopolymeric materials. 
The main objective of the proposed research is the recycling of the major portion of construction and demolition wastes (CDWs) to develop new structural and 100\% green geopolymer binders. In addition, this research explores new mix designing method for optimizing the mechanical strengths of CW, RCBW and CTW-based mono, binary and ternary system of geopolymer binders. The originality of the method of composition consists on the calculation of different quantities of precursor powders and alkalineactivators by targeting specific chemical and physical ratios of $\mathrm{SiO}_{2} / \mathrm{Al}_{2} \mathrm{O}_{3}, \mathrm{Na}_{2} \mathrm{O} / \mathrm{SiO}_{2}$ and $\mathrm{L} / \mathrm{S}$ ratios.

Other objectives of this research include the following:

I. To verify the fresh properties of the optimized compositions by measuring the slump flow and setting time of all mixes. No superplasticizers or retarders are added in any mix.

II. To investigate the effect of applying a high temperature curing of $50^{\circ} \mathrm{C}, 75^{\circ} \mathrm{C}$ and $100^{\circ} \mathrm{C}$ to the developed compositions of mono, binary and ternary system of CW, RCBW and CTW. In order to comply with the sustainable part of this study, the high temperature curing is applied for a short time curing of $24 \mathrm{~h}$.

III. To study the addition of several SCMs, namely GBFS, FA-F, FA-C and MK, to the best compressive strength compositions of mono, binary and ternary system of $\mathrm{CW}, \mathrm{RCBW}$ and CTW. The SCMs are added by replacement of different CDWs at limited percentages of $15 \%$, $30 \%$ and $45 \%$.

IV. To inspect the most suitable molarity, $\mathrm{Na}_{2} \mathrm{O}$ content and silica modulus of the alkaline solution by exploring their relation to the compressive strength results of the geopolymeric mixes.

V. To extensively consider the microstructural properties of CDW-based mono, binary and ternary compositions by analysing different specimens of ambient and high temperature curing and those incorporated GBFS, FA-F, FA-C and MK. Scanning Electron Microscopy (SEM), EnergyDispersive X-Ray Spectroscopy (EDS), X-Ray Diffraction (XRD), and Thermogravimetric Analysis (TGA) are used in this study. 


\subsection{Thesis Outline}

CHAPTER 1 Presents abstract of this research and general introduction. Introduces geopolymers, types of geopolymeric systems and describes objectives and scopes and the outline of this thesis.

CHAPTER 2 Presents the background of geopolymers and their application, a literature review of research studies on CDW and SCM based geopolymers.

CHAPTER 3 Presents research program and methodology, types of CDW and SCM materials and specimen utilized. It also presents overview of the mix designing procedures and the experimental tests procedures.

CHAPTER 4 Presents results and discussion of the tested geopolymeric binders based on the fresh and mechanical properties, comparing findings of this research with literature on

CHAPTER 5 Presents general conclusion and future research needs 


\section{CHAPTER TWO \\ BACKGROUND AND LITERATURE REVIEW}

\subsection{Introduction}

There is no doubt that concrete forms the backbone of construction industry all over the world on the materials basis. As a result of the growing use of concrete, the cement production is increasing by more than $4 \%$ annually, contributing significantly to the release of carbon-dioxide $\left(\mathrm{CO}_{2}\right)$ regarded as the first cause of global warming and climate change. The impact of carbon footprint from concrete production is estimated to be almost 2 billion tonnes/year. This currently accounts for 8 to $10 \%$ of global $\mathrm{CO}_{2}$ emissions and is expected to account for 10 to 15\% by 2020 (Szabo et al., 2006; McLellan et al., 2011; Turner and Collins, 2013; Robayo-Salazar et al., 2017). Environmental protection and energy conservation concerns have led researchers to seek alternatives to OPC in order to alleviate the effect of high carbon footprint of concrete production. Among the various alternatives which have been investigated by researchers, alkali-activated cements or geopolymer binders are considered as the most effective materials because of their ability to completely eliminate the use of OPC.

This chapter covers the background of geopolymers and alkali-activated materials, their design mechanisms, applications, terminology and the difference between these two closely related yet subtly diverse materials. Also, detailed literature review and current state-of-the-art research investigations on CDWs-based geopolymers is presented in this chapter.

\subsection{Overview and Historical Development of Geopolymers and Alkali-Activated Binders}

Geopolymers were first syntehsized at the dawn of the $20^{\text {th }}$ century. According to Shi et al. (2011), a German scientist named Khul was the first researcher to investigate the use of alkalis as potential activators, when he studied the setting behaviour of ground slag mixture with KOH solution in 1930. Provis and van Deventer (2009) credits Purdon in 1940s as the first to study the synthesis of slag based cement activated with $\mathrm{NaOH}$. However, they recognized later that a patent granted to Khul in 1908 was the first attempt to the alkali actiavation of aluminosilicate precursors. A breakthrough in the geopolymer technology was by Glukhovsky (1967) who investigated the development of binders from low calcium or non-calcium based aluminosilicate precursors and alkaline solutions. This researcher divided binders into two categories based on their precursor compositons; first type was called "alkaline binding systems" $\left(\mathrm{Me}_{2} \mathrm{O}-\mathrm{SiO}_{2}-\mathrm{Al}_{2} \mathrm{O}_{3}-\mathrm{H}_{2} \mathrm{O}\right)$ and second was categorized as "alkali-alkaline-earth binding systems" 
$\left(\mathrm{Me}_{2} \mathrm{O}-\mathrm{MO}-\mathrm{SiO}_{2}-\mathrm{Al}_{2} \mathrm{O}_{3}-\mathrm{H}_{2} \mathrm{O}\right)$ where $\mathrm{Me}=\mathrm{Na}, \mathrm{K}, \ldots$ and $\mathrm{M}=\mathrm{Ca}, \mathrm{Mg}, \ldots$ (Shi et al., 2011). Scandnavian reserachers such as Forss worked later on the development of low-porosity slag-based cement which was named as F-cement or "a binder based on alkali-activated blastfurnace slag" (Forss, 1983). However, the F-cement develped by Forss was based on the second type of alkali bidning systems “alkali-alkaline-earth binding systems" classified by Glukhovsky.

The term geopolymer was first coined by Davidovits in 1979 (Pacheco-Torgal, 2015). Davidovits produced geopolymer binders by syntheisizing burnt kaolinite, lime and dolomite with alkali activators. He patented his findings under trademarks such as Geopolycem, Pyrament and Geopolymite (Davidovits, 1984; Shi et al., 2011). In 1988, Davidovits organized a conference called "Geopolymer 88”, publications of this conference have been an important literature and introduction to geopolymers. Meanwhile, Davidovits authored several papers in 1980s and 1990s which laid to the foundation for geopolymer research (Provis and van Deventer, 2009). Numerous authors has contributed to the geopolymer and alkali-activated binder researchs since 1980s. Palomo and Glasser (1992) published their investigation on the synthesis of metakaolin, according to Provis and van Deventer (2009), this has been the first detailed scientific study on metakaolin geopolymers.

Published investigations by (Rahier et al.,1997), (Alonso and Palomo, 2001), (Barbosa et al., 2000), (Kaps and Buchwald, 2002), (Duxson et al., 2003) and conference publication in 1999 by (Davidovits et al., 1999) lays the fundamental understanding of metakaolin-based geopolymers (Provis and van Deventer, 2009). Fly ash-based geopolymers are highly hetergeous in nature which results in difficulty in scientifcally understanding them and therefore there is a widening gap between FA-based and metakaolin-based geopolymers (Provis and van Deventer., 1999).

According to Pacheco-Torgal (2015) three scholarly articles on geopolymers and alkali-activated materials are the most prominent published research in recent years by authors: Shi et al. (2011), van Deventer et al., (2012) and Provis (2014). Meanwhile, a book edited by Provis and van Deventer (2009) and last but not the least a book by Davidovits (2015) comprise the cornerstone of modern geopolymer science, chemistry and application. The International Union of Laboratories and Experts in Construction Materials Systems and Structures (RILEM) established a technical committee on Alkali-Activated Materials (TC 224-AAM) in 2007 and published its findings in 2012 (Provis and van Deventer, 2013; Pacheco-Torgal, 2015). The RILEM has also established a separate committiee on the durability study of alkali-activated materials (247 DTA) in 2012. Durability of geopolymers and alkali-activated materials is an area that researcher still do not seem to agree on (Pacheco-Torgal et al., 2012a; PachecoTorgal, 2015). According to Duxson et al. (2007) and van Deventer et al. (2012) durability of alkali- 
activated materials is a key issue and it remains an impediment to the AAMs application in structures. Efflorescence is another issue that some geopolymer and alkali-activated materials suffer. It is the formation of a white surface deposit and is formed when soluble gepolymeric components transfer through porous material and appear on its surface, which may or may not affects the material performance (Allahverdi et al., 2015). Efforesecence is casued the formation of salt crystals on geopolymer surface due to evaporation of water containing salt and it is a distintive chemcial process than carbonation. Another topic of controversy in alkali-activated binders is the reduction in $\mathrm{CO}_{2}$ emission during geopolymer synthesis compared to OPC production. Davidovits et al. (2009) reported that each ton of geopolymer produced results in 0.184 tons of $\mathrm{CO}_{2}$ whereas other researchers reported significanlty low reduction in $\mathrm{CO}_{2}$ emissions (Pacheco-Torgal, 2015).

\subsection{Geopolymer and Alkali-activated Binders, Synthesis, Process and Mechanism}

Geopolymer is defined as a man-made mineral-based polymer which is synthesized from inorganic polymeric materials possessing amorphous structure. Geopolymerization involves three main processes which include dissolution of aluminosilicates in alkaline solutions, development of temporary gel or gelation process and final hardening (poly-condensation) and polymerization. The solid aluminosilicates source dissolves by alkaline hydrolysis which produces aluminate and silicates in the process. These aluminates and silicates take up aqueous phase shape as a result a complex mix of silicate, aluminate and aluminosilicates forms. Amorphous aluminosilicates dissolve quickly at alkaline environments, generating a supersaturated aluminosilicate solution, this leads to the formation of gel in the process of gelation, reorganization of gels and thus polymerization and poly-condensation take place and an aluminosilicate binder takes shape. Geopolymers develop three-dimensional Si-O-Al and Al-O-Si polymeric networks or bonds of alkali-aluminosilicates compounds (McDonald et al., 2005; Duxson et al., 2007; Allahverdi and Kani, 2015).

The geopolymeric (low-calcium alkali-activated system) binder structure is a highly cross-linked aluminosilicate gel (Provis and van Deventer, 2014). Glukhovsky (1994) outlined the geopolymerization process in three stages of (1) destruction-coagulation, (2) coagulation-condensation and (3) condensation-crystallization. In the destruction-coagulation stage $\mathrm{OH}^{-}$ions in the alkaline reagent destroys the $\mathrm{Si}-\mathrm{O}-\mathrm{Si}$ bonds which results in silanol $(-\mathrm{Si}-\mathrm{OH})$ and sialate $\left(-\mathrm{Si}-\mathrm{O}^{-}\right)$, these cations neutralises negative charge in the system and $\mathrm{Si}-\mathrm{O}^{-}-\mathrm{Na}^{+}$forms which prevents the reformation of 


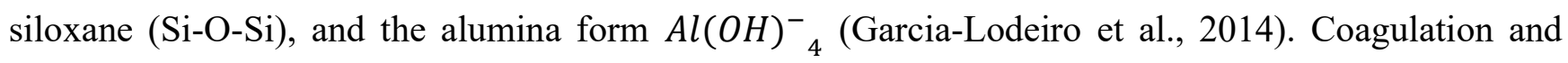
polycondensation start when the dissolved ionic species contact each other. The Silica monomers react to form dimers ( $\mathrm{Si}-\mathrm{O}-\mathrm{Si}$ bonds), which react with other monomers and forms polymers. $\mathrm{OH}^{-}$ions act as catalysts. The aluminates replace the silicon tetrahedra and participate in polymerization. In the condensation-crystallization stage the precipitation further takes place and geopolymer forms. The mineralogical composition of the precursors in the first stage, type of alkaline activator and the curing conditions determine the composition of the crystallized geopolymeric product (Shi et al., 2011).

Provis (2014) developed a schematic depiction (Figure 2.1) of the mathematical model of the dissolution of aluminosilicate minerals and formation of aluminosilicate products with dense cross-linking. When the dissolution of metakaolin or fly ash type F precursors starts, the aluminosilicates dissolves into silicate and aluminate monomers which then forms aluminosilicate oligomers. Initial gel formation begins when amorphous aluminosilicate polymers forms which eventually develop to aluminosilicate gel that hardens into geopolymers.

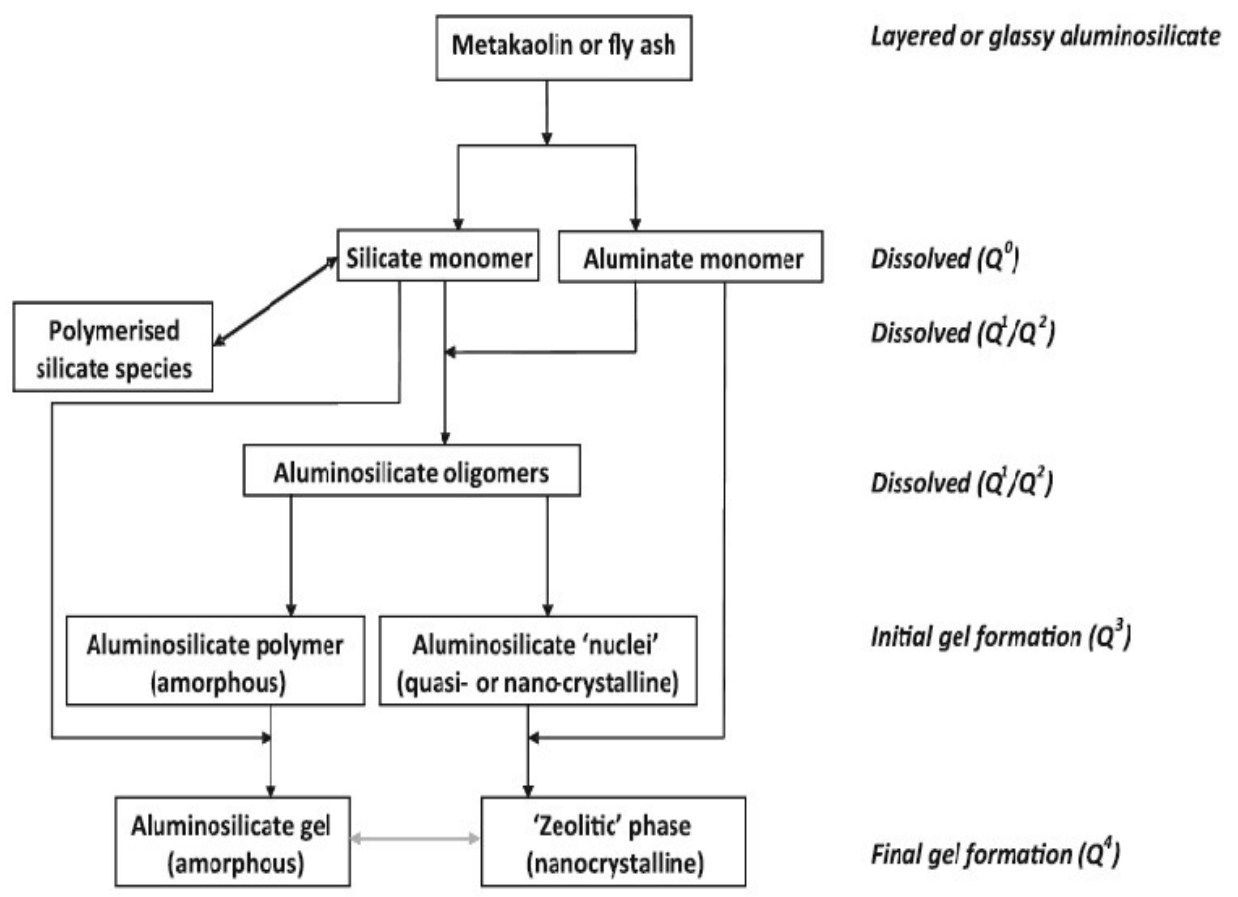

Figure 2.1 Schematic diagram of conceptual model of alkali-activation of aluminosilicate precursor (J. L. Provis, 2014)

The final geopolymer or alkali activated materials are different in their microstructure and chemistry which depend on their precursor source material depending on their calcium content. The calcium content 
determines whether the alkali activated binder's structure is network or chain formation (J. L. Provis, 2014). Metakaolin and fly ash type $F$ which are low calcium aluminosilicate precursors are activated with metal hydroxide and silicate solutions. The strucutre of this type of geopolymers is expected to be a disorderd aluminosilicate zeolite like strucutre, the ordering of $\mathrm{Si}$ and $\mathrm{Al}$ is related to the thermodynamic energy of Al-O-Al bonds (J. L. Provis, 2014; J. L. Provis, Lukey, \& Van Deventer, 2005). The alkali cations are associated with oxygen atoms which are connected to the $\mathrm{Al}$ atoms. K cations are larger compared to the $\mathrm{Na}$ cations and more rapidly forms polymeric gel than $\mathrm{Na}$ at early age. Geopolymers mixed with high liquids/solids ratio results in the leaching of alkali which results in effloresence (J. L. Provis, 2014). Higher-calcium alkali-activated binders synthesized from blast furnace slag can be activated with alkali metal carbonate and sulfate soultions as well as hydroxide and silicates. The final alkali activated binder will be C-A-S-H or calcium aluminosilicate hydrate gel which will include substantial amounts of $\mathrm{Na}$ that can be designated as $\mathrm{C}-(\mathrm{N})-\mathrm{A}-\mathrm{S}-\mathrm{H}$. This type of alkali-activated gel has chain-like strcture resembling that of tobermorite (Figure 2.2) and it is formed by aluminum substituted calcium silicate hydrate gel.

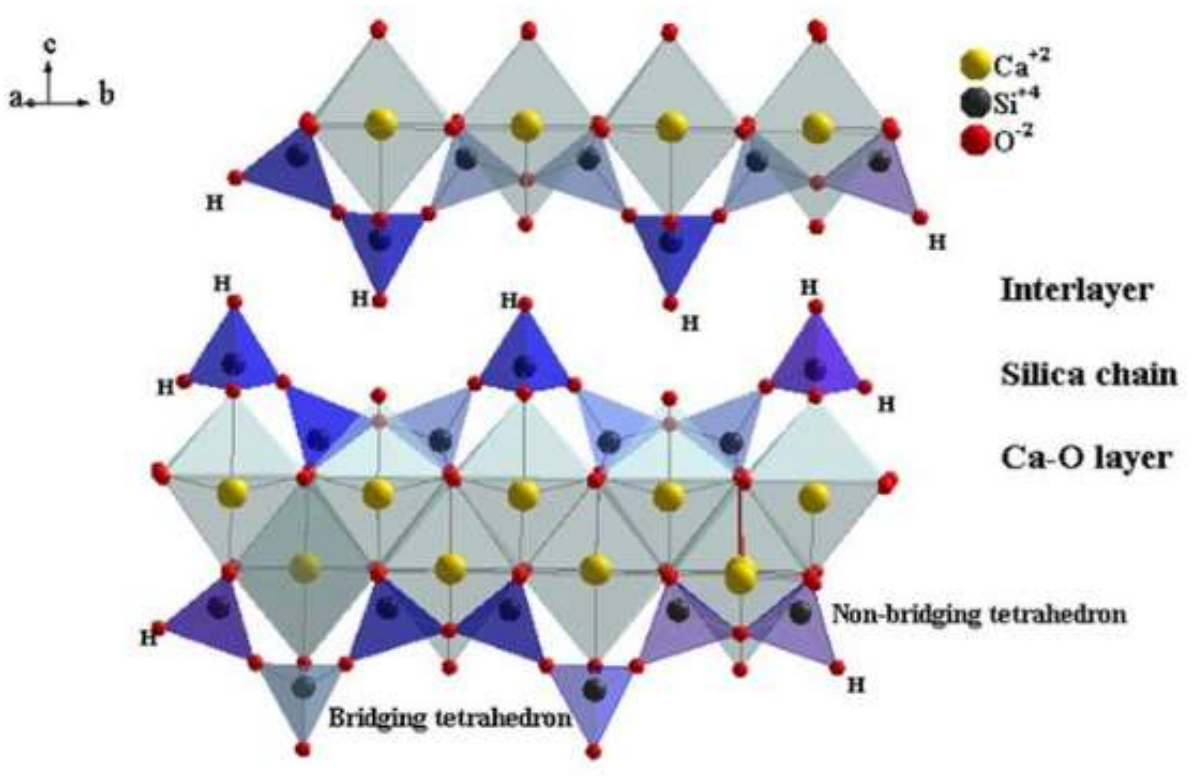

Figure 2. 2 Schematic diagram of tobermorite-like structure of Calcium based aluminosilicate gel (Richardson, 2004).

Another model (Figure 2.3) of the alkali activation of metakaoilin and fly ash based precursors which forms N-A-S-H gel is described in several stages. The aluminosilicates are dissolved when the alkaline 
solution is added to the mix, monomers of silica and alumina species forms, these monomers then form dimers, then trimers, tetramers and so on and finally the sodium aluminosilicate hydrate (N-A-S-H) gel forms, the gel at this stage is called Gel 1 (Garcia-Lodeiro et al., 2014). High content of $A l^{3+}$ ions are present at this stage, the Al-O bonds quickly dissovles as they are weaker than Si-O bonds which results in increased silicon content in the gel thus Gel 2 forms, a supersaturated aluminosilicate solution is fomed after the dissolution of amorphous alumisilicates in hilgy alkaline $\mathrm{pH}$ environemnts, which forms $\mathrm{N}-\mathrm{A}-\mathrm{S}-\mathrm{H}$ gel, as the oligomers in this aqueous phase forms polymers, the water used during the dissolution process is released and it stays inside the gel pores, this type of structrure where aluminosilicate and water coexist is called biphaisc (Garcia-Lodeiro et al., 2014; Shi et al., 2011).

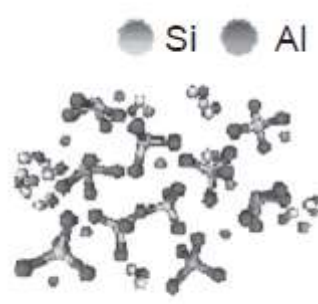

Dissolution

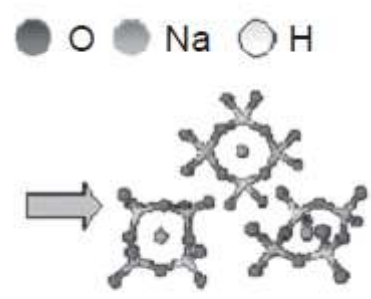

Phase rich in $\mathrm{Al}$

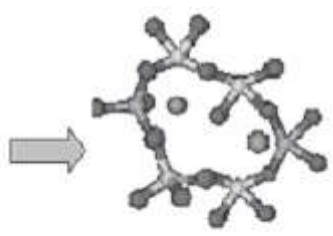

Phase rich in Si
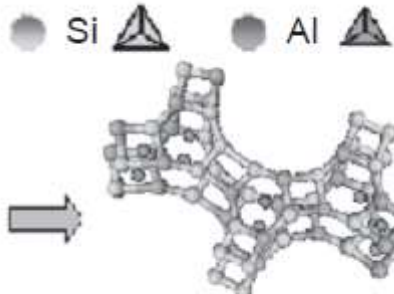

Polymerisation

Figure 2.3 Model proposed for N-A-S-H gel formation (Shi et al., 2011).

Fernandez-Jimenez and Palomo (2005) developed a graphic model (Figure 2.4) of alkali activation of aluminosilicate binders using MAS-NMR and FTIR investigations. This model describes the stages of geopolymerization of aluminosilicate-based alkali activated materials which is consistent with the Glukhovsky (1967) description of three stages of alkali activation process (Shi et al., 2011). 


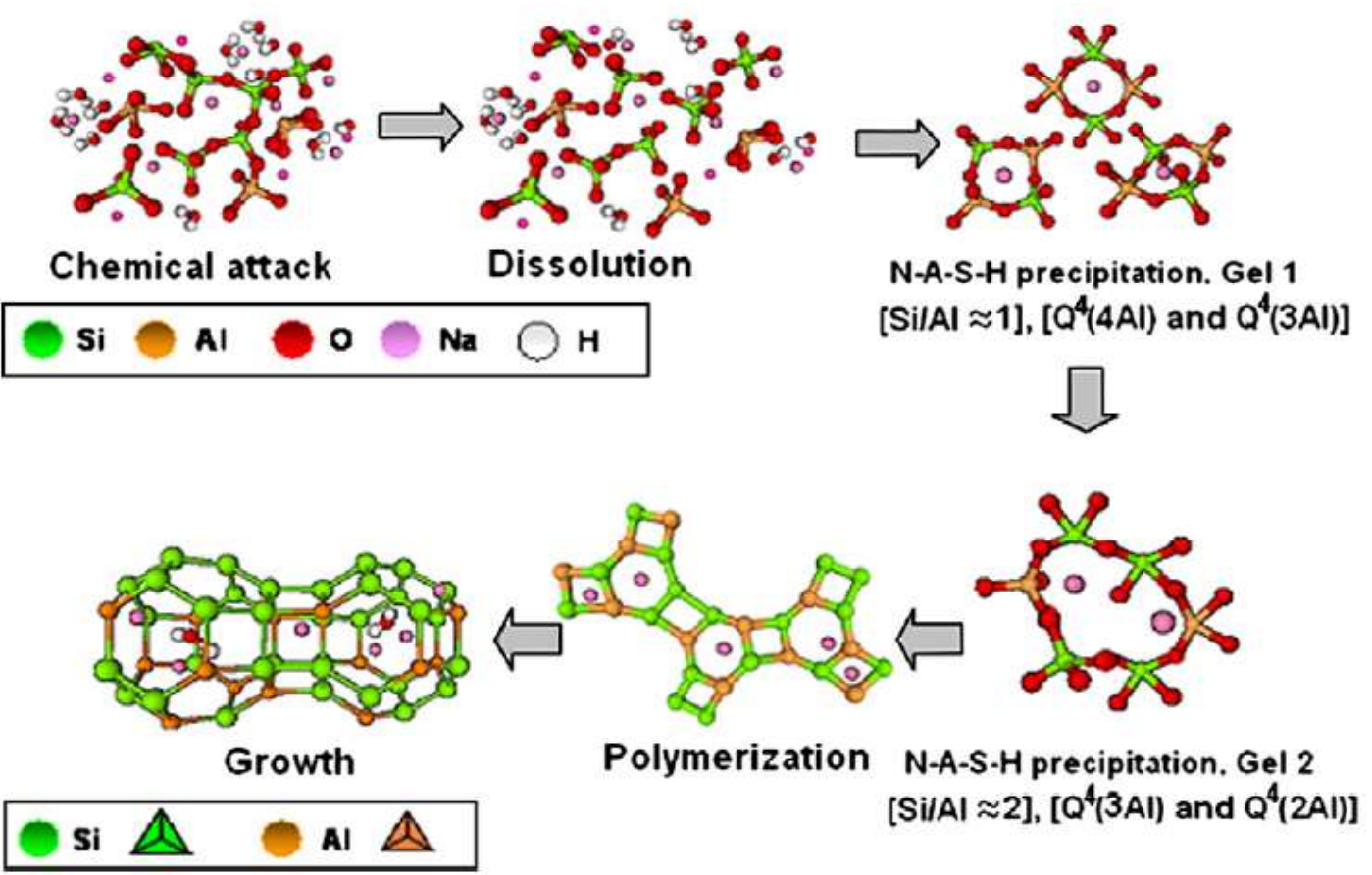

Figure 2.4 Descriptive model for alkali-activation of aluminosilicates (Fernandez-Jiminez and Palomo, 2005; Shi et al., 2011).

(Davidovits, 1991, 2015) chemically designated geopolymers as poly (sialate). Sialate is an abbreviation for silicon-oxo-aluminate. The sialate network consists of $\mathrm{SiO}_{4}$ and $\mathrm{AlO}_{4}$ tetrahedral ions sharing oxygens which need positive ions $\left(\mathrm{Na}^{+}, \mathrm{K}^{+}, \mathrm{Li}^{+}, \mathrm{Ca}^{+}, \mathrm{Ba}^{+}, \mathrm{NH}_{4}{ }^{+}, \mathrm{H}_{3} \mathrm{O}^{+}\right)$in the geopolymeric framework cavities to balance the negative charge of $A l^{3+}$ in poly (silate). (J. Davidovits, 1991) suggested following empirical formula for Poly (silate):

$M_{n}\left\{-\left(\mathrm{SiO}_{2}\right)_{z} \mid \mathrm{AlO}_{2}\right\}_{n} \cdot w H 2 O \quad \ldots \quad$ Eq. 2.1

Where $\mathrm{n}$ is the degree of polymerization, $\mathrm{z}$ is 1,2,3 and $\mathrm{M}$ is an alkali cation such as sodium, lithium and potassium. Varying Si:Al ratios creates different types of poly(sialates). Geopolymers are made of different types of molecular units and the name and type of geopolymer depends on its Si:Al ratio in the molecular units. Some of the poly-sialates (Figure 2.4) identified by (J. Davidovits, 1991) are as follows:

- Si-O-Si- Siloxo, poly (siloxo)

- Si-O-Al-O- Sialate, poly (sialate)

- Si-O-Al-O-Si-O- Sialate-siloxo, poly (sialate-siloxo)

- Si-O-Al-O-Si-O-Si-O- Sialate-disiloxo, poly (sialate-disilxo) 

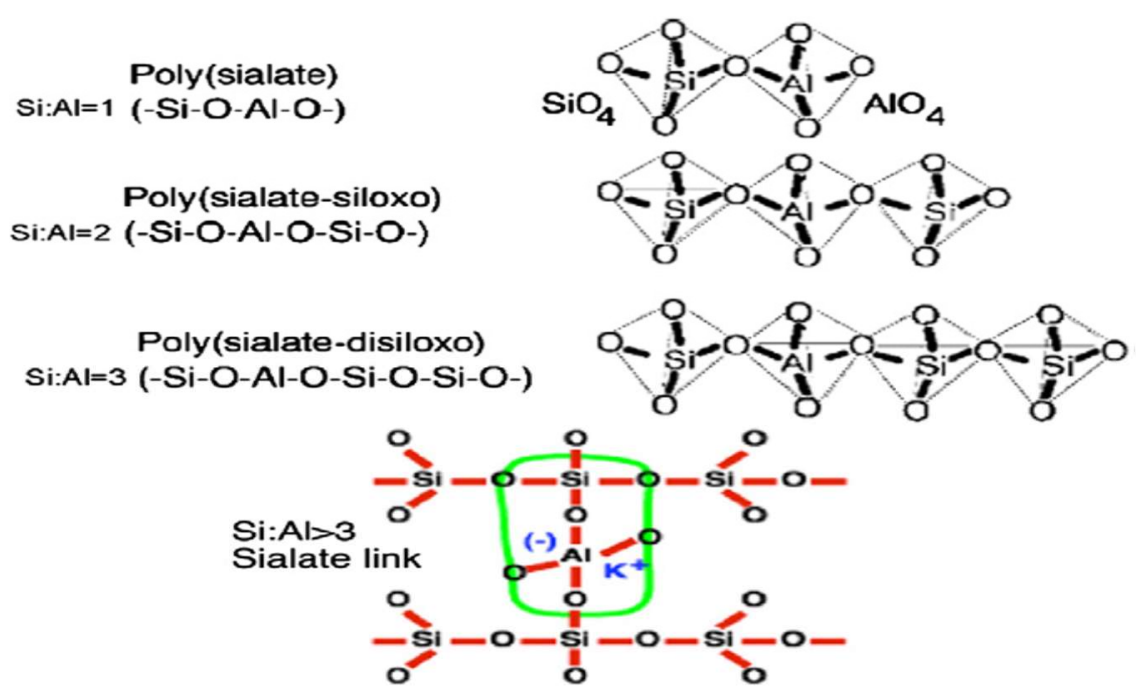

Figure 2.5 Poly(sialate) geopolymeric structure according to Davidovits ( Davidovits, 1991; PachecoTorgal etal., 2008).

Poly(sialates) has amorphous to semi-crystalline polymeric structure. X-ray diffraction pattern of geopolymer can identify the degree of disorder in a geopolymer. In non-crystalline geopolymers $\mathrm{x}$-ray diffraction results in broad diffuse halo diffraction peaks (Davidovits, 1991).

The geopolymeric mechanism also depends on the type and combination of alkaline activators. For instance, Granizo (1998) studied th activation of metakaolin with sodium hydroxide alone and in combination with sodium silicate (waterglass). In the first scenario, the dissolution of aluminosilicates and induction period follows the accummulation of destroyed product. Whereas, in the second scenario, a quick dissolution phase is followed by a fast polycondensation phase (Pacheco-Torgal et al., 2008). (Palomo, A., M. Grutzeck, 1999) and Pacheco-Torgal et al. (2008) described two models of alkaliactivation. First, activation of GBFS ( $\mathrm{Si}+\mathrm{Ca}$ ) with a mild alkaline activator and the reaction gel is $\mathrm{CSH}$. While, the second form of alkali-activation is that of metakaolin $(\mathrm{Si}+\mathrm{Al})$ in medium to high alkaline environment which results in amorphous polymeric structure like zeolite. Regarding the activation of fly ashes, it was showed to take place through an exothermic process where the dissolution of aluminosilicate and calcium-aluminosilicates starts with the breakdown of covalent bonds of Si-O-Si and Al-O-Al. The destructed product due to alkaline activation of fly ash accumulates over time and condenses which results in a poorly ordered geopolymeric structure with a high mechanical strength (Pacheco-Torgal et al., 2008). 


\subsection{Reaction Products of Geopolymer and Alkali-Activated Materials}

Despite similar nature of microstructures and molecular structures of different geopolymers, difference in their properties is evident due to different precursor source materials (Duxson et al., 2007). Figure 2.6 shows a simplified reaction mechanism of geopolymerization proposed by Duxson et al. (2007). It describes the main processes occurring during the modification of solid aluminosilicate precursor into an alkali aluminosilicate based geopolymer. Dissolution of aluminosilicate precursors by alkaline reagents through alkaline hydrolysis produces aluminate and silicate species in the monomeric form. These aluminate and silicate species are integrated into the aqueous phase, which may contain silicate in the solution. A mix of silicate, aluminate and aluminosilicate species is formed, and the speciation equilibrium process takes place. The dissolution of amorphous aluminosilicates takes place faster in high $\mathrm{pH}$ environment which creates a supersaturated aluminosilicate solution. This results in the creation of gel after the development of large networks from the condensation of oligomers in the aqueous phase. Subsequently, the water used in the dissolution process releases, playing the role of a reaction medium (Duxson et al., 2007). The gelation stage is followed by the reorganization process in which the connectivity of gel network improves resulting in the formation of three-dimensional aluminosilicate network (N-A-S-H), commonly designated as geopolymer.

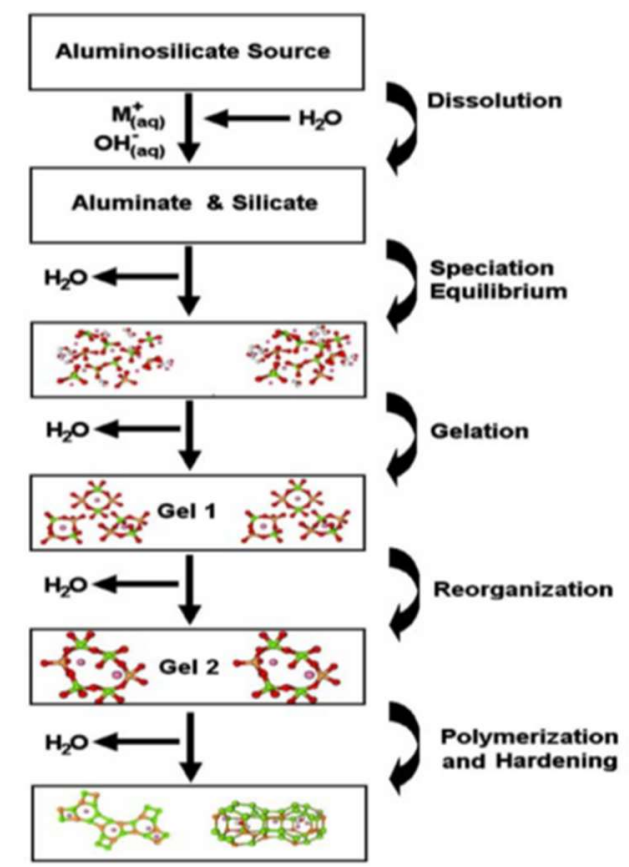

Figure 2.6 Conceptual model for geopolymerization (Duxson et al. 2007). 
The main product from the above described polymerization process is an amorphous to semi-crystalline alkaline-aluminosilicate-hydrate such as sodium-aluminosiliate-hydrate (N-A-S-H), as presented in Figure 2.7 (Palomo et al., 2005; Garcia-Lodeiro et al., 2014). In this figure, the three dimensional network of geopolymers is a result of the random distribution of silica and alumina tetrahedra during the polycondensation stage of geopolymerization (Garcia-Lodeiro et al., 2014; J. L. Provis, 2014; J. L. Provis et al., 2005). Secondary products from the formation of geopolymers are zeolites such as hyroxysodalite, zeolite P and fujasite (Duxson et al., 2007; Garcia-Lodeiro et al., 2014; Palomo et al.,1999).

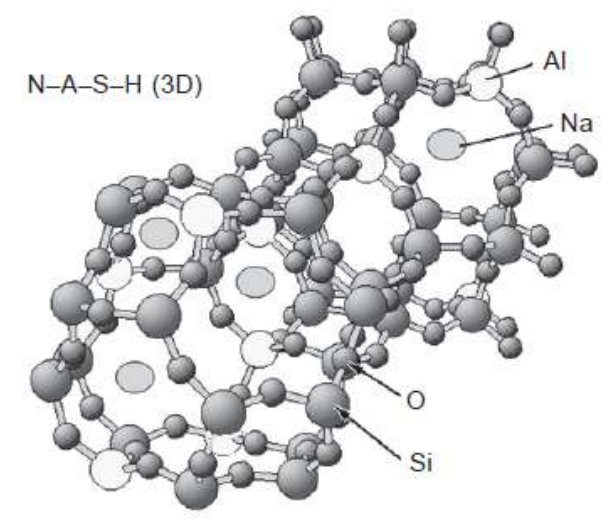

Figure 2.7 Plan view projection of the three-dimensional structure of a N-A-S-H gel (Garcia-Lodeiro et al., 2015).

\subsection{Factors Influencing the Geopolymerisation Process}

The degree of geopolymerization depends on the curing temperature, curing time and the type of activators. Curing temperture and curing time also paly an important role in the formation of silicaintensive geopolymeric gels, the main component responsible of the mechanical strength development. In addition, polymerization degree depends on the silica modulus $\left(\mathrm{SiO}_{2} / \mathrm{Na}_{2} \mathrm{O}\right.$ ratio $)$ of the alkaine activator solution (Garcia-Lodeiro et al., 2014). This is explained by the fact that silica from the precursor materials and the activators (sodiumsilicate) is being utilized, the silica from sodium silicate is higly soluble and is utilized by the N-A-S-H gel upon mixing of waterglass with the aluminosilicagte precursor.

The following factors and conditions are also shown to affect the rate of geopolymerization:

- The percentage of amorphous or reactive silica and alumina in the source material

- Particle size of the source materials, the finer the particle size the better reaction process and geopolymerization degree

- Curing process and curing temperature; geopolymeric formation process is enhanced by higher temperatures 
- Type of aluminosilicate source materials

- Silica to Alumina $\left(\mathrm{SiO}_{2} / \mathrm{Al}_{2} \mathrm{O}_{3}\right)$ ratio

- Sodium to Silica $\left(\mathrm{Na}_{2} \mathrm{O} / \mathrm{SiO}_{2}\right)$ ratio

- Water to Sodium $\left(\mathrm{H}_{2} \mathrm{O} / \mathrm{Na}_{2} \mathrm{O}\right)$ ratio, which represents the alkalinity of the geopolymeric structure

- Alkaline activators types and concentration

- Liquid to solid ratio of the geopolymeric composition

In the literature, there are many publications which discussed the importance of these parameters. For instance:

- Davidovits (2015) used NMR to study the nanostructure of geopolymers and alkali-activated materials (N-A-S-H and K-A-S-H) during the geopolymerization of metakaolin. The N-A-S-H gels has threedimensional (3D) microstructure. The oxygen bonds connect the tetrahedrally coordinated $\mathrm{Si}^{4+}$ and $\mathrm{Al}^{3+}$ cations. Alkaline cations $\left(\mathrm{Na}^{+}\right.$or $\left.\mathrm{K}^{+}\right)$neutralizes the negative charge of the $\mathrm{AlO}^{4-}$ group. He concluded that the degree polymerization and gel structure development depends on the degree of reaction, curing temperature and the presence of soluble silica in the activator (Garcia-Lodeiro et al., 2014).

- Garcia-Lodeiro et al., (2014) and Provis and van Deventer, (2009) explained that the Si/Al ratio and the type of alkali cations of N-A-S-H generated during the geopolymerization of metakaolin has a significant effect on the final geopolymeric structure. The metal alkali cations neutralize the negative charge generated by the substitution of aluminum by silicon tetrahedral. Important to note that, alkali cations are not directly connected with aluminum atoms, they are connected to the negative charged oxygen atoms that surround the aluminum. The nanostructure of the gel consists of small and large sized pores which depends on the chemistry and thermal history of the specimen. One of the major differences between the N-A-S-H and C-S-H gels is that the water in the aluminosilicate gels is not chemically bonded to the structure of the matrix.

- Fernandez-Jimenez et al. (2006) and Garcia-Lodeiro et al., (2014) showed that alumina plays an important role in the geopolymerization process of aluminosilicate materials as it is a sort of stabilizer species in the chemically unstable system. When the alumina and silica species form a N-A-S-H gel, it precipitates into alkaline silicates, which are metastable and not able to generate chemically hardened binder. Hence, alumina comes to action in this important aspect of gelation process by inducing the condensation stage. This action is essential for the formation of a stable geopolymeric structure. 
- Shi et al. (2006) who studied another type of aluminosilicate source materials that is ground blast furnace slag (GBFS) confirmed that $(\mathrm{Na}, \mathrm{K})_{2} \mathrm{O}-\mathrm{CaO}-\mathrm{Al}_{2} \mathrm{O}_{3}-\mathrm{SiO}_{2}-\mathrm{H}_{2} \mathrm{O}$ system is the second type of alkali-activated materials. This is structure of calcium rich aluminosilicate hydrate or C-A-S-H is generated by alkali-activation of calcium rich materials, such as GBFS, in comparatively moderate alkaline conditions. The process of alkaline activation of slag is like OPC. However, the structure and composition of its main reaction product is different than that of the OPC CSH (Figure 2.8). According to Shi et al. (2006) and Provis and van Deventer (2009), for slag to be suitable for alkali activation, it must be granulated with a vitreous phase content of $>85-95 \%$, have a $\mathrm{CaO}+\mathrm{MgO} / \mathrm{SiO}_{2}>1$ and a specific surface of $400-600 \mathrm{~m}^{2} / \mathrm{kg}$. Slag alkali activation takes place by particle destruction stage and polycondensation of reaction products. The process induces the formation of C-A-S-H which compared to the OPC C-S-H has lower $\mathrm{C} / \mathrm{S}$ ratio of $0.9-1.2$.

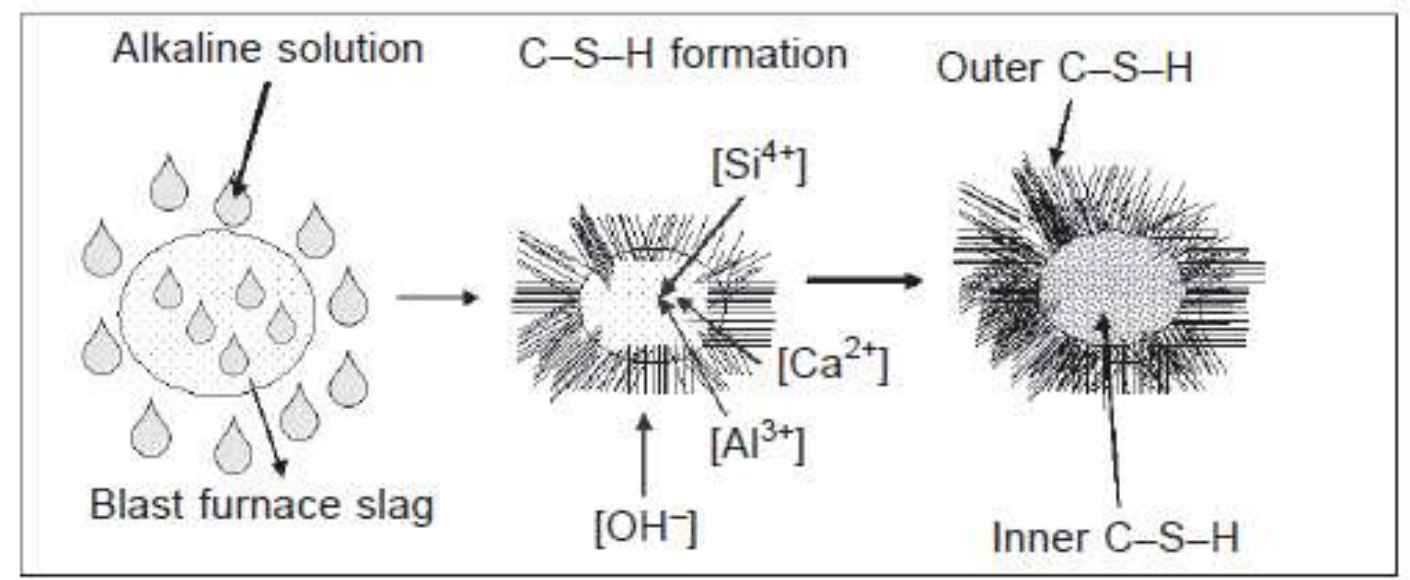

Figure 2.8 Theoretical model for the reaction mechanism in alkali activated slag (Glasser. 1990; Garcia-Lodeiro et al., 2014).

Table 2.1 presents different types of primary and secondary products of hydration, geopolymerization and alkali-activation of various aluminosilicate source materials. 
Table 2.1 Products precipitating in different types of binders (Garcia-Lodeiro et al., 2014)

\begin{tabular}{|c|c|c|c|c|}
\hline \multicolumn{2}{|c|}{ Binder Type } & \multirow{2}{*}{$\mathrm{OPC}$} & \multicolumn{2}{|c|}{ Aluminosilicate source materials } \\
\hline & & & GGBS and FA-C & Metakaolin, Fly ash-F \\
\hline \multirow[b]{2}{*}{ 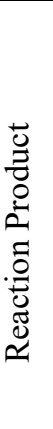 } & Primary & C-S-H & C-A-S-H & N-A-S-H \\
\hline & Secondary & $\begin{array}{c}\mathrm{Ca}(\mathrm{OH})_{2} \\
\mathrm{~A} F_{m} \\
\mathrm{~A} F_{t}\end{array}$ & $\begin{array}{c}\text { Hydrotalcite } \\
{\left[\mathrm{Mg}_{6} \mathrm{Al}_{2} \mathrm{CO}_{3}(\mathrm{OH})_{16} \cdot 4 \mathrm{H}_{2} \mathrm{O}\right]} \\
\mathrm{C}_{4} \mathrm{AH}_{13} \mathrm{CASH}_{8} \\
\mathrm{C}_{4} \mathrm{AcH}_{11} \mathrm{C}_{8} \mathrm{Ac}_{2} \mathrm{H}_{24}\end{array}$ & $\begin{array}{c}\text { Zeolites; } \\
\text { hydroxysodalite, } \\
\text { zeolite } \mathrm{P}, \mathrm{Na}- \\
\text { chabazite, Zeolite Y, } \\
\text { Fujasite }\end{array}$ \\
\hline \multicolumn{5}{|c|}{$\mathrm{C}=\mathrm{CaO}, \mathrm{S}=\mathrm{SiO}_{2}, \mathrm{~A}=\mathrm{Al}_{2} \mathrm{O}_{3}, \mathrm{~N}=\mathrm{Na}_{2} \mathrm{O}, \mathrm{H}=\mathrm{H}_{2} \mathrm{O}, \mathrm{C}=\mathrm{CO}_{2}$} \\
\hline
\end{tabular}

- Garcia-Lodeiro et al. (2014) who tested the activation of slag with different alkaline activators explained that slag-based binder gel activated with sodium silicate, or waterglass, is uniformly amorphous, while $\mathrm{NaOH}$ as activator results in a semi-crystalline C-S-G gel. Also, with the sodium silicate, the crystallinity is very low during the first year of activation. EDX microanalysis of the pastes activated with sodium silicate and sodium hydroxide has $\mathrm{Ca} / \mathrm{Si}$ ratios of (0.6-0.7) and (0.9-1.0), respectively. Aluminum and sodium were present in the composition of binders and a secondary phase of hydrotalcite, a magnesium and aluminum rich material, was detected as well.

- According to Hardjito \& Rangan, 2005 and Rangan, 2014, $\mathrm{NaOH}$ is commonly used as alkaline activator, compared to $\mathrm{K}^{+}$cations $\mathrm{Na}^{+}$has lower level of activation. However, they are smaller and can easily migrate throughout the aluminosilicate binder network which results in better geopolymeric network formation. Higher molarity of $\mathrm{NaOH}$ in a binder results in accelerated dissolution but it also retards ettringite formation. It also leads to excessive hydroxyl groups $\left(\mathrm{OH}^{+}\right)$which cause unwanted morphology and non-uniformity of geopolymeric material (Khale and Chaudhary, 2007; Petermann \& Saeed, 2012). High early age mechanical strength is obtained with the use of $\mathrm{KOH}$ in different concentrations. $\mathrm{K}^{+}$helps achieve higher rate of polymeric ionization dissolution which leads to a denser network formation and as a result greater compressive strength is achieved. However, some researchers found that $\mathrm{NaOH}$ in low concentration provides higher reactivity. Higher concentration of both $\mathrm{KOH}$ and $\mathrm{NaOH}$ results in increased mechanical properties. Khale and Chaudhary (2007) concluded that geopolymeric samples with 13-14 pH produce higher mechanical strengths. A geopolymer with a $\mathrm{pH}$ of 14 obtained five times greater strength than that with a $\mathrm{pH}$ of 12 . Meanwhile, excessive $\mathrm{NaOH}$ leaches 
out of the geopolymer and reacts with the environmental carbon resulting in carbonation and efflorescence. Although, $\mathrm{KOH}$ produce higher mechanical strengths and improved porosity in geopolymeric cements, strength reduction was observed above 10 molarity because the excessive $\mathrm{K}^{+}$ cations leaches $\mathrm{Si} / \mathrm{Al}$ in $\mathrm{KOH}$ based geopolymers (Petermann et al., 2010).

\subsection{Classification and Characteristics of Alkali-Activated Binders}

Alkali-activated cements require precusors or the source of aluminosilicates and alkaline activartors which are usually caustic alkalis or alkaline salts. Glukhovsky (1967) classified the alkaline activators into six groups accordign to their chemical compositions: Caustic alkalies (MOH), Non-silicate weak acid salts $\left(\mathrm{M}_{2} \mathrm{CO}_{3}, \mathrm{M}_{3} \mathrm{PO}_{4}, \mathrm{M}_{2} \mathrm{SO}_{3}, \mathrm{MF}\right)$; Silicates $\left(\mathrm{M}_{2} \mathrm{O} . n \mathrm{SiO}_{2}\right) ;$ Aluminates $\left(\mathrm{M}_{2} \mathrm{O} . n \mathrm{Al}_{2} \mathrm{O}_{3}\right)$; Aluminosilicates $\left(\mathrm{M}_{2} \mathrm{O} \cdot \mathrm{nAl}_{2} \mathrm{O}_{3} \cdot(2-6) . \mathrm{SiO}_{2}\right)$; Non-silicate strong acid salts $\left(\mathrm{M}_{2} \mathrm{SO}_{4}\right)$. Based on their availabilty and cost $\mathrm{NaOH}, \mathrm{Na}_{2} \mathrm{CO}_{3}, \mathrm{Na}_{2} \mathrm{O} . \mathrm{nSiO}_{2}$ and $\mathrm{Na}_{2} \mathrm{SO}_{4}$ are most widely used alkaline activtors (Shi et al., 2012).

Taking into account the composition of the cementitous precursor, alkali-activated cements are classified into five categories (J. Davidovits, 2015; Shi et al., 2011):

1. Alkali-activated slag-based cements

2. Alkali-activated pozzolan cements

3. Alkali-activated lime-pozzolan/slag cements

4. Alkali-activated calcium-aluminate blended cements

5. Alkali-activated portland blended cements (hybrid cements)

\subsubsection{Alkali-activated Slag Based Cement}

Alkali-activated slag-based cements are divided into the following systems (Shi et al., 2011):

- Alkali-activated blast furnace slag cement

- Alkali-activated phosphorus slag cement

- Alkali-activated blast furnace slag-fly ash

- Alkali-activated blast furnace slag-steel slag

- Alkali-activated blast furnace slag-MGO

- Alkali-activated blast furnace slag-based multiple component cement 
Slag-based alkali-activated binders have been widley studied, the mechanical and microsturcural properties these cements are contolled by the type of slag and the type and dosage of the activators. Welldesigned alkali-activated slag cements showed higher mechanical properties than Portland cements. Figure (2.9) shows that slag activated with sodium silicate alkline activator achieves much higher compressive strengths in early and later ages compared to OPC, whereas sodium carbonate or $\mathrm{NaOH}$ activated slag binders show lower mechanical properties.

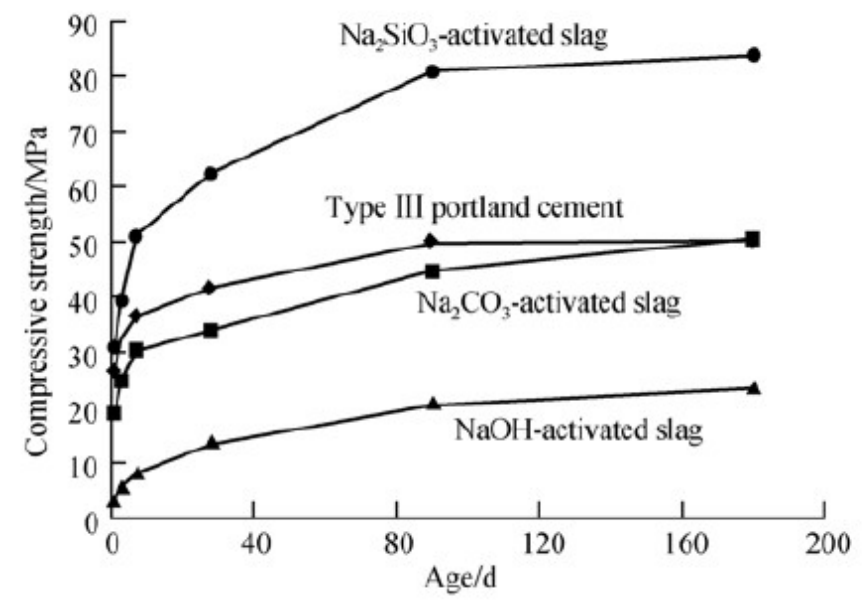

Figure 2.9 Strength development of alkali-activated slag and Portland cement mortars (Shi et al., 2012).

\subsubsection{Alakli-activated Pozzolan Cements}

Glukhovsky in 1950s and 60s described the alkali-actiavtion of aluminosilicate materials. He explained the mechanism behind the alkali-activation process and divided the process into three stages of (1) destruction-coagulation, (2) coagulation-condensation and (3) condensation-crystallization. He called these materials "soil cements". Krivenko (1997) called them "geocements" and Davidovits (2008) called them "geopolymers" based on their polymeric structure. Following cementitious systems of alkaliactivated pozzolan cements are defined by Shi et al. (2011). Current research studies are mostly performed on this class of alkali-activated cements, especially the study of metakaolin and fly ash based geopolymer after the term was coined by Davidovits in 1979:

- Alkali-activated fly ash cement

- Alkali-activated natural pozzolan cemnent

- Alkali-activated metakaolin cement

- Alkalia-activated soda lime glass cement 


\subsubsection{Alakli-activated Lime-Pozzolan/slag Cements}

Lime pozzolan mortars have been used since Neolithic period (7000 BC) long before Greek and Roman application (Malinowski and Garfinkel, 1991; Shi et al., 2011). Different structures were build from these cemetns such as aqueducts, dykes, harbours, buildings, arch bridges and retaining walls. The invention of Portalnd cement almost removed the use of lime-pozzolan cements in the construction, the alkaliactivated lime-pozzolan/slag cements include following systems:

- Alkali-activated lime-natural pozzolan cement

- Alkali-activated lime-fly ash cement

- Alkali-activated lime-metakaolin cement

- Alkali-activated lime-blast furnace slag cement

According to Shi et al. $(2012,2011)$ alkali-activated lime-pozzolan cements can only be activated by alkali hydroxides and alkali sulphastes, the early age strengths of this type cements can be significantly improved when activated with alkine solutions. C-A-S-H gel is formed as the main reaction product during alkaline-activation of lime-pozzolan cements, nontheless, a co-precipitation of C-S-H and N-AS-H gels is possible in highly alkaline systems (Garcia-Lodeiro, Palomo, Fernández-Jiménez, \& MacPhee, 2011).

\subsubsection{Alakli-Activated Calcium Aluminate Blended Cements}

In order to activae aluminosilicate materials the alkaline activator must be highly soluble, and high amount of soluble silica and alumia in the system. Highly soluble silica is more readily available compred to alumina and therefore, more recent studies focus on the additon of calcium aluminate cements (CAC) as a reactive alumina source, folliwng systems are studied thus far:

- Alkali-activated metakaolin/CAC

- Alkali-activated pozzolan/CAC

- Alkali-activated fly ash/CAC

Addition of calcium aluminate cements (CAC) in the alkali-activation of aluminosilicate materials forms a metastable intermediate compound, the alumina and calcium in CAC is utilized in the N-A-S-H gel and depending on the blend proportion and mixing conditions, two types of gels co-precipitates as result, a majority N-A-S-H and minority C-A-S-H. Added reactive aluminum plays important role in the formation of N-A-S-H and the tetrahedral alumina which help create a stable system, this reactive 
alumina is supplie by addintion of CAC, less than $30 \%$ of CAC should be added to the blended system (Fernández-Jiménez, Palomo, Sobrados, \& Sanz, 2006; Shi et al., 2011).

\subsubsection{Alakli-Activated Portland Blended Cements: Hybrid Cements}

Addition of Portland cement to different supplementary cementitious materials in alkalis-activated system have been widely studied. This material improves setting time and early age characteristics of most precursor materials such as fly ash, blast furnace slag and natural pozzolan. The following cementitious systems have been investigated thus far:

- Alkali-activated Portland blast furnace slag cement

- Alkali-activated Portland phosphorus slag cement

- Alkali-activated Portland fly ash cement

- Alkali-activated Portland blast furnace slag-steel slag cement

- Alkali-activated Portland blast furnace slag-fly ash cement

- Alkali-activated multiple components blended cements

\subsection{Construction and Demolition Wastes (CDWs) Based Geopolymers}

Although, construction and demolition wastes (CDWs) constitute a large amount of waste solid materials going to landfills, and their chemical composition is rich in silica and alumina, limited research has taken place on CDW based geopolymers. However, a recent agreement about the suitability of CDW powders to be activated through geopolymerization processes has attracted global attention from specialists (Allahverdi \& Kani, 2013; Reig et al., 2013; Robayo-Salazar, Rivera, \& Mejía de Gutiérrez, 2017). Indeed, CDWs such as brick, tile and concrete wastes which have the suitable contents of silica and alumina have been used successfully to generate geopolymer binders. Figure 2.10 shows the position of concrete wastes $(\mathrm{CW})$, red clay brick wastes (RCBW) and tiles, compared to that of different SCMs, in the triangular chemical compounds (Dadsetan et al. 2019). From this figure, RCBW and tiles have higher $\mathrm{SiO}_{2}$ and $\mathrm{Al}_{2} \mathrm{O}_{3}$ and reduced $\mathrm{CaO}$ amounts compared to CW. However, Dadsetan et al. (2019) noticed that most CDW materials considered in Figure 2.10 have diverse chemical compositions from one region to another in the world. Therefore, the comparison between the results of the literature remain more qualitative, if not considering the chemical composition and the physical properties of CDW materials objects of geopolymerisation processes. 


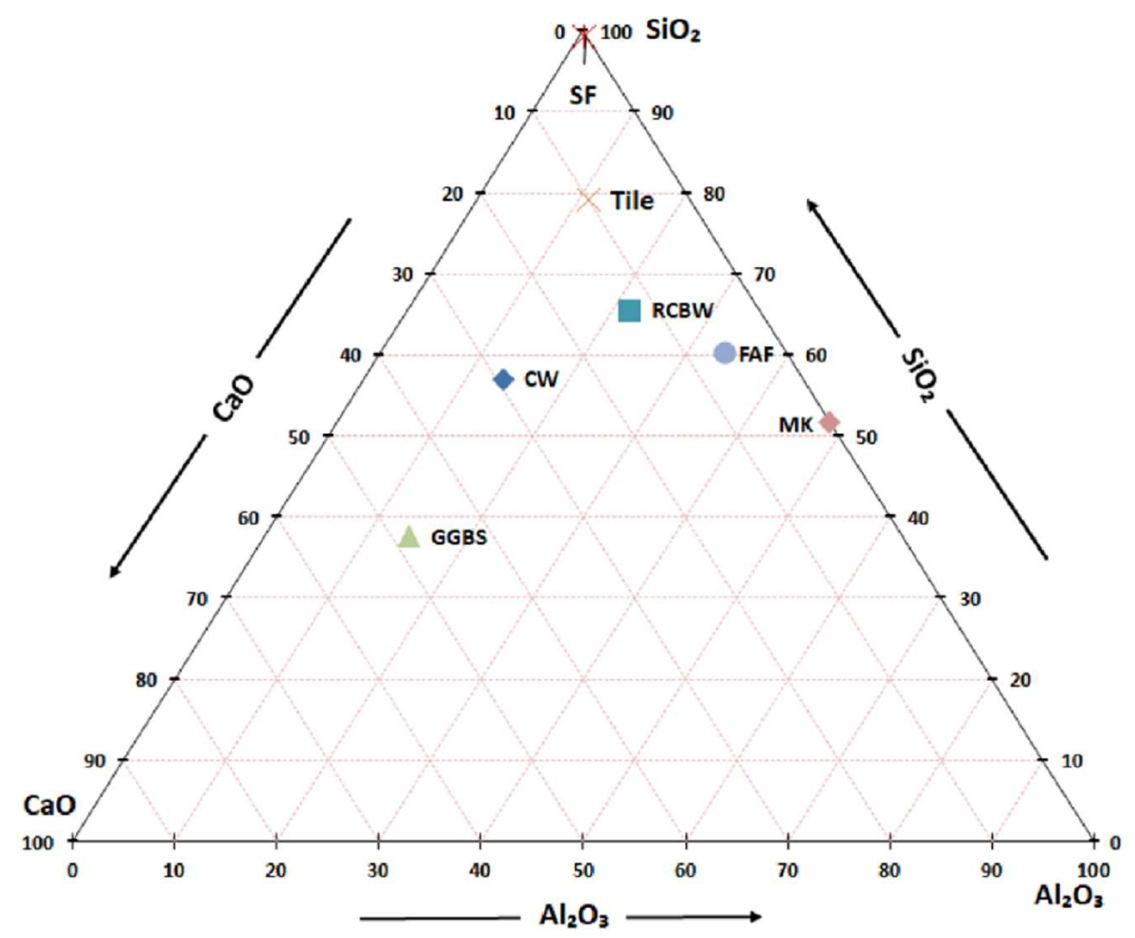

Figure 2.10 The positions of most concrete waste (CW), red clay brick waste (RCBW), tile, class F Fly ash (FAF), ground granulated blast furnace slag (GGBS), silica fume (SF), and Metakaolin (MK) in the triangular chemical compounds (Dadsetan et al. 2019)

\subsubsection{Literature Review on the Use of CDWs in Geopolymer Systems}

Brick, tile, ceramic and concrete wastes are CDW components that are most widely studied by researchers and the potential of these materials to produce structural and non-structural geopolymer concretes is confirmed in literature (Robayo et al., 2016). However, adding different SCMs was also showed to highly improve the mechanical strengths of various CDW-based geopolymers. Table 2.2 presents a summary of the previous research studies that investigated the application of CDWs in geopolymer concretes. 
Table 2.2 Summary of research papers on the use of CDWs in geopolymer systems

\begin{tabular}{|c|c|c|c|c|}
\hline Reference & $\begin{array}{l}\text { Major CDW } \\
\text { Precursors and } \\
\text { Alkali-Activators }\end{array}$ & $\begin{array}{l}\text { Studied } \\
\text { Parameters }\end{array}$ & Results & $\begin{array}{l}\text { Important } \\
\text { Conclusions }\end{array}$ \\
\hline $\begin{array}{l}\text { Robayo et } \\
2016\end{array}$ & $\begin{array}{lr}\text { Red clay } & \text { brick } \\
\text { waste with } & \text { sodium } \\
\text { hydroxide } & \text { or/and } \\
\text { sodium } & \text { silicate } \\
\text { solutions } & \end{array}$ & $\begin{array}{l}\text { Compressive } \\
\text { Strength, SEM, } \\
\text { FTIR. } \\
\text { Evaluation } \\
\text { adding OPC }\end{array}$ & $\begin{array}{l}28 \text { days maximum } \\
\text { strength of } 54.38 \\
\mathrm{MPa}\end{array}$ & $\begin{array}{l}\text { Suitability of RCBW } \\
\text { for } \\
\text { geopolymerization } \\
\text { was demonstrated, - } \\
10 \% \mathrm{Na}_{2} \mathrm{O} \text { is the } \\
\begin{array}{l}\text { optimum for } \\
\text { achieving } \\
\begin{array}{l}\text { compressive } \\
\text { strengths }\end{array}\end{array}\end{array}$ \\
\hline $\begin{array}{l}\text { Allahverdi } \\
\text { and Kani, } \\
2009\end{array}$ & $\begin{array}{l}\text { Waste brick and } \\
\text { concrete waste } \\
\text { with various \%. } \\
\mathrm{Na}_{2} \mathrm{O}(\mathrm{wt} \% \text { ) and } \\
\text { water/dry binder } \\
\text { ratio }\end{array}$ & $\begin{array}{l}\text { Compressive } \\
\text { strength, } \\
\text { setting time, } \\
\text { infrared } \\
\text { spectroscopy, } \\
\text { SEM analysis }\end{array}$ & $\begin{array}{lr}\text { Max } & \text { 28-day } \\
\text { compressive } & \text { strength } \\
\text { was } 50 \mathrm{MPa} \\
\text { Severe efflorescence } \\
\text { was observed }\end{array}$ & $\begin{array}{l}\text { Waste brick is more } \\
\text { suitable for } \\
\text { geopolymerization } \\
\text { than concrete waste. } \\
8 \% \mathrm{Na}_{2} \mathrm{O} \text { by weight of } \\
\text { dry binder provides } \\
\text { highest compressive } \\
\text { strength. }\end{array}$ \\
\hline $\begin{array}{l}\text { Allahverdi } \\
\text { and Kani, } \\
2013\end{array}$ & $\begin{array}{l}\text { Waste brick and } \\
\text { waste concrete } \\
\text { activated with } \\
\text { sodium hydroxide } \\
\text { and sodium silicate }\end{array}$ & 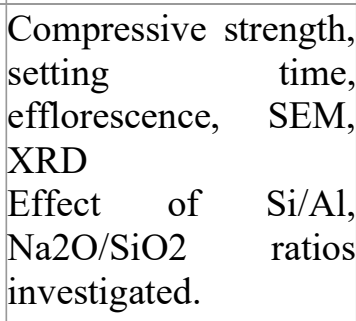 & $\begin{array}{l}\text { Max } \\
\text { compressive } \\
\text { strength at } 28 \\
\text { days was } 50 \mathrm{MPa} \\
-\quad \text { Severe } \\
\text { Efflorescence } \\
\text { observed }\end{array}$ & $\begin{array}{l}\text { The optimized } \\
\text { compositions of } \\
\text { brick waste } \\
\text { geopolymers } \\
\text { were confirmed } \\
\text { to be suitable for } \\
\text { structural use. }\end{array}$ \\
\hline $\begin{array}{l}\text { Rakhimova } \\
\text { and } \\
\text { Rakhimov, } \\
2015\end{array}$ & $\begin{array}{l}\text { Various } \\
\text { concentration of } \\
\text { RCBW and slag. } \\
\text { Sodium } \\
\text { carbonate or } \\
\text { sodium silicate }\end{array}$ & $\begin{array}{l}\text { Influence } \quad \text { of } \\
\text { grinding } \\
\text { method, setting } \\
\text { time } \quad \text { and } \\
\text { compressive } \\
\text { strength }\end{array}$ & $\begin{array}{l}28 \text { Day-strengths } \\
\text { Of } \\
\text { RCBW/GGBFS: } \\
0 / 100-97 \mathrm{MPa} \\
20 / 80-15 \mathrm{MPa} \\
40 / 60-12 \mathrm{MPa} \\
60 / 40-91 \mathrm{MPa} \\
80 / 20-75 \mathrm{MPa} \\
100 / 0-0 \mathrm{MPa}\end{array}$ & $\begin{array}{l}\text { The strength was } \\
\text { affected by the type } \\
\text { of alkali-activator, } \\
\text { concentration of } \\
\text { RCBW, grinding } \\
\text { method and curing } \\
\text { conditions }\end{array}$ \\
\hline $\begin{array}{l}\text { Komnistas } \\
\text { et al. } \\
(2015)\end{array}$ & $\begin{array}{l}\text { Bicks, tiles and } \\
\text { concrete waste. } \\
\text { Sodium } \\
\text { hydroxide and } \\
\text { sodium silicate } \\
\text { solutions }\end{array}$ & $\begin{array}{l}\text { - Effects of } \\
\text { alkali-activators, } \\
\text { curing } \\
\text { temperature, } \\
\text { NaOH molarity } \\
\text { and particle size. } \\
\text { - Freeze-thaw } \\
\text { cycles and water } \\
\text { immersion was } \\
\text { also investigated }\end{array}$ & $\begin{array}{l}\text { Best results were } \\
\text { at } 90^{\circ} \mathrm{C} \text { curing, } \\
\text { with } 8-14 \quad \mathrm{M} \\
\mathrm{NaOH} \text { molarity } \\
\text { - Max strengths } \\
\text { were: Brick } 57.8 \\
\mathrm{MPa} \\
\text { Tile } 49.5 \mathrm{MPa} \\
\mathrm{CW}-13 \mathrm{MPa}\end{array}$ & $\begin{array}{l}\text { Bricks and tiles } \\
\text { have better } \\
\text { geopolymerization } \\
\text { ability } \\
\text { than waste } \\
\text { concrete. } \\
\text { Sodium hydroxide } \\
\text { molarity in the } \\
\text { range of } 8 \text { to } 10 \mathrm{M} \\
\text { results in optimal } \\
\mathrm{CS}\end{array}$ \\
\hline
\end{tabular}




\begin{tabular}{|c|c|c|c|c|}
\hline $\begin{array}{l}\text { Reig et al., } \\
2013\end{array}$ & $\begin{array}{l}\text { Red clay brick } \\
\text { waste and. } \\
\text { NaOH and } \\
\text { sodium silicate } \\
\text { solutions }\end{array}$ & $\begin{array}{l}\text { Type and } \\
\text { concentration of } \\
\text { alkali activators, } \\
\text { optimization of } \\
\text { water/binder, } \\
\text { binder/Sand and } \\
\mathrm{SiO}_{2} / \mathrm{Na}_{2} \mathrm{O} \text { ratios } \\
\text { for mortar } \\
\text { compositions }\end{array}$ & $\begin{array}{l}\text { - At } 65^{\circ} \mathrm{C} \text { curing } 30 \\
\mathrm{MPa} \\
\text { - Up to } 50 \mathrm{MPa} \text { by } \\
\text { optimizing the } \mathrm{W} / \mathrm{B} \text {, } \\
\mathrm{B} / \mathrm{S} \text { and } \mathrm{SiO} 2 / \mathrm{Na} 2 \mathrm{O} \\
\text { ratios. }\end{array}$ & $\begin{array}{l}\text { Strength can be } \\
\text { enhanced by } \\
\text { optimizing } \\
\text { silica/sodium } \\
\text { oxide, water/binder } \\
\text { and binder/sand } \\
\text { ratios. }\end{array}$ \\
\hline $\begin{array}{l}\text { Robayo et al., } \\
2017\end{array}$ & $\begin{array}{l}\text { Recycled clay brick } \\
\text { waste, concrete } \\
\text { waste and glass } \\
\text { waste activated by } \\
\mathrm{NaOH}, \text { with and } \\
\text { without } \mathrm{Na}_{2} \mathrm{SiO}_{3} \\
\text { solutions. }\end{array}$ & $\begin{array}{l}\text { Effects of } \mathrm{NaOH} \text {, } \\
\text { and combined } \\
\mathrm{NaOH}+\mathrm{Na} 2 \mathrm{SiO} 3 \\
\text { activators. } \\
\mathrm{Si} / \mathrm{A} 1, \mathrm{Na}_{2} \mathrm{O} / \mathrm{SiO}_{2} \\
\text { moral ratios, } \\
\text { concentration of } \\
\mathrm{Na}_{2} \mathrm{O} \\
\text { and effect of up to } \\
20 \% \text { OPC in the } \\
\text { geopolymeric mix. }\end{array}$ & $\begin{array}{l}28 \text { Days compressive } \\
\text { strength of } 102 \mathrm{MPa} \\
\text { for } 80 \% \mathrm{RCBW}+20 \% \\
\mathrm{OPC} \text {, and } 33 \text { and } 57 \\
\mathrm{MPa} \text { for } \mathrm{CW} \text { and } \\
\mathrm{GW} \text {, respectively. }\end{array}$ & $\begin{array}{l}\text { Viability of RCBW, CW } \\
\text { and GW to create useful } \\
\text { building materials. These } \\
\text { materials can easily } \\
\text { comply with the } \\
\text { construction codes in } \\
\text { developing world. }\end{array}$ \\
\hline $\begin{array}{l}\text { Zaharaki } \\
\text { et al. } \\
2016\end{array}$ & $\begin{array}{l}\text { Concrete waste, brick, } \\
\text { tile, red mud and } \\
\text { electric arc furnace } \\
\text { slag. } \\
\begin{array}{l}\mathrm{NaOH} \text { and } \mathrm{Na}_{2} \mathrm{SiO}_{3} \\
\text { solutions }\end{array}\end{array}$ & $\begin{array}{l}\text { Effects of slag } \\
\text { replacements with } \\
\mathrm{CW}, \text { tile and brick } \\
\text { along with red } \\
\text { mud in quaternary } \\
\text { mixes. NaOH } \\
\text { molarity and } \\
\text { liquid/solid ratio }\end{array}$ & $\begin{array}{l}2.5-76.1 \mathrm{MPa} \\
\text { binder }\end{array}$ & $\begin{array}{l}\text { Silica/alumina and } \\
\text { silica/calcium oxide } \\
\text { ratios, with } \\
\text { adequate sodium } \\
\text { hydroxide } \\
\text { concentration, are } \\
\text { important to } \\
\text { reach high strengths and } \\
\text { properties. }\end{array}$ \\
\hline $\begin{array}{l}\text { Ahmari et al. } \\
2012\end{array}$ & $\begin{array}{l}\text { Waste concrete with } \\
\text { FA class F. } \\
\text { NaOH and } \mathrm{Na} 2 \mathrm{SiO} 3 \\
\text { solutions }\end{array}$ & \multicolumn{2}{|c|}{\begin{tabular}{l|l} 
Different replacement & $6-34 \mathrm{MPa}$ \\
levels of WC with FA. binder \\
$\mathrm{NaOH}$ molarity and & \\
$\mathrm{Na}_{2} \mathrm{SiO}_{3}$ to $\mathrm{NaOH}$ & \\
ratios. & \\
Compressive strength, & \\
XRD, SEM and & \\
infrared spectroscopy &
\end{tabular}} & $\begin{array}{l}\text { Adding FA-F enhanced } \\
\text { the strength; however, } \\
\text { under a threshold of } \\
\text { elemental ratios. } \\
\text { Increased NaOH } \\
\text { concentration resulted in } \\
\text { better strengths }\end{array}$ \\
\hline $\begin{array}{l}\text { Sun et al. } \\
(2013)\end{array}$ & $\begin{array}{l}\text { Waste ceramic. } \\
\text { Combinations of } \\
\mathrm{NaOH}, \mathrm{KOH} \text { and } \\
\mathrm{Na}_{2} \mathrm{SiO}_{3} \text { solutions } \\
\text { solution }\end{array}$ & $\begin{array}{l}\text { Compressive strength, } \\
\text { TGA, XRD, SEM } \\
\text { Analyses and infrared } \\
\text { spectroscopy }\end{array}$ & $\begin{array}{l}26-71 \mathrm{MPa} \\
\text { Binder at } 60^{\circ} \mathrm{C} \text { initial } \\
\text { curing temperature. }\end{array}$ & $\begin{array}{l}\text { The type of alkaline } \\
\text { activators highly } \\
\text { influenced the strengths } \\
\text { of the geopolymeric } \\
\text { binders. }\end{array}$ \\
\hline
\end{tabular}




\begin{tabular}{|c|c|c|c|c|}
\hline $\begin{array}{l}\text { Rovnaník } \\
\text { et al. } \\
(2016)\end{array}$ & $\begin{array}{l}\text { Brick powder and FA } \\
\mathrm{NaOH} \text { and } \mathrm{Na}_{2} \mathrm{SiO}_{3} \\
\text { solutions }\end{array}$ & $\begin{array}{l}\text { Different } \\
\text { replacements of Fly } \\
\text { ash by brick powder } \\
\text { with a } \mathrm{SiO}_{2} / \mathrm{Na}_{2} \mathrm{O} \\
\text { ratio of } 1 . \\
\text { Compressive and } \\
\text { flexural strengths, } \\
\text { bulk density, SEM } \\
\text { analysis }\end{array}$ & $\begin{array}{l}5-65 \mathrm{MPa} \\
\text { Binder at } 21 \pm 2{ }^{\circ} \mathrm{C} \text { and } \\
50 \pm 5 \% \text { relative } \\
\text { humidity }\end{array}$ & $\begin{array}{l}50 \% \text { FA level with brick } \\
\text { powder replacement } \\
\text { was achieved the } \\
\text { optimum strengths. } \\
\text { The structure of mono } \\
\text { brick-based } \\
\text { geopolymer was less } \\
\text { compact than that of FA- } \\
\text { based geopolymer. }\end{array}$ \\
\hline $\begin{array}{l}\text { Khater et al. } \\
(2016)\end{array}$ & $\begin{array}{l}\text { RCBW, Ceramic } \\
\text { waste. } \\
\mathrm{NaOH} \text { solution }\end{array}$ & $\begin{array}{l}\text { Different } \\
\text { compositions of } \\
\text { RCBW and ceramic } \\
\text { wastes with a step of } \\
20 \% \text { for NaOH } \\
\text { molarity of } 8 \text {. Effect } \\
\text { of Water/binder ratio. } \\
\text { Compressive strength, } \\
\text { and water absorption }\end{array}$ & $\begin{array}{l}19-48 \mathrm{MPa} \\
\text { Mortar at } 40{ }^{\circ} \mathrm{C} \text { curing } \\
\text { temperature and } 100 \% \\
\text { relative humidity }\end{array}$ & $\begin{array}{l}\text { Increased ceramic waste } \\
\text { levels resulted an higher } \\
\text { mechanical } \\
\text { properties compared to } \\
\text { RCBW. }\end{array}$ \\
\hline
\end{tabular}

\subsubsection{Effect of Particle Size of CDW Powders}

The particle size of CDW powders were showed to play an important role in the development of mechanical and durability properties of geopolymers. Smaller particles were confirmed with higher bonding and compressive strengths. For instance, Komnitsas et al. (2015) studied the compressive strengths of tile geopolymer pastes prepared with different fineness of tile particles, as presented in Figure 2.11a. The results indicated that, as the particle size decreased from 477 to 140 micron (d50 decreases from 76 to $14 \mu \mathrm{m}$ ), the compressive strength increased from 38-58 $\mathrm{MPa}$ at $80{ }^{\circ} \mathrm{C}$ curing temperature and $10 \mathrm{M} \mathrm{NaOH}$. Also, brick geopolymer results presented in Figure $2.11 \mathrm{~b}$ explained that strengths increased from $5 \mathrm{MPa}$ to $35 \mathrm{MPa}$ when the particle size was reduced from $351 \mu \mathrm{m}$ to $140 \mu \mathrm{m}$ at $8 \mathrm{M} \mathrm{NaOH}$ and $80^{\circ} \mathrm{C}$ curing temperature. The reduced particle size of concrete waste was also studied by Komnitsas et al. (2015). The compressive strengths of concrete waste geopolymer increased from $2 \mathrm{MPa}$ to almost 4.5 $\mathrm{MPa}$ when the particle size was reduced from 400 microns to 190 microns (Figure 2.11c). 


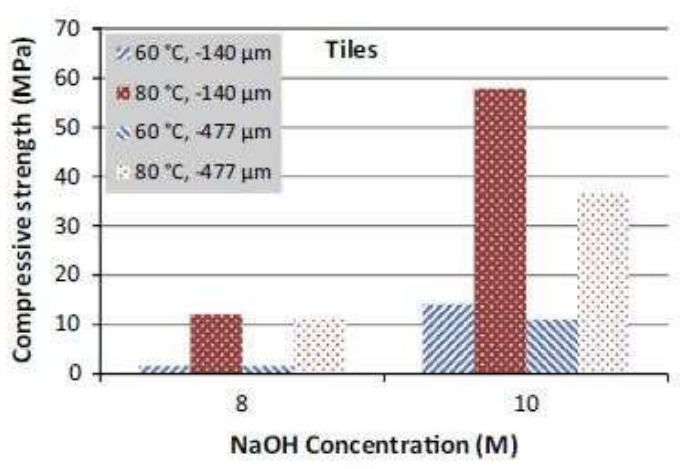

(a)

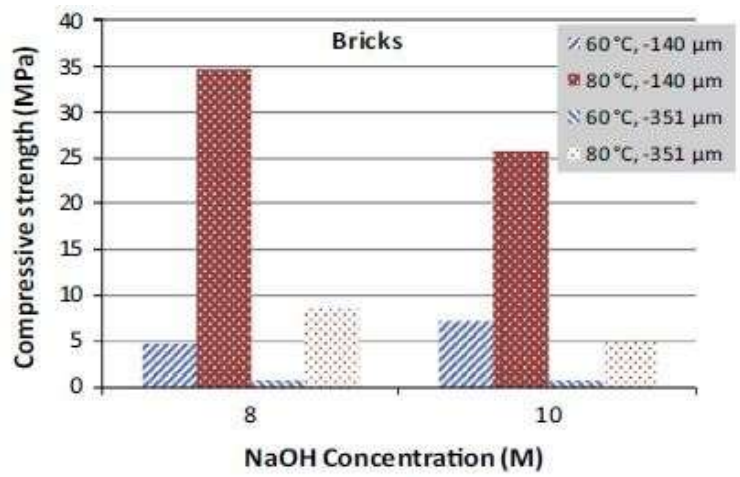

(b)

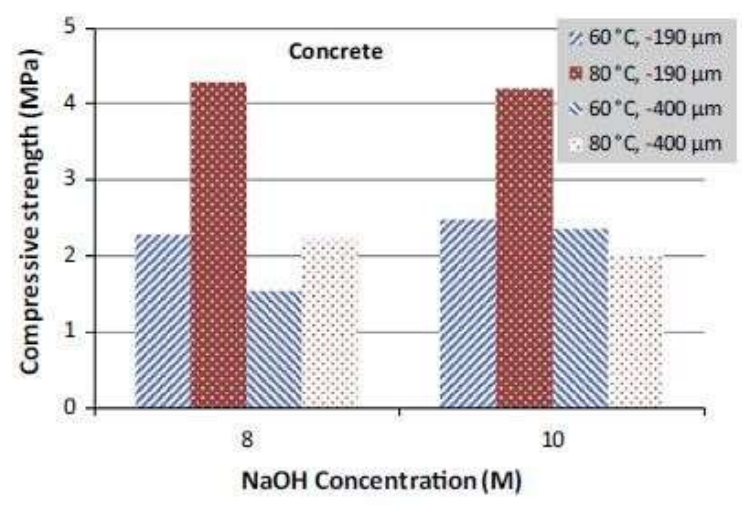

(c)

Figure 2. 11 Effect of particle size of raw materials on the compressive strength of geopolymers produced from (a) tiles (b) bricks and (c) concrete waste (Komnitsas et al. 2015).

\subsubsection{Effects of $\mathrm{NaOH}$ Concentration of CDW-based Geopolymers}

The change in $\mathrm{NaOH}$ concentration was confirmed to be an important parameter that can influence the density and homogeneity of geopolymer matrices. A threshold level of sodium hydroxide concentration can result in a denser system of CDW-based geopolymers; however, excessing certain amount of $\mathrm{NaOH}$ can negatively affect their stability and mechanical properties (Kourti et al., 2010). Dadsetan et al. (2019) reviewed the effect of various $\mathrm{NaOH}$ molarities on the compressive strengths of different CDW materials. They used the data reported or calculated from eleven publications to arrange the curves shown in Figure 2.12. The threshold level range of $\mathrm{NaOH}$ molarities was between 8 and $11 \mathrm{M}$ as indicated by the vertical red lines. For instance, Komnitsas et al. (2015) tested the compressive strengths of CW, brick and tilegeopolymer pastes at $\mathrm{NaOH}$ molarity range of $8-14 \mathrm{M}$ and curing temperatures of 60 and $80^{\circ} \mathrm{C}$. The 
results indicated peak $\mathrm{NaOH}$ concentrations of $10 \mathrm{M}$ and $8 \mathrm{M}$ for tile and brick respectively, at curing temperature of $80^{\circ} \mathrm{C}$. However, the concentration of $\mathrm{NaOH}$ was showed with negligible effect on the strengths of $\mathrm{CW}$-pastes cured at $60{ }^{\circ} \mathrm{C}$ and $80{ }^{\circ} \mathrm{C}$. In addition, Allahverdi and Najafi Kani (2009) investigated a $\mathrm{NaOH}$ concentration of 2 to10 $\mathrm{M}$ for brick and 6 to $8 \mathrm{M}$ for concrete waste-based geopolymers. The authors explained that the maximum strength was reached at an optimum $\mathrm{NaOH}$ molarity of $8 \mathrm{M}$ for both brick and tile-geopolymers cured at temperatures of $60{ }^{\circ} \mathrm{C}$ and $80{ }^{\circ} \mathrm{C}$.

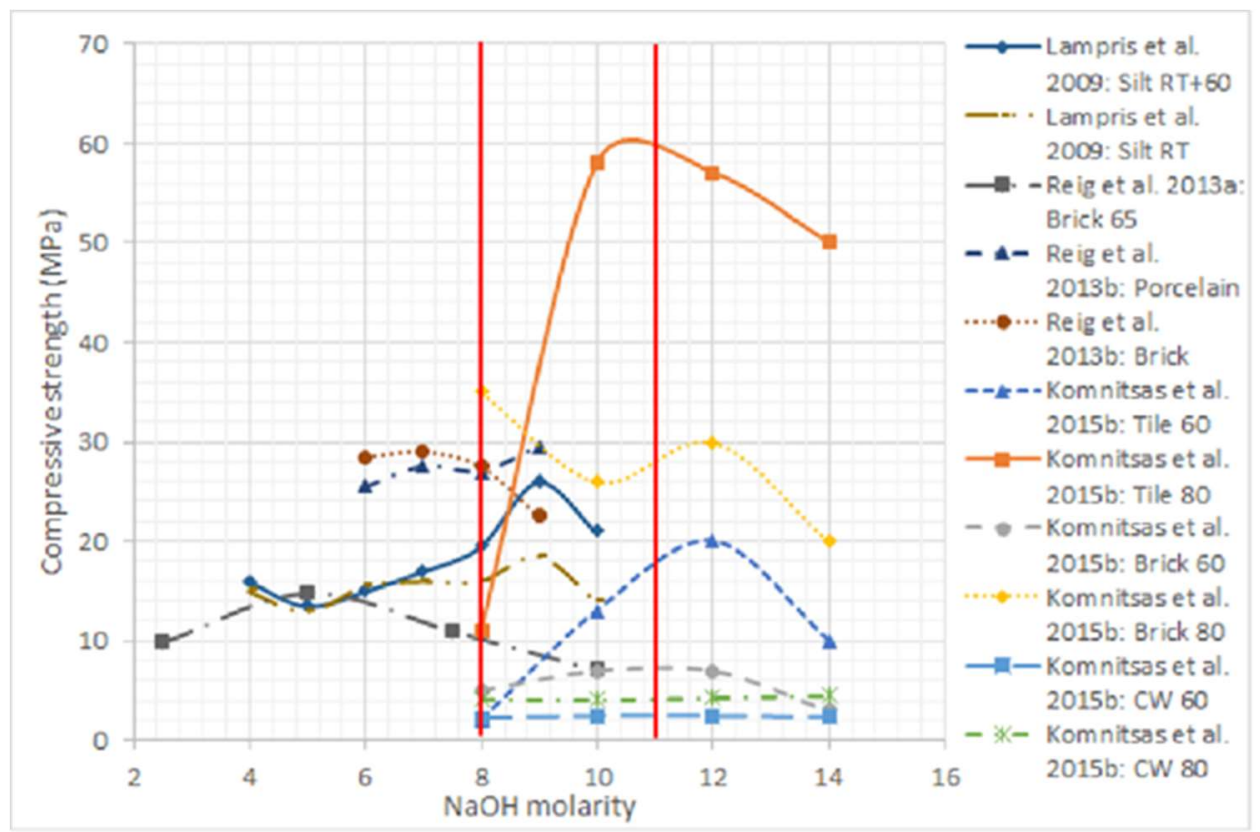

Figure 2.12 Effect of $\mathrm{NaOH}$ molarity on the compressive strengths of alkali-activated CDW materials (RT: room temperature, 60 and 80: curing at $60^{\circ} \mathrm{C}$ and $80^{\circ} \mathrm{C}$ ) (Dadsetan et al. 2019)

Alkali activated RCBW pastes and mortars with $\mathrm{NaOH}$ concentrations of 2.5, 5, 7 and 10 molality and a constant water to binder ratio of 0.45 were studied by Reig et al. (2013b). As presented in Figure 2.13, at 7 days curing, composition with 5 molar $\mathrm{NaOH}$ demonstrated the best compressive strength (almost $15 \mathrm{MPa}$ ). The compressive strength decreased as the molality of $\mathrm{NaOH}$ concentration increased. According to the authors, the optimum concentration of $\mathrm{Na}^{+}$depends on the aluminosilicate powders, its concentration should be enough to balance $\mathrm{Si}$ and $\mathrm{Al}$ in the geopolymeric bonds, and $\mathrm{NaOH}$ should not be excessive in the reaction to don't create efflorescence by reacting with atmospheric carbon. 


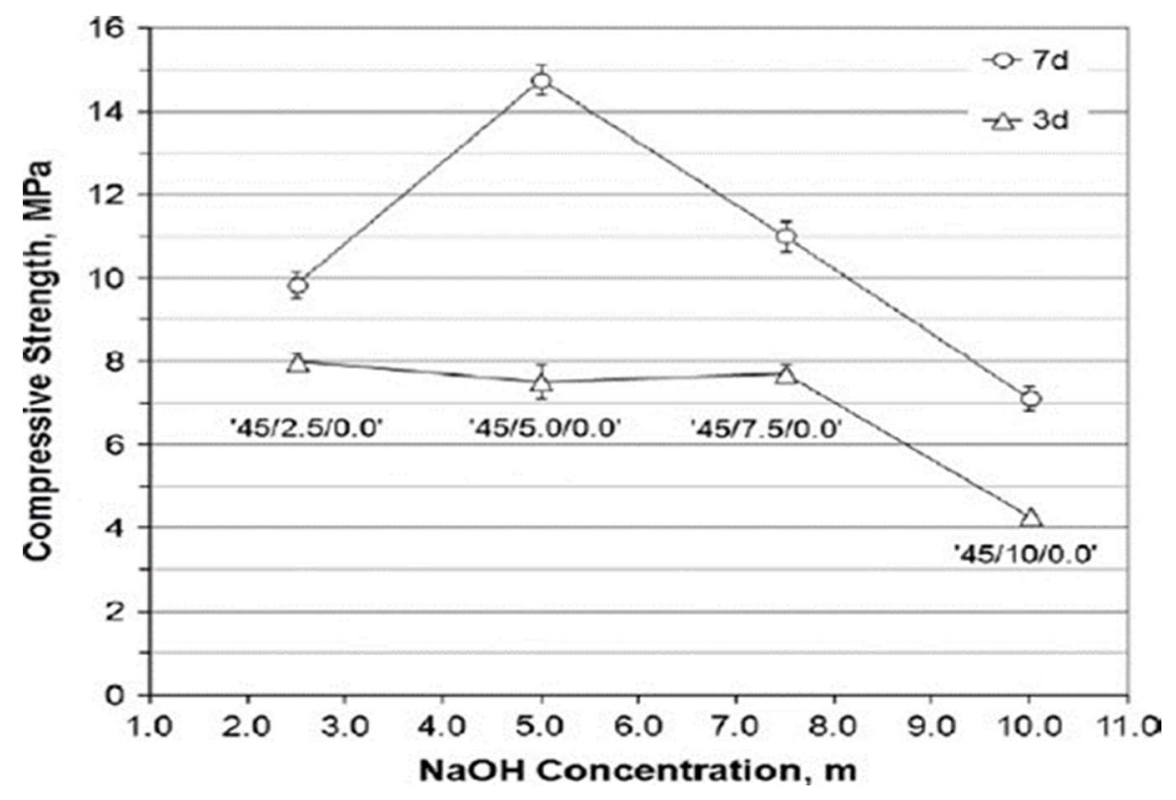

Figure 2.13 Influence of $\mathrm{NaOH}$ solution on compressive strength of alkali activated RCBW mortars cured 3 and 7 days at $65 \mathrm{C}$ (Reig et al. 2013b).

In order to investigate the effect of the activator alkalinity, Komnitsas et al. (2015) prepared four different molarities of alkaline solutions. The geopolymeric paste was composed of tile, brick or concrete wastes and cured at 60,80 and $90^{\circ} \mathrm{C}$ for 7 days. According to these authors, alkaline activators have an optimum concentration which is related to the particle size and composition of the aluminosilicate source materials. A concentration of alkaline activator varying from the optimum concentration resulted in significant reduction of compressive strength. Mechanical and durability properties were also based on the ageing and the curing temperature. The compressive strength of tiles presented the optimum results at $10 \mathrm{M} \mathrm{NaOH}$ and $80^{\circ} \mathrm{C}$ curing temperature, with an optimum compressive strength of $57.8 \mathrm{MPa}$ at 7 days (Figure 2.14a). $\mathrm{NaOH}$ concentration at lower level cannot provide enough alkalinity to fully active the aluminosilicate materials. On the other hand, higher $\mathrm{NaOH}$ molarity results in excessive $\mathrm{Na}_{2} \mathrm{O}$ concentration which resulted in leaching of the $\mathrm{Na}$ cation from the geopolymeric paste and thus reducing the compressive strength. The higher strength of recycled brick waste was $49.5 \mathrm{MPa}$ at $8 \mathrm{M} \mathrm{NaOH}$ and $90{ }^{\circ} \mathrm{C}$. The compressive strength decreases as the molarity of $\mathrm{NaOH}$ increases at every curing temperature $\left(60,80\right.$ and $\left.90^{\circ} \mathrm{C}\right)$. Geopolymerization of brick also showed that $60^{\circ} \mathrm{C}$ curing temperature is not able to fully activate the geopolymeric reaction and a maximum of $4.7 \mathrm{MPa}$ was reached at 10 molarity and $60{ }^{\circ} \mathrm{C}$ (Figure 2.14b). In addition, a maximum compressive strength of $13 \mathrm{MPa}$ was achieved for concrete waste mixed at $14 \mathrm{M} \mathrm{NaOH}$ and cured at $90{ }^{\circ} \mathrm{C}$. At $60^{\circ} \mathrm{C}$ the compressive strength of concrete waste geopolymer was 3.5 MPa regardless of $\mathrm{NaOH}$ molarity (Figure 2.14c). 


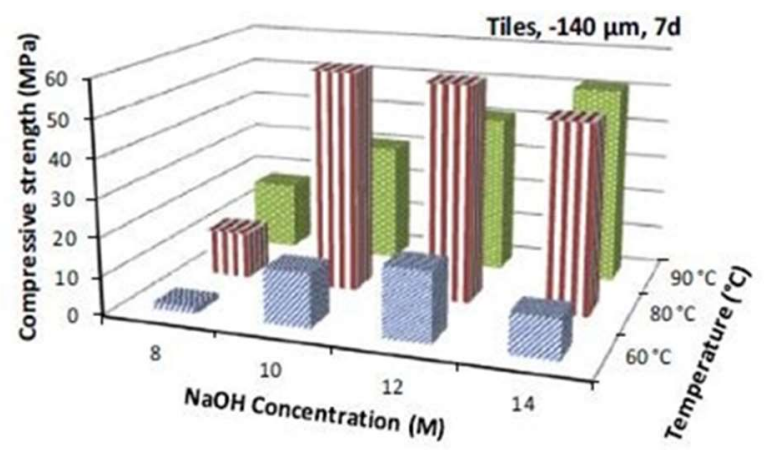

(a)

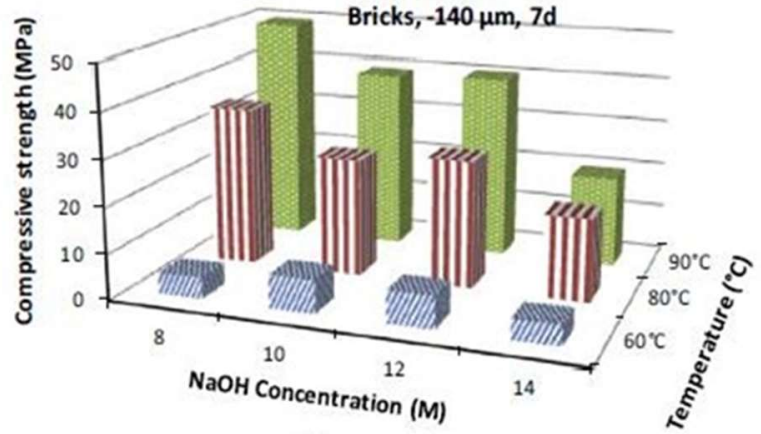

(b)

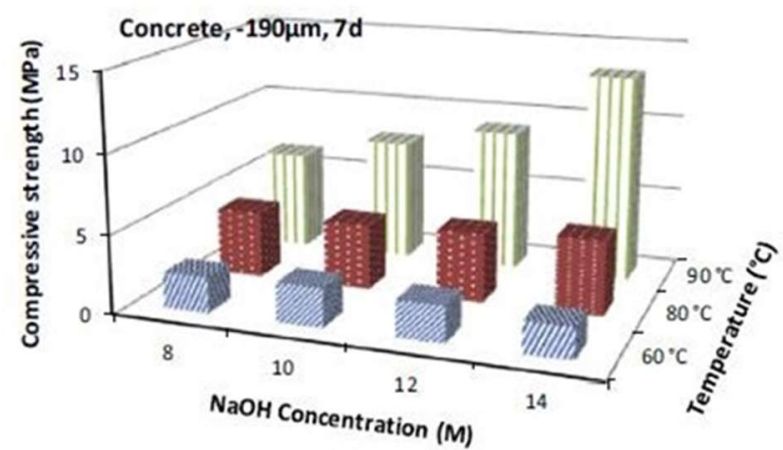

(c)

Figure 2.14 Development of the compressive strength of geopolymers produced from (a) tiles, (b) bricks and (c) concrete vs. $\mathrm{NaOH}$ concentration and curing temperature (Komnitsas et al., 2015).

\subsection{Influence of $\mathrm{SiO}_{2} / \mathrm{Na}_{2} \mathrm{O}$ Molar Ratio of the Geopolymer System}

The $\mathrm{SiO} 2 / \mathrm{A} 12 \mathrm{O} 3$ ratio of the geopolymer system was showed as one of the significant parameters influencing the mechanical, physical and microstructural characteristics of CDW-geopolymers. Many ranges of $\mathrm{SiO} 2 / \mathrm{Na} 2 \mathrm{O}$ ratios have been defined in the literature. However, the threshold level of the molar ratio of $\mathrm{SiO} 2 / \mathrm{Na} 2 \mathrm{O}$ was confirmed to be highly depend on the chemical composition of CDW materials and alkaline activators. Dadsetan et al. (2019) presented the relation between different SiO2/A12O3 ratios and the compressive strength of CDW materials. According to these authors, regardless of CDW materials, a threshold level of $\mathrm{SiO} 2 / \mathrm{A} 12 \mathrm{O} 3$ ratio exists. However, the curing temperature can affect the pattern of the threshold level, as the mechanical strengths were showed to increase with the increased $\mathrm{SiO} 2 / \mathrm{A} 12 \mathrm{O} 3$ ratio at high temperature curing (Figure 2.15) (Robayo-Salazar, Rivera and Mejía De 
Gutiérrez, 2017).

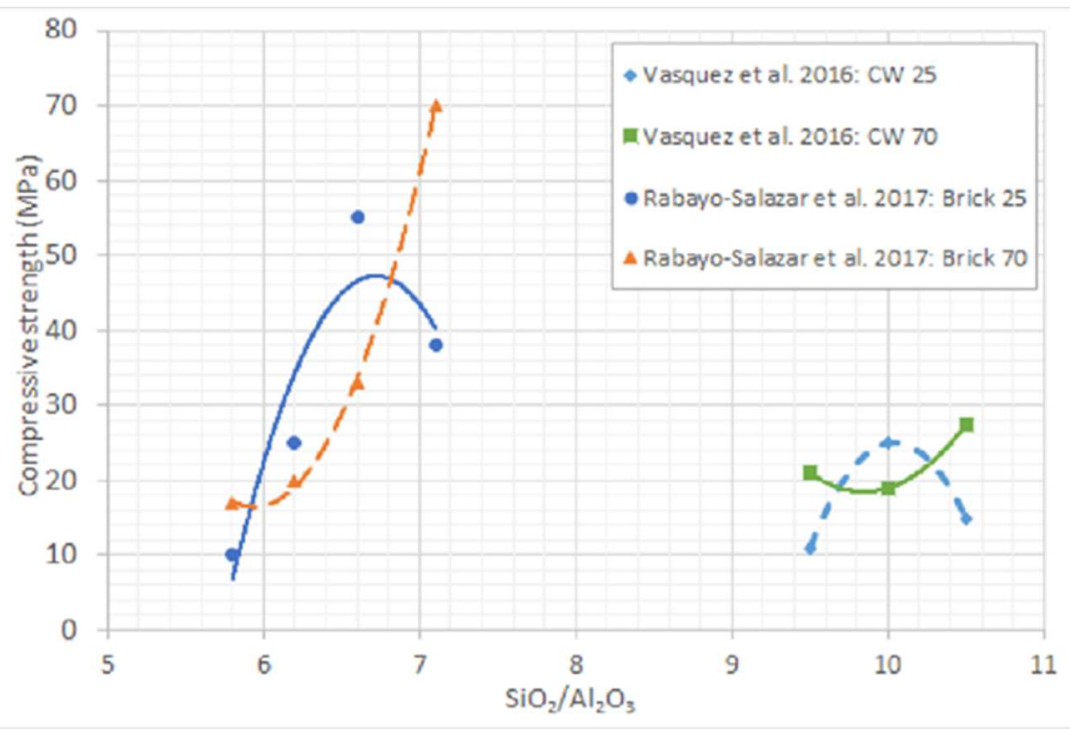

Figure 2.15 The effect of $\mathrm{SiO} 2 / \mathrm{Al} 2 \mathrm{O} 3$ molar ratio on the compressive strengths of CDW materials (Dadsetan et al. 2019)

The effect of $\mathrm{SiO} 2 / \mathrm{Na} 2 \mathrm{O}$ molar ratios of $0.73,1.46$ and 1.60 on the compressive strengths of alkali activated RCBW mortars were studied by Reig et al. (2013b). A constant molal NaOH concentration of 5 and $65{ }^{\circ} \mathrm{C}$ curing temperature was used. Their results presented in Figure 2.16 indicate that the compressive strength increased as the $\mathrm{SiO} 2 / \mathrm{Na} 2 \mathrm{O}$ molar ratio increased. However, when the ratio reached 1.60, the geopolymeric paste was not feasible for casting. The reason for the quick setting was the increased soluble silica from the excess amount of sodium silicate in the geopolymeric system. Thus the increased $\mathrm{SiO} 2 / \mathrm{Na} 2 \mathrm{O}$ ratio accelerated the geopolymeric reaction. Therefore, depending on the precursor material, a specific amount of sodium silicate should be added to the geopolymeric mix to avoid the quick setting time. 


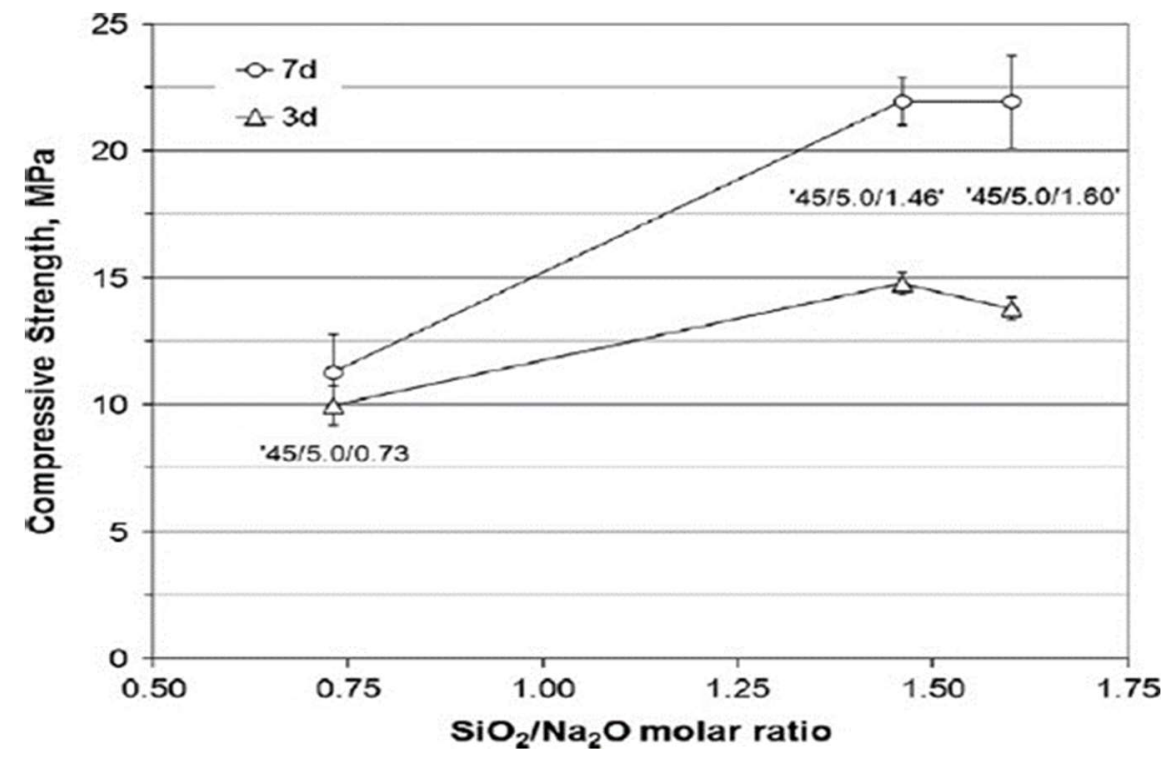

Figure 2. 16 Influence of $\mathrm{SiO} 2 / \mathrm{Na} 2 \mathrm{O}$ molar ratio on the compressive strength, for a constant 5 molal Na+ concentration (Reig et al. 2013b).

\subsubsection{Influence of Water/Binder (w/b) ratio of CDW Geopolymers}

The water to binder ratio was proven to highly influence the compressive strengths of all CDW-based geopolymers. Most studies agreed that compressive strengths of geopolymer materials increased when water to binder ration reduced (Komnitsas et al. 2015). As an example, Figure 2.17 shows the effect of water/binder ratio on the compressive strength of RCBW geopolymer as investigated by Reig et al., 2013b. From this figure, the compressive strength at 7 days curing increased from $28 \mathrm{MPa}$ for a water/binder ratio of $0.45(45 / 7.0 / 1.60)$ to $42 \mathrm{MPa}$ for a ratio of $0.35(35 / 9.0 / 1.60)$. However, an optimization of the water to binder ratio to 0.3 resulted in significant improvements of compressive strengths of up to $50 \mathrm{MPa}$, when $\mathrm{Na}$ concentration of 7 molality and $\mathrm{SiO} 2 / \mathrm{Na} 2 \mathrm{O}$ ratio of 2 were also used. Reig et al. (2013b) concluded that the amount of water is the dominant parameter in achieving higher compressive strengths. 


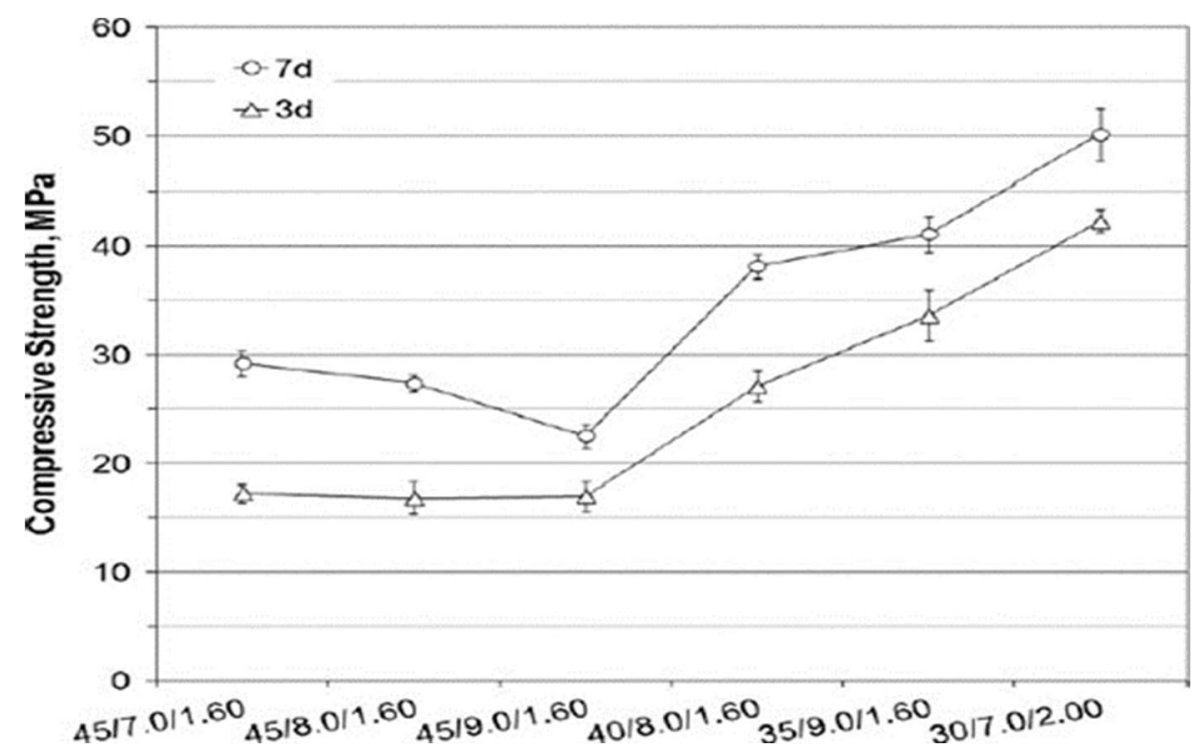

Figure 2. 17 Influence of w/b ratio on compressive strength of alkali activated RCBW (Reig et al., 2013b).

\subsubsection{Effect of High Temperature Curing}

Curing conditions play a significant role in availability of water during the polycondensation of CDW matrix and consequently in the development of microstructural characteristics and mechanical strengths. Curing at temperatures between 75 and $100^{\circ} \mathrm{C}$ resulted in significant improvements of compressive strengths (Dadsetan et al. 2019). Robayo et al., (2017) investigated the effect of high temperature curing of $70^{\circ} \mathrm{C}$ compared to a room temperature of $25^{\circ} \mathrm{C}$ on the compressive strength of RCBW geopolymers (Figure 2.18). The high temperature curing of $70^{\circ} \mathrm{C}$ was applied for $24 \mathrm{~h}$ and $48 \mathrm{~h}$. At $25^{\circ} \mathrm{C}$, the RCBW geopolymer activated by $\mathrm{NaOH}$ presented a maximum strength of around 7.5MPa. After applying a $24 \mathrm{~h}$ of high temperature curing of $70^{\circ} \mathrm{C}$ the higher strength increased to around $12 \mathrm{MPa}$. However, by using a $48 \mathrm{~h}$ initial curing at $70^{\circ} \mathrm{C}$, the strength jumped to around $17 \mathrm{MPa}$. 


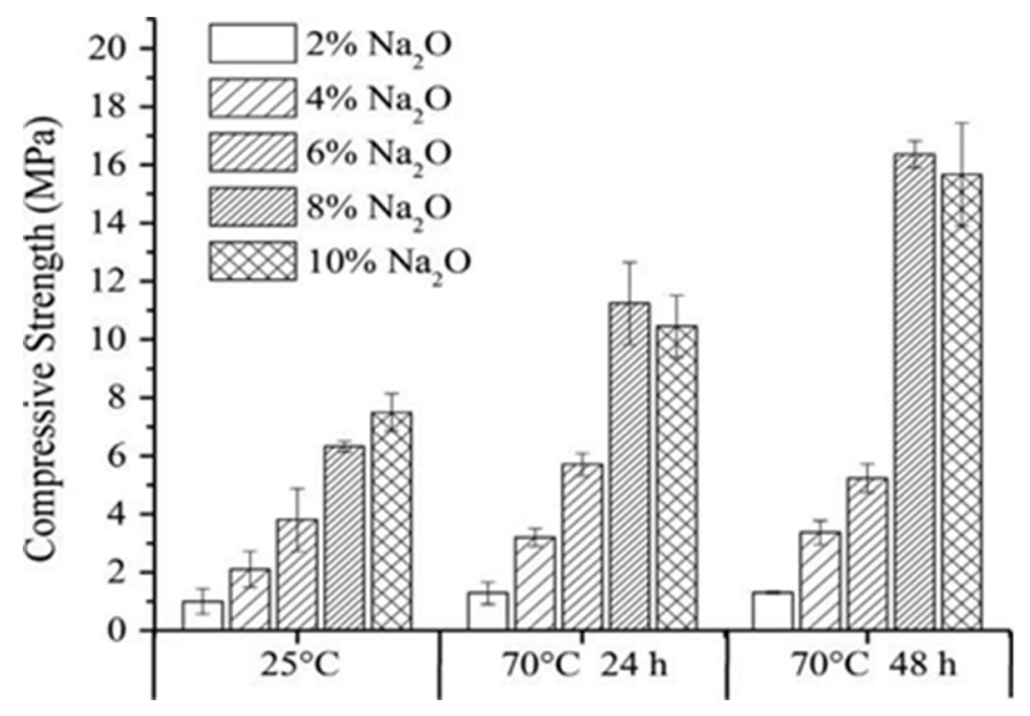

Figure 2.18 Effect of curing temperature and $\mathrm{Na}_{2} \mathrm{O}(\mathrm{NaOH}$ sole activator) concentration on the compressive strength of RCBW geopolymers (Robayo et al. 2016).

The effect of high temperature curing of $70^{\circ} \mathrm{C}$ was also applied on $\mathrm{RCBW}, \mathrm{CW}$ and glass waste $(\mathrm{GW})$ for 24 h by Robayo et al., (2017). Compressive strength was studied with $\mathrm{NaOH}$ as alkali-activator in the first phase then combined with $\mathrm{Na} 2 \mathrm{SiO}$. High temperature curing results in higher compressive strengths compared to $25^{\circ} \mathrm{C}$ curing for RCBW, CW and GW. CW geopolymer achieved a compressive strength of $7.5 \mathrm{MPa}$ at $25{ }^{\circ} \mathrm{C}$ temperature. While, it improved to almost $12 \mathrm{MPa}$ at $70{ }^{\circ} \mathrm{C}$ curing temperature. Interestingly, the high temperature curing presented negligible effect when CW geopolymer included $\mathrm{Na} 2 \mathrm{SiO} 3+\mathrm{NaOH}$ as alkaline activators. When $\mathrm{GW}$ geopolymer was activated with $\mathrm{NaOH}$, a $0 \mathrm{MPa}$ strength was found at $25^{\circ} \mathrm{C}$. The high temperature curing of $70^{\circ} \mathrm{C}$ increased significantly the strength to achieve around $56 \mathrm{MPa}$. The study concluded that, at higher temperature curing, greater amount of soluble silica is consumed by the geopolymeric structure compared to room temperature curing. This is due to the higher number of soluble silicas being consumed by aluminosilicate molecules and thus resulting in denser microstructure and better compressive strengths. 


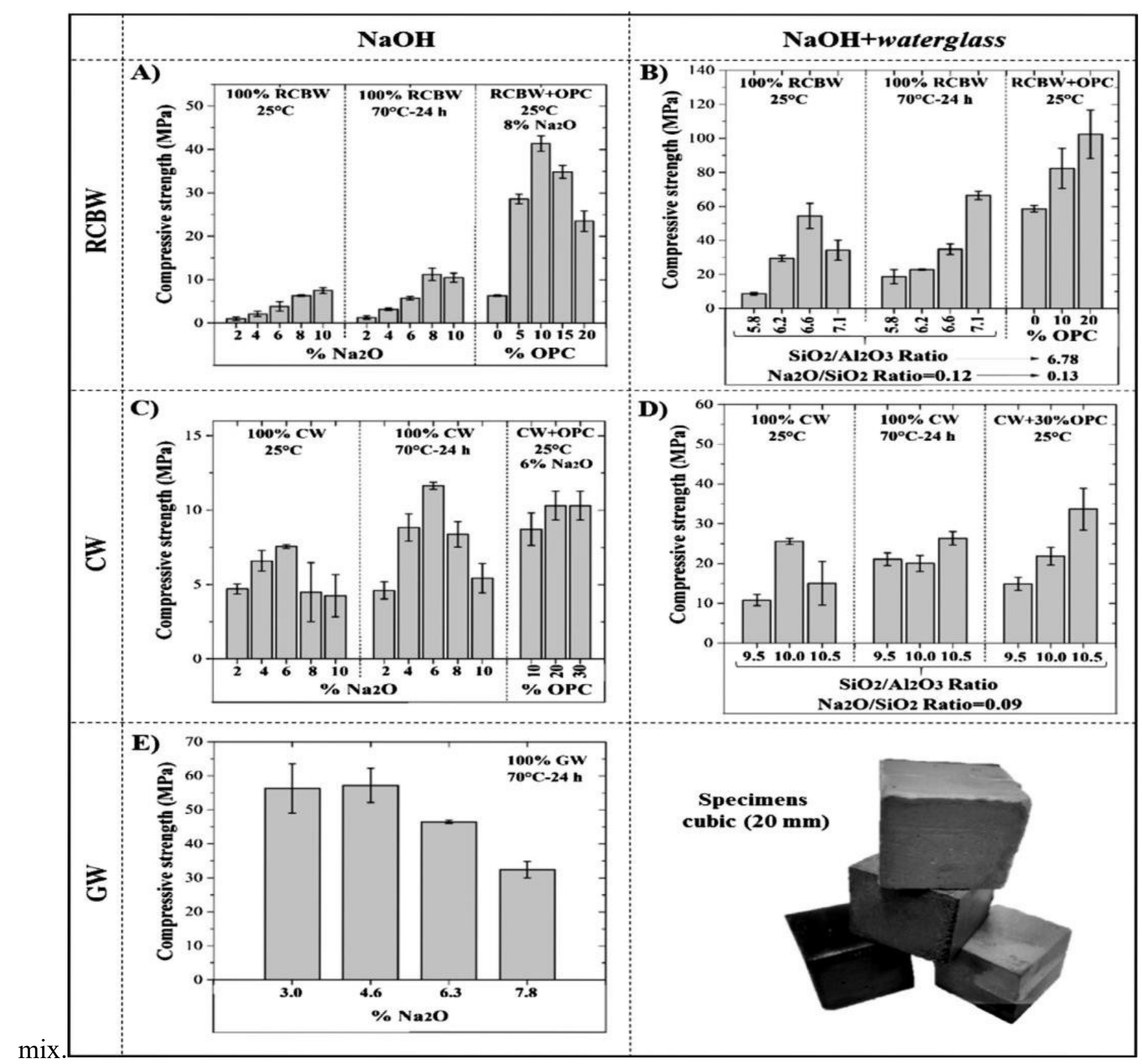

Figure 2.19 Compressive strengths of RCBW, CW and GW activated with $\mathrm{NaOH}$ and/or Sodium silicate and cured at 25 and $70^{\circ} \mathrm{C}$ temperature (Robayo-Salazar et al., 2017).

\subsubsection{Effect of Other Parameters}

The following publications can be detailed as an example of other important parameters, such as the type of alkali-activator, adding SCMs and the use of binary CDW materials, which are shown to influence the properties of different CDW geopolymers:

- Robayo et al. $(2013,2016)$ investigated the synthesis of alkali-activated red clay brick waste (RCBW) using sodium silicate (SS) with and without sodium hydroxide ( $\mathrm{SH}$ ) as alkaline reagents. The liquid to 
solid (L/S) ratio was 0.25 in all compositions. The results showed in Figure 2.20 confirmed that adding $\mathrm{NaOH}$ as a sole alkaline activator to RCBW powder will not produce a high strength paste in any curing temperatures. Below a concentration of $8 \%$ of $\mathrm{Na}_{2} \mathrm{O}$, the geopolymer paste produced the best results of around $12 \mathrm{MPa}$ when $24 \mathrm{~h}$ of $70^{\circ} \mathrm{C}$ curing was used. However, by using sodium silicate and sodium hydroxide as activators, the compressive strength increased significantly to attain $56.6 \mathrm{MPa}$ in the same temperature and curing conditions. The study concluded that RCBW geopolymer pastes activated with $\mathrm{SH}+\mathrm{SS}$ have a denser and more homogeneous microstructure than RCBW pastes activated with $\mathrm{NaOH}$ only.

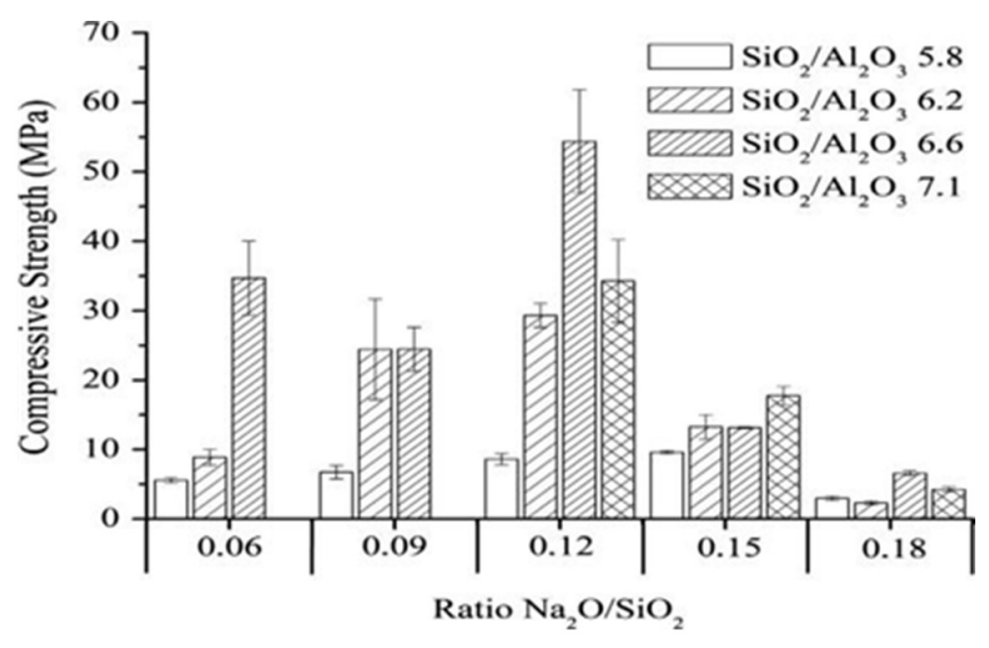

Figure 2.20 Effect of $\mathrm{SiO} 2 / \mathrm{A} 12 \mathrm{O} 3$ and $\mathrm{Na} 2 \mathrm{O} / \mathrm{SiO} 2$ ratios on the compressive strength of $100 \% \mathrm{RCBW}$ at $25 \mathrm{C}$ at 28 days (sodium silicate + sodium hydroxide as activators)

(Robayo et al. 2016).

- Allahverdi and Kani (2009) utilized construction waste namely waste brick and concrete waste as raw materials for geopolymerization process. Proportions from 40 to $100 \%$ of waste brick were mixed with concrete wastes at different sodium oxide $\mathrm{Na}_{2} \mathrm{O}$ contents of 6,7 and $8 \%$ and water to binder ratios between 0.26 and 0.30 . A silica modulus of 0.60 was maintained throughout the test regime by adding enough sodium hydroxide to sodium silicate. The study found that the initial setting times of most of the compositions were too short as it is less than 5 minutes. The authors explained that $\mathrm{Na}_{2} \mathrm{O}$ concentration resulted in accelerated geopolymerization by activating the gelation process, leading to a shorter final setting time. The compressive strengths results indicated that aluminosilicate present in waste brick were better in creating geopolymeric pastes than the concrete waste. A compressive strength of $40 \mathrm{MPa}$ was reached in the mix composed of $100 \%$ brick and $\mathrm{Na}_{2} \mathrm{O}$ concentration of $8 \%$, as showed in Figure 2.21 . 

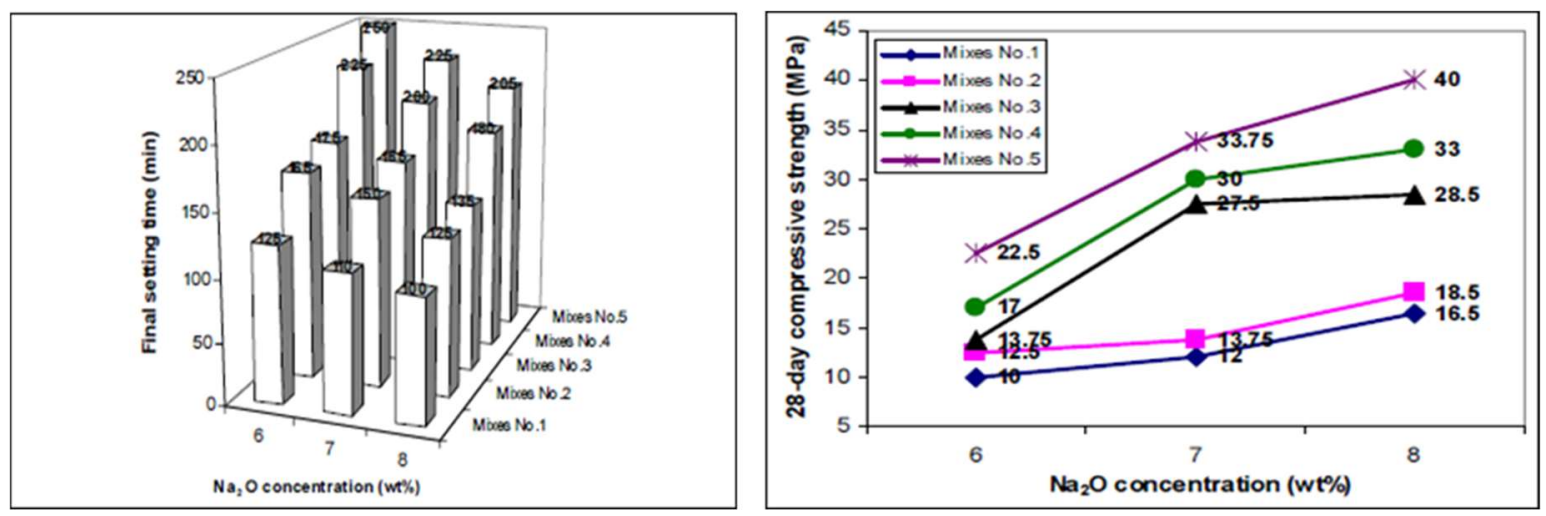

Figure 2.21 (a) Effect of $\mathrm{Na} 2 \mathrm{O}$ concentration on final setting time (b) Effect of $\mathrm{Na} 2 \mathrm{O}$ concentration on 28-day compressive strength (Allahverdi and Kani, 2009).

- Another publication of Allahverdi and Kani (2013) warns severe efflorescence in waste brick and concrete geopolymers when brick content is higher than 60\%. Efflorescence was investigated quantitatively by visually comparing efflorescence in different specimens. Up to $3 \%$ of $\mathrm{Na}_{2} \mathrm{O}$ by weight did not show any efflorescence. However, higher contents of $\mathrm{Na}_{2} \mathrm{O}$ concentrations resulted in efflorescence that was explained by the high leaching of non-reacted sodium hydroxide. This problem was solved by the authors by adding alumina-based admixtures or curing at higher temperature.

- Rakhimova \& Rakhimov (2015) investigated geopolymerization of red clay brick waste (RCBW) and granulated blast furnace slag (GBFS) at various percentages. This research assesses the effect of separate and conjoint grinding of GBFS and RCBW, their fineness $\left(300-900 \mathrm{~m}^{2} / \mathrm{kg}\right)$, alkali-activator type (sodium carbonate or sodium silicate) and curing condition. The authors showed that conjoint grinding provides better results than separate grinding. Also, the use of sodium silicate provided higher compressive strengths compared to the compositions activated with sodium carbonate. The 40/60 ratio of RCBW/GGBFS was the optimum composition, which provided a maximum compressive strength of $120 \mathrm{MPa}$ at 28 days. However, an increase in RCBW percentage above $40 \%$ resulted in reduced compressive strengths (Figure 2.13). 


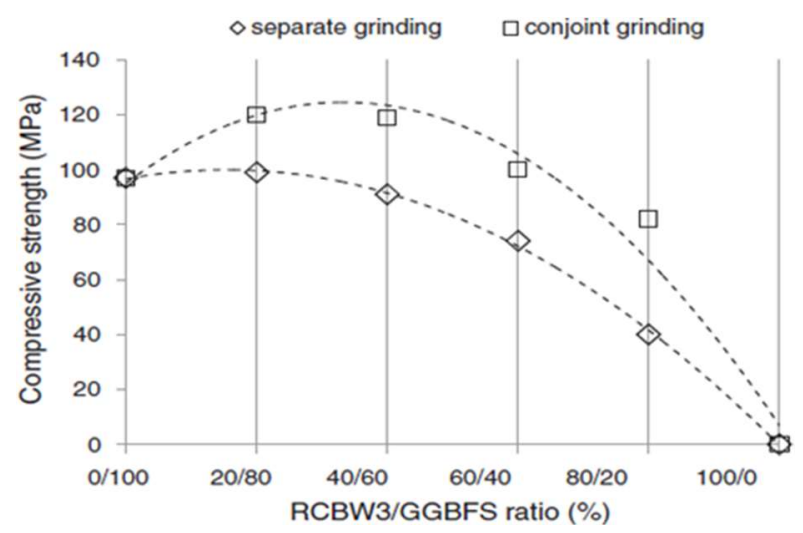

Figure 2. 22 Compressive strength of lkali-activated pastes with different RCBW/GBFS ratios and grinding methods (Rakhimova and Rakhimov, 2015)

\subsection{Summary}

This chapter summarizes the historical and technical aspects of geopolymer materials prepared from different aluminosilicate precursors. A literature review about the existing research into the use of construction and demolition wastes (CDWs) in geopolymer technology was also detailed. It has been established that the use of CDWs in geopolymer systems is one of the most economical and environmentally friendly ways to reutilize CDWs and reduce the carbon footprint from the construction industry.

Due to the recent improvement in modern grinding and powdering technologies, CDWs such as red clay brick waste $(\mathrm{RCBW})$, ceramic tile waste $(\mathrm{CTW})$ and concrete waste $(\mathrm{CW})$ can be utilized in the production of geopolymer materials such as pastes, mortars and concretes. At an optimized particle size of CDW powders, the type of alkali-activators, the concentration of $\mathrm{NaOH}, \mathrm{SiO}_{2} / \mathrm{Na}_{2} \mathrm{O}$ ratio and water/binder ratio of the geopolymer system were reported as the main parameters which highly influenced the mechanical strengths and microstructure of the final geopolymer product. Important results were achieved from using mono-system of RCBW and CTW, or binary-system of RCBW and $\mathrm{CW}$ in geopolymer binders. However, they were mostly accomplished by using an initial high temperature curing larger than $65^{\circ} \mathrm{C}$ or/and adding supplementary cementitious materials (SCMs) such as GGBS and FA. In addition, there were no clear mix designing method. Although the relation between the mechanical properties and different chemical ratios of alkali-system were reported by many authors, the optimum compositions were attained by physical method, mainly based on the contents of activators and/or precursor materials. Limitations were also noticed in vu of considering the fresh properties of CDW-based geopolymers in most of the current literature. Very limited studies investigated the binary 
and ternary use of different CDW materials. Thus, further research is needed to develop better method to the complete recycling of CDW portions in geopolymer systems, and to use the chemical and physical ratios in the mix design procedures for enhanced mechanical properties, yet at normal temperature curing. 


\section{CHAPTER THREE}

\section{EXPERIMENTAL PROGRAM}

\subsection{Introduction}

The aim of this research study was to develop $100 \%$ green geopolymer binders at ambient temperature utilizing Construction and Demolition Wastes (CDWs) collected from construction sites. The CDW materials were classified into three different categories of 1) Red Clay Brick Waste (RCBW) 2) Ceramic Tile Waste (CTW) and 3) Concrete Waste (CW). Each piece of CDW material was separately crushed using a jaw crusher and pulverized using a ball mill. The pulverized materials were then sieved through a $75 \mu \mathrm{m}$ sieve to obtain the required powders for the geopolymerization process. X-ray Fluorescence (XRF) analysis was utilized to determine chemical and elemental oxide compositions (weight percentages) of these materials. It was determined that RCBW and CTW have high silica and alumina contents and CW has a high amount of calcium oxide. Furthermore, particle size distribution (PSD) of the pulverized CDWs was determined to ensure a good fineness of these powders.

The alkaline reagent used in all CDW-geopolymers was a mix of sodium hydroxide and sodium silicate. This was chosen after a preliminary investigation of its suitability for the CDWgeopolymerization processes compared to potassium hydroxide and potassium silicate. Various concentrations of sodium hydroxide were prepared and utilized in combination with sodium silicate solutions. The different combinations of alkaline reagents and CDW powders were arranged based on targeted values of $\mathrm{SiO}_{2} / \mathrm{Al}_{2} \mathrm{O}_{3}, \mathrm{Na} 2 \mathrm{O} / \mathrm{SiO}_{2}$ and liquid/solid ratios.

\subsection{Materials}

\subsubsection{Selection and Preparation of CDW Materials}

CDW materials used in this research were acquired from demolished buildings and construction stockpiled by Parkview Building Supplies in Toronto. These wastes were classified into three various groups of RCBW, CTW and CW materials, as presented in Figure 3.1. 

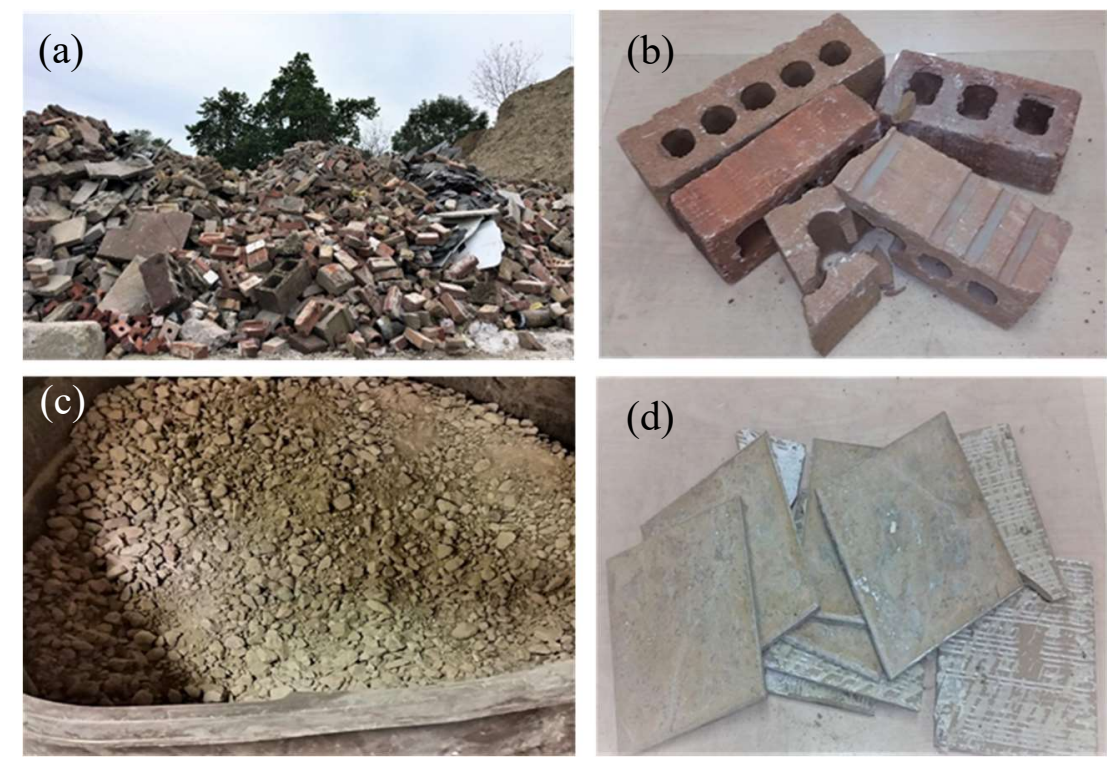

Figure 3. 1 (a) Construction and Demolition Wastes (CDWs) classified into (b) Red Clay Brick Waste (RCBW), (c) Concrete Waste (CW) and (d) Ceramic Tile Waste (CTW)

The selected RCBW, CW and CTW solid wastes were first crushed using a jaw crusher to obtain a maximum particle size material of 0.25 inch $(6.35 \mathrm{~mm})$ (Figure 3.2 (a)). A ball mill was used for pulverizing the CDW pieces by applying similar milling conditions for all powders.
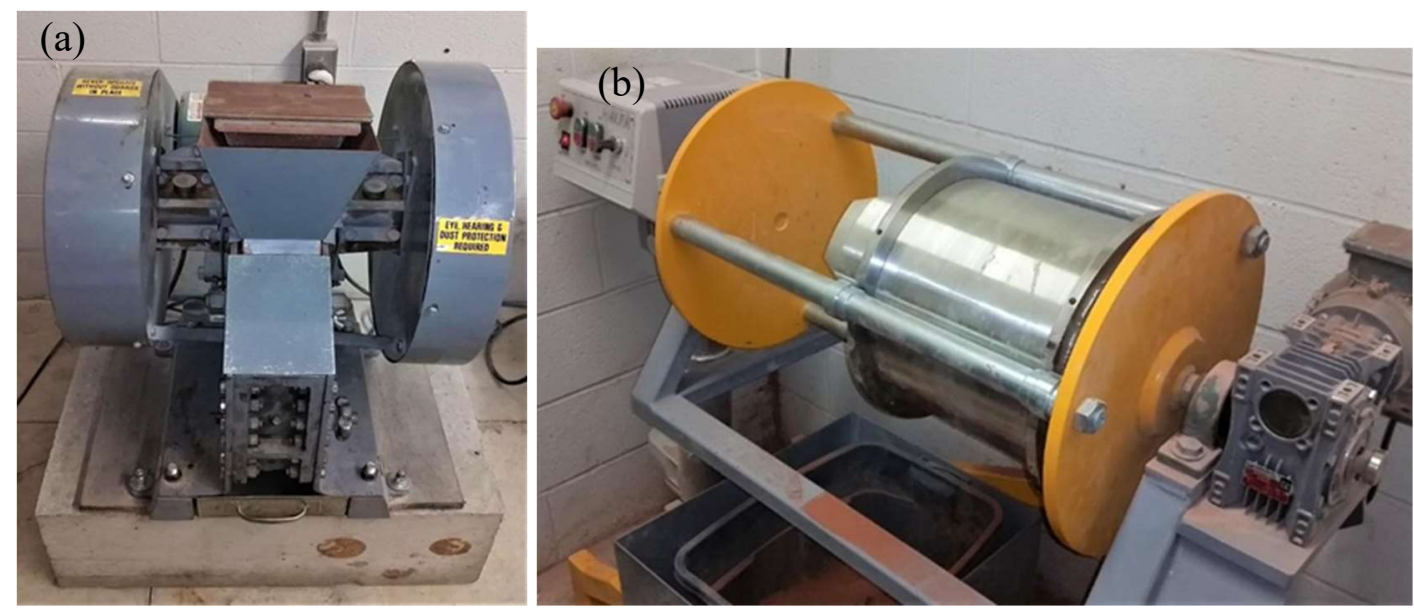

Figure 3.2 (a) Jaw Crusher, (b) Ball Mill

Subsequently, the pulverized materials were sieved through a $75 \mu \mathrm{m}$ (ASTM designation No. 200) sieve and the final powders were obtained for the development of geopolymer binders.

The crushed and powdered forms of the construction and demolition wastes (CDWs) are shown in Figure 3.3 . 

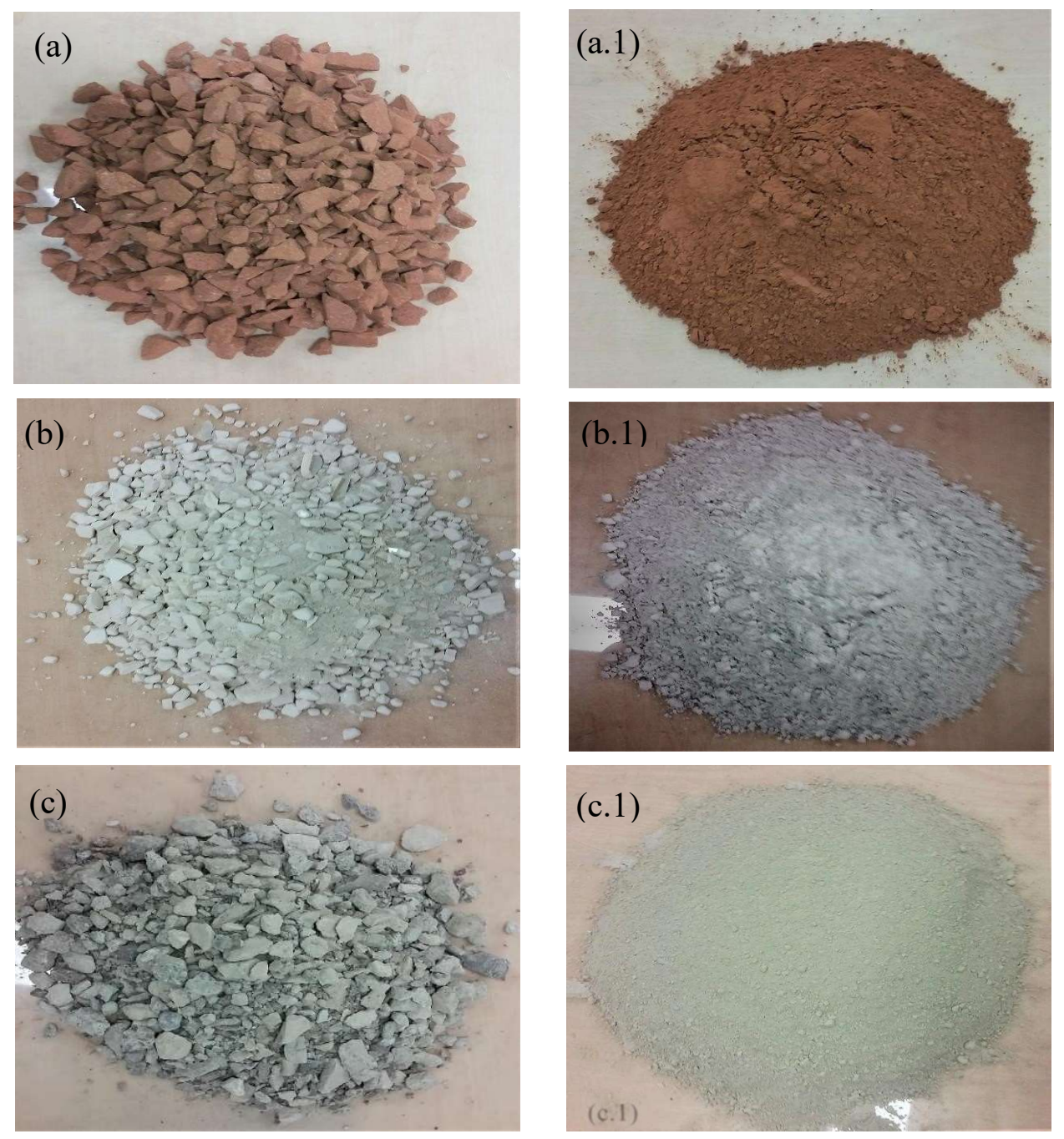

Figure 3.3 (a) Crushed RCBW (a.1) powdered RCBW (b) crushed CTW (b.1) powdered CTW (c) crushed CW (c.1) powdered CW

\subsubsection{Characterization of CDW Powders}

\section{- Particle Size Distribution (PSD)}

Figure 3.4 presents the particle size distribution of CW, RCBW and CTW powders. Also, Table 3.1 displays the median and mean sizes and D0.1, D0.5 and D0.9 of various CDWs.

Although similar grinding and sieving conditions (time and rotation speed) were applied for all CDWs, the mean particle size of CW $(28.8 \mu \mathrm{m})$ and CTW $(29.5 \mu \mathrm{m})$ were remarkably lower than that of RCBW $(73.554 \mu \mathrm{m})$. This indicates that CW and CTW have the ability to be pulverized with 
less energy and time than RCBW.

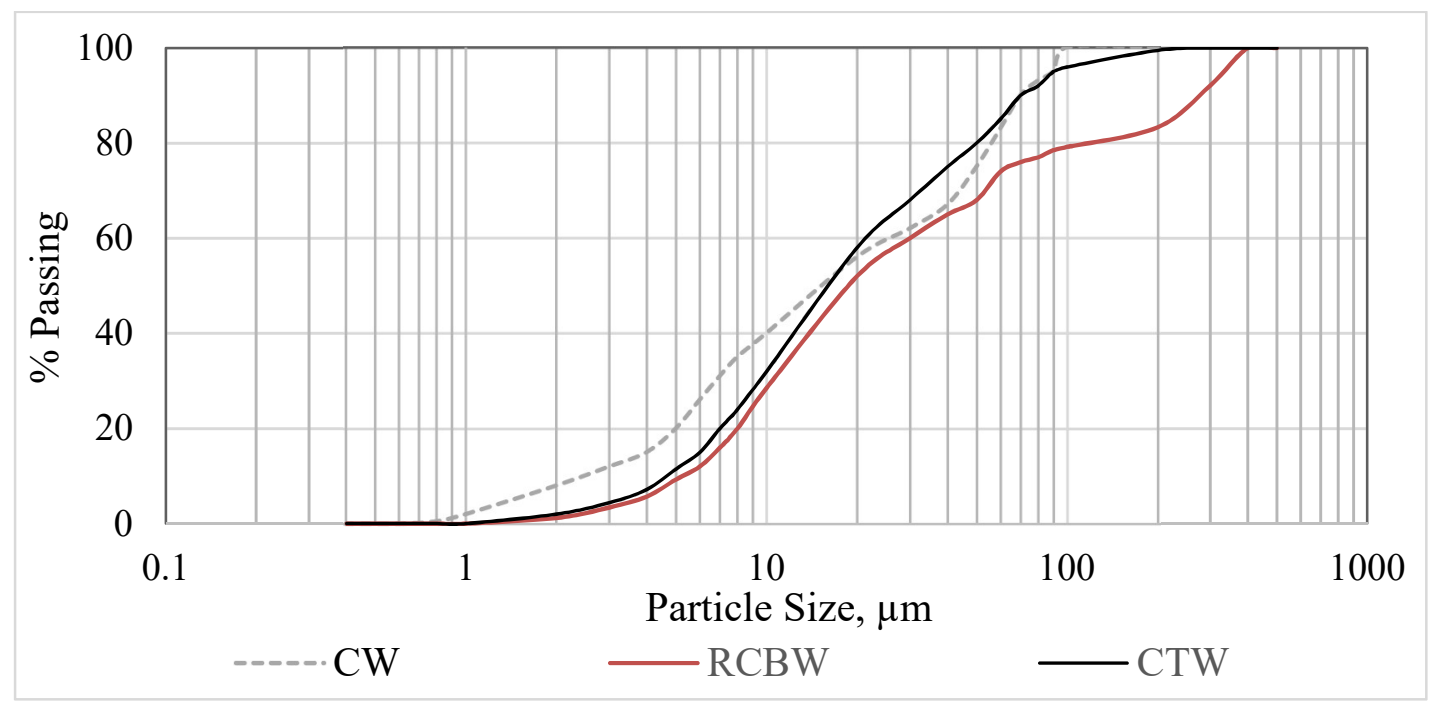

Figure 3.4 Particle size distribution of CW, RCBW and CTW powders

Table 3.1 Mean particle size, D10, D50 and D90 of CDWs and SCMs Utilized in this research

\begin{tabular}{|l|l|l|l|l|l|}
\hline Material & $\begin{array}{l}\text { Median Size } \\
(\mu \mathrm{m})\end{array}$ & $\begin{array}{l}\text { Mean Size } \\
(\mu \mathrm{m})\end{array}$ & $\begin{array}{l}\mathrm{D}(0.1) \\
(\mu \mathrm{m})\end{array}$ & $\begin{array}{l}\mathrm{D}(0.5) \\
(\mu \mathrm{m})\end{array}$ & $\begin{array}{l}\mathrm{D}(0.90) \\
(\mu \mathrm{m})\end{array}$ \\
\hline CW & 15.158 & 28.827 & 2.342 & 15.158 & 72.495 \\
\hline RCBW & 18.983 & 73.554 & 5.308 & 18.983 & 280.77 \\
\hline CTW & 15.469 & 29.511 & 4.699 & 15.469 & 72.479 \\
\hline
\end{tabular}

\section{- Chemical Composition and Physical Properties of CDW Powders}

The chemical composition of RCBW, CTW and CW was analyzed using XRF. The specific gravity was determined according to (ASTM C188-17) using Le Chatelier's flask. The results of chemical compositions and specific gravities are shown in Table 3.2.

Table 3.2 indicates that both RCBW and CTW contain higher percentages of silica and alumina, and lower amounts of $\mathrm{CaO}$ compared to $\mathrm{CW}$. The elevated loss on ignition in $\mathrm{CW}$ is related to its high amount of $\mathrm{CaO}(29.6 \%)$. 
Table 3.2 Chemical composition of CDWs and SCMs by XRF analysis

\begin{tabular}{|l|l|l|l|}
\hline Chemical Composition (\%) & CW & RCBW & CTW \\
\hline $\mathrm{SiO} 2$ & 23.81 & 60.31 & 61.22 \\
\hline $\mathrm{Al}_{2} \mathrm{O} 3$ & 4.16 & 15.61 & 10.33 \\
\hline $\mathrm{Fe} 2 \mathrm{O} 3$ & 1.96 & 7.72 & 1.01 \\
\hline $\mathrm{MnO}$ & 0.077 & 0.11 & 0.01 \\
\hline $\mathrm{MgO}$ & 8.41 & 3.05 & 17.63 \\
\hline $\mathrm{CaO}$ & 30.33 & 5.6 & 6.01 \\
\hline $\mathrm{Na} 2 \mathrm{O}$ & 0.6 & 0.56 & 0.27 \\
\hline $\mathrm{K} 2 \mathrm{O}$ & 0.67 & 4.48 & 0.75 \\
\hline $\mathrm{TiO} 2$ & 0.2 & 0.88 & 0.46 \\
\hline Loss on ignition & 29.6 & 0.41 & 0.3 \\
\hline Specific gravity $\left(\mathrm{g} / \mathrm{cm}^{3}\right)$ & 2.71 & 2.69 & 2.87 \\
\hline
\end{tabular}

When presenting the position of each CDW in the triangular chemical compounds (Figure 3.5), the position of RCBW and CTW looks to be in the range of those studied in the literature. However $\mathrm{CW}$ powder is different from others, especially regarding the amount of $\mathrm{SiO}_{2}$ and $\mathrm{Al}_{2} \mathrm{O}_{3}$. This can be attributed to the diverse content of aggregates and pastes in $\mathrm{CW}$ materials used in various studies.

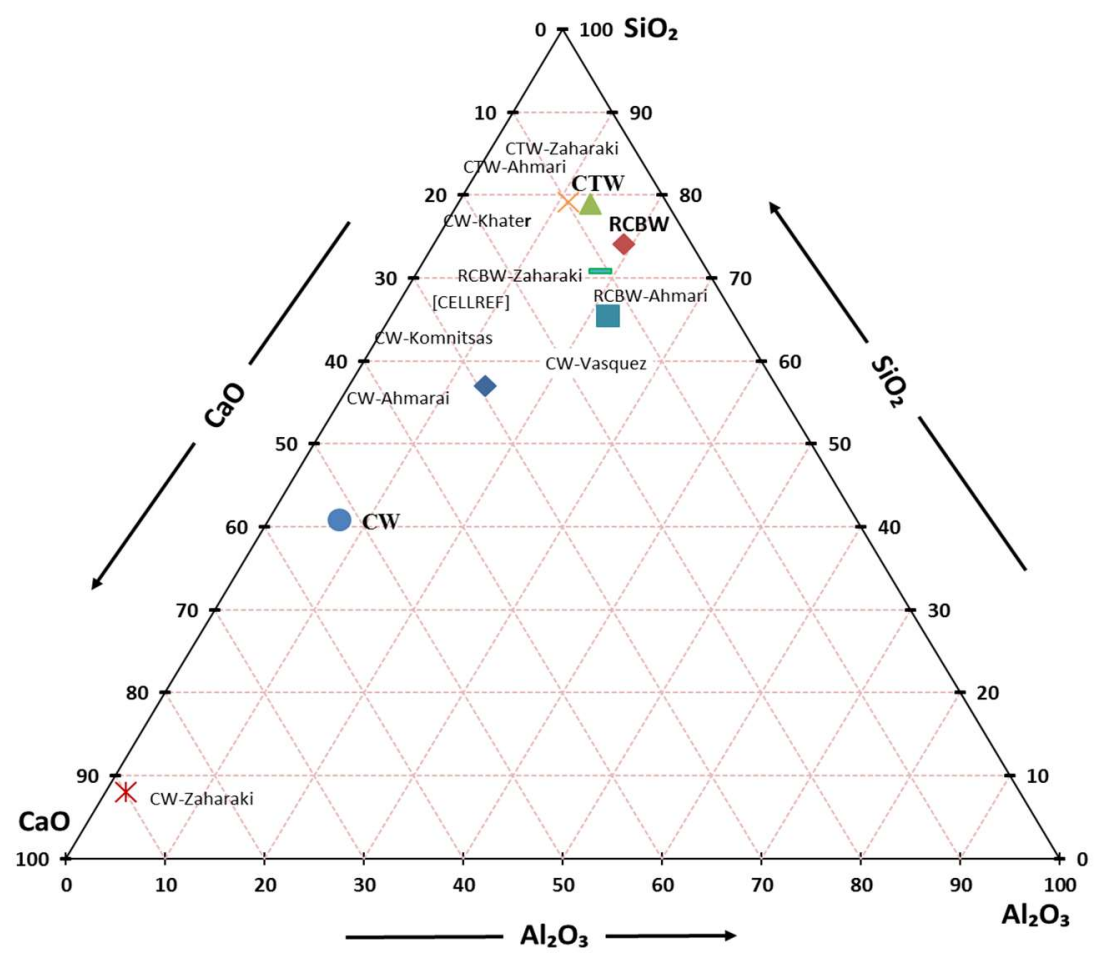

Figure 3.5 The position of CW, RCBW and CTW powders compared to those studied in the literature 


\section{- SEM-EDS Analysis of CDWs}

SEM micrographs and their related EDS spectra of CW, RCBW and CTW powders are presented in Figure 3.6.


Figure 3.6 SEM-EDS analysis of CW, RCBW and CTW

SEM micrographs of CW powder show most particles with an angular shape and a small amount of rounded morphology constituents. This indicates a mix of grains originating from ground aggregates and cement paste. The EDS analysis of CW proves the high percentage of calcium (16.9\%) compared to silica (5.7\%) and alumina (1.5\%) content. RCBW and CTW particles mostly have a semi-crystalline irregular shape. The EDS analysis of these powders confirms higher 
percentages of silica (23\% and $24.2 \%$ respectively) and alumina ( $8.2 \%$ and $4.9 \%$ respectively) compared to those of calcium oxide (5.3\% and $4.4 \%$ respectively). These predict CDW powders have a good ability to be used as aluminosilicate precursors in the geopolymerization process.

\section{- $\quad$ X-ray Diffraction (XRD) of CDW Powders}

X-ray diffraction (XRD) patterns of CW, RCBW and CTW powders are presented in Figure 3.7. From this figure, the concentration of the quartz peaks (Q) in RCBW and CTW was slightly higher than that of $\mathrm{CW}$, especially around $27.3^{\circ} 2 \theta$. However, other crystal patterns were better identified in $\mathrm{CW}$ compared to RCBW and CTW, such as peaks around $41.5^{\circ}$ and $42.8^{\circ} 2 \theta$. These suggest the presence of quartz with different crystallinities in CW and RCBW or CTW. High intensity muscovite (Ms) and montmorillonite (Mt) peaks were also present in CW, RCBW and CTW powders, particularly at around $8.88^{\circ}$ and $17.8^{\circ} 2 \theta$ for muscovite and $6.8^{\circ} 2 \theta$ for montmorillonite. Additionally, minor albite (Al) was found in all CDWs, though with diverse intensity.

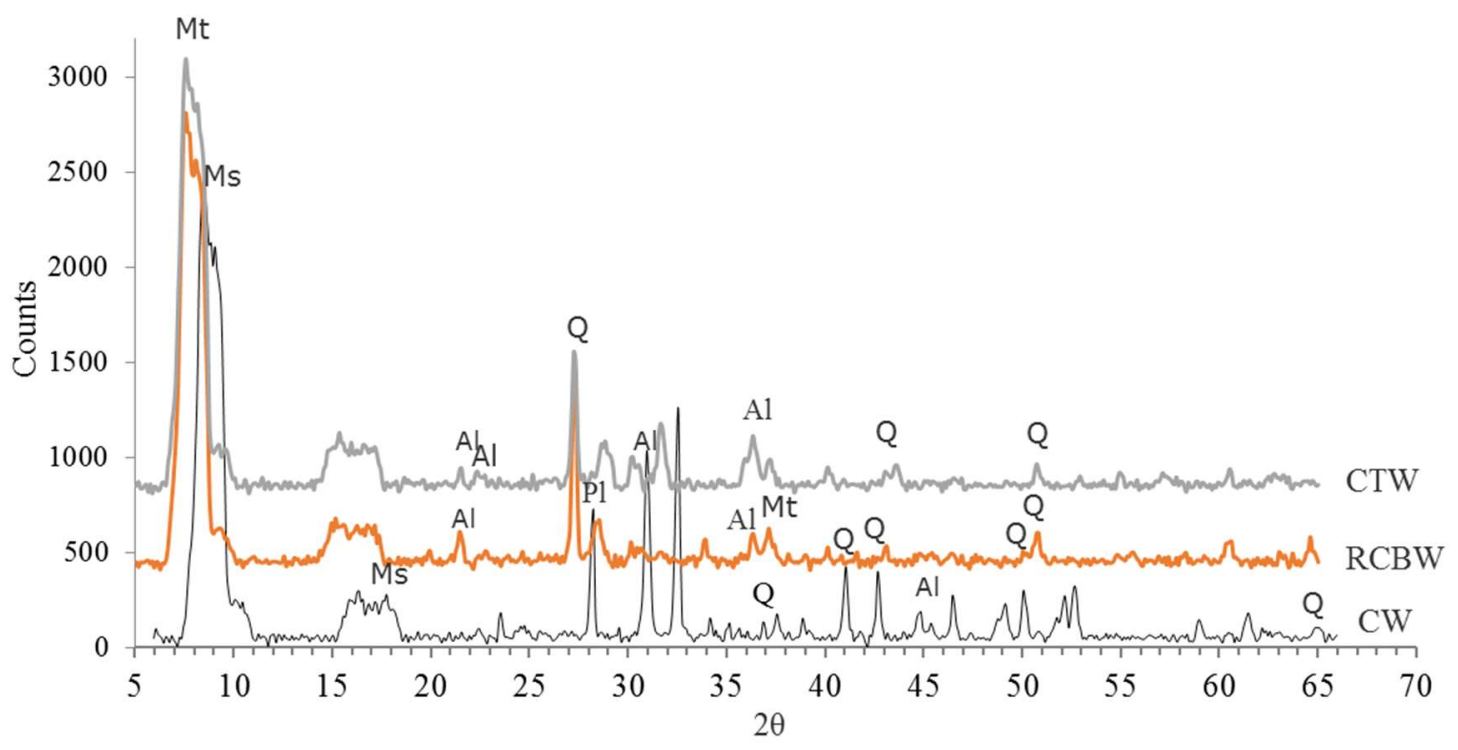

Figure 3.7 XRD patterns of concrete, red clay brick and ceramic tile wastes (Q: Quartz; Mt: Montmorillonite, Ms: Muscovite; Al: Albite)

\subsubsection{Characterization of Supplementary Cementitious Materials (SCMs)}

Fly ash type F (FA-F), ground granulated blast furnace slag (GGBS), metakaolin (MK) and fly ash type F (FA-C) were used to test the effect of adding pozzolanic materials on the properties of the optimized compositions of CDW-geopolymeric binders. FA-F, MK, GGBS and FA-C conformed to ASTM C618 Class F, ASTM C989, ASTM C618 Class N and ASTM C618 Class C respectively. 
The particle size distribution of different SCMs is presented in Figure 3.8 and their chemical and physical characteristics are displayed in Table 3.3. The specific gravity of SCM powders was provided by the suppliers and confirmed in the lab using Le Chatelier's flask according to ASTM C188-17

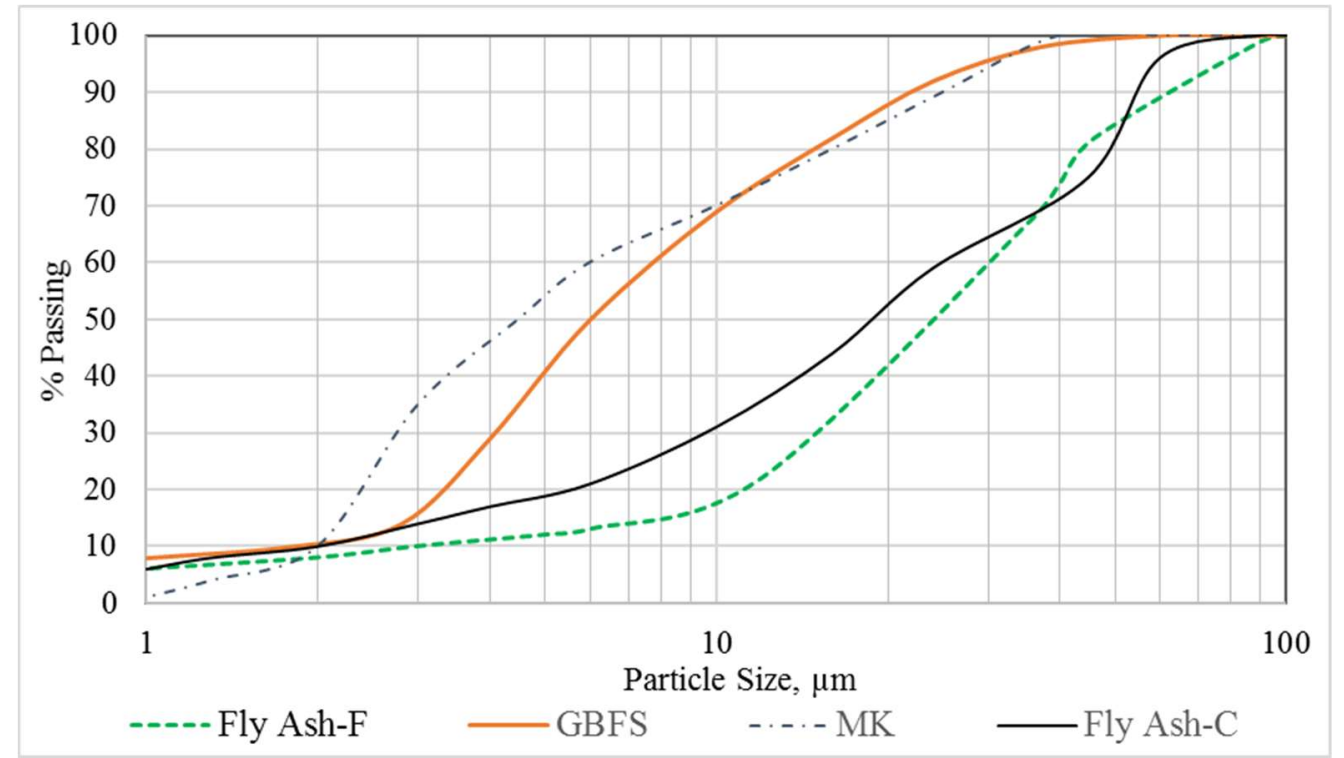

Figure 3.8 Particle size distribution of FA-F, GBBS, MK and Fly Ash-C

Table 3.3 Chemical composition and physical properties of SCMs

\begin{tabular}{|l|c|c|c|c|}
\hline Chemical composition (\%) & FA-F & MK & Slag & FA-C \\
\hline $\mathrm{SiO}_{2}$ & 44.60 & 55.47 & 36.84 & 37.04 \\
\hline $\mathrm{Al}_{2} \mathrm{O} 3$ & 21.30 & 38.07 & 8.72 & 18.59 \\
\hline $\mathrm{Fe} 2 \mathrm{O} 3$ & 20.53 & 1.84 & 0.55 & 5.83 \\
\hline $\mathrm{MnO}$ & 0.02 & 0.001 & 0.33 & 0.027 \\
\hline $\mathrm{MgO}$ & 1.20 & 0.18 & 11.03 & 4.99 \\
\hline $\mathrm{CaO}$ & 5.23 & 0.03 & 38.08 & 20.96 \\
\hline $\mathrm{Na} 2 \mathrm{O}$ & 0.58 & 0.02 & 0.21 & 4.43 \\
\hline $\mathrm{K} 2 \mathrm{O}$ & 1.66 & 0.27 & 0.31 & 0.69 \\
\hline $\mathrm{TiO} 2$ & 1.05 & 1.47 & 0.37 & 1.32 \\
\hline Loss on Ignition & 1.74 & 1.17 & 1.1 & 0.28 \\
\hline Specific gravity $\left(\mathrm{gr} / \mathrm{cm}^{3}\right)$ & 2.25 & 2.4 & 3.1 & 2.4 \\
\hline
\end{tabular}

From Table 3.3, percentages of $\mathrm{SiO}_{2}+\mathrm{Al}_{2} \mathrm{O}_{3}$ in $\mathrm{FA}-\mathrm{F}$ and $\mathrm{MK}$ were $65.9 \%$ and $93.54 \%$ respectively higher than those of GGBS and FA-C with amounts of $45.6 \%$ and $55.6 \%$ respectively. However, GBBS and FA-C were rich in $\mathrm{CaO}$ compared to FA-F and MK. This suggests a strong ability of geopolymerization for all SCMs, though the reaction products are expected to be different according to the literature (Dadsetan et al., 2019). This point will be discussed further in the next chapter. 


\subsubsection{Alkaline activators}

The selection of alkaline reagents is an important aspect in the geopolymer production process. Alkaline activators have significant effect on the dissolution of aluminosilicates in precursors and consequently on the properties of the final geopolymerization product (Petermann et al., 2012).

Sodium hydroxide $(\mathrm{NaOH})$ in combination with sodium silicates $(\mathrm{Na} 2 \mathrm{SiO} 3)$ was selected to be used in this study based on the results of a preliminary experimental program and a comprehensive review of the literature.

\section{- Sodium Hydroxide (NaOH)}

Sodium hydroxide reagent grade in white pellets form was used in this study (Figure 3.8). This product was supplied by VWR Canada with purity $\geq 97 \%$. Table 3.4 presents the properties of sodium hydroxide, as provided by the supplier.
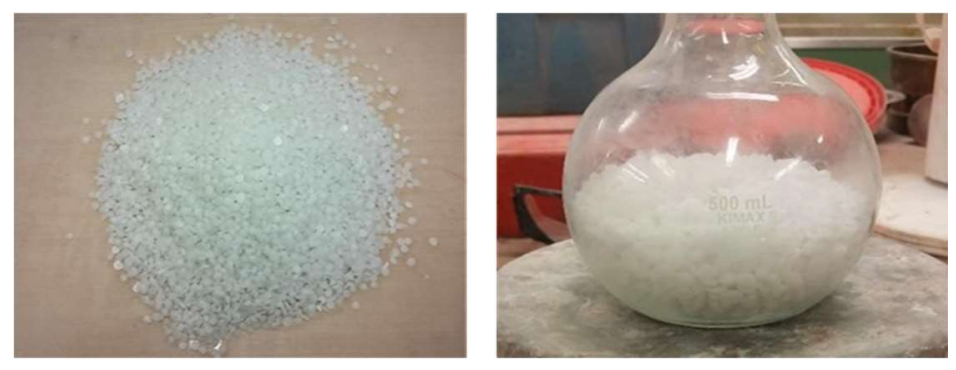

Figure 3.9 Sodium hydroxide pellets

Table 3.4 Properties of sodium hydroxide pellets

\begin{tabular}{|l|l|}
\hline Analysis Note & Results \\
\hline Assay (alkalinity) & $98-100 \%$ \\
\hline Assay (Na) & $54-59.8 \%$ \\
\hline Appearance & White flakes, passes test \\
\hline Sodium Carbonate $\mathrm{Na}_{2} \mathrm{CO}_{3}$ & $\leq 0.5 \%$ \\
\hline Chloride $(\mathrm{Cl})$ & $\leq 0.015 \%$ \\
\hline Sulfate $\left(\mathrm{SO}_{4}\right)$ & $\leq 0.010 \%$ \\
\hline $\begin{array}{l}\text { Total nitrogen }(\mathrm{N}) \text { Heavy } \\
\text { metals }(\text { as } \mathrm{Pb})\end{array}$ & $\leq 0.0005 \%$ \\
\hline $\mathrm{Al}($ Aluminium) & $\leq 0.0005 \%$ \\
\hline $\mathrm{As}$ (Arsenic) & $\leq 0.001 \%$ \\
\hline $\mathrm{Cu}($ Copper) & $\leq 0.0003 \%$ \\
\hline $\mathrm{K}$ (Potassium) & $\leq 0.00001 \%$ \\
\hline
\end{tabular}




\section{- Sodium Silicate $\left(\mathrm{Na}_{2} \mathrm{SiO}_{3}\right)$}

Sodium silicate solution was produced by Westlab Canada with a silica modulus ( $\mathrm{SiO} 2 / \mathrm{Na} 2 \mathrm{O}$ wt ratio) of 3.25. Other specifications of this product are shown in Table 3.5.

Table 3. 5 Properties of sodium silicate solution

\begin{tabular}{|l|l|}
\hline $\mathrm{SiO}_{2}$ & $27.5 \%$ \\
\hline $\mathrm{Na} 2 \mathrm{O}$ & $8.5 \%$ \\
\hline Specific Gravity (Relative Density) & $1.39 \mathrm{~g} / \mathrm{cm}^{3}$ \\
\hline $\mathrm{pH}$ & $11.2-11.8$ \\
\hline Silica Modulus ( $\left.\mathrm{SiO}_{2} / \mathrm{Na} 20\right)$ & 3.23 \\
\hline
\end{tabular}

\subsection{Experimental Methods}

\subsubsection{Mix Design Technique}

In this section, a new mix design method specifically developed for the mix designing of geopolymer binders is presented. Indeed, most researchers employed physical ratios to calculate the composition of their geopolymer mixes. For instance, they used aluminosilicate precursor to alkaline activator, sodium silicate to sodium hydroxide and water to binder ratios. Although some studies have used chemical factors such as silica/alumina, sodium/silica, Na content and silica modulus of the alkaline activator in their mix designing method, no comprehensive algorithmic mix design has been used up to now.

The mix design developed during this research considered calculating the $\mathrm{SiO}_{2} / \mathrm{Al}_{2} \mathrm{O}_{3}, \mathrm{Al}_{2} \mathrm{O}_{3} / \mathrm{Na}_{2} \mathrm{O}$ and $\mathrm{Na}_{2} \mathrm{O} / \mathrm{SiO}_{2}$ molar ratios in powder precursors first, then targeting specific $\mathrm{SiO}_{2} / \mathrm{Al}_{2} \mathrm{O}_{3}$ and $\mathrm{Na} 2 \mathrm{O} / \mathrm{SiO}_{2}$ and liquid/solid (L/S) ratios in the geopolymeric system. Subsequently, based on the above-mentioned targeted ratios, the mix design algorithm will calculate the amounts of required aluminosilicate precursors, the quantity of alkaline reagents of both sodium hydroxide and sodium silicate and the volume of the additional water. Figure 3.9 summarizes the sequential steps of the new design method used in calculating of the quantities of precursors and alkaline reagents.

The mix design algorithm relies on the elemental oxide percentages of precursor powders determined by X-ray fluorescence. The solid and liquid phases of sodium hydroxide and sodium silicate were calculated and considered in determining the total liquid to solid ratios. This method has been developed based on 1 cubic meter binder volume, while considering the specific gravity or relative density of each precursor powder and alkaline reagents. The molar mass (gr/mole) of $\mathrm{SiO}_{2}, \mathrm{Al}_{2} \mathrm{O}_{3}$, 
$\mathrm{Na}_{2} \mathrm{O}, \mathrm{NaOH}, \mathrm{H}_{2} \mathrm{O}$ is required for calculating the molar weights $\left(\mathrm{kg} / \mathrm{m}^{3}\right)$ of these oxides.

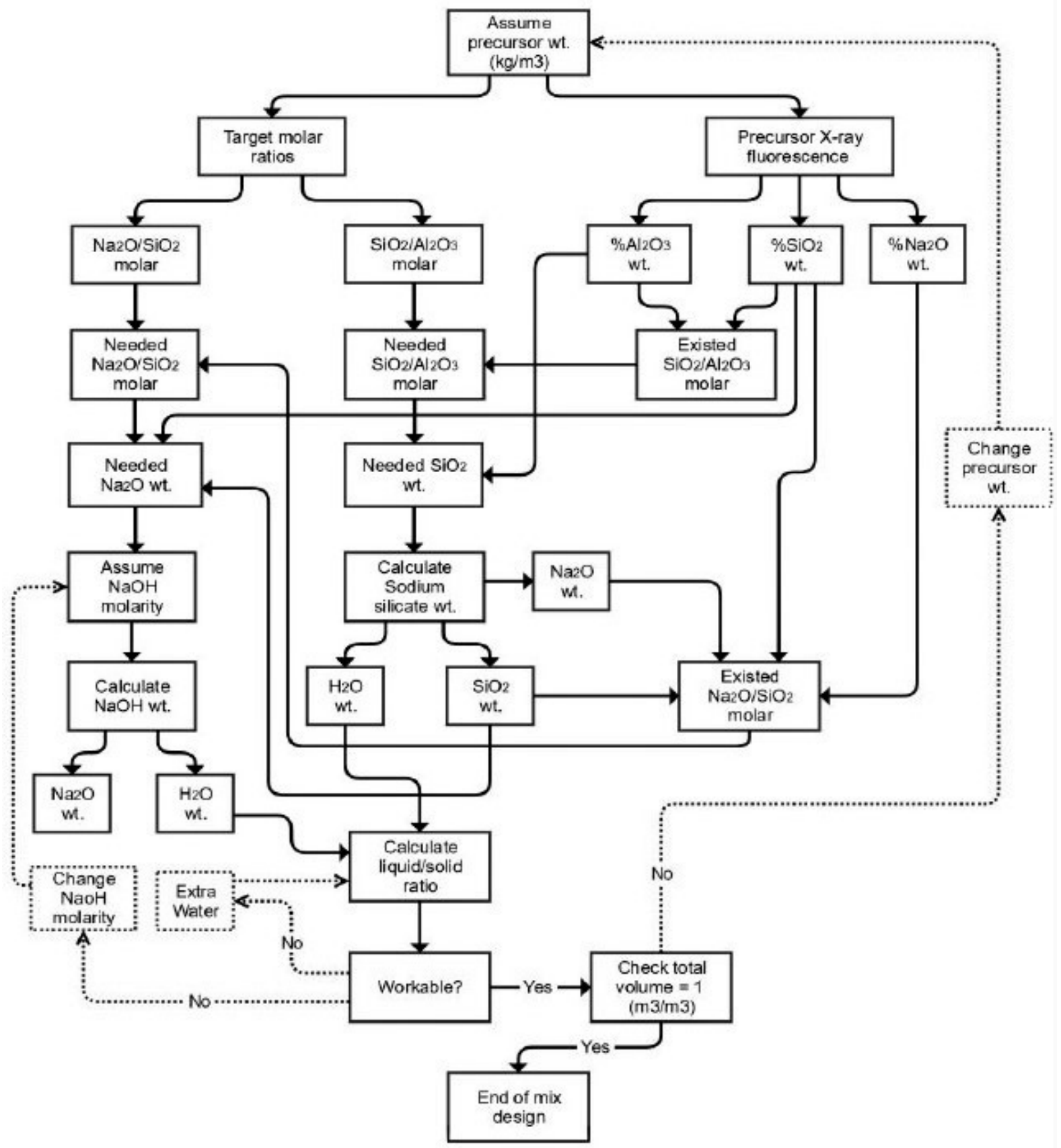

Figure 3.10 Flowchart of sequential mix design method

The initial targeted ratios were determined based on the results of a preliminary testing program taking into account previous studies from the literature. In this program, numerous geopolymer compositions were prepared and the following aspects were studied to determine the best threshold limits for RCBW, CTW and CW-based geopolymer binders:

1. Investigation of the effect of different sodium silicate to sodium hydroxide ratios. 
2. Investigation of the effect of liquid/solid ratios on the workability and mechanical properties of CDW-geopolymers.

3. Investigation of the effect of alkaline reagent concentration.

4. Investigation of the effect of $\mathrm{SiO}_{2} / \mathrm{Al}_{2} \mathrm{O}_{3}, \mathrm{Na}_{2} \mathrm{O} / \mathrm{SiO}_{2}$ and $\mathrm{H}_{2} \mathrm{O} / \mathrm{Na}_{2} \mathrm{O}$ ratios.

5. Investigation of the effect of $\mathrm{Na} 2 \mathrm{O}$ concentration.

Additional ratios were determined throughout the experimental program depending on the fresh and mechanical properties of the developed geopolymer binders.

\subsubsection{Preparation of Sodium Hydroxide (NaOH) Solution}

Sodium hydroxide is made of crystalline pellets in solid form with a $318{ }^{\circ} \mathrm{C}$ melting point, its liquid solution has $78 \mathrm{mPa}$.s (millipascal-second) viscosity. Alkaline reagents or activators were prepared by dissolving sodium hydroxide pellets in distilled water at various molarities. The effects of 6, 9, 12, 14 and 16 molarities were investigated and the best molarities providing the higher compressive strength were selected for the mix design of future experiments.

The amount of solid sodium hydroxide pellets was selected based on the atomic weight or molar mass (gr/mole) of $\mathrm{NaOH}$ and then the required moles were multiplied to achieve a specific molarity. The amount of $\mathrm{NaOH}$ pellets was then dissolved in a liter of distilled water and stirred for 15-20 minutes to prepare the targeted molarity of $\mathrm{NaOH}$. Table 3.6 presents the quantities of solid $\mathrm{NaOH}$ pellets used for the preparation of different $\mathrm{NaOH}$ solutions.

Table 3.6 Molar mass of $\mathrm{NaOH}$ solutions

\begin{tabular}{|l|l|}
\hline Molar Mass of $\mathrm{NaOH}(\mathrm{gr} / \mathrm{mole})$ \\
\hline $\mathrm{Na}$ & $22.899 \approx 23 \mathrm{~g}$ \\
\hline $\mathrm{O}$ & $15.999 \approx 16 \mathrm{~g}$ \\
\hline $\mathrm{H}$ & $1.00784 \approx 1 \mathrm{~g}$ \\
\hline Total molar mass of NaOH/mole & $\approx 40 \mathrm{~g} / \mathrm{mole}$ \\
\hline 6 Molarity $\mathrm{NaOH}$ Solution & 240 grams/liter solution \\
\hline 9 Molarity $\mathrm{NaOH}$ Solution & 360 grams/liter solution \\
\hline 12 Molarity NaOH Solution & 480 grams/liter solution \\
\hline 14 Molarity NaOH Solution & 560 grams/liter solution \\
\hline 16 Molarity NaOH Solution & 640 grams/liter solution \\
\hline
\end{tabular}

The dissolution of $\mathrm{NaOH}$ in water is an exothermic reaction which produces excessive heat. Prepared 
solutions were kept in graduated cylinders in a laboratory fume hood for 24 hours to release any exothermic heat. A specific amount of $\mathrm{NaOH}$ solution of a targeted molarity was calculated based on the mix design specifically developed for this research. It was then mixed with sodium silicate and water to acquire the final alkaline reagent and stirred to fully mix sodium hydroxide, sodium silicate and water in the alkaline solution medium. The amounts of solid $\mathrm{NaOH}$ flakes and water in a one-liter solution of $\mathrm{NaOH}$ was determined for calculating the liquid/solid (L/S) ratios of the mix. The solid phases of $\mathrm{NaOH}$ for 6 to 20-M solutions are shown in Table 3.6.

Table 3.7 Amount of solid $\mathrm{NaOH}$ and water content in one-liter $\mathrm{NaOH}$ solution

\begin{tabular}{|c|c|c|}
\hline $\begin{array}{c}\text { NaOH Solution } \\
\text { Molarity }\end{array}$ & $\mathrm{NaOH} \%$ & Water $\%$ \\
\hline $6 \mathrm{M}$ & $21.30 \%$ & $78.70 \%$ \\
\hline $8 \mathrm{M}$ & $26.23 \%$ & $73.77 \%$ \\
\hline $9 \mathrm{M}$ & $28.80 \%$ & $71.20 \%$ \\
\hline $10 \mathrm{M}$ & $31.37 \%$ & $68.63 \%$ \\
\hline $11 \mathrm{M}$ & $33.94 \%$ & $66.06 \%$ \\
\hline $12 \mathrm{M}$ & $36.09 \%$ & $63.91 \%$ \\
\hline $13 \mathrm{M}$ & $38.66 \%$ & $61.34 \%$ \\
\hline $14 \mathrm{M}$ & $41.23 \%$ & $58.77 \%$ \\
\hline $16 \mathrm{M}$ & $44.44 \%$ & $55.56 \%$ \\
\hline $18 \mathrm{M}$ & $51.66 \%$ & $48.34 \%$ \\
\hline $20 \mathrm{M}$ & $58.88 \%$ & $41.12 \%$ \\
\hline
\end{tabular}

\subsubsection{Mixing Procedure}

A 10 liter-volume Hobart mixer equipped with 3 different speeds was used to mix all the geopolymer compositions. Required sodium hydroxide, sodium silicate and water contents were first mixed in a graduated cylinder, stirred for 60 seconds and then kept for 1 hour inside the fume hood. The precursor powders were placed in the mixer and stirred for 60 seconds in dry form using the lowest speed 1 (140 $\mathrm{rpm})$. Then the alkaline reagent solution was poured into the mixer at the same speed 1 for 30 seconds. Consequently, the speed was increased to medium (speed 2) at $210 \mathrm{rpm}$ for 90 seconds and increased to high speed 3 at $285 \mathrm{rpm}$ for 30 seconds before it was returned to medium (2) for 30 seconds. At the completion of these mixing processes, the mixer was stopped and the geopolymer paste was poured into $(50 \times 50 \times 50) \mathrm{mm}$ cubes. The molds were vibrated for 60 seconds using a vibration table to remove the excessive air in the geopolymer system. They were covered with plastic sheets and kept in 
the ambient laboratory environment for $24 \mathrm{~h}$. After this time, the specimens were demolded and placed in plastic bags at an ambient temperature of around $25 \pm 2^{\circ} \mathrm{C}$ until achieving the required curing ages of 7 and 28 days. Figure 3.10 summarizes the mixing process of geopolymer binders.

Precursor powders in mono, binary, ternary or quaternary form were added into the mixer - Speed 1 for $60 \mathrm{~S}$
Alkaline reagents (sodium hydroxide and sodium silicate) and additional water, if needed, were added.

- Speed 1 for $30 \mathrm{~S}$
Alkaline solution and precursor powders were mixed.

- Speed 2 for $90 \mathrm{~S}$.

- Speed 3 for $30 \mathrm{~S}$.

- Speed 2 for $30 \mathrm{~S}$.
The mixer was stopped, and binders poured into the molds

Figure 3.11 Mixing procedures of geopolymer binders

\subsubsection{Specimen Coding}

Produced geopolymers were coded based on the precursor materials and the values of different ratios of $\mathrm{SiO}_{2} / \mathrm{Al}_{2} \mathrm{O}_{3}, \mathrm{Na} 2 \mathrm{O} / \mathrm{SiO}_{2}$ and $\mathrm{L} / \mathrm{S}$. Examples of the codes used are presented in Table 3.8.

Table 3.8 Coding examples of geopolymer specimens

\begin{tabular}{|l|l|l|l|}
\hline Geopolymer Specimen Coding Description \\
\hline Specimen Code (Mono) & B-7.1-0.24-0.3 & $\begin{array}{l}\text { Specimen Code } \\
\text { (Ternary) }\end{array}$ & BCT-7.6-0.18-0.3 \\
\hline Precursor & RCBW & Precursors & CDW, RCBW, CTW \\
\hline $\mathrm{SiO}_{2} / \mathrm{Al}_{2} \mathrm{O}_{3}$ & 7.1 & $\mathrm{SiO}_{2} / \mathrm{Al}_{2} \mathrm{O}_{3}$ & 7.6 \\
\hline $\mathrm{Na}_{2} \mathrm{O} / \mathrm{SiO}_{2}$ & 0.24 & $\mathrm{Na}_{2} \mathrm{O} / \mathrm{SiO}_{2}$ & 0.18 \\
\hline $\mathrm{L} / \mathrm{S}$ & 0.3 & $\mathrm{~L} / \mathrm{S}$ & 0.3 \\
\hline $\begin{array}{l}\text { Specimen Code high } \\
\text { temperature curing }\end{array}$ & $\mathrm{B}-7.1-0.24-0.3-\mathrm{HT}-75^{\circ} \mathrm{C}$ & $\begin{array}{l}\text { Specimen Code } \\
\mathrm{CDW}+\mathrm{SCM}\end{array}$ & $\begin{array}{l}\mathrm{BMK}-4.2-0.24-0.3- \\
\text { MK15 }\end{array}$ \\
\hline Precursor & $\mathrm{RCBW}$ & $\mathrm{Precursors}$ & $\mathrm{RCBW}(85 \%)+\mathrm{MK}(15 \%)$ \\
\hline $\mathrm{SiO} / \mathrm{Al}_{2} \mathrm{O}_{3}$ & 7.1 & $\mathrm{SiO} / \mathrm{Al}_{2} \mathrm{O}_{3}$ & 4.2 \\
\hline $\mathrm{Na} 2 \mathrm{O} / \mathrm{SiO}_{2}$ & 0.24 & $\mathrm{Na} 2 \mathrm{O} / \mathrm{SiO}_{2}$ & 0.24 \\
\hline $\mathrm{L} / \mathrm{S}$ & 0.3 & $\mathrm{~L} / \mathrm{S}$ & 0.3 \\
\hline $\mathrm{High}$ temperature curing & $75{ }^{\circ} \mathrm{C}$ & - & - \\
\hline
\end{tabular}

\subsection{Testing Methods}




\subsubsection{Fresh Properties}

\section{- Flowability Test}

The flowability test was used to evaluate the workability and consistency of geopolymeric pastes. This test was conducted according to ASTM C230/C230M-14. After completing the mixing procedure presented in section 3.3.3, the geopolymer paste was placed into a conical mold with a height of $(50.0 \pm 0.5$ $\mathrm{mm})$, top opening diameter $(70.0 \pm 0.5 \mathrm{~mm})$ and bottom opening diameter $(100.0 \pm 0.5 \mathrm{~mm})$. A flow table connected to an automated motor was used to apply 25 drops to the filled flow mold. After removing the mold, the flow diameter was recorded at three different directions to record their average value as the flow diameter of a specific geopolymer paste. Figure 3.11 shows the flowability test completed on CDWgeopolymer pastes.
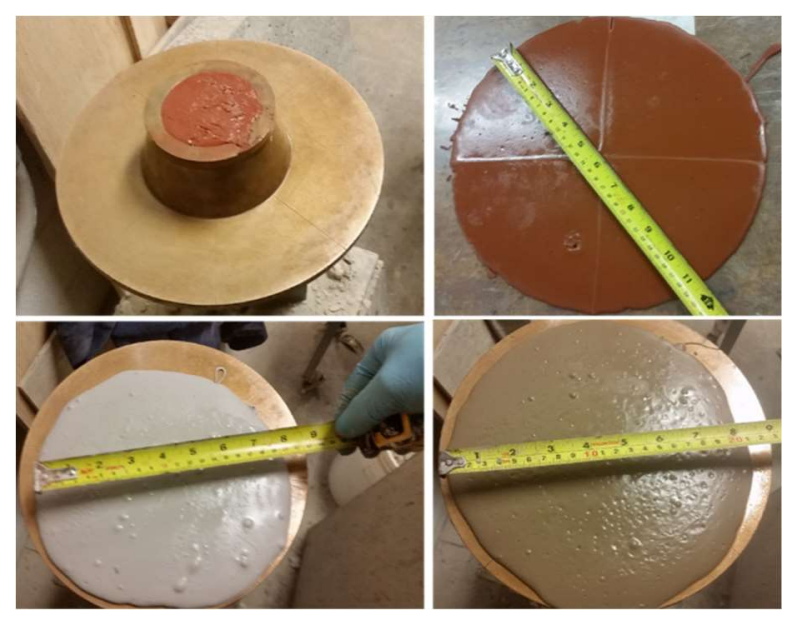

Figure 3.12 Flow test of RCBW geopolymer binders

\section{- Time of Setting of Geopolymer Binders}

The setting time test of geopolymer binders was performed in accordance with ASTM designation C19113. A Vicat needle using a manually operated Vicat apparatus was used in this test presented in Figure 3.12. The geopolymer paste was poured into a Vicat conical mold and the needle was released into the paste. The initial setting time was determined when the needle penetrated $25 \mathrm{~mm}$ into the paste. The final setting time was recorded when the Vicat needle did not leave any mark on the surface of the geopolymer binders. 

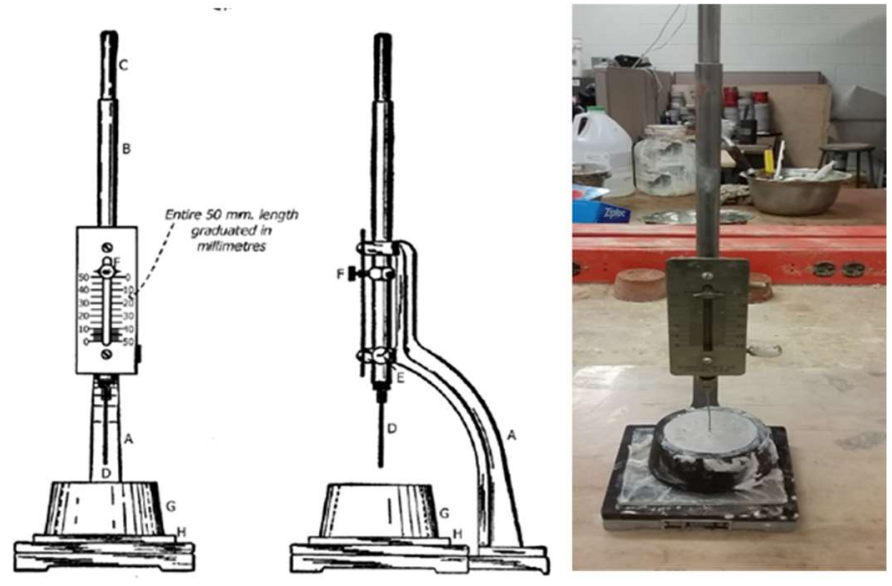

Figure 3.13 Setting time test of CTW

\subsubsection{Mechanical Properties}

Compressive strengths were determined in accordance with ASTM standard designation C109/C109M - 16a using 50-mm (2-in) cubic specimens. The 50-mm cubes were placed inside the plastic bags directly after demolding to prevent any moisture loss. They were then cured in a laboratory environment at an average temperature of around $25 \pm 2^{\circ} \mathrm{C}$. Compressive strengths were tested at 7 and 28 days of curing using a universal compressive strength machine conforming to ASTM C109. The compressive load was applied at $1.5 \mathrm{kN} / \mathrm{sec}$. Figure 3.13 shows some CDW samples casted for compressive strength testing.
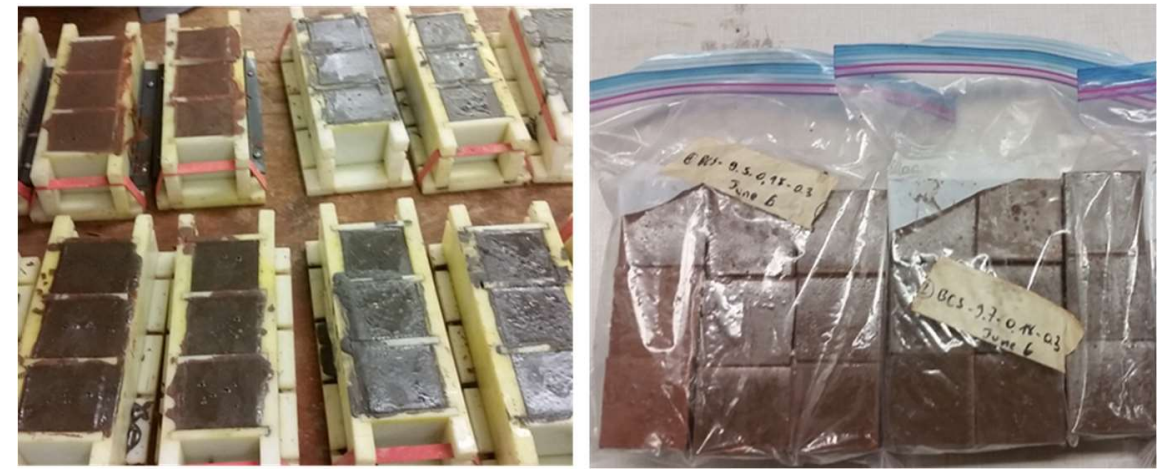

Figure 3.14 Curing of CDW geopolymer specimens

\subsubsection{Microstructure Investigation}

Microstructural characterizations were performed after 28 days of curing using scanning electron microscopy (SEM) coupled with energy-dispersive spectroscopy (EDS) and X-Ray diffraction (XRD) analysis. A JEOL JSM-6380LV SEM-EDS with a resolution of $3.0 \mathrm{~nm}$ was used in this study. The samples analyzed were broken pieces from the cubic specimens used to determine the compressive strengths after 28 days. They were kept inside the desiccator until the date of the microstructural 
investigation. A gold coating was applied to the samples before being analyzed. XRD analysis was performed on powders using a PANalytical X'Pert Pro X-ray diffraction device, equipped with a $5^{\circ} \leq 2 \theta \leq 80^{\circ}$ scanning range. $\mathrm{Cu}-\mathrm{K} \alpha \mathrm{X}$-ray radiation was used to acquire the diffraction data with a characteristic wavelength of 1.5418 A. Figure 3.14 shows the SEM-EDS and XRD machines used to perform the microstructural analysis.
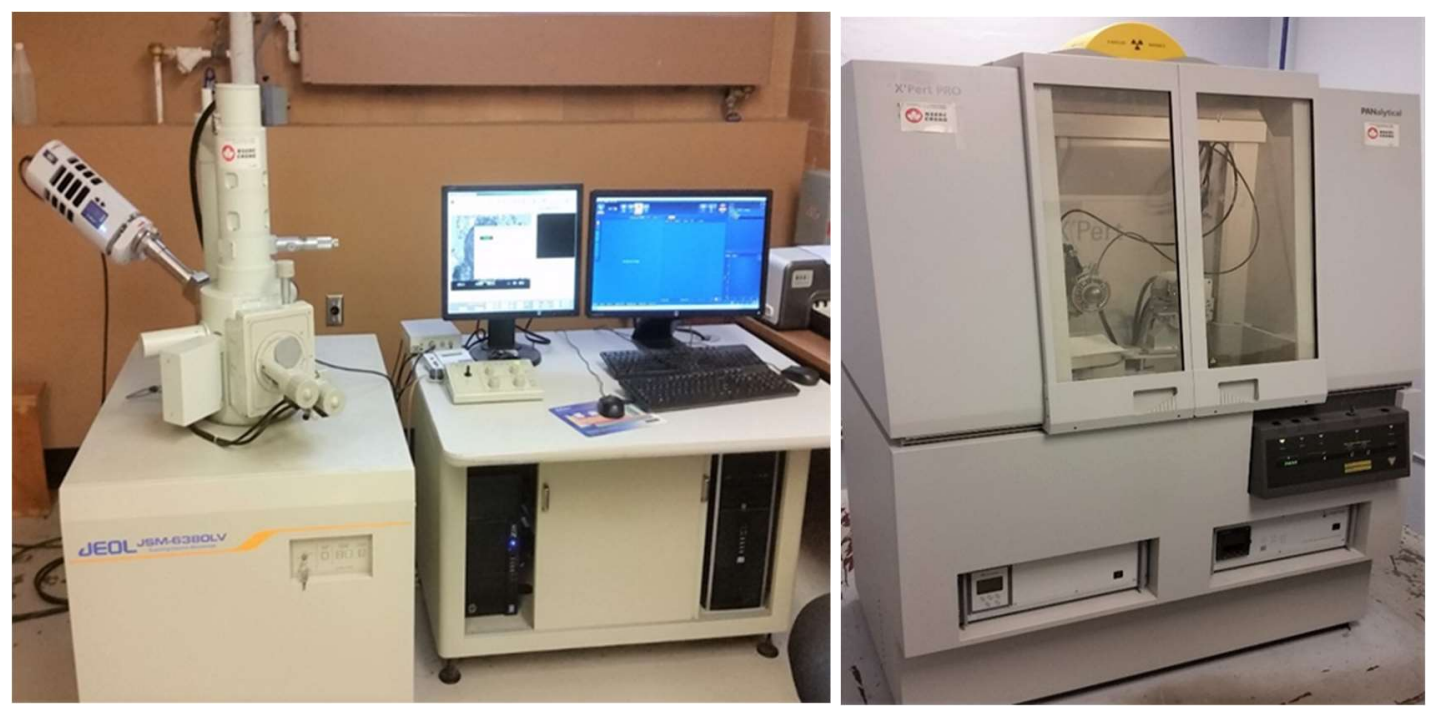

Figure 3.15 JEOL JSM-6380LV Scanning Electron Microscope and EDS

\subsection{Experimental Methodology}

A comprehensive experimental methodology was developed to investigate the most suitable mix composition to optimize the compressive strengths of CDW, RCBW and CTW based geopolymer binders. The flow chart presented in Figure 3.15 shows the tasks performed for reaching the objectives of this research. 
Task 1: Materials selection

Materials selected from CDW piles and

sorted into RCBW, CTW and CW

Task 2: Materials investigation Chemical composition and microstructure investigation of materials using XRF, XRD and SEM

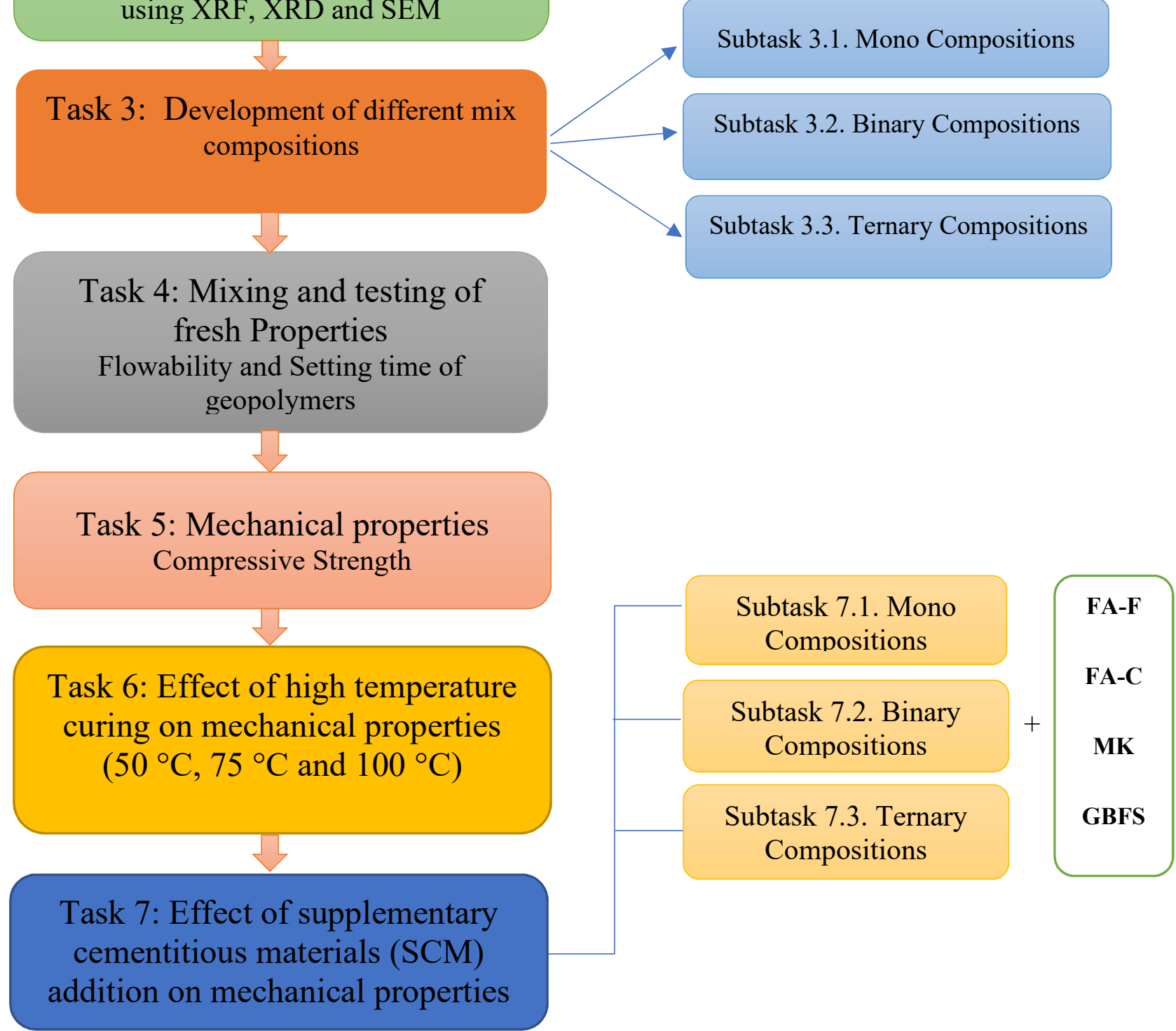

Figure 3.16 Experimental Methodology Flowchart 


\section{Chapter Four \\ Results and Discussion}

\subsection{Introduction}

In this section, the results of the current research about the use of CDWs to develop new geopolymeric networks are presented and discussed. CW-, RCBW- and CTW-based mono, binary and ternary geopolymer compositions were arranged by targeting specific values of $\mathrm{SiO}_{2} / \mathrm{Al}_{2} \mathrm{O}_{3}, \mathrm{Na}_{2} \mathrm{O} / \mathrm{SiO}_{2}$ and liquid/solid ratios. All geopolymer pastes were prepared and cured in the same conditions at laboratory ambient temperature, close to that of a real construction site. However, the effect of high temperature (HT) curing was also investigated by considering applying a $24 \mathrm{~h}$ initial curing of 50,75 and $100{ }^{\circ} \mathrm{C}$ on four optimized compositions of each geopolymeric system. Furthermore, the effects of adding SCMs such as FA-F, MK, FA-C and GGBS on the properties of the optimized compositions of mono, binary and ternary CDW-systems were also investigated. The results of the fresh and mechanical characteristics of all compositions are presented and the effect of $\mathrm{SiO}_{2} / \mathrm{Al}_{2} \mathrm{O}_{3}, \mathrm{Na}_{2} \mathrm{O} / \mathrm{SiO}_{2}$ and $\mathrm{H}_{2} \mathrm{O} / \mathrm{Na}_{2} \mathrm{O}$ ratios and $\mathrm{Na}_{2} \mathrm{O}$ concentration and silica modulus are discussed.

To optimize as much as possible, the chemical ratios of $\mathrm{SiO}_{2} / \mathrm{Al}_{2} \mathrm{O}_{3}, \mathrm{Na} 2 \mathrm{O} / \mathrm{SiO}_{2}$, various molar ratios were tested with a 0.2 step increment. The effect of one parameter was studied each time, while keeping other parameters constant. When adding SCMs into the geopolymer system, $\mathrm{SiO}_{2} / \mathrm{Al}_{2} \mathrm{O}_{3}$ molar ratios were changed based on the new precursor powders. Nevertheless, $\mathrm{Na}_{2} \mathrm{O} / \mathrm{SiO}_{2}$ and $\mathrm{L} / \mathrm{S}$ ratios were kept the same as those of the optimized compositions initially tested.

\subsection{Determination of Different Mix Compositions}

\subsubsection{Mono-system Geopolymer Compositions}

Mono compositions were prepared from a single CDW precursor material. The composition either contained red clay brick waste $(\mathrm{RCBW})$, ceramic tile waste (CTW) or concrete waste $(\mathrm{CW})$. The quantities of CDW precursor powders, alkaline reagents (sodium silicate and sodium hydroxide) and water were determined based on the mix design procedure presented in chapter 3. First, specific ratios of $\mathrm{SiO}_{2} / \mathrm{Al}_{2} \mathrm{O}_{3}$ and $\mathrm{Na}_{2} \mathrm{O} / \mathrm{SiO}_{2}$ in precursor powders were calculated and the initial molar ratios of the whole geopolymer binder mix were decided. These molar ratios were targeted and achieved by adding alkaline reagents (i.e. sodium silicate and sodium hydroxide) to the mix. Subsequently, the molarity 
of sodium hydroxide was regulated to achieve specific liquid/solid (L/S) ratios. The maximum and minimum $\mathrm{SiO}_{2} / \mathrm{Al}_{2} \mathrm{O}_{3}, \mathrm{Na}_{2} \mathrm{O} / \mathrm{SiO}_{2}$ and $\mathrm{L} / \mathrm{S}$ ratios were decided throughout the experimental program by taking into account the results of the previous compositions.

\section{- Mono-system RCBW Compositions}

Based on XRF analysis, RCBW powders have a $\mathrm{SiO}_{2} / \mathrm{Al}_{2} \mathrm{O}_{3}$ molar ratio of 6.56. Mono RCBW-based geopolymer binders were initially investigated for $\mathrm{SiO}_{2} / \mathrm{Al}_{2} \mathrm{O}_{3}$ molar ratios between 6.7 and 7.9, with 0.2 step increment, $\mathrm{Na}_{2} \mathrm{O} / \mathrm{SiO}_{2}$ molar ratios between 0.12 and 0.16 , and $\mathrm{L} / \mathrm{S}$ ratios of 0.4, 0.45 and 0.5. In these initial investigations, L/S ratios were arranged by considering the ratios of alkaline reagents to precursor powders, which we can also call activator to powder ratios. The initial testing program showed that the optimum strengths were reached at $\mathrm{SiO}_{2} / \mathrm{Al}_{2} \mathrm{O}_{3}$ of $7.1, \mathrm{Na}_{2} \mathrm{O} / \mathrm{SiO}_{2}$ of 0.16 and $\mathrm{L} / \mathrm{S}$ of 0.4. Therefore, mono RCBW-based geopolymer compositions were recast at new $\mathrm{SiO}_{2} / \mathrm{Al}_{2} \mathrm{O}_{3}$ ratios of 7.1, 7.3, 7.5, 7.7 and 7.9, $\mathrm{Na}_{2} \mathrm{O} / \mathrm{SiO}_{2}$ ratios of $0.16,0.18,0.2,0.22$ and 0.24 , with 0.2 step increment, and constant $\mathrm{L} / \mathrm{S}$ ratio of 0.3 . However, the amount of $\mathrm{L} / \mathrm{S}$ ratio was decided by separating the liquid and solid phases in the alkaline activators. Consequently, the liquid phase of sodium silicate and

sodium hydroxide solutions was added to the water content of the mix and the solid phase was added to its total powder content. The twenty-five mix compositions prepared for the mono-system RCBW geopolymers are presented in Table 4.1 
Table 4.1 Mix proportions of mono RCBW Geopolymers RCBW Geopolymer Matrix

Mix Proportions $\left(\mathrm{kg} / \mathrm{m}^{3}\right)$

\begin{tabular}{|c|c|c|c|c|c|c|c|c|}
\hline No. & Composition Code & $\mathrm{SiO}_{2} / \mathrm{Al}_{2} \mathrm{O}_{3}$ & $\mathrm{Na}_{2} \mathrm{O} / \mathrm{SiO}_{2}$ & $\mathrm{~L} / \mathrm{S}$ & RCBW & SS & $\mathrm{SH}$ & Water \\
\hline 1 & B-7.1-0.16-0.30 & 7.1 & 0.16 & 0.30 & 1220 & 222.18 & 331.11 & 100 \\
\hline 2 & B-7.1-0.18-0.30 & 7.1 & 0.18 & 0.30 & 1200 & 218.54 & 376.29 & 70 \\
\hline 3 & B-7.1-0.20-0.30 & 7.1 & 0.20 & 0.30 & 1180 & 214.89 & 419.79 & 40 \\
\hline 4 & B-7.1-0.22-0.30 & 7.1 & 0.22 & 0.30 & 1155 & 210.34 & 459.6 & 20 \\
\hline 5 & B-7.1-0.24.-0.30 & 7.1 & 0.24 & 0.30 & 1130 & 205.79 & 497.31 & 0 \\
\hline 6 & B-7.3-0.16-0.30 & 7.3 & 0.16 & 0.30 & 1280 & 318.75 & 336.78 & 60 \\
\hline 7 & B-7.3-0.18-0.30 & 7.3 & 0.18 & 0.30 & 1180 & 293.84 & 361.63 & 30 \\
\hline 8 & B-7.3-0.20-0.30 & 7.3 & 0.20 & 0.30 & 1170 & 291.35 & 409.3 & 0 \\
\hline 9 & B-7.3-0.22-0.30 & 7.3 & 0.22 & 0.30 & 1120 & 278.9 & 440.37 & 0 \\
\hline 10 & B-7.3-0.24.-0.30 & 7.3 & 0.24 & 0.30 & 1070 & 266.45 & 467.11 & 0 \\
\hline 11 & B-7.5-0.16-0.30 & 7.5 & 0.16 & 0.30 & 1220 & 385.43 & 310.87 & 0 \\
\hline 12 & B-7.5-0.18-0.30 & 7.5 & 0.18 & 0.30 & 1170 & 369.64 & 350.25 & 0 \\
\hline 13 & B-7.5-0.20-0.30 & 7.5 & 0.20 & 0.30 & 1120 & 353.84 & 385.18 & 0 \\
\hline 14 & B-7.5-0.22-0.30 & 7.5 & 0.22 & 0.30 & 1100 & 347.52 & 427.3 & 0 \\
\hline 15 & B-7.5-0.24.-0.30 & 7.5 & 0.24 & 0.30 & 1050 & 331.72 & 454.66 & 0 \\
\hline 16 & B-7.7-0.16-0.30 & 7.7 & 0.16 & 0.30 & 1160 & 444.09 & 285.96 & 0 \\
\hline 17 & B-7.7-0.18-0.30 & 7.7 & 0.18 & 0.30 & 1110 & 424.95 & 324.4 & 0 \\
\hline 18 & B-7.7-0.20-0.30 & 7.7 & 0.20 & 0.30 & 1060 & 405.8 & 358.27 & 0 \\
\hline 19 & B-7.7-0.22-0.30 & 7.7 & 0.22 & 0.30 & 1020 & 390.49 & 391.4 & 0 \\
\hline 20 & B-7.7-0.24.-0.30 & 7.7 & 0.24 & 0.30 & 1000 & 382.83 & 429.46 & 0 \\
\hline 21 & B-7.9-0.16-0.30 & 7.9 & 0.16 & 0.30 & 1220 & 548.69 & 290.63 & 0 \\
\hline 22 & B-7.9-0.18-0.30 & 7.9 & 0.18 & 0.30 & 1120 & 503.71 & 319.36 & 0 \\
\hline 23 & B-7.9-0.20-0.30 & 7.9 & 0.20 & 0.30 & 1030 & 463.23 & 342.03 & 0 \\
\hline 24 & B-7.9-0.22-0.30 & 7.9 & 0.22 & 0.30 & 1000 & 449.74 & 378.99 & 0 \\
\hline 25 & B-7.9-0.24-0.30 & 7.9 & 0.24 & 0.30 & 980 & 440.75 & 417.4 & 0 \\
\hline
\end{tabular}

\section{- Mono-system CTW Compositions}

Because CTW has a $\mathrm{SiO}_{2} / \mathrm{Al}_{2} \mathrm{O}_{3}$ molar ratio of 10.06 , it was decided to study mixes with $\mathrm{SiO}_{2} / \mathrm{Al}_{2} \mathrm{O}_{3}$ molar ratios ranging from 10.5 and 11.7 , with 0.2 step increment, and $\mathrm{Na}_{2} \mathrm{O} / \mathrm{SiO}_{2}$ molar ratios between 0.14 and 0.24 , with 0.2 step increment, while keeping the L/S ratio constant at 0.3 . Table 4.2 presents the thirty compositions arranged for CTW mono system binders. 
Table 4.2 Mix Proportions of mono-system CTW Geopolymers

\begin{tabular}{|c|c|c|c|c|c|c|c|c|}
\hline \multicolumn{5}{|c|}{ CTW Geopolymer Matrix } & \multicolumn{4}{|c|}{ Mix Proportions $\left(\mathrm{kg} / \mathrm{m}^{3}\right)$} \\
\hline No. & Composition Code & $\mathrm{SiO}_{2} / \mathrm{Al}_{2} \mathrm{O}_{3}$ & $\mathrm{Na}_{2} \mathrm{O} / \mathrm{SiO}_{2}$ & $\mathrm{~L} / \mathrm{S}$ & CTW & SS & $\mathrm{SH}$ & Water \\
\hline 1 & $\mathrm{~T}-10.5-0.14-0.30$ & 10.5 & 0.14 & 0.30 & 1280 & 125.85 & 371.86 & 115 \\
\hline 2 & $\mathrm{~T}-10.5-0.16-0.30$ & 10.5 & 0.16 & 0.30 & 1250 & 122.9 & 422.02 & 80 \\
\hline 3 & $\mathrm{~T}-10.5-0.18-0.30$ & 10.5 & 0.18 & 0.30 & 1225 & 120.44 & 471.4 & 50 \\
\hline 4 & $\mathrm{~T}-10.5-0.20-0.30$ & 10.5 & 0.20 & 0.30 & 1205 & 118.47 & 520.52 & 20 \\
\hline 5 & $\mathrm{~T}-10.5-0.22-0.30$ & 10.5 & 0.22 & 0.30 & 1170 & 115.03 & 560.57 & 0 \\
\hline 6 & $\mathrm{~T}-10.5-0.24-0.33$ & 10.5 & 0.24 & 0.30 & 1120 & 110.11 & 589.42 & 0 \\
\hline 7 & $\mathrm{~T}-10.7-0.14-0.30$ & 10.7 & 0.14 & 0.30 & 1270 & 181.09 & 359.85 & 87 \\
\hline 8 & $\mathrm{~T}-10.7-0.16-0.30$ & 10.7 & 0.16 & 0.30 & 1245 & 177.53 & 474.65 & 0 \\
\hline 9 & $\mathrm{~T}-10.7-0.18-0.30$ & 10.7 & 0.18 & 0.30 & 1215 & 173.25 & 461.02 & 25 \\
\hline 10 & $\mathrm{~T}-10.7-0.20-0.30$ & 10.7 & 0.20 & 0.30 & 1200 & 171.11 & 512.99 & 0 \\
\hline 11 & $\mathrm{~T}-10.7-0.22-0.30$ & 10.7 & 0.22 & 0.30 & 1200 & 171.11 & 512.99 & 0 \\
\hline 12 & T-10.7-0.24-0.30 & 10.7 & 0.24 & 0.30 & 1200 & 171.11 & 512.99 & 0 \\
\hline 13 & $\mathrm{~T}-10.9-0.14-0.30$ & 10.9 & 0.14 & 0.30 & 1265 & 236.39 & 349.36 & 62 \\
\hline 14 & T-10.9-0.16-0.30 & 10.9 & 0.16 & 0.30 & 1240 & 231.72 & 403.15 & 0 \\
\hline 15 & $\mathrm{~T}-10.9-0.18-0.30$ & 10.9 & 0.18 & 0.30 & 1215 & 227.05 & 454.5 & 0 \\
\hline 16 & $\mathrm{~T}-10.9-0.20-0.30$ & 10.9 & 0.20 & 0.30 & 1180 & 220.51 & 499.16 & 0 \\
\hline 17 & $\mathrm{~T}-10.9-0.22-0.30$ & 10.9 & 0.22 & 0.30 & 1180 & 220.51 & 499.16 & 0 \\
\hline 18 & T-10.9-0.24-0.30 & 10.9 & 0.24 & 0.30 & 1180 & 220.51 & 499.16 & 0 \\
\hline 19 & T-11.1-0.14-0.3 & 11.1 & 0.14 & 0.30 & 1250 & 288.93 & 336.26 & 35 \\
\hline 20 & T-11.1-0.16-0.3 & 11.1 & 0.16 & 0.30 & 1240 & 286.62 & 395.38 & 0 \\
\hline 21 & T-11.1-0.18-0.3 & 11.1 & 0.18 & 0.30 & 1200 & 277.37 & 442.44 & 0 \\
\hline 22 & T-11.1-0.20-0.3 & 11.1 & 0.20 & 0.30 & 1160 & 268.13 & 458.51 & 0 \\
\hline 23 & T-11.1-0.22-0.3 & 11.1 & 0.22 & 0.30 & 1120 & 258.88 & 524.59 & 0 \\
\hline 24 & T-11.1-0.24-0.3 & 11.1 & 0.24 & 0.30 & 1080 & 249.64 & 559.69 & 0 \\
\hline 25 & T-11.3-0.14-0.3 & 11.3 & 0.14 & 0.30 & 1255 & 345.65 & 328.61 & 0 \\
\hline 26 & T-11.3-0.16-0.3 & 11.3 & 0.16 & 0.30 & 1230 & 338.77 & 384.47 & 0 \\
\hline 27 & T-11.3-0.18-0.3 & 11.3 & 0.18 & 0.30 & 1200 & 330.51 & 435.99 & 0 \\
\hline 28 & T-11.3-0.20-0.3 & 11.3 & 0.20 & 0.30 & 1150 & 316.73 & 476.18 & 0 \\
\hline 29 & T-11.3-0.22-0.3 & 11.3 & 0.22 & 0.30 & 1100 & 302.96 & 511.29 & 0 \\
\hline 30 & T-11.3-0.24-0.3 & 11.3 & 0.24 & 0.30 & 1050 & 289.19 & 541.33 & 0 \\
\hline
\end{tabular}

\section{- Mono-system CW Compositions}

From XRF analysis of CW, the $\mathrm{SiO}_{2} / \mathrm{Al}_{2} \mathrm{O}_{3}$ molar ratio of this precursor powder is 9.71. Consequently, $\mathrm{SiO}_{2} / \mathrm{Al}_{2} \mathrm{O}_{3}$ molar ratios of geopolymer mixes were decided to be ranging from 12 and 13.2, with 0.3 step increment. $\mathrm{Na}_{2} \mathrm{O} / \mathrm{SiO}_{2}$ molar ratios were between 0.20 and 0.35 with 0.3 step increment, and $\mathrm{L} / \mathrm{S}$ ratio was 0.3 for all compositions. The reason for considering higher $\mathrm{Si} / \mathrm{Al}$ and $\mathrm{Na} / \mathrm{Si}$ ratios in $\mathrm{CW}$ compositions compared to those of RCBW and CTW is the low silica, alumina and sodium oxide contents in the dry $\mathrm{CW}$ powders. The thirty mix proportions arranged for mono-system $\mathrm{CW}$ geopolymers are presented in Table 4.3. 
Table 4.3 Mix proportions of mono-system CW geopolymers

\begin{tabular}{|c|c|c|c|c|c|c|c|c|}
\hline \multicolumn{5}{|c|}{ CW Geopolymer Matrix } & \multicolumn{4}{|c|}{ Mix Proportions $\left(\mathrm{kg} / \mathrm{m}^{3}\right)$} \\
\hline No. & Composition Code & $\mathrm{SiO}_{2} / \mathrm{Al}_{2} \mathrm{O}_{3}$ & $\mathrm{Na}_{2} \mathrm{O} / \mathrm{SiO}_{2}$ & $\mathrm{~L} / \mathrm{S}$ & $\mathrm{CW}$ & SS & $\mathrm{SH}$ & Water \\
\hline 1 & CW-12-0.2-0.3 & 12 & 0.2 & 0.30 & 1395 & 284.59 & 172.18 & 140 \\
\hline 2 & CW-12-0.23-0.3 & 12 & 0.23 & 0.30 & 1360 & 277.48 & 207.81 & 115 \\
\hline 3 & CW-12-0.26-0.3 & 12 & 0.26 & 0.30 & 1345 & 274.39 & 245.03 & 90 \\
\hline 4 & CW-12-0.29-0.3 & 12 & 0.29 & 0.30 & 1325 & 270.31 & 280.31 & 70 \\
\hline 5 & CW-12-0.32-0.3 & 12 & 0.32 & 0.30 & 1305 & 266.23 & 314.42 & 50 \\
\hline 6 & CW-12-0.35-0.3 & 12 & 0.35 & 0.30 & 1285 & 262.15 & 347.35 & 30 \\
\hline 7 & CW-12.3-0.2-0.3 & 12.3 & 0.2 & 0.30 & 1370 & 316.14 & 165.75 & 120 \\
\hline 8 & CW-12.3-0.23-0.3 & 12.3 & 0.23 & 0.30 & 1350 & 311.52 & 203.98 & 96 \\
\hline 9 & CW-12.3-0.26-0.3 & 12.3 & 0.26 & 0.30 & 1332 & 307.37 & 241.37 & 75 \\
\hline 10 & CW-12.3-0.29-0.3 & 12.3 & 0.29 & 0.30 & 1310 & 302.29 & 276.83 & 52 \\
\hline 11 & CW-12.3-0.32-0.3 & 12.3 & 0.32 & 0.30 & 1297 & 299.29 & 309.37 & 32 \\
\hline 12 & CW-12.3-0.35-0.3 & 12.3 & 0.35 & 0.30 & 1282 & 295.83 & 344.39 & 10 \\
\hline 13 & CW-12.6-0.2-0.3 & 12.6 & 0.2 & 0.30 & 1365 & 351.49 & 157.85 & 103 \\
\hline 14 & CW-12.6-0.23-0.3 & 12.6 & 0.23 & 0.30 & 1346 & 346.6 & 197.17 & 80 \\
\hline 15 & CW-12.6-0.26-0.3 & 12.6 & 0.26 & 0.30 & 1330 & 342.48 & 235.85 & 55 \\
\hline 16 & CW-12.6-0.29-0.3 & 12.6 & 0.29 & 0.30 & 1305 & 336.04 & 271.67 & 33 \\
\hline 17 & CW-12.6-0.32-0.3 & 12.6 & 0.32 & 0.30 & 1287 & 331.41 & 307.62 & 13 \\
\hline 18 & CW-12.6-0.35-0.3 & 12.6 & 0.35 & 0.30 & 1260 & 324.45 & 340.04 & 0 \\
\hline 19 & CW-12.9-0.2-0.3 & 12.9 & 0.2 & 0.30 & 1355 & 385.16 & 153.39 & 85 \\
\hline 20 & CW-12.9-0.23-0.3 & 12.9 & 0.23 & 0.30 & 1337 & 380.04 & 193.58 & 62 \\
\hline 21 & CW-12.9-0.26-0.3 & 12.9 & 0.26 & 0.30 & 1320 & 375.21 & 232.8 & 37 \\
\hline 22 & CW-12.9-0.29-0.3 & 12.9 & 0.29 & 0.30 & 1300 & 369.52 & 270.33 & 15 \\
\hline 23 & CW-12.9-0.32-0.3 & 12.9 & 0.32 & 0.30 & 1275 & 362.42 & 305.39 & 0 \\
\hline 24 & CW-12.9-0.35-0.3 & 12.9 & 0.35 & 0.30 & 1240 & 352.47 & 336.17 & 0 \\
\hline 25 & CW-13.2-0.20-0.3 & 13.2 & 0.2 & 0.30 & 1355 & 421.4 & 150.09 & 65 \\
\hline 26 & CW-13.2-0.23-0.3 & 13.2 & 0.23 & 0.30 & 1340 & 416.73 & 191.73 & 40 \\
\hline 27 & CW-13.2-0.26-0.3 & 13.2 & 0.26 & 0.30 & 1320 & 410.51 & 231.52 & 16 \\
\hline 28 & CW-13.2-0.29-0.3 & 13.2 & 0.29 & 0.30 & 1295 & 402.74 & 268.98 & 0 \\
\hline 29 & CW-13.2-0.32-0.3 & 13.2 & 0.32 & 0.30 & 1260 & 391.85 & 302.43 & 0 \\
\hline 30 & CW-13.2-0.35-0.3 & 13.2 & 0.35 & 0.30 & 1220 & 379.41 & 332.25 & 0 \\
\hline
\end{tabular}

\subsubsection{Binary-system Geopolymer Compositions}

Binary precursor compositions were designed by combining two CDW materials based on the optimized results achieved during the mono-system investigations. Combinations of $\mathrm{CW}+\mathrm{RCBW}, \mathrm{CW}+\mathrm{CTW}$ and $\mathrm{RCBW}+\mathrm{CTW}$ were studied by targeting different chemical ratios of the binary-system binders.

\section{- Binary-system RCBW+CW Compositions}

RCBW and CW were combined at various percentages and compositions were designed based on the results of mono-system binders. This was completed by considering $\mathrm{SiO}_{2} / \mathrm{Al}_{2} \mathrm{O}_{3}$ molar ratios of the combined powders and studying different ratios of $\mathrm{Na}_{2} \mathrm{O} / \mathrm{SiO}_{2}$ with constant $\mathrm{L} / \mathrm{S}$ ratio of 0.3 . Twelve 
compositions were designed for binary-system of RCBW+CW pastes, as presented in Table 4.5.

Table 4.4 Compositions of binary-system RCBW+CW binders

\begin{tabular}{|c|c|c|c|c|c|c|c|c|c|c|c|}
\hline \multicolumn{7}{|c|}{ RCBW + CW Geopolymer Matrix } & \multicolumn{5}{|c|}{ Mix Proportions $(\mathrm{kg} / \mathrm{m} 3)$} \\
\hline No & ition Code & $\begin{array}{l}\text { RCB } \\
\text { W \% }\end{array}$ & $\begin{array}{c}\mathrm{CW} \\
\%\end{array}$ & $\begin{array}{c}\mathrm{SiO}_{2} / \mathrm{Al} \\
{ }_{2} \mathrm{O}_{3}\end{array}$ & $\begin{array}{l}\mathrm{Na}_{2} \mathrm{O} \\
/ \mathrm{SiO}_{2}\end{array}$ & $\mathrm{~L} / \mathrm{S}$ & $\begin{array}{l}\mathrm{RC} \\
\mathrm{BW}\end{array}$ & $\mathrm{CW}$ & SS & $\mathrm{SH}$ & $\begin{array}{l}\text { Wat } \\
\text { er }\end{array}$ \\
\hline 1 & $0.18-0.30$ & 80 & 20 & 7.7 & 0.18 & 0.3 & 976 & 244 & & 319 & 36 \\
\hline 2 & BC-7.7-0.21-0.30 & 80 & 20 & 7.7 & 0.21 & 0.3 & 948 & 237 & 320.4 & 379.3 & 5 \\
\hline 3 & BC-7.7-0.24-0.30 & 80 & 20 & 7.7 & 0.24 & 0.3 & 912 & 228 & 308.3 & 431.6 & 0 \\
\hline 4 & BC-8.4-0.18-0.30 & 60 & 40 & 8.4 & 0.18 & 0.3 & 7.7 & 494 & 399.4 & 263.3 & 30 \\
\hline 5 & BC-8.4-0.21-0.30 & 60 & 40 & 8.4 & 0.21 & 0.3 & 7.7 & 484 & 391.4 & 323 & 0 \\
\hline 6 & BC-8.4-0.24-0.30 & 60 & 40 & 8 & 0.24 & 0 & 7.7 & 460 & 372 & 366.8 & 0 \\
\hline 7 & BC-9. & 40 & 60 & 9 & 0.18 & 0 . & 7.7 & 750 & 431.5 & 210.3 & 40 \\
\hline 8 & BC-9.0-0.21-0.30 & 40 & 60 & 9 & 0.21 & 0.3 & 7.7 & 735 & 422.9 & 262.9 & 15 \\
\hline 9 & BC-9.0-0.24-0.30 & 40 & 60 & 9 & 0.24 & 0.3 & 7.7 & 711 & 409.1 & 309.3 & 0 \\
\hline 10 & BC-10.5-0.18-0.30 & 20 & 80 & 10.5 & 0.18 & 0.3 & 7.7 & 1032 & 413 & 165.4 & 85 \\
\hline 11 & BC-10.5-0.21-0.30 & 20 & 80 & 10.5 & 0.21 & 0.3 & 7.7 & 1012 & 405 & 211.1 & 60 \\
\hline 12 & BC-10.5-0.24-0.30 & 20 & 80 & 10.5 & 0.24 & 0.3 & 7.7 & 994 & 397.6 & 255.3 & 35 \\
\hline
\end{tabular}

\section{- Binary-system CTW+CW Compositions}

In binary-system CTW+CW geopolymers, $\mathrm{SiO}_{2} / \mathrm{Al}_{2} \mathrm{O}_{3}$ molar ratio was calculated from the combined dry powders, while $\mathrm{Na}_{2} \mathrm{O} / \mathrm{SiO}_{2}$ molar ratios of $0.18,0.21$ and 0.24 were decided based on the results of monosystem geopolymers. L/S ratio of 0.3 was used for all mixes. Twelve compositions were designed by changing the amounts of each powder from $20 \%$ to $80 \%$ of the total contents of precursors. Table 4.6 presents the binary-system compositions deduced from the described method of design.

Table 4.5 Compositions of binary-system CTW $+\mathrm{CW}$ binders

\begin{tabular}{|r|l|r|r|r|r|r|r|r|r|r|r|}
\hline \multicolumn{9}{|c|}{ CTW + CW Geopolymer Matrix } & \multicolumn{4}{c|}{ Mix Proportions $\left(\mathrm{kg} / \mathrm{m}^{3}\right)$} \\
\hline No. & Composition Code & $\begin{array}{c}\mathrm{CTW} \\
\%\end{array}$ & $\begin{array}{c}\mathrm{CW} \\
\%\end{array}$ & $\begin{array}{c}\mathrm{SiO}_{2} / \\
\mathrm{Al}_{2} \mathrm{O}_{3}\end{array}$ & $\begin{array}{c}\mathrm{Na}_{2} \mathrm{O} / \\
\mathrm{SiO}_{2}\end{array}$ & $\mathrm{~L} / \mathrm{S}$ & $\mathrm{CTW}$ & $\mathrm{CW}$ & $\mathrm{SS}$ & $\mathrm{SH}$ & Water \\
\hline 1 & TC-11.4-0.18-0.30 & 80 & 20 & 11.4 & 0.18 & 0.3 & 976 & 244 & 327.1 & 333.4 & 30 \\
\hline 2 & TC-11.4-0.21-0.30 & 80 & 20 & 11.4 & 0.21 & 0.3 & 944 & 236 & 316.4 & 392.3 & 0 \\
\hline 3 & TC-11.4-0.24-0.30 & 80 & 20 & 11.4 & 0.24 & 0.3 & 888 & 222 & 297.7 & 434.7 & 0 \\
\hline 4 & TC-12-0.18-0.30 & 60 & 40 & 12 & 0.18 & 0.3 & 738 & 492 & 418 & 270.7 & 14 \\
\hline 5 & TC-12-0.21-0.30 & 60 & 40 & 12 & 0.21 & 0.3 & 708 & 472 & 401 & 323.3 & 0 \\
\hline 6 & TC-12-0.24-0.30 & 60 & 40 & 12 & 0.24 & 0.3 & 672 & 448 & 380.6 & 367.1 & 0 \\
\hline 7 & TC-12.3-0.18-0.30 & 40 & 60 & 12.3 & 0.18 & 0.3 & 502 & 753 & 423.2 & 219.4 & 42 \\
\hline 8 & TC-12.3-0.21-0.30 & 40 & 60 & 12.3 & 0.21 & 0.3 & 492 & 738 & 414.7 & 272.3 & 15 \\
\hline 9 & TC-12.3-0.24-0.30 & 40 & 60 & 12.3 & 0.24 & 0.3 & 476 & 714 & 401.2 & 318.8 & 0 \\
\hline 10 & TC-12.5-0.18-0.30 & 20 & 80 & 12.5 & 0.18 & 0.3 & 258 & 1032 & 396.1 & 170.9 & 90 \\
\hline 11 & TC-12.5-0.21-0.30 & 20 & 80 & 12.5 & 0.21 & 0.3 & 254 & 1016 & 390 & 217.1 & 65 \\
\hline 12 & TC-12.5-0.24-0.30 & 20 & 80 & 12.5 & 0.24 & 0.3 & 248 & 994 & 381.4 & 260.2 & 42 \\
\hline
\end{tabular}




\section{- Binary-system RCBW+CTW Compositions}

Twelve compositions of binary-system RCBW+CTW pastes were arranged by replacing RCBW with CTW at 20, 60 and $80 \%$, as presented in Table 4.7. As for other binary systems, $\mathrm{SiO}_{2} / \mathrm{Al}_{2} \mathrm{O}_{3}$ molar ratios were selected based on the chemical compositions of dry powders and different $\mathrm{Na}{ }_{2} \mathrm{O} / \mathrm{SiO}_{2}$ ratios were decided by taking into account the mono system RCBW and CTW results. S/L ratio of all compositions was kept constant at 0.3 .

Table 4.6 Compositions of binary-system RCBW+CTW binders

\begin{tabular}{|r|l|r|r|r|r|r|r|r|r|r|r|}
\hline \multicolumn{9}{|c|}{ RCBW + CTW Geopolymer matrix } & \multicolumn{4}{c|}{ Mix Proportions $\left(\mathrm{kg} / \mathrm{m}^{3}\right)$} \\
\hline No. & Composition Code & $\begin{array}{c}\mathrm{RCBW} \\
\%\end{array}$ & $\begin{array}{c}\mathrm{CTW} \\
\%\end{array}$ & $\begin{array}{r}\mathrm{SiO}_{2} / \\
\mathrm{Al}_{2} \mathrm{O}_{3}\end{array}$ & $\begin{array}{c}\mathrm{Na}_{2} \mathrm{O} / \\
\mathrm{SiO}_{2}\end{array}$ & $\mathrm{~L} / \mathrm{S}$ & $\mathrm{BW}$ & $\mathrm{TW}$ & $\mathrm{SS}$ & $\mathrm{SH}$ & Water \\
\hline 1 & BT-7.8-0.18-0.30 & 80 & 20 & 7.8 & 0.18 & 0.3 & 960 & 240 & 279.8 & 373.2 & 30 \\
\hline 2 & BT-7.8-0.21-0.30 & 80 & 20 & 7.8 & 0.21 & 0.3 & 928 & 232 & 270.5 & 436 & 0 \\
\hline 3 & BT-7.8-0.24-0.30 & 80 & 20 & 7.8 & 0.24 & 0.3 & 880 & 220 & 256.5 & 485 & 0 \\
\hline 4 & BT-8.4-0.18-0.30 & 60 & 40 & 8.4 & 0.18 & 0.3 & 726 & 484 & 270.5 & 381.1 & 35 \\
\hline 5 & BT-8.4-0.21-0.30 & 60 & 40 & 8.4 & 0.21 & 0.3 & 702 & 468 & 261.6 & 444.2 & 0 \\
\hline 6 & BT-8.4-0.24-0.30 & 60 & 40 & 8.4 & 0.24 & 0.3 & 678 & 452 & 252.6 & 502.1 & 0 \\
\hline 7 & BT-9.2-0.18-0.30 & 40 & 60 & 9.2 & 0.18 & 0.3 & 482 & 723 & 289.4 & 380.8 & 24 \\
\hline 8 & BC-9.2-0.22-0.28 & 40 & 60 & 9.2 & 0.21 & 0.3 & 462 & 693 & 277.4 & 440.5 & 0 \\
\hline 9 & BC-9.2-0.24-0.28 & 40 & 60 & 9.2 & 0.24 & 0.3 & 448 & 672 & 269 & 500.3 & 0 \\
\hline 10 & BT-10-0.18-0.30 & 20 & 80 & 10 & 0.18 & 0.3 & 242 & 968 & 266.9 & 388.4 & 34 \\
\hline 11 & BT-10-0.21-0.30 & 20 & 80 & 10 & 0.21 & 0.3 & 234 & 936 & 258.1 & 451.6 & 0 \\
\hline 12 & BT-10-0.24-0.30 & 20 & 80 & 10 & 0.24 & 0.3 & 226 & 904 & 249.2 & 509.6 & 0 \\
\hline
\end{tabular}

\subsubsection{Ternary System Geopolymer Compositions}

Table 4.8 shows the mixes arranged for ternary-system geopolymer binders.

Table 4.7 Compositions of ternary-system RCBW+CTW+CW binders

\begin{tabular}{|c|c|c|c|c|c|c|c|c|c|c|c|c|c|}
\hline \multicolumn{8}{|c|}{ RCBW + CTW + CW geopolymer Matrix } & \multicolumn{6}{|c|}{ Mix Proportions $(\mathrm{kg} / \mathrm{m} 3)$} \\
\hline No. & Composition Code & $\begin{array}{l}\text { RCB } \\
\text { W \% }\end{array}$ & $\begin{array}{c}\text { CTW } \\
\%\end{array}$ & $\begin{array}{c}\mathrm{CW} \\
\%\end{array}$ & $\begin{array}{l}\mathrm{SiO}_{2} / \\
\mathrm{Al}_{2} \mathrm{O}_{3}\end{array}$ & $\begin{array}{l}\mathrm{Na}_{2} \mathrm{O} / \\
\mathrm{SiO}_{2}\end{array}$ & $\mathrm{~L} / \mathrm{S}$ & RCBW & CTW & $\mathrm{CW}$ & SS & $\mathrm{SH}$ & Water \\
\hline 1 & BCT1-7.6-0.18-0.3 & 80 & 10 & 10 & 7.6 & 0.18 & 0.3 & 984 & 123 & 123 & 253.8 & 358.1 & 61 \\
\hline 2 & BCT2-7.6-0.21-0.3 & 80 & 10 & 10 & 7.6 & 0.21 & 0.3 & 956 & 119.5 & 119.5 & 246.5 & 420.1 & 26 \\
\hline 3 & ВCT3-7.6-0.24-0.3 & 80 & 10 & 10 & 7.6 & 0.24 & 0.3 & 920 & 115 & 115 & 237.3 & 473.8 & 0 \\
\hline 4 & ВСТ4-8.4-0.18-0.3 & 60 & 20 & 20 & 8.4 & 0.18 & 0.3 & 738 & 246 & 246 & 336.4 & 324.8 & 32 \\
\hline 5 & ВCT5-8.4-0.21-0.3 & 60 & 20 & 20 & 8.4 & 0.21 & 0.3 & 717 & 239 & 239 & 326.8 & 385.8 & 0 \\
\hline 6 & ВСТ6-8.4-0.24-0.3 & 60 & 20 & 20 & 8.4 & 0.24 & 0.3 & 690 & 230 & 230 & 314.5 & 438.9 & 0 \\
\hline 7 & ВСТ7-9.2-0.18-0.3 & 40 & 30 & 30 & 9.2 & 0.18 & 0.3 & 496 & 372 & 372 & 351.3 & 301.5 & 40 \\
\hline 8 & ВСТ8-9.2-0.21-0.3 & 40 & 30 & 30 & 9.2 & 0.21 & 0.3 & 482 & 361.5 & 361.5 & 341.4 & 360 & 10 \\
\hline 9 & ВСТ9-9.2-0.24-0.3 & 40 & 30 & 30 & 9.2 & 0.24 & 0.3 & 460 & 345 & 345 & 325.8 & 407.5 & 0 \\
\hline 10 & ВСТ10-10.2-0.18-0.3 & 20 & 40 & 40 & 10.2 & 0.18 & 0.3 & 252 & 504 & 504 & 345.3 & 282.5 & 55 \\
\hline 11 & ВCT11-10.2-0.21-0.3 & 20 & 40 & 40 & 10.2 & 0.21 & 0.3 & 246 & 492 & 492 & 337 & 339.7 & 25 \\
\hline 12 & ВCT12-10.2-0.24-0.3 & 20 & 40 & 40 & 10.2 & 0.24 & 0.3 & 239 & 478 & 478 & 327.4 & 392 & 0 \\
\hline
\end{tabular}




\begin{tabular}{|c|c|c|c|c|c|c|c|c|c|c|c|c|c|}
\hline 13 & ВСТ13-10.6-0.18-0.3 & 10 & 80 & 10 & 10.6 & 0.18 & 0.3 & 124 & 992 & 124 & 297.1 & 369 & 36 \\
\hline 14 & ВCT14-10.6-0.21-0.3 & 10 & 80 & 10 & 10.6 & 0.21 & 0.3 & 120.5 & 964 & 120.5 & 288.7 & 433.3 & 0 \\
\hline 15 & ВСТ15-10.6-0.24-0.3 & 10 & 80 & 10 & 10.6 & 0.24 & 0.3 & 118 & 944 & 118 & 282.7 & 497.4 & 0 \\
\hline 16 & ВСТ16-10-0.18-0.3 & 20 & 60 & 20 & 10 & 0.18 & 0.3 & 251 & 753 & 251 & 286.4 & 344.7 & 55 \\
\hline 17 & BCT17-10-0.21-0.3 & 20 & 60 & 20 & 10 & 0.21 & 0.3 & 242 & 726 & 242 & 276.1 & 402.4 & 25 \\
\hline 18 & BCT18-10-0.24-0.30 & 20 & 60 & 20 & 10 & 0.24 & 0.3 & 234 & 702 & 234 & 267 & 456.9 & 0 \\
\hline 19 & ВСТ19-9.7-0.18-0.3 & 30 & 40 & 30 & 9.7 & 0.18 & 0.3 & 373.5 & 498 & 373.5 & 353.3 & 304.4 & 37 \\
\hline 20 & ВСТ20-9.7-0.21-0.3 & 30 & 40 & 30 & 9.7 & 0.21 & 0.3 & 363 & 484 & 363 & 343.3 & 363.3 & 10 \\
\hline 21 & BCT21-9.7-0.24-0.3 & 30 & 40 & 30 & 9.7 & 0.24 & 0.3 & 346.5 & 462 & 346.5 & 327.7 & 411.1 & 0 \\
\hline 22 & ВСТ22-9.1-0.18-0.3 & 40 & 20 & 40 & 9.1 & 0.18 & 0.3 & 502 & 251 & 502 & 346.8 & 277.5 & 56 \\
\hline 23 & BCT23-9.1-0.21-0.3 & 40 & 20 & 40 & 9.1 & 0.21 & 0.3 & 490 & 245 & 490 & 338.5 & 334.3 & 25 \\
\hline 24 & ВСТ24-9.1-0.24-0.3 & 40 & 20 & 40 & 9.1 & 0.24 & 0.3 & 476 & 238 & 476 & 328.8 & 386.2 & 0 \\
\hline 25 & ВCТ25-12-0.18-0.3 & 10 & 10 & 80 & 12 & 0.18 & 0.3 & 128 & 128 & 1024 & 497.1 & 156.7 & 40 \\
\hline 26 & ВСТ26-12-0.21-0.3 & 10 & 10 & 80 & 12 & 0.21 & 0.3 & 125 & 125 & 1000 & 485.5 & 203.7 & 20 \\
\hline 27 & ВCT27-12-0.24-0.3 & 10 & 10 & 80 & 12 & 0.24 & 0.3 & 122 & 122 & 976 & 473.8 & 248.3 & 0 \\
\hline 28 & ВСТ28-10.6-0.18-0.3 & 20 & 20 & 60 & 10.6 & 0.18 & 0.3 & 254 & 254 & 762 & 434.6 & 217.7 & 42 \\
\hline 29 & ВСТ29-10.6-0.21-0.3 & 20 & 20 & 60 & 10.6 & 0.21 & 0.3 & 248 & 248 & 744 & 424.3 & 270 & 15 \\
\hline 30 & ВСТ30-10.6-0.24-0.3 & 20 & 20 & 60 & 10.6 & 0.24 & 0.3 & 240 & 240 & 720 & 410.7 & 317.3 & 0 \\
\hline 31 & ВCT31-9.8-0.18-0.3 & 30 & 30 & 40 & 9.8 & 0.18 & 0.3 & 375 & 375 & 500 & 389.7 & 273.5 & 35 \\
\hline 32 & ВСТ32-9.8-0.21-0.3 & 30 & 30 & 40 & 9.8 & 0.21 & 0.3 & 366 & 366 & 488 & 380.4 & 331.4 & 5 \\
\hline 33 & ВСТ33-9.8-0.24-0.3 & 30 & 30 & 40 & 9.8 & 0.24 & 0.3 & 351 & 351 & 468 & 364.8 & 379.6 & 0 \\
\hline 34 & ВСТ34-9-0.18-0.3 & 40 & 40 & 20 & 9 & 0.18 & 0.3 & 500 & 500 & 250 & 276.1 & 340.7 & 63 \\
\hline 35 & ВСТ35-9-0.21-0.3 & 40 & 40 & 20 & 9 & 0.21 & 0.3 & 484 & 484 & 242 & 267.3 & 399.4 & 30 \\
\hline 36 & ВСТ36-9-0.24-0.3 & 40 & 40 & 20 & 9 & 0.24 & 0.3 & 472 & 472 & 236 & 260.7 & 457.5 & 0 \\
\hline 37 & ВСТ37-9.4-0.18-0.3 & 33.3 & 33.3 & 33.3 & 9.4 & 0.18 & 0.3 & 418.3 & 418.3 & 418.3 & 325.7 & 300 & 57 \\
\hline 38 & ВСТ38-9.4-0.18-0.3 & 33.3 & 33.3 & 33.3 & 9.4 & 0.21 & 0.3 & 408.3 & 408.3 & 408.3 & 317.9 & 358.7 & 25 \\
\hline 39 & ВСТ39-9.4-0.18-0.3 & 33.3 & 33.3 & 33.3 & 9.4 & 0.24 & 0.3 & 395 & 395 & 395 & 307.5 & 410.8 & 0 \\
\hline
\end{tabular}

Ternary-system RCBW+CTW $+\mathrm{CW}$ compositions were designed by combining the three different materials at various percentages based on the optimized results of binary-system pastes. $\mathrm{SiO}_{2} / \mathrm{Al}_{2} \mathrm{O}_{3}$ molar ratios were deduced from powder precursors and $\mathrm{Na} 2 \mathrm{O} / \mathrm{SiO}_{2}$ and $\mathrm{L} / \mathrm{S}$ ratios were the same used for binary-system compositions $\left(0.18,0.21\right.$ and 0.24 for $\mathrm{Na}_{2} \mathrm{O} / \mathrm{SiO}_{2}$ and 0.3 for $\mathrm{L} / \mathrm{S}$ ratio).

\subsection{Fresh Properties of Geopolymer Pastes}

\subsubsection{Fresh Properties of Mono-system Compositions}

\section{- Mono-system RCBW Pastes}

Flow spread diameters and initial and final setting times of mono-system RCBW pastes are presented in Figures 4.1 and 4.2 respectively.

The flowability of a paste is a measure to determine the ease of casting and use of the mix. The flow diameter of RCBW-pastes was between $157 \mathrm{~mm}$ and $295 \mathrm{~mm}$ for different $\mathrm{Si} / \mathrm{Al}$ and $\mathrm{Na} / \mathrm{Si}$ ratios indicating a flowability range within the standard results reported in literature for geopolymeric pastes 
(Allahverdi \& Kani, 2013, Allahverdi \& Najafi Kani, 2009 and Tuyan et al., 2018).

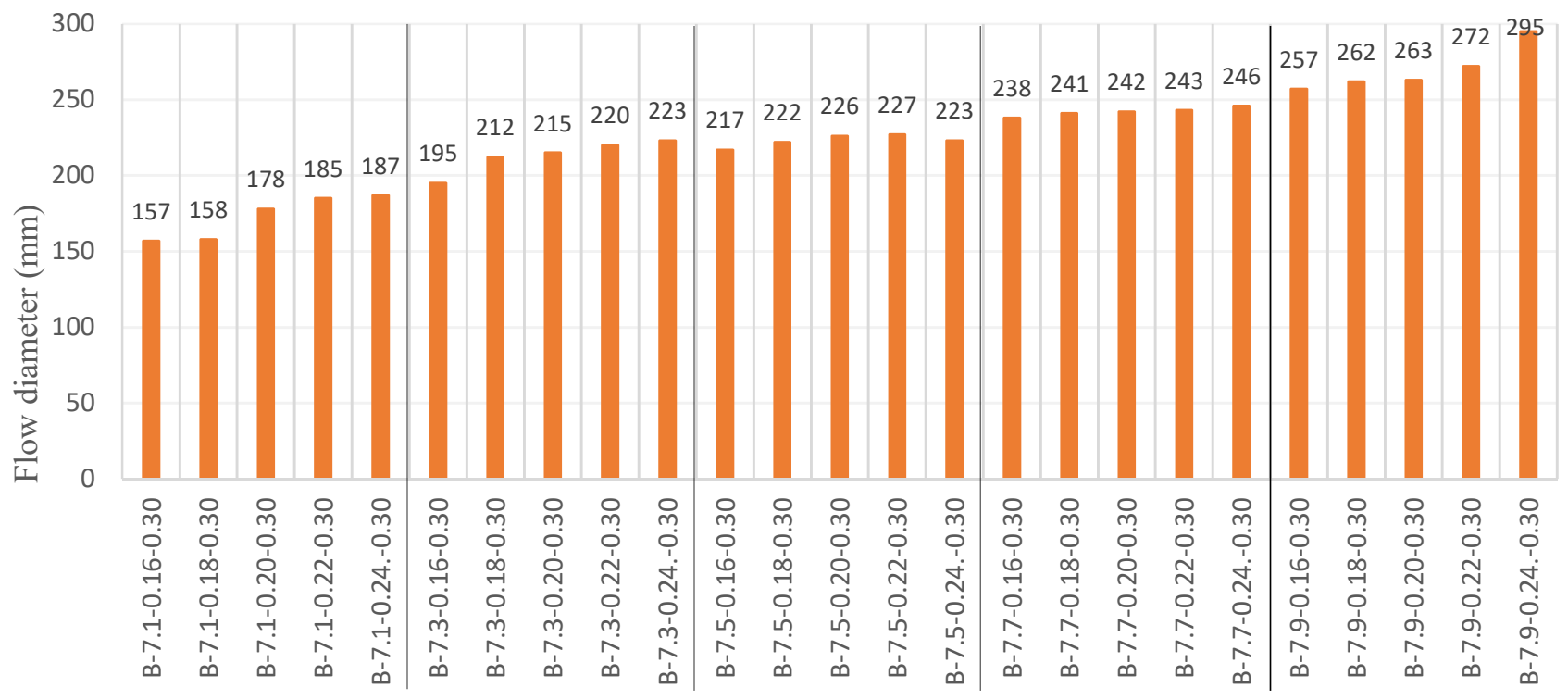

Figure 4.1 Flow diameter of mono-system RCBW geopolymers

Form Figure 4.1, the flowability of pastes increased with increased $\mathrm{SiO}_{2} / \mathrm{Al}_{2} \mathrm{O}_{3}$ and $\mathrm{Na}_{2} \mathrm{O} / \mathrm{SiO}_{2}$ molar ratios. However, the change in $\mathrm{Si} / \mathrm{Al}$ ratio seemed more influential on the value of flow than $\mathrm{Na} / \mathrm{Si}$ ratio. For instance, for the same $\mathrm{SiO}_{2} / \mathrm{Al}_{2} \mathrm{O}_{3}$ ratio of 7.1, the flow spread diameter was $157 \mathrm{~mm}$ and $187 \mathrm{~mm}$ at $\mathrm{Na}_{2} \mathrm{O} / \mathrm{SiO}_{2}$ ratio of 0.16 and 0.24 respectively. However, for the same $\mathrm{Na}_{2} \mathrm{O} / \mathrm{SiO}_{2}$ ratio of 0.3 , the flow diameter increased significantly between $187 \mathrm{~mm}$ and $295 \mathrm{~mm}$ for $\mathrm{SiO}_{2} / \mathrm{Al}_{2} \mathrm{O}_{3}$ ratios of 7.1 and 7.9 respectively. The large effect of $\mathrm{SiO}_{2} / \mathrm{Al}_{2} \mathrm{O}_{3}$ ratio on the flowability of $\mathrm{RCBW}$ pastes is maybe related to the fact that when a higher $\mathrm{SiO}_{2} / \mathrm{Al}_{2} \mathrm{O}_{3}$ molar ratio was targeted, more soluble silica was added to the system, resulting in higher content of sodium silicate made up of $64 \%$ water. Nevertheless, higher $\mathrm{Na}_{2} \mathrm{O}$ concentration, known also as a caustic soda, possibly provided the bulk of $\mathrm{Na}^{+}$cations to the reaction products, which are necessary for the stability of the geopolymer mix. This explanation agreed with the findings of Kani \& Allahverdi, 2009; Tuyan, Andiç-Çakir, and Ramyar, 2018 who reported an increase in the flow spread diameter with increased $\mathrm{Na}_{2} \mathrm{O}$ concentration in geopolymer systems. In addition, the higher $\mathrm{Na}_{2} \mathrm{O} / \mathrm{SiO}_{2}$ molar ratio was attained by increasing the $\mathrm{NaOH}$ concentration in the mix resulting also in higher water content and spread flow diameter. 


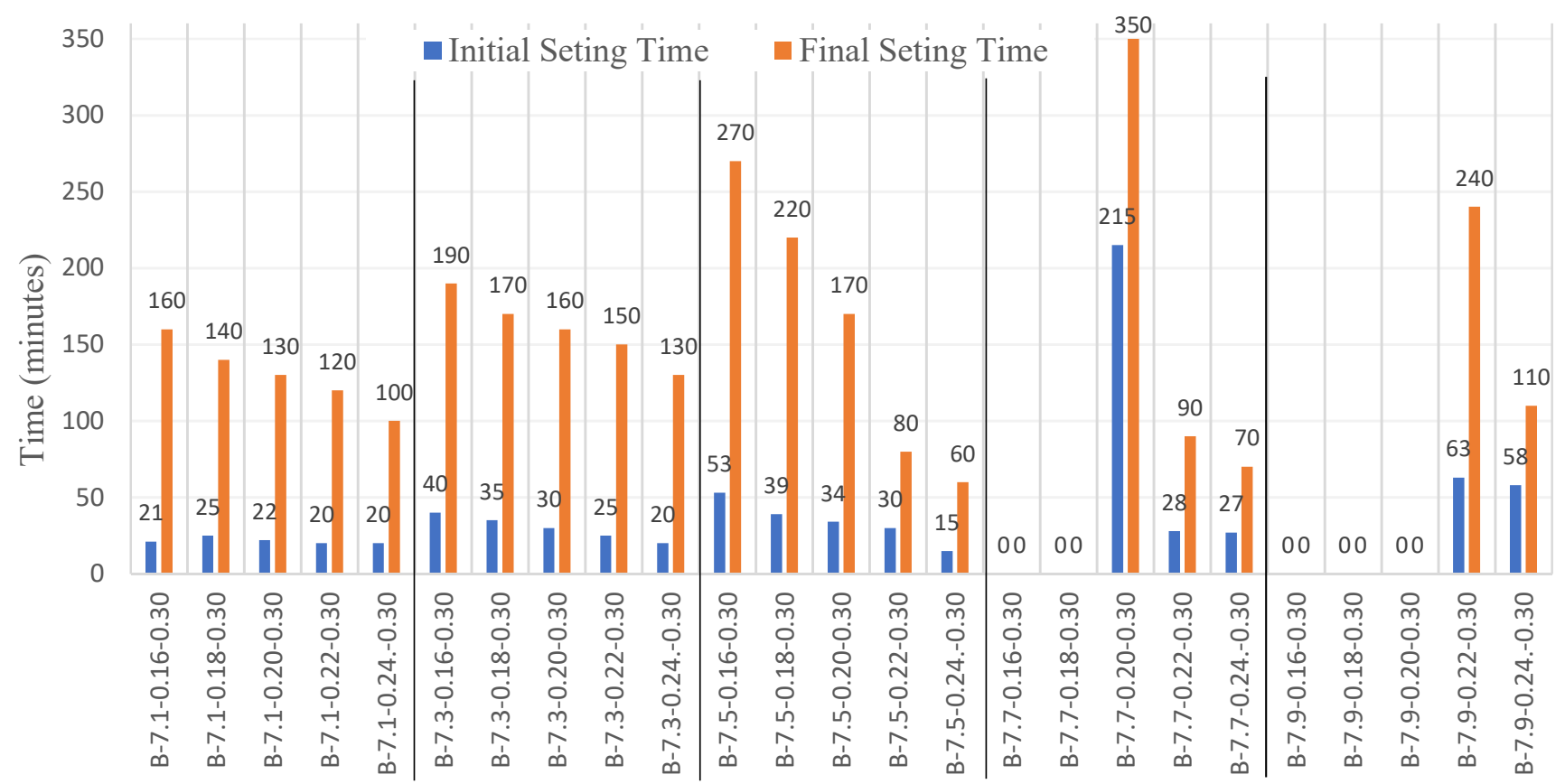

Figure 4.2 Initial and final setting times of mono-system RCBW geopolymers

As can be seen from Figure 4.2, the initial and final setting times of mono RCBW mixes ranged from 15 to $63 \mathrm{~min}$ and from 60 to $350 \mathrm{~min}$ respectively. However, mixes B-7.7-0.16-0.30, B-7.7-0.18-0.30, B7.9-0.16-0.30, B-7.9-0.18-0.30 and B-7.9-0.20-0.30 did not present any form of setting, confirming that their combinations are inappropriate to produce a geopolymer binder. As for flow diameter, the initial and final setting times of mono RCBW geopolymers were significantly affected by $\mathrm{SiO}_{2} / \mathrm{Al}_{2} \mathrm{O}_{3}$ and $\mathrm{Na}_{2} \mathrm{O} / \mathrm{SiO}_{2}$ molar ratios. Except for compositions with $\mathrm{SiO}_{2} / \mathrm{Al}_{2} \mathrm{O}_{3}$ of 7.5 and 7.7 and $\mathrm{Na} 2 \mathrm{O} / \mathrm{SiO} 2$ of 0.22 and 0.24 , for the same $\mathrm{Na} / \mathrm{Si}$, the final setting time of compositions with low $\mathrm{Si} / \mathrm{Al}$ molar ratio was shorter than those with higher $\mathrm{Si} / \mathrm{Al}$ value. For example, at $\mathrm{Na} / \mathrm{Si}$ content of 0.20 , the final setting time for RCBW mix with $\mathrm{SiO}_{2} / \mathrm{Al}_{2} \mathrm{O}_{3}$ of 7.7 was 350 min which reduced to 10 min at $\mathrm{SiO}_{2} / \mathrm{Al}_{2} \mathrm{O}_{3}$ of 7.1 . This is maybe due to the content of soluble silica in the mix composition that helped the movement of $\mathrm{Na}+$ and resulted in shorter setting time of pastes. However, the increase in setting time due to $\mathrm{Si} / \mathrm{Al}$ increment was applicable only to a certain extent between 7.1 and 7.7. As Si/Al increased to 7.9, the excessive amount of soluble silica may have hindered the movement of $\mathrm{Na}^{+}$cations in the system which retarded or prevented the geopolymerization process. Another reason is related to the amount of Al versus that of Si. Although the soluble silica increased, the alumina bonds to silicon atoms stayed the same, because the precursor powder is the only source of alumina in the system. This resulted in a very fluid system requiring a high $\mathrm{Na}_{2} \mathrm{O}$ concentration to stabilize the geopolymer gel and help initiate the polycondensation stage. This suggestion agrees with the flow diameter results which revealed a 
maximum flowability at $\mathrm{Si} / \mathrm{Al}$ ratio of 7.9 .

It is worth mentioning that all compositions which achieved setting state complied with the maximum setting time required for OPC pastes (375 min), as per ASTM C150/150M specifications. However, a small number of compositions satisfied the initial setting time specified in this standard, which is $45 \mathrm{~min}$.

\section{- Mono-system CTW Pastes}

Figures 4.3 and 4.4 show the flow spread diameter and initial and final setting times of mono-system CTW pastes. The flow diameter of CTW-pastes ranged from $200 \mathrm{~mm}$ to $287 \mathrm{~mm}$ for all compositions. Except for mixes with $\mathrm{Si} / \mathrm{Al}$ ratio of 10.9, the general trend of flowability of CTW-based geopolymers increased with increased $\mathrm{SiO} 2 / \mathrm{A} 12 \mathrm{O} 3$ and $\mathrm{Na} 2 \mathrm{O} / \mathrm{SiO} 2$ molar ratios. For example, at the same $\mathrm{Na} / \mathrm{Si}$ ratio of 0.24, the flow spread diameter was $227 \mathrm{~mm}$ at $\mathrm{SiO} 2 / \mathrm{A} 12 \mathrm{O} 3$ of 10.5 and increased to 228, 282 and 287 $\mathrm{mm}$ at $\mathrm{SiO} 2 / \mathrm{A} 12 \mathrm{O} 3$ of 10.7, 11.1 and 11.3 respectively. However, this was not true for all mixes because the flowability decreased at $\mathrm{Si} / \mathrm{Al}$ of 10.9 compared to that of 10.5 and 10.7 . This result is maybe due to the unbalanced amounts of soluble silica and $\mathrm{Na} 2 \mathrm{O}$ in the system, which resulted in reduced formation of siloxane ( $\mathrm{Si}-\mathrm{O}-\mathrm{Si}$ ) bonds and reduced the flowability of mixes. Furthermore, the high Na2O concentration resulted in increased flowability of mix compositions regardless of their similar $\mathrm{Si} / \mathrm{Al}$ and $\mathrm{L} / \mathrm{S}$ ratios. The increased $\mathrm{Na} 2 \mathrm{O}$ concentration maybe resulted in a high dissolution rate of aluminosilicates from the precursor, leading to a higher fluidity of CTW geopolymer binders.

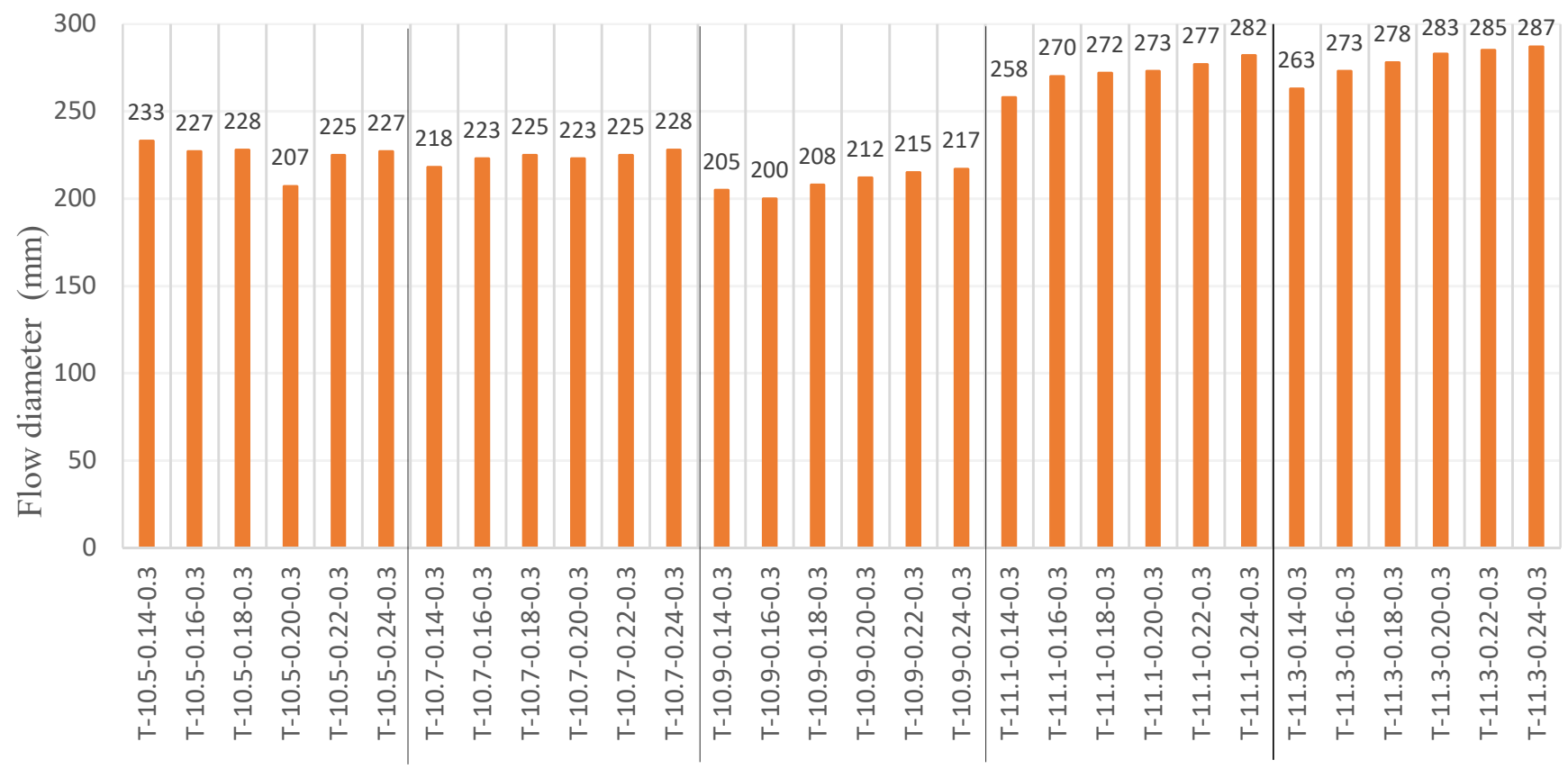

Figure 4.3 Flow diameter of mono-system CTW geopolymers 


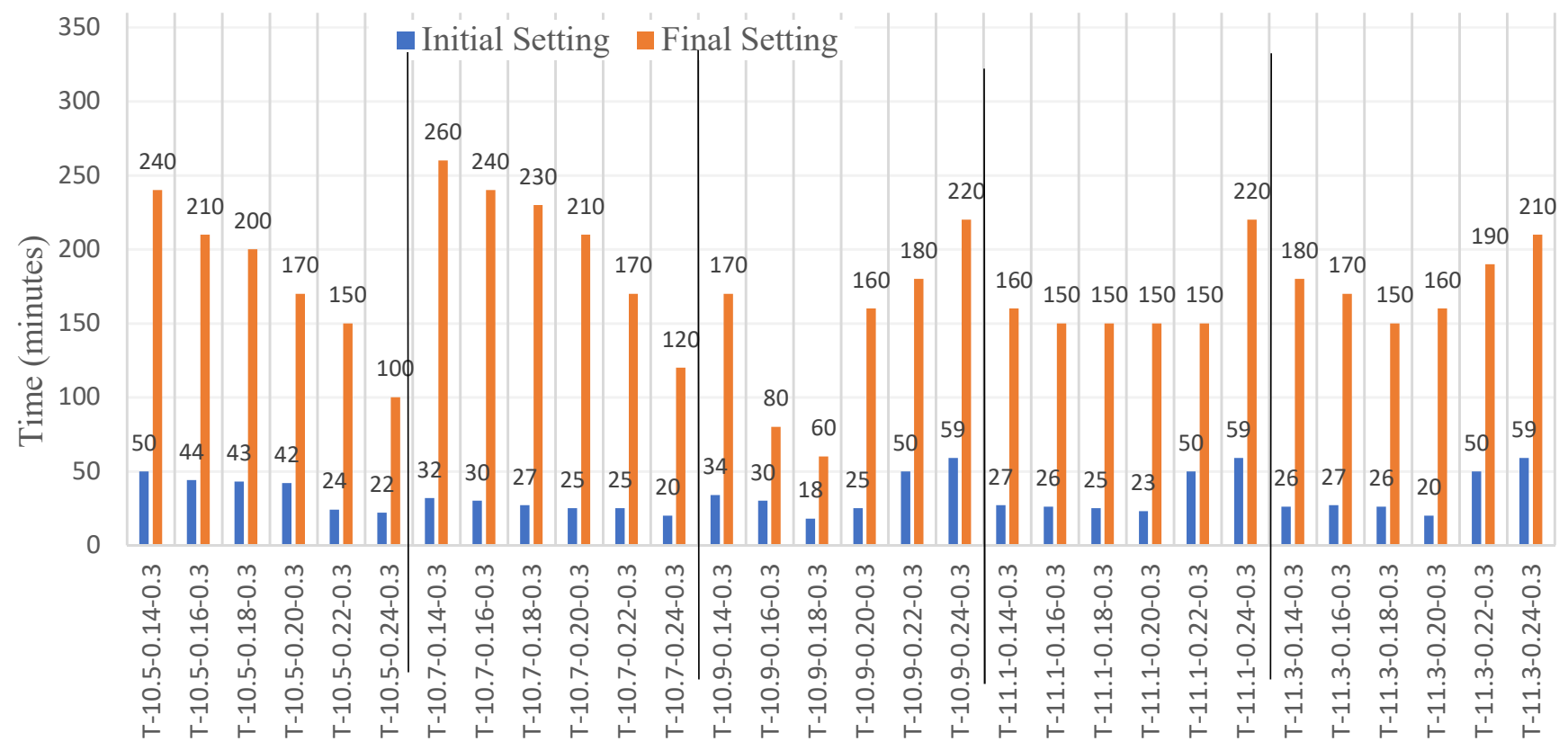

Figure 4.4 Initial and final setting times of mono-system CTW geopolymers

As can be seen in Figure 4.4, the initial and final setting times of mono CTW geopolymers range from 18 to 59 min and from 60 to 260 min respectively. The change in $\mathrm{SiO}_{2} / \mathrm{Al}_{2} \mathrm{O}_{3}$ and $\mathrm{Na} 2 \mathrm{O} / \mathrm{SiO}_{2}$ affected the initial and final setting times of different compositions. Although, for compositions with low Si/Al ratio of 10.5 and 10.7, the initial and final setting times followed a clear trend of reduction with increased $\mathrm{Na}_{2} \mathrm{O} / \mathrm{SiO}_{2}$, there was no general trend for compositions with $\mathrm{Si} / \mathrm{Al}$ ratios of 10.9, 11.1 and 11.3. For instance, at the same $\mathrm{Na}_{2} \mathrm{O} / \mathrm{SiO}_{2}=0.14$, the final setting time was 240, 260, 170, 160 and $180 \mathrm{~min}$ at $\mathrm{Si} / \mathrm{Al}$ ratios of $10.5,10.7,10.9,11.1$ and 11.3 respectively.

When comparing CTW and RCBW pastes, the initial and final setting times of their compositions were generally in comparable ranges as the initial setting time was between 15 to 63 min and from 18 to 59 min and the final setting time was between 60 to $350 \mathrm{~min}$ ad between 60 to $260 \mathrm{~min}$ for RCBW and CTW-geopolymers.

\section{- Mono-system CW Pastes}

Figures 4.5 and 4.6 display the results of flow spread diameter and initial and final setting times respectively, for mono-system $\mathrm{CW}$ pastes. 


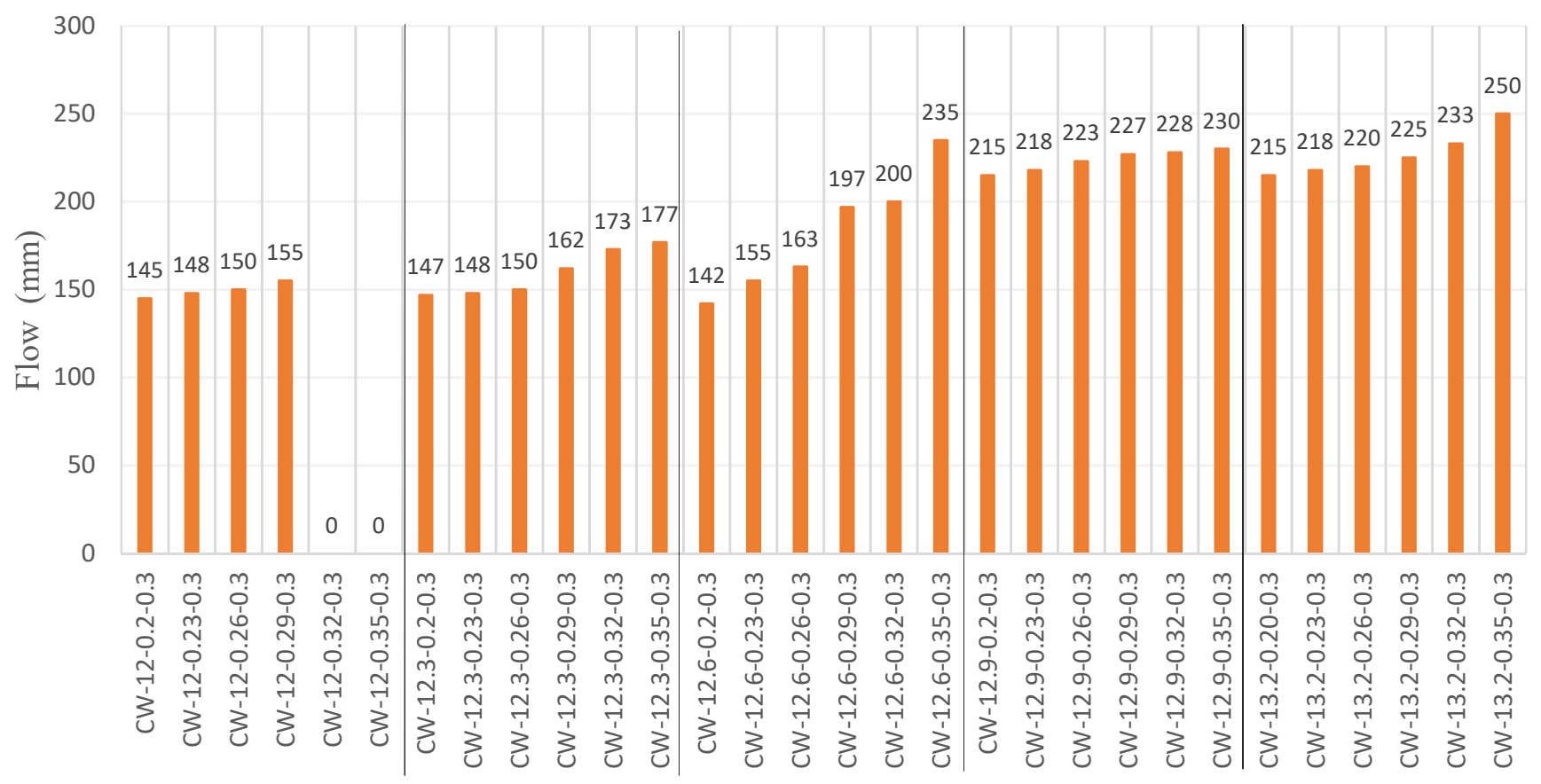

Figure 4.5 Flow diameter of mono-system CW geopolymers

Figure 4.5 presented a flowability range from 142 to $250 \mathrm{~mm}$, except for CW-12-0.32-0.3 and CW-120.35-0.3 which were not castable. For all compositions, the increased values of $\mathrm{SiO}_{2} / \mathrm{Al}_{2} \mathrm{O}_{3}$ and $\mathrm{Na}_{2} \mathrm{O} / \mathrm{SiO}_{2}$ ratios caused the flow spread diameter to increase. For example, at the same $\mathrm{SiO}_{2} / \mathrm{Al}_{2} \mathrm{O}_{3}$ ratio of 12.6, the flow diameter increased from 142 to $200 \mathrm{~mm}$ when $\mathrm{Na}_{2} \mathrm{O} / \mathrm{SiO}_{2}$ ratio increased between 0.20 and 0.35. Also, the flow spread diameter was $145 \mathrm{~mm}$ and increased to $215 \mathrm{~mm}$ at $\mathrm{SiO}_{2} / \mathrm{Al}_{2} \mathrm{O}_{3}$ ratios of 12 and 13.2 and the same $\mathrm{Na}_{2} \mathrm{O} / \mathrm{SiO}_{2}$ ratio of 0.2 . Higher amounts of sodium silicates and $\mathrm{Na}_{2} \mathrm{O}$ resulted in more fluid geopolymer gels due to the presence of large amounts of water and soluble silica species from sodium silicate solutions and $\mathrm{OH}^{-}$hydroxyl groups from $\mathrm{NaOH}$.

From Figure 4.6, initial and final setting times of mono $\mathrm{CW}$ geopolymers ranged from 7 to $42 \mathrm{~min}$ and from 60 to 132 minutes respectively. At the same $\mathrm{Si} / \mathrm{Al}$ ratio, the final setting time presented a clear trend of reduction with increased $\mathrm{Na} / \mathrm{Si}$. However, except for mixes with $\mathrm{Si} / \mathrm{AL}$ ratio of 13.2 , the initial setting time was not significantly influenced by the change in $\mathrm{Na}_{2} \mathrm{O} / \mathrm{SiO}_{2}$ ratio, as the maximum difference between the results of the same $\mathrm{Si} / \mathrm{Al}$ ratio compositions was $8 \mathrm{~min}$. Furthermore, for the same $\mathrm{Na} / \mathrm{Si}$ ratio, the increased value of $\mathrm{Si} / \mathrm{Al}$ ratio from 12 to 13.2 does not show a large effect on the initial and final setting times. For instance, at $\mathrm{Na}_{2} \mathrm{O} / \mathrm{SiO}_{2}$ of 0.20 , the final setting time was in equivalent range of $110,100,110,120$ and 132 at $\mathrm{SiO}_{2} / \mathrm{Al}_{2} \mathrm{O}_{3}$ ratios of $12,12.3,12.6,12.9$ and 13.2 respectively. An important aspect of CW-geopolymers is the short initial setting or flash setting of some compositions, especially at $\mathrm{Si} / \mathrm{Al}$ ratio of 12.6 where the pastes started to set as quickly as 7 minutes. This is maybe 
due to the large amount of $\mathrm{Na}^{+}$cations in the geopolymer mix which resulted in faster reaction and flash setting of geopolymers.

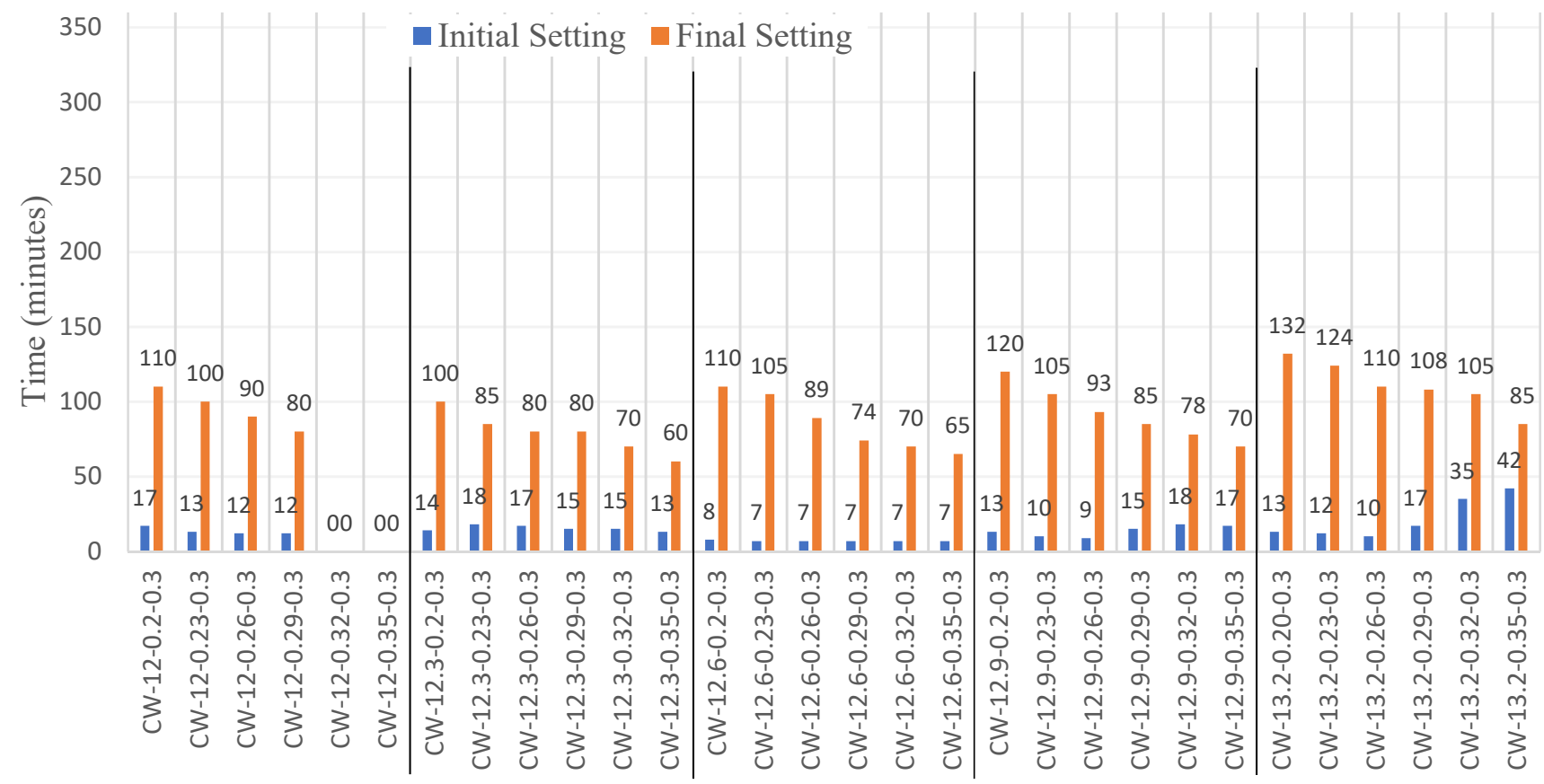

Figure 4.6 Initial and final setting times of mono-system CW geopolymers

By comparing the results of mono system compositions, the initial and final setting times of all mono CW-compositions were very low compared to those of mono RCBW and CTW mixes. This is probably related to the diverse reaction products between $\mathrm{CW}$ and $\mathrm{RCBW}$ or $\mathrm{CTW}$ geopolymers.

\subsubsection{Fresh Properties of Binary-system Compositions}

\section{- Binary-system RCBW+CW Pastes}

The flow spread diameters and initial and final setting times of binary-system RCBW+CW pastes are presented in Figures 4.7 and 4.8 respectively.

As can be seen in Figure 4.7, the flow spread diameter was between 180 and $240 \mathrm{~mm}$ for all binary $\mathrm{RCBW}+\mathrm{CW}$ geopolymers. The flowability of pastes increased as the $\mathrm{SiO}_{2} / \mathrm{Al}_{2} \mathrm{O}_{3}$ and $\mathrm{Na}_{2} \mathrm{O} / \mathrm{SiO}_{2}$ molar ratios increased, though the increments were not very significant for the same $\mathrm{SiO}_{2} / \mathrm{Al}_{2} \mathrm{O}_{3}$ or $\mathrm{Na}_{2} \mathrm{O} / \mathrm{SiO}_{2}$ ratios. For example, at the same $\mathrm{Na}_{2} \mathrm{O} / \mathrm{SiO}_{2}$ of 0.18 , the flow spread diameter increased from $180 \mathrm{~mm}$ to $213 \mathrm{~mm}$ when $\mathrm{SiO}_{2} / \mathrm{Al}_{2} \mathrm{O}_{3}$ ratio increased between 7.7 and 10.5 respectively. The extent of flow diameter and the good relation between the flowability and the variation of $\mathrm{Si} / \mathrm{Al}$ and $\mathrm{Na} / \mathrm{Si}$ ratios agree with those of mono-RCBW and mono-CW systems. This may indicate that the same reasons explained earlier for the flowability of mono-systems are valid for binary-systems. 


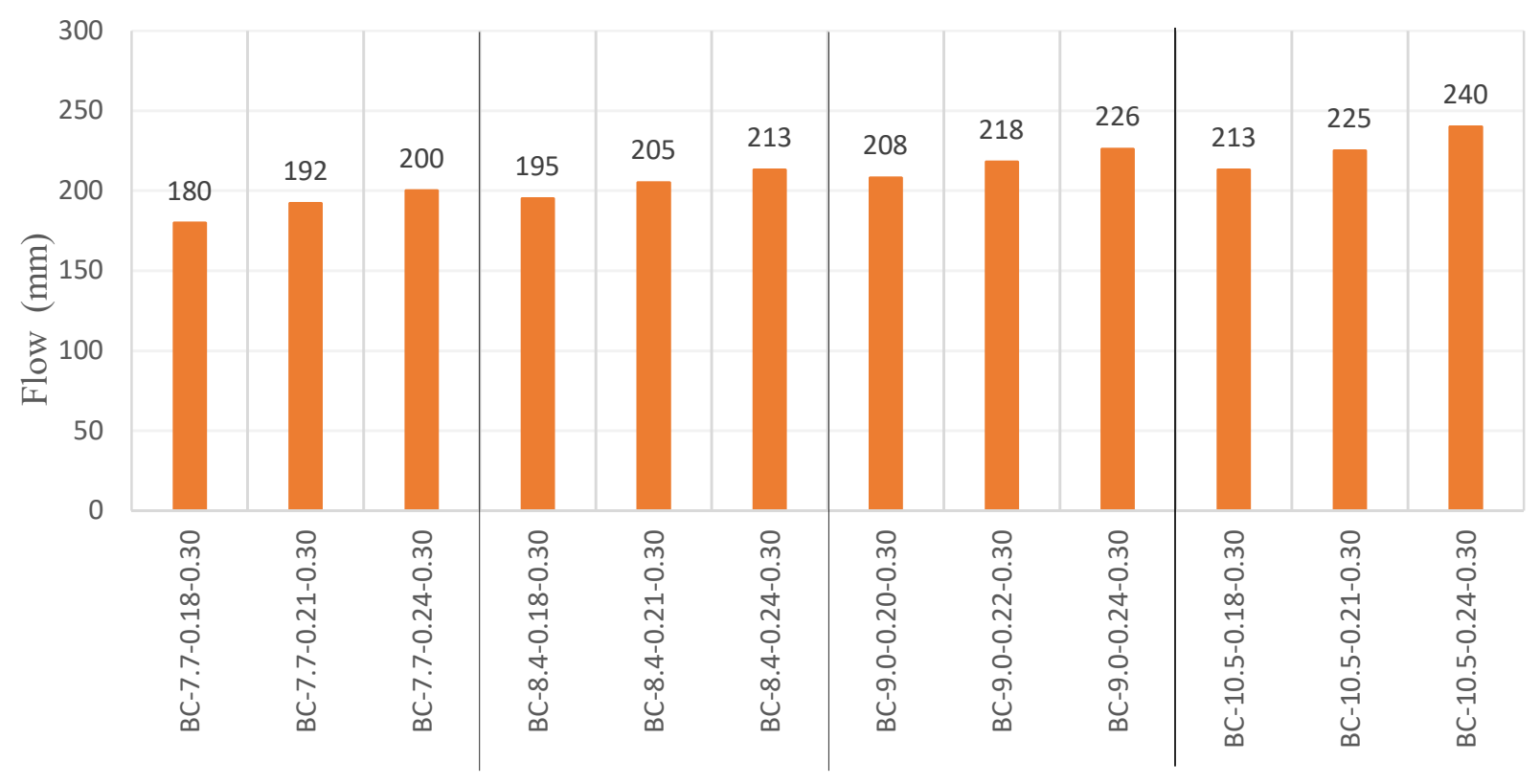

Figure 4.7 Flow diameter of binary-system RCBW+CW geopolymers

Figure 4.8 showed a range of 20 to $52 \mathrm{~min}$ and 70 to $180 \mathrm{~min}$ for the initial and the final setting times respectively of binary $\mathrm{RCBW}+\mathrm{CW}$ geopolymer binders. A clear relationship can be determined between the values of $\mathrm{SiO}_{2} / \mathrm{Al}_{2} \mathrm{O}_{3}$ and $\mathrm{Na}_{2} \mathrm{O} / \mathrm{SiO}_{2}$ ratios and the initial and final setting times of different compositions. At the same $\mathrm{Si} / \mathrm{Al}$ or $\mathrm{Na} / \mathrm{Si}$ ratios, the results of setting time reduced with increased $\mathrm{Na} / \mathrm{Si}$ ratio. For instance, at $\mathrm{Na}_{2} \mathrm{O} / \mathrm{SiO}_{2}$ value of 0.18 , the initial and final setting times for compositions with $\mathrm{SiO}_{2} / \mathrm{Al}_{2} \mathrm{O}_{3}$ of 7.7 were 52 and 180 min, which decreased to 34 and 110 min when $\mathrm{SiO}_{2} / \mathrm{Al}_{2} \mathrm{O}_{3}$ increased to 10.5. The effect of $\mathrm{SiO}_{2} / \mathrm{Al}_{2} \mathrm{O}_{3}$ on setting time of binary $\mathrm{RCBW}+\mathrm{CW}$ was different than that of mono$\mathrm{RCBW}$ or CW geopolymers in which the increased $\mathrm{SiO}_{2} / \mathrm{Al}_{2} \mathrm{O}_{3}$ ratios resulted generally in increased setting time. One reason for this inverse effect is maybe related to the presence of $\mathrm{CaO}$ from $\mathrm{CW}$ resulting in different geopolymer reaction product compared to that of mono-system RCBW or CW. Also, the reduced setting time with increased $\mathrm{Na} / \mathrm{Si}$ ratio of binary $\mathrm{RCBW}+\mathrm{CW}$ mixes is possibly associated with the increased $\mathrm{Na}_{2} \mathrm{O}$ concentration in the mix. According to Allahverdi and Kani, (2013), the increased $\mathrm{Na}_{2} \mathrm{O}$ concentration can enhance the activation level of geopolymer gel during the dissolution process resulting in faster precipitation and polycondensation processes and decreased setting times. 


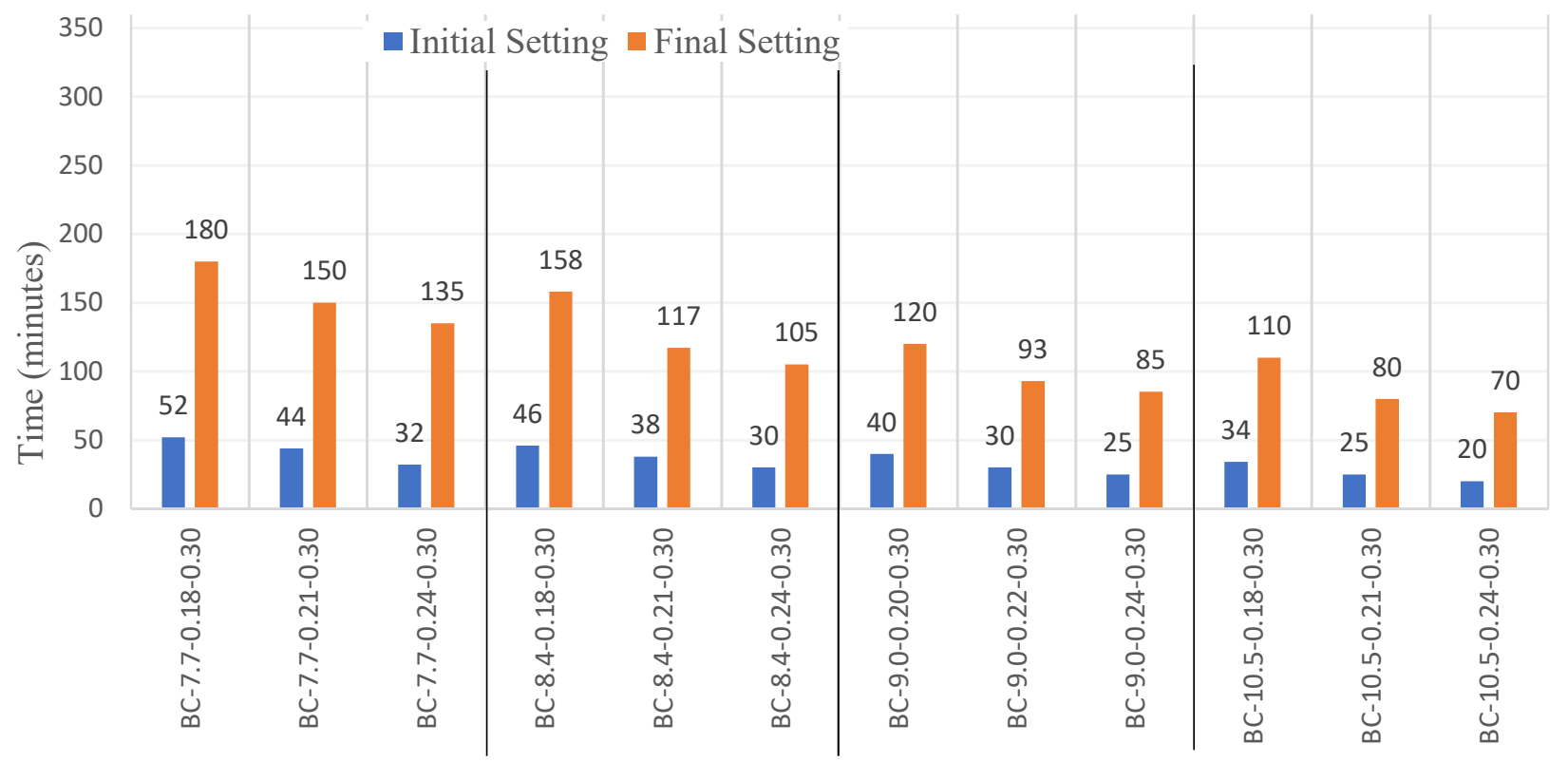

Figure 4.8 Initial and final setting times of binary-system RCBW+CW geopolymers

\section{- Binary-system CTW+CW Pastes}

The flow spread diameter and initial and final setting times of binary CTW+CW geopolymers are shown in Figures 4.9 and 4.10 respectively. As for binary $\mathrm{RCBW}+\mathrm{CW}$, the flow diameter of binary $\mathrm{CTW}+\mathrm{CW}$ was increased as the $\mathrm{SiO}_{2} / \mathrm{Al}_{2} \mathrm{O}_{3}$ and $\mathrm{Na}_{2} \mathrm{O} / \mathrm{SiO}_{2}$ molar ratios increased. For example, the flow spread diameter was $175 \mathrm{~mm}$ and increased to $200 \mathrm{~mm}$ when $\mathrm{Na}_{2} \mathrm{O} / \mathrm{SiO}_{2}$ increased from 0.18 to 0.24 , at equivalent $\mathrm{SiO}_{2} / \mathrm{Al}_{2} \mathrm{O}_{3}$ ratio of 11.4. Also, it increased from 200 to $235 \mathrm{~mm}$ as the $\mathrm{SiO}_{2} / \mathrm{Al}_{2} \mathrm{O}_{3}$ increased from 11.4 to 12.5 , at the same $\mathrm{Na}_{2} \mathrm{O} / \mathrm{SiO}_{2}$ of 0.24 . The combined use of CTW and CW in the same geopolymer system produced intermediate flow results of mono-CTW and mono-CW pastes. 


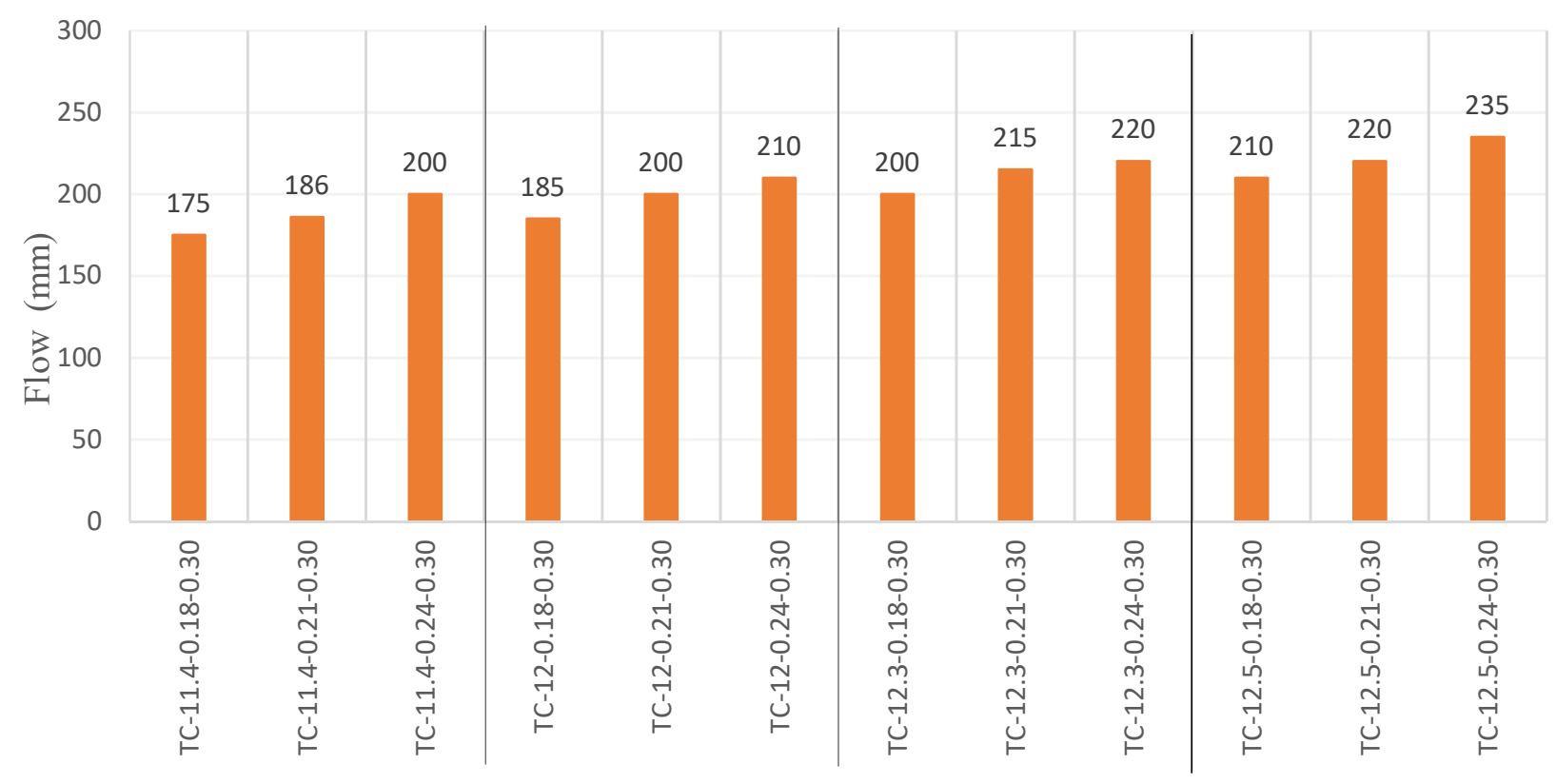

Figure 4.9 Flow diameter of binary-system CTW+CW geopolymers

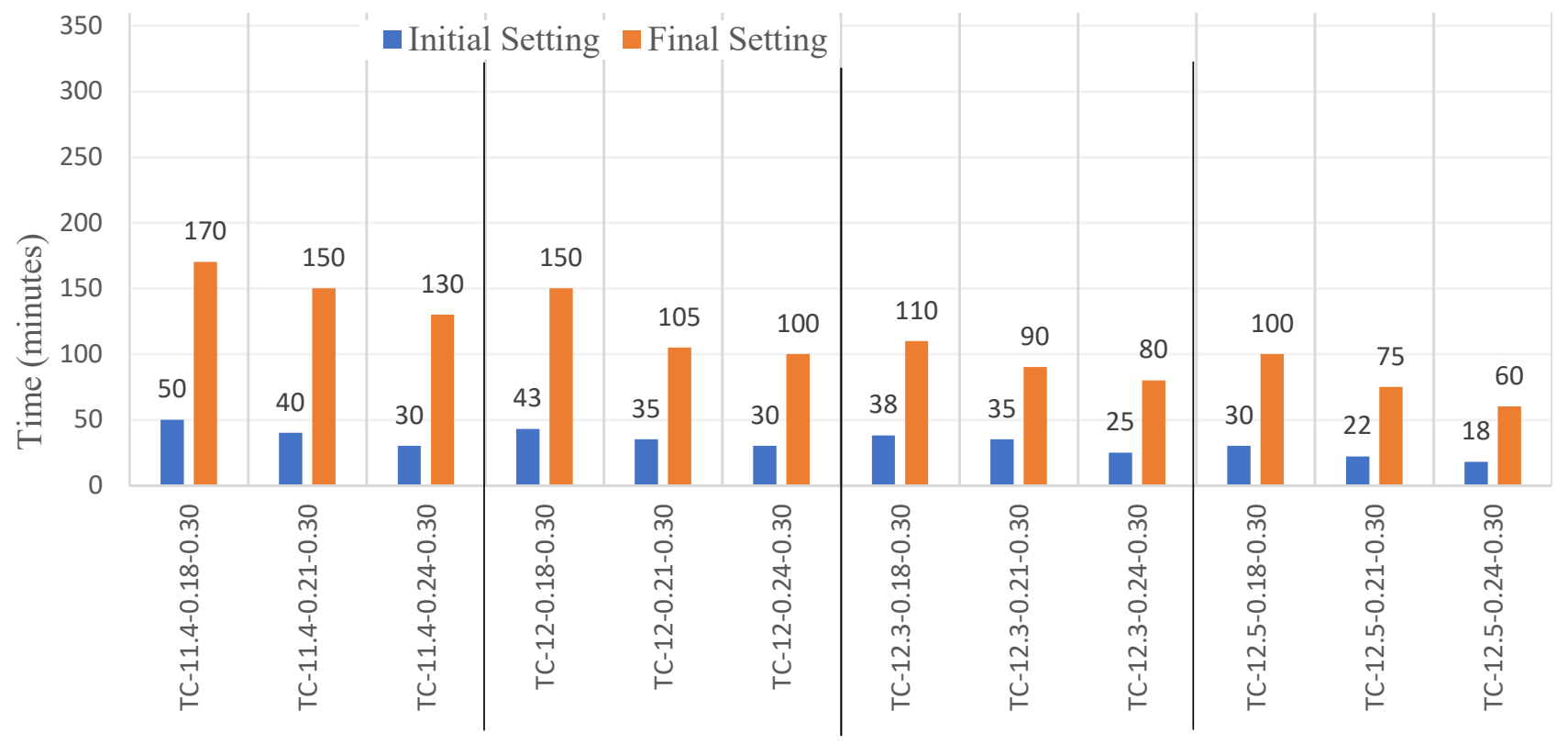

Figure 4.10 Initial and final setting times of binary-system CTW+CW geopolymers

When considering the results displayed in Figure 4.10, the initial and final setting times of binary $\mathrm{CTW}+\mathrm{CW}$ geopolymer pastes were ranging from 18 to $50 \mathrm{~min}$ and from 60 to 170 min respectively. $\mathrm{SiO}_{2} / \mathrm{Al}_{2} \mathrm{O}_{3}$ and $\mathrm{Na}_{2} \mathrm{O} / \mathrm{SiO}_{2}$ molar ratios greatly affected the initial and final setting times of binary $\mathrm{CTW}+\mathrm{CW}$ geopolymers. A clear reduction trend of both initial and final setting times can be seen with increased $\mathrm{SiO}_{2} / \mathrm{Al}_{2} \mathrm{O}_{3}$ and $\mathrm{Na}_{2} \mathrm{O} / \mathrm{SiO}_{2}$ molar ratios. At the same $\mathrm{Na} 2 \mathrm{O} / \mathrm{SiO}_{2}$ ratio of 0.18 , the initial and 
final setting times reduced from $50 \mathrm{~min}$ to $30 \mathrm{~min}$ and from $170 \mathrm{~min}$ to $100 \mathrm{~min}$ respectively. Also, it reduced from 50 to 30 and from 170 to $130 \mathrm{~min}$ when $\mathrm{Na}_{2} \mathrm{O} / \mathrm{SiO}_{2}$ increased between 0.18 and 0.24 , at similar $\mathrm{SiO}_{2} / \mathrm{Al}_{2} \mathrm{O}_{3}$ of 11.4. The setting of binary $\mathrm{CTW}+\mathrm{CW}$ follows the same trend as the binary $\mathrm{RCBW}+\mathrm{CW}$, as the percentage of $\mathrm{CW}$ in the mix increases the $\mathrm{SiO}_{2} / \mathrm{Al}_{2} \mathrm{O}_{3}$ molar ratio which resulted in a decreased setting time due to the presence of high amounts of $\mathrm{CaO}$ in recycled concrete waste.

\section{- Binary-system RCBW+CTW Pastes}

Figure 4.11 presents the flow spread diameter of all binary RCBW+CTW mix geopolymers. Unlike binary $\mathrm{RCBW}+\mathrm{CW}$ and $\mathrm{CTW}+\mathrm{CW}$, the flow diameter of binary system RCBW $+\mathrm{CTW}$ increased only with increased $\mathrm{Na}_{2} \mathrm{O} / \mathrm{SiO}_{2}$ molar ratio. However, it reduced with increased $\mathrm{SiO}_{2} / \mathrm{Al}_{2} \mathrm{O}_{3}$ in the mix composition. For example, the flow spread diameter was $210 \mathrm{~mm}$ and increased to $250 \mathrm{~mm}$ at $\mathrm{SiO}_{2} / \mathrm{Al}_{2} \mathrm{O}_{3}$ of 7.8 and different $\mathrm{Na}_{2} \mathrm{O} / \mathrm{SiO}_{2}$ of 0.18 and 0.24 , while it was $250 \mathrm{~mm}$ and reduced to $185 \mathrm{~mm}$ at $\mathrm{Na}_{2} \mathrm{O} / \mathrm{SiO}_{2}$ of 0.24 various $\mathrm{SiO}_{2} / \mathrm{Al}_{2} \mathrm{O}_{3}$ ratios of 7.8 and 10 . In addition to the chemical ratios, the flowability of binary RCBW+CTW geopolymers was also controlled by the proportions of RCBW and CTW. As the amount of CTW in the binary system increased, the flowability decreased and the contrary is valid for RCBW content.

Figure 4.12 displays the initial and final setting times of binary RCBW+CTW geopolymer pastes, showing ranges from 25 to $60 \mathrm{~min}$ for the initial setting time and from 100 to $200 \mathrm{~min}$ for the final setting time. As for binary $\mathrm{RCBW}+\mathrm{CW}$ and $\mathrm{CTW}+\mathrm{CW}$ mixes, the setting of binary $\mathrm{RCBW}+\mathrm{CTW}$ pastes decreased with increased $\mathrm{SiO}_{2} / \mathrm{Al}_{2} \mathrm{O}_{3}$ and $\mathrm{Na}_{2} \mathrm{O} / \mathrm{SiO}_{2}$ ratios. Also, both initial and final setting times decreased as the percentage of CTW increased in the composition. 


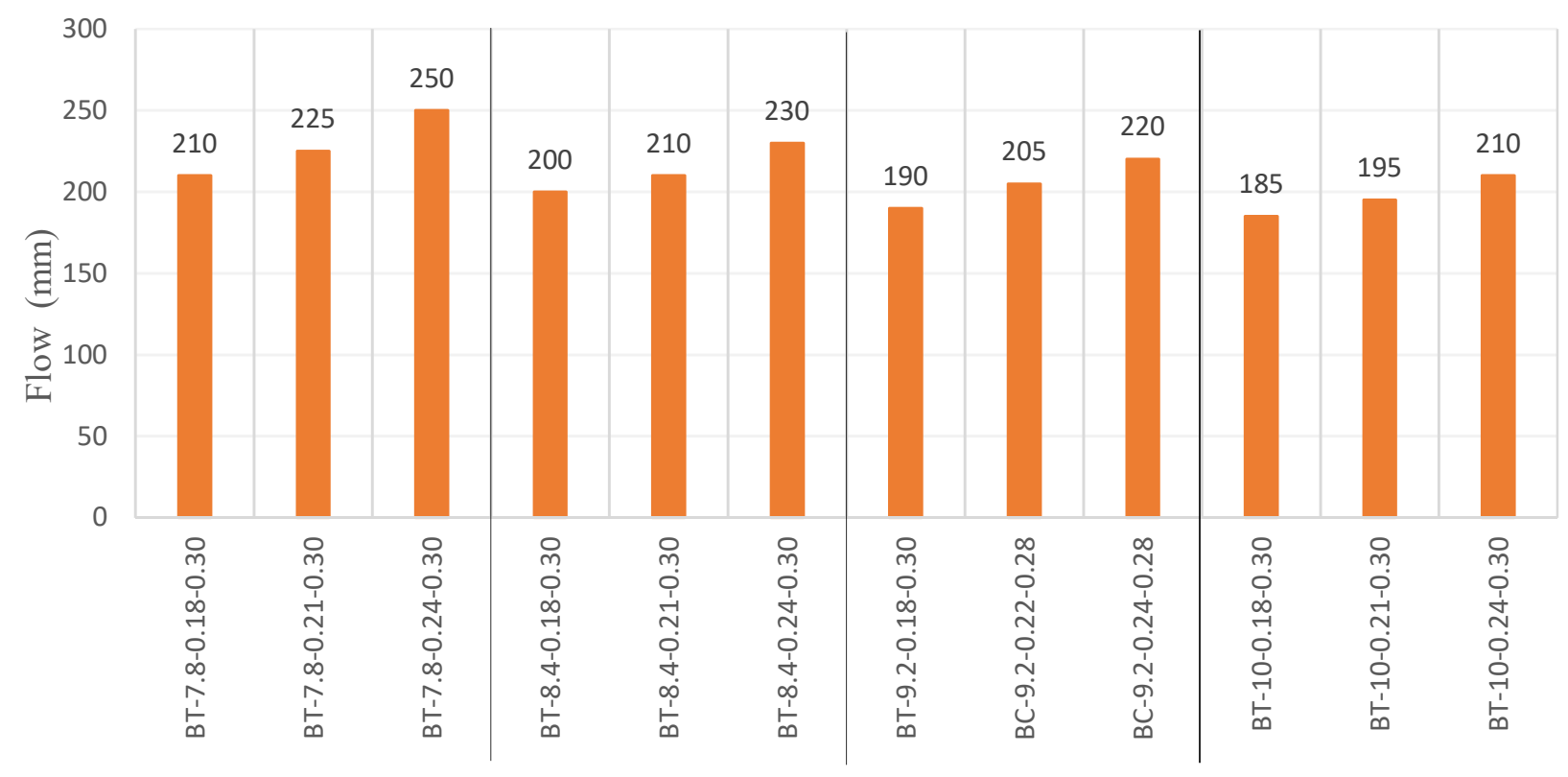

Figure 4.11 Flow diameter of binary-system RCBW+CTW geopolymers

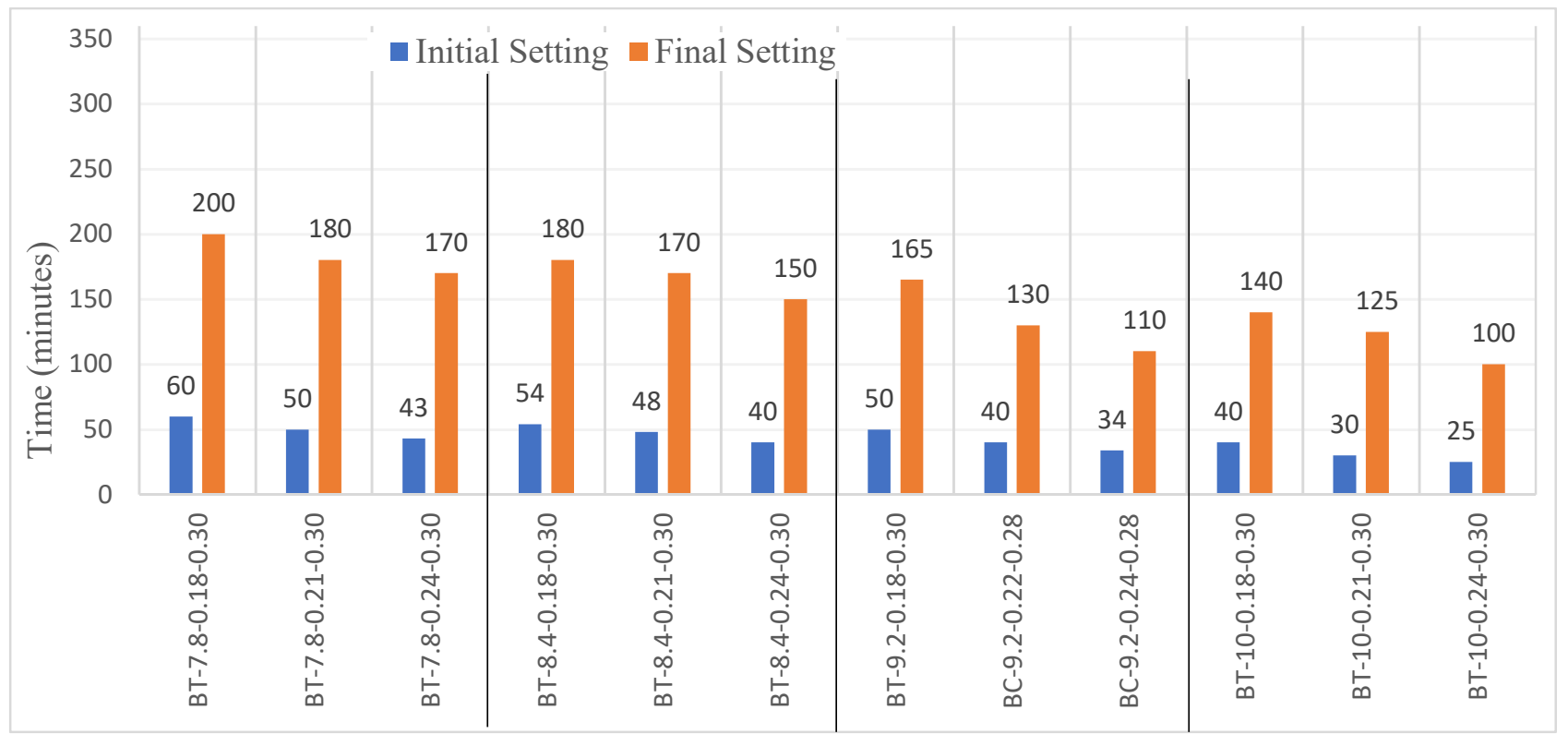

Figure 4.12 Initial and final setting times of binary-system RCBW+CTW geopolymers

\subsubsection{Fresh Properties of Ternary-system Compositions}

The flow diameter and initial and final setting time of ternary $\mathrm{RCBW}+\mathrm{CTW}+\mathrm{CW}$ geopolymer mixes are shown in Figures 4.13 and 4.14 respectively. As can be seen in Figure 4.13, in general the flow decreased as the $\mathrm{SiO}_{2} / \mathrm{Al}_{2} \mathrm{O}_{3}$ molar ratio increased, whereas it increased with increased $\mathrm{Na}_{2} \mathrm{O} / \mathrm{SiO}_{2}$ molar ratio. For 
example, in equivalent $\mathrm{Na}_{2} \mathrm{O} / \mathrm{SiO}_{2}$ ratio of 0.18 , the flow spread diameter was $200,190,185$ and $170 \mathrm{~mm}$ at $\mathrm{SiO}_{2} / \mathrm{Al}_{2} \mathrm{O}_{3}$ of 7.6, 8.4, 9.2 and 10.2 respectively, and in the same $\mathrm{SiO}_{2} / \mathrm{Al}_{2} \mathrm{O}_{3}$ ratio of 7.6, it increased from 200 to $240 \mathrm{~mm}$ when $\mathrm{Na}_{2} \mathrm{O} / \mathrm{SiO}_{2}$ ratio increased from 0.18 to 0.24 . The enhanced flow with increased $\mathrm{Na}_{2} \mathrm{O} / \mathrm{SiO}_{2}$ ratio can be associated with the increased amount of $\mathrm{Na}_{2} \mathrm{O}$ in the mix and its large effect on the dissolution rate of aluminosilicates in CDW precursors. However, the flowability was also affected by the percentage of each material in the combined ternary system. Overall, as the percentage of RCBW was higher compared to other materials the flow was high. This can be seen for mixes BCT1, BCT2 and BCT3 with 80\% RCBW content. Also, it increased as the percentage of CW reduced, especially for mixes between BCT25 and BCT36 where the range of flow diameter increased from 170$200 \mathrm{~mm}$ to $200-240 \mathrm{~mm}$ at CW amounts of $20 \%$ and $80 \%$ respectively.

The initial and final setting times shown in Figure 4.14 were between 15 and 52 min, and 170 and 240 min respectively. The results were mostly affected by the values of $\mathrm{SiO}_{2} / \mathrm{Al}_{2} \mathrm{O}_{3}$ and $\mathrm{Na} 2 \mathrm{O} / \mathrm{SiO}_{2}$ molar ratios when using variable percentages of CDW materials in the mix. For all compositions, at a similar $\mathrm{SiO}_{2} / \mathrm{Al}_{2} \mathrm{O}_{3}$ ratio, the increased $\mathrm{Na}_{2} \mathrm{O} / \mathrm{SiO}_{2}$ molar caused the initial and final setting times to reduce. This reduction is maybe due to the strong relationship between the amount of $\mathrm{Na}_{2} \mathrm{O}$ and the $\mathrm{Na}_{2} \mathrm{O} / \mathrm{SiO}_{2} \mathrm{ratio}$ in the mix. As explained earlier, when the $\mathrm{Na}_{2} \mathrm{O}$ concentration increased, the activation level of geopolymer gels during the dissolution process increased, which accelerate the precipitation and polycondensation of geopolymer products (Allahverdi et all, 2013). The relationship between the change in $\mathrm{SiO}_{2} / \mathrm{Al}_{2} \mathrm{O}_{3}$ ratio and the time of initial and final settings depends also on the content of each CDW material in the ternary system. When the percentage of $\mathrm{CW}$ decreased and the $\mathrm{SiO}_{2} / \mathrm{Al}_{2} \mathrm{O}_{3}$ molar ratio decreased, the initial and final setting times increased. For example, at the same $\mathrm{Na} 2 \mathrm{O} / \mathrm{SiO}_{2}$ of 0.18 , for BCT25, BCT28, BCT31 and BCT34, the amount of CW reduced from $80 \%$ to $20 \%$ and $\mathrm{SiO}_{2} / \mathrm{Al}_{2} \mathrm{O}_{3}$ from 12 to 9 and the initial and final setting times increased from 25 and 90 min to 38 and 120 respectively. These prolonged initial and final setting times at higher $\mathrm{SiO}_{2} / \mathrm{Al}_{2} \mathrm{O}_{3}$ ratio are possibly related to the increased silica modulus content due to the reduction in $\mathrm{Na}_{2} \mathrm{O}$ concentration, which resulted in slower geopolymerization reaction because of the small amount of alkalis available to start the dissolution and subsequently the geopolymerization processes. 


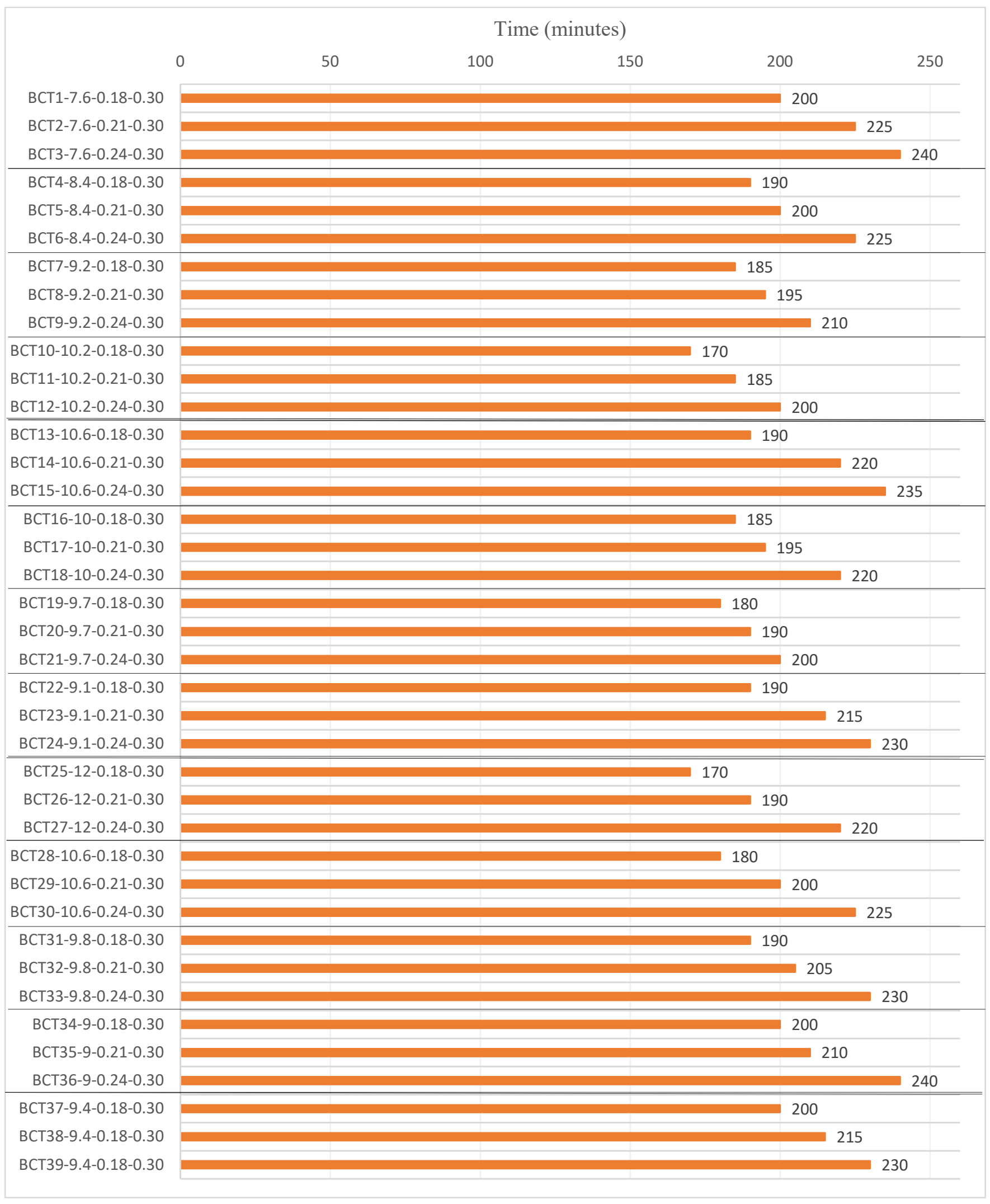

Figure 4.13 Flow diameter of ternary-system RCBW+CTW+CW geopolymers 


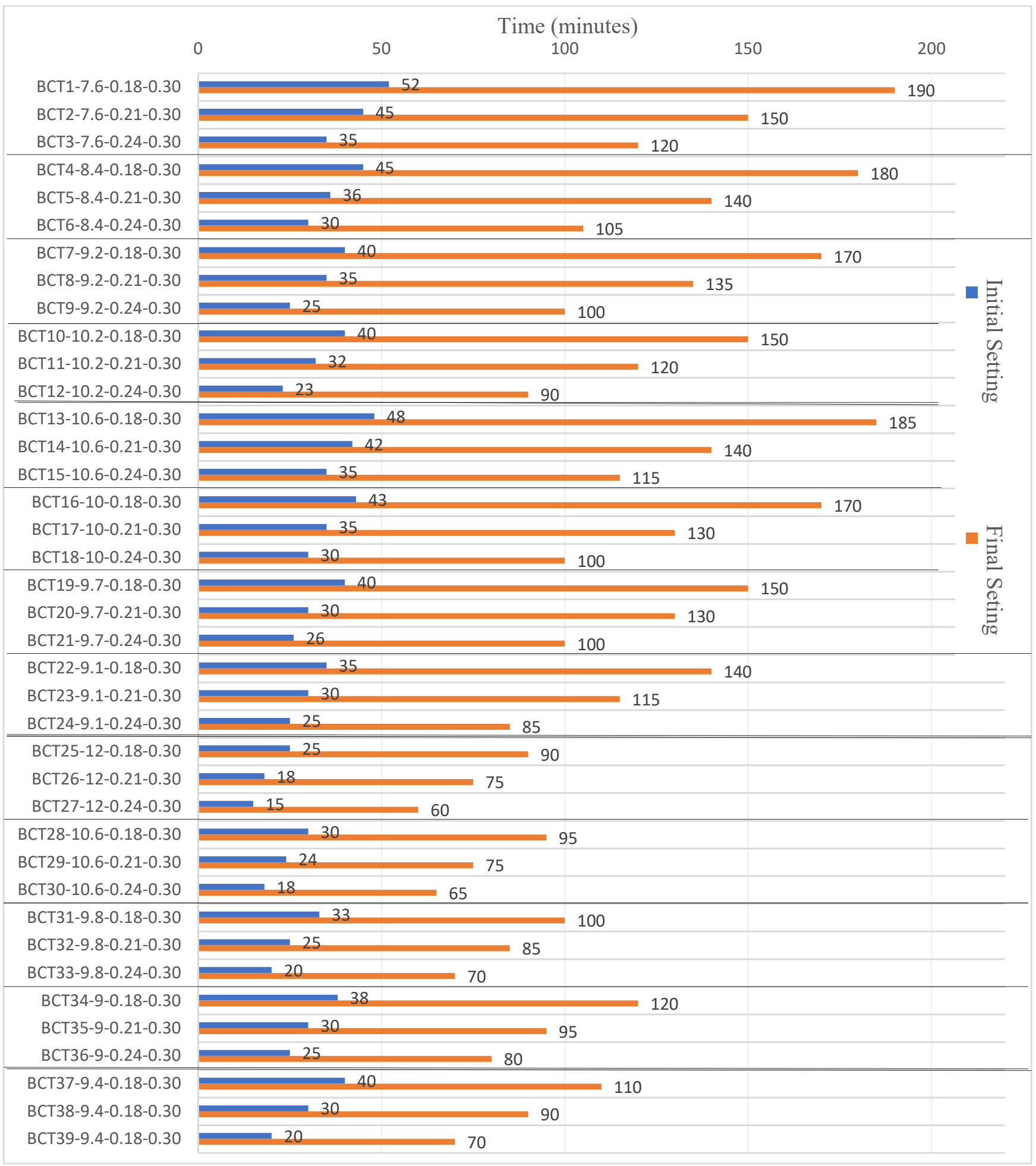

Figure 4.14 Initial and final setting times of ternary-system $\mathrm{RCBW}+\mathrm{CTW}+\mathrm{CW}$ geopolymers 


\subsection{Mechanical Strengths at Ambient Temperature Curing}

The change in $\mathrm{SiO}_{2} / \mathrm{Al}_{2} \mathrm{O}_{3}$ and $\mathrm{Na}_{2} \mathrm{O} / \mathrm{SiO}_{2}$ molar ratios is an important parameter to optimize the geopolymerization reaction and compressive strengths of geopolymer binders. As explained earlier, the main goal of this experimental investigation was to develop CDW-based geopolymer binders with optimized compressive strengths at ambient curing conditions. This section investigates the effect of these chemical ratios on the compressive strengths of mono, binary and ternary CDW geopolymer binders, while the full time of curing was at ambient temperature of $25 \pm 2{ }^{\circ} \mathrm{C}$.

\subsubsection{Mechanical Strengths of Mono-system compositions}

\section{- Mechanical Strengths of Mono-system RCBW Geopolymers}

Table 4.10 shows the 7- and 28-day compressive strengths of mono-RCBW binders cured at room temperature. As it was explained in the previous section related to the results of fresh properties, five various mixes were not castable for mono-system RCBW geopolymers. These compositions were identified with $0 \mathrm{MPa}$ strengths in the table of results.

Different optimum results were achieved at 7 and 28 days. The higher compressive strength achieved at 7 days (16.9 $\mathrm{MPa}$ ) was for mix B-7.3-0.24.-0.30. Whereas at 28 days, the optimum strength was registered for B-7.1-0.24-0.3 with 31MPa. The $\mathrm{SiO}_{2} / \mathrm{Al}_{2} \mathrm{O}_{3}$ and $\mathrm{Na} 2 \mathrm{O} / \mathrm{SiO}_{2}$ molar ratios highly affected the compressive strengths of mono-RCBW binders, as presented in Figure 4.15. The results increased as the $\mathrm{Na}_{2} \mathrm{O} / \mathrm{SiO}_{2}$ increased from 0.16 to 0.24 at all $\mathrm{SiO}_{2} / \mathrm{Al}_{2} \mathrm{O}_{3}$ molar ratios and curing ages. For example, at $\mathrm{SiO}_{2} / \mathrm{Al}_{2} \mathrm{O}_{3}=7.1$, the 28-day strength was $13.1 \mathrm{MPa}$ and increased to $31 \mathrm{MPa}$ when $\mathrm{Na} 2 \mathrm{O} / \mathrm{SiO}_{2}$ increased from 0.16 and 0.24 respectively. The increased strengths with increased $\mathrm{Na}_{2} \mathrm{O} / \mathrm{SiO}_{2}$ ratios maybe related to $\mathrm{Na}_{2} \mathrm{O}$ and related $\mathrm{N}^{+}$concentrations which are mostly provided from $\mathrm{NaOH}$ in the geopolymer system. According to Robayo et al., (2016), the appropriate $\mathrm{Na}_{2} \mathrm{O}$ concentration identified in this project by an optimal $\mathrm{Na}_{2} \mathrm{O} / \mathrm{SiO}_{2}$, is important to balance the charges of $\mathrm{Si}$ and $\mathrm{Al}$ tetrahedrons in the geopolymer gels. Lower than this optimal concentration of sodium may not be able to provide sufficient hydroxyl groups $\left(\mathrm{OH}^{-}\right)$to dissolve $\mathrm{Si}$ and $\mathrm{Al}$ and provide the required alkalinity for the precursor powder. Also, higher than the optimal $\mathrm{Na}_{2} \mathrm{O}$ was shown to cause the formation of carbonate salts which results in efflorescence ( Allahverdi \& Kani, 2013; Reig et al., 2013). 
Table 4.8 Compressive strengths of mono-system RCBW binders

\begin{tabular}{|c|c|c|c|}
\hline \multirow[b]{2}{*}{ No. } & \multirow[t]{2}{*}{ Composition Code } & \multicolumn{2}{|c|}{ Compressive Strength (MPa) } \\
\hline & & 7 Days & 28 Days \\
\hline 1 & B-7.1-0.16-0.30 & 9.2 & 13.1 \\
\hline 2 & B-7.1-0.18-0.30 & 10.3 & 16.3 \\
\hline 3 & B-7.1-0.20-0.30 & 10.7 & 20.7 \\
\hline 4 & B-7.1-0.22-0.30 & 10.8 & 25.4 \\
\hline 5 & B-7.1-0.24.-0.30 & 11.4 & 31.0 \\
\hline 6 & B-7.3-0.16-0.30 & 6.2 & 10.4 \\
\hline 7 & B-7.3-0.18-0.30 & 11.5 & 14.6 \\
\hline 8 & B-7.3-0.20-0.30 & 12.1 & 18.3 \\
\hline 9 & B-7.3-0.22-0.30 & 13.2 & 21.2 \\
\hline 10 & B-7.3-0.24.-0.30 & 16.9 & 24.0 \\
\hline 11 & B-7.5-0.16-0.30 & 2.4 & 4.5 \\
\hline 12 & B-7.5-0.18-0.30 & 7.4 & 10.6 \\
\hline 13 & B-7.5-0.20-0.30 & 10.1 & 12.2 \\
\hline 14 & B-7.5-0.22-0.30 & 10.2 & 18.4 \\
\hline 15 & B-7.5-0.24.- -0.30 & 14.7 & 20.7 \\
\hline 16 & B-7.7-0.16-0.30 & 0.0 & 0.0 \\
\hline 17 & B-7.7-0.18-0.30 & 0.0 & 0.0 \\
\hline 18 & B-7.7-0.20-0.30 & 5.3 & 8.1 \\
\hline 19 & B-7.7-0.22-0.30 & 9.8 & 12.5 \\
\hline 20 & B-7.7-0.24.-0.30 & 12.3 & 16.1 \\
\hline 21 & B-7.9-0.16-0.30 & 0.0 & 0.0 \\
\hline 22 & B-7.9-0.18-0.30 & 0.0 & 0.0 \\
\hline 23 & B-7.9-0.20-0.30 & 0.0 & 0.0 \\
\hline 24 & B-7.9-0.22-0.30 & 5.0 & 9.2 \\
\hline 25 & B-7.9-0.24-0.30 & 10.1 & 12.6 \\
\hline
\end{tabular}

The effect of $\mathrm{SiO}_{2} / \mathrm{Al}_{2} \mathrm{O}_{3}$ ratio on the compressive strength results was based on the age of curing. At 7 days, the strength increased from $\mathrm{SiO}_{2} / \mathrm{Al}_{2} \mathrm{O}_{3}$ of 7.1 to 7.3 and reduced after this optimum of 7.3. However, at 28 days, the results decreased as $\mathrm{SiO}_{2} / \mathrm{Al}_{2} \mathrm{O}_{3}$ ratio increased from 7.1 to 7.9, with an optimum of 7.1. This is due to the unbalanced amounts of $\mathrm{SiO}_{2} / \mathrm{Al}_{2} \mathrm{O}_{3}$ and $\mathrm{Na} 2 \mathrm{O} / \mathrm{SiO}_{2}$ ratios which resulted in geopolymer systems with lower stability. Higher than the optimal required of $\mathrm{SiO}_{2} / \mathrm{Al}_{2} \mathrm{O}_{3}$ ratio can cause the presence of a high amount of soluble silica ( $\mathrm{Si}-\mathrm{O}-)$ in the system while $\mathrm{Al}$ and $\mathrm{Na}_{2} \mathrm{O}$ contents are comparatively small. This statement is supported by the compressive strength development between 7 and 28 days in which mixes B-7.3-0.24.-0.30 and B-7.1-0.24-0.3 displayed increments of $42.4 \%$ and $170.9 \%$ respectively. Thus, for mix B-7.3-0.24.-0.30, most of the available alumina and sodium was bonded at 7 days. According to Criado et al., (2010), in proper geopolymer mixes, the geopolymer reaction products can highly develop with extended curing age resulting in reduced porosity and improved compressive strength (Criado et al., 2010). 

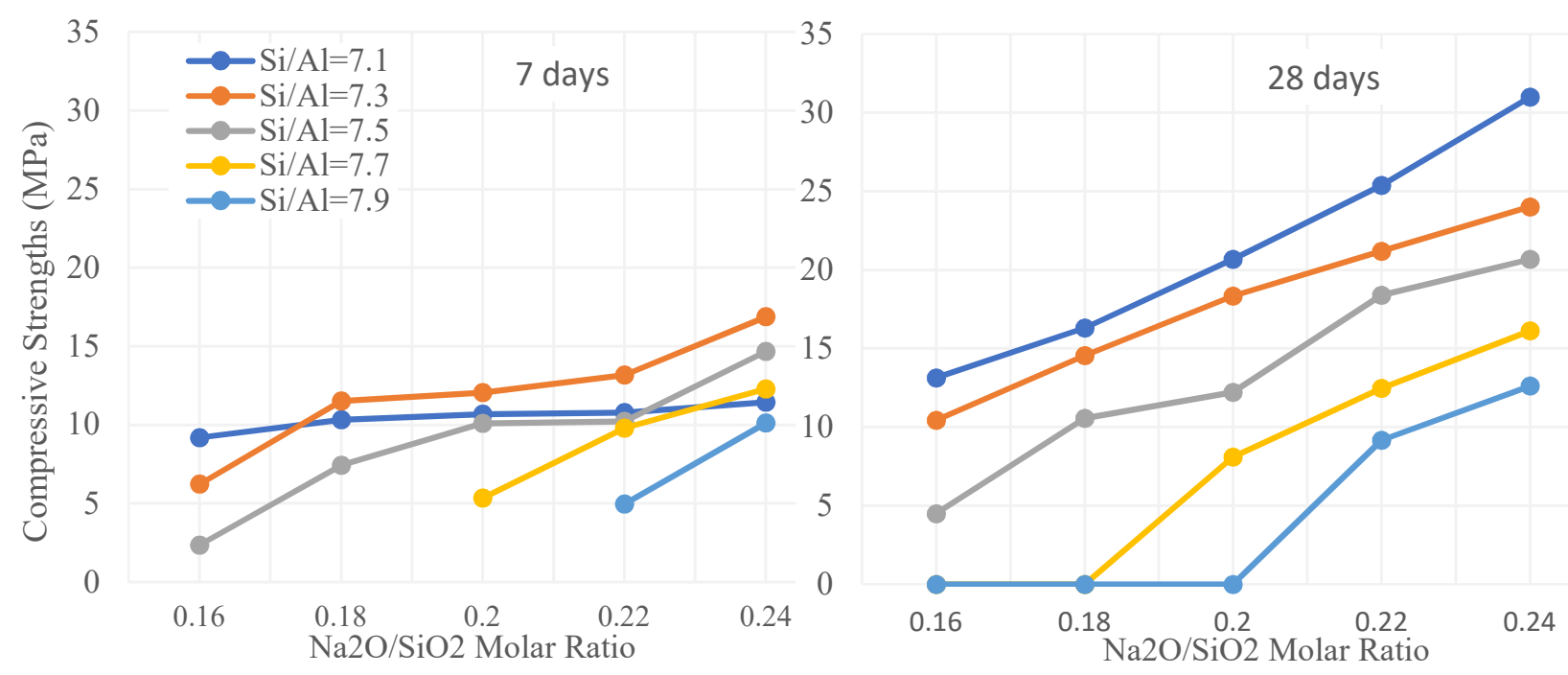

Figure 4.15 Effect of $\mathrm{SiO}_{2} / \mathrm{Al}_{2} \mathrm{O}_{3}$ and $\mathrm{Na}_{2} \mathrm{O} / \mathrm{SiO}_{2}$ ratios on the strengths of mono-system RCBW pastes

\section{- Mechanical Strengths of Mono-system CTW Geopolymers}

The compressive strengths of mono-system CTW geopolymers are presented in Table 411 and the effect of $\mathrm{SiO}_{2} / \mathrm{Al}_{2} \mathrm{O}_{3}$ and $\mathrm{Na}_{2} \mathrm{O} / \mathrm{SiO}_{2}$ ratios on these results is presented in Figure 4.16. Mix T-11.1-0.20-0.30 presented the optimum compressive strengths of $23.2 \mathrm{MPa}$ and $31.8 \mathrm{MPa}$ at 7 and 28-days respectively. This indicates an increase of around $37 \%$ between 7 and 28 days of curing. The lower strength achieved was for mix T-10.5-0.24-0.3 with $0.4 \mathrm{MPa}$ and $2.1 \mathrm{MPa}$ at 7 and 28 days, respectively. $\mathrm{SiO}_{2} / \mathrm{Al}_{2} \mathrm{O}_{3}$ and $\mathrm{Na}_{2} \mathrm{O} / \mathrm{SiO}_{2}$ molar ratios played an important role on the strength changes of mono CTW geopolymer binders. The results increased with increased $\mathrm{SiO}_{2} / \mathrm{Al}_{2} \mathrm{O}_{3}$ molar ratio from 10.5 to 11.1; however further increase in $\mathrm{SiO}_{2} / \mathrm{Al}_{2} \mathrm{O}_{3}$ ratio affected negatively the mechanical strengths. The optimal value of $\mathrm{Na}_{2} \mathrm{O} / \mathrm{SiO}_{2}$ ratio depends also on the $\mathrm{SiO}_{2} / \mathrm{Al}_{2} \mathrm{O}_{3}$ part. Higher content of $\mathrm{Na}_{2} \mathrm{O} / \mathrm{SiO}_{2}$ was required when the $\mathrm{SiO}_{2} / \mathrm{Al}_{2} \mathrm{O}_{3}$ ratio increased. For example, the optimal content of $\mathrm{Na}_{2} \mathrm{O} / \mathrm{SiO}_{2}$ in compositions with $\mathrm{SiO}_{2} / \mathrm{Al}_{2} \mathrm{O}_{3}$ ratios of 10.7 and 10.9 was 0.18 , which increased to 0.20 and 0.24 at $\mathrm{SiO}_{2} / \mathrm{Al}_{2} \mathrm{O}_{3}$ ratio of 11.1 and 11.3 respectively. 
Table 4.9 Compressive strengths of mono-system CTW binders

\begin{tabular}{|c|c|c|c|}
\hline \multirow[b]{2}{*}{ No. } & \multirow[t]{2}{*}{ Composition Code } & \multicolumn{2}{|c|}{ Compressive Strength (MPa) } \\
\hline & & 7 Days & 28 Days \\
\hline 1 & T-10.5-0.14-0.30 & 7.4 & 13.1 \\
\hline 2 & T-10.5-0.16-0.30 & 7.0 & 14.6 \\
\hline 3 & T-10.5-0.18-0.30 & 6.7 & 14.1 \\
\hline 4 & T-10.5-0.20-0.30 & 4.1 & 8.7 \\
\hline 5 & $\mathrm{~T}-10.5-0.22-0.30$ & 1.1 & 5.1 \\
\hline 6 & T-10.5-0.24-0.33 & 0.4 & 2.1 \\
\hline 7 & T-10.7-0.14-0.30 & 6.6 & 13.4 \\
\hline 8 & T-10.7-0.16-0.30 & 12.7 & 20.1 \\
\hline 9 & $\mathrm{~T}-10.7-0.18-0.30$ & 11.6 & 19.9 \\
\hline 10 & $\mathrm{~T}-10.7-0.20-0.30$ & 8.0 & 14.7 \\
\hline 11 & $\mathrm{~T}-10.7-0.22-0.30$ & 6.9 & 12.4 \\
\hline 12 & T-10.7-0.24-0.30 & 6.2 & 11.8 \\
\hline 13 & T-10.9-0.14-0.30 & 7.6 & 13.9 \\
\hline 14 & T-10.9-0.16-0.30 & 15.8 & 23.0 \\
\hline 15 & T-10.9-0.18-0.30 & 21.1 & 28.7 \\
\hline 16 & T-10.9-0.20-0.30 & 17.0 & 27.6 \\
\hline 17 & T-10.9-0.22-0.30 & 15.5 & 26.3 \\
\hline 18 & T-10.9-0.24-0.30 & 15.1 & 25.8 \\
\hline 19 & T-11.1-0.14-0.3 & 5.6 & 12.7 \\
\hline 20 & T-11.1-0.16-0.3 & 17.2 & 25.4 \\
\hline 21 & Т-11.1-0.18-0.3 & 16.7 & 26.7 \\
\hline 22 & T-11.1-0.20-0.3 & 23.2 & 31.8 \\
\hline 23 & T-11.1-0.22-0.3 & 19.6 & 29.6 \\
\hline 24 & T-11.1-0.24-0.3 & 18.8 & 27.9 \\
\hline 25 & Т-11.3-0.14-0.3 & 2.8 & 6.6 \\
\hline 26 & T-11.3-0.14-0.3 & 8.7 & 18.0 \\
\hline 27 & T-11.3-0.16-0.3 & 12.9 & 21.6 \\
\hline 28 & T-11.3-0.18-0.3 & 12.2 & 21.8 \\
\hline 29 & $\mathrm{~T}-11.3-0.20-0.3$ & 18.1 & 22.8 \\
\hline 30 & $\mathrm{~T}-11.3-0.22-0.3$ & 18.3 & 24.5 \\
\hline
\end{tabular}
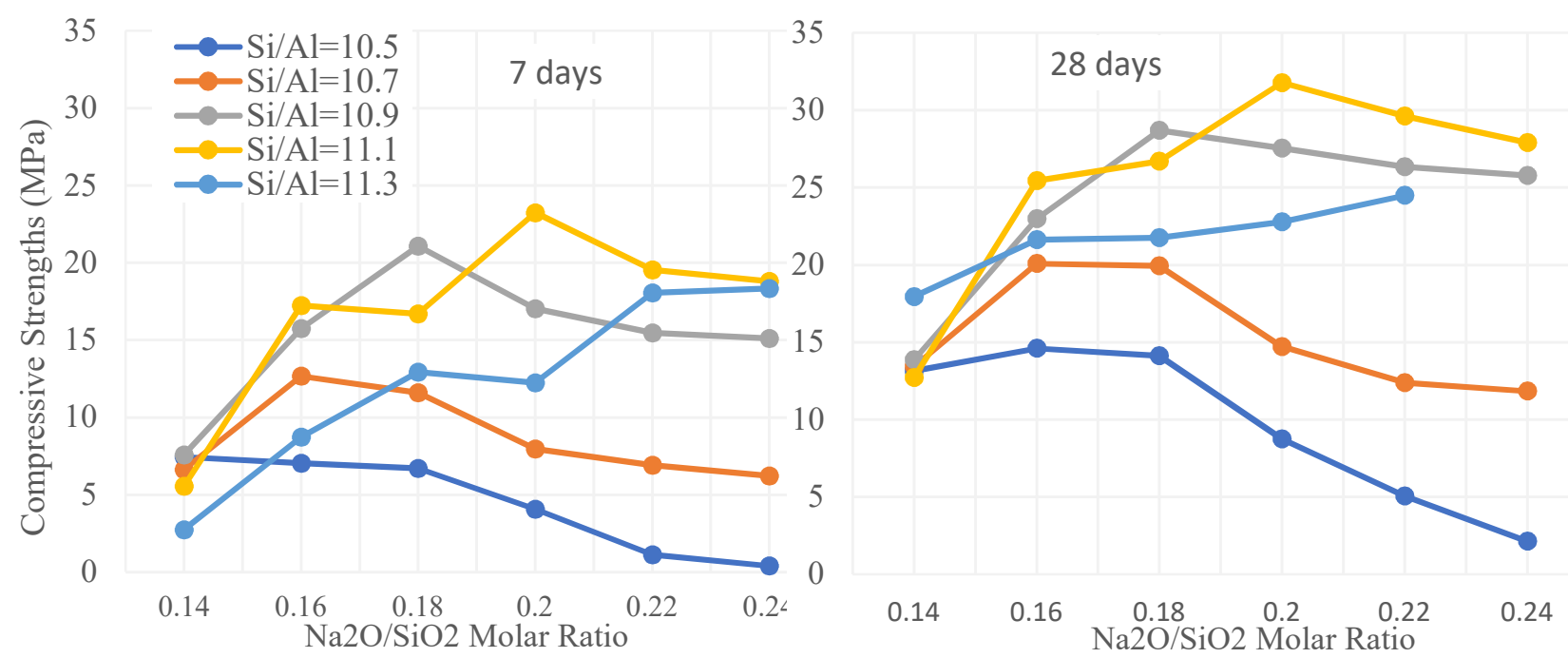

Figure 4.16 Effect of $\mathrm{SiO}_{2} / \mathrm{Al}_{2} \mathrm{O}_{3}$ and $\mathrm{Na}_{2} \mathrm{O} / \mathrm{SiO}_{2}$ ratios on the strengths of mono-system CTW pastes 


\section{- Mechanical Strengths of Mono-system CW Geopolymers}

Table 4.12 presents the compressive strengths of $\mathrm{CW}$-based geopolymer binders. It is worth noting that specimens of compositions CW-12-0.32-0.3 and CW-12-0.35-0.3 had rapid false settings. Thus, there was not enough time for molding and their compressive strengths could not be measured. Therefore, their strengths were shown as zero value in the table of results.

Table 4.10 Compressive strengths of mono-system CW binders

\begin{tabular}{|c|c|c|c|}
\hline \multirow[b]{2}{*}{ No. } & \multirow[t]{2}{*}{ Composition Code } & \multicolumn{2}{|c|}{ Compressive Strength (MPa) } \\
\hline & & 7 Days & 28 Days \\
\hline 1 & CW-12-0.2-0.3 & 12.0 & 18.5 \\
\hline 2 & CW-12-0.23-0.3 & 12.9 & 15.3 \\
\hline 3 & CW-12-0.26-0.3 & 12.0 & 15.1 \\
\hline 4 & CW-12-0.29-0.3 & 10.8 & 14.6 \\
\hline 5 & CW-12-0.32-0.3 & 0.0 & 0.0 \\
\hline 6 & CW-12-0.35-0.3 & 0.0 & 0.0 \\
\hline 7 & CW-12.3-0.2-0.3 & 12.8 & 14.6 \\
\hline 8 & CW-12.3-0.23-0.3 & 13.2 & 15.3 \\
\hline 9 & CW-12.3-0.26-0.3 & 13.4 & 13.6 \\
\hline 10 & CW-12.3-0.29-0.3 & 11.5 & 13.3 \\
\hline 11 & CW-12.3-0.32-0.3 & 10.1 & 13.6 \\
\hline 12 & CW-12.3-0.35-0.3 & 12.1 & 15.5 \\
\hline 13 & CW-12.6-0.2-0.3 & 9.9 & 15.0 \\
\hline 14 & CW-12.6-0.23-0.3 & 11.5 & 14.5 \\
\hline 15 & CW-12.6-0.26-0.3 & 12.6 & 14.0 \\
\hline 16 & CW-12.6-0.29-0.3 & 12.4 & 14.0 \\
\hline 17 & CW-12.6-0.32-0.3 & 13.3 & 13.5 \\
\hline 18 & CW-12.6-0.35-0.3 & 14.0 & 14.4 \\
\hline 19 & CW-12.9-0.2-0.3 & 13.7 & 19.8 \\
\hline 20 & CW-12.9-0.23-0.3 & 15.9 & 20.5 \\
\hline 21 & CW-12.9-0.26-0.3 & 14.6 & 16.4 \\
\hline 22 & CW-12.9-0.29-0.3 & 13.9 & 13.8 \\
\hline 23 & CW-12.9-0.32-0.3 & 11.7 & 14.4 \\
\hline 24 & CW-12.9-0.35-0.3 & 6.8 & 11.4 \\
\hline 25 & CW-13.2-0.20-0.3 & 9.4 & 12.5 \\
\hline 26 & CW-13.2-0.23-0.3 & 9.7 & 11.5 \\
\hline 27 & CW-13.2-0.26-0.3 & 9.6 & 9.7 \\
\hline 28 & CW-13.2-0.29-0.3 & 9.3 & 10.4 \\
\hline 29 & CW-13.2-0.32-0.3 & 8.9 & 12.1 \\
\hline 30 & CW-13.2-0.35-0.3 & 9.5 & 9.7 \\
\hline
\end{tabular}

The optimum compressive strengths were achieved for mix CW-12.9-0.23-0.3 with 15.9 and 20.5 MPa at 7 and 28 days respectively. Unlike the large improvement noticed for mono-RCBW, the optimum strengths of CW-paste increased around 28\% between 7 and 28 days. Figure 4.17, which presents the effect $\mathrm{SiO}_{2} / \mathrm{Al}_{2} \mathrm{O}_{3}$ and $\mathrm{Na}_{2} \mathrm{O} / \mathrm{SiO}_{2}$ ratios on the compressive strengths of mono $\mathrm{CW}$-based geopolymer, 
showed that overall there was no clear trend of results based on the single change of $\mathrm{SiO}_{2} / \mathrm{Al}_{2} \mathrm{O}_{3}$ or $\mathrm{Na}_{2} \mathrm{O} / \mathrm{SiO}_{2}$ ratios. This explains the importance of using a balanced amount of $\mathrm{SiO}_{2} / \mathrm{Al}_{2} \mathrm{O}_{3}$ and $\mathrm{Na}_{2} \mathrm{O} / \mathrm{SiO}_{2}$ in the geopolymer composition of mono-CW binders. However, the strengths reduced after reaching a $\mathrm{SiO}_{2} / \mathrm{Al}_{2} \mathrm{O}_{3}$ of 12.9 and $\mathrm{Na}_{2} \mathrm{O} / \mathrm{SiO}_{2}$ of 0.23 . The reason for this could be the extra content of soluble silica after reaching the optimum amount needed in the geopolymer system. This additional silica possibly prevented the contact between the unreacted particles of $\mathrm{CW}$ and the alkaline activators resulting in low geopolymerization and compressive strengths. In addition, the excessive silica in the mono-system CW geopolymer likely hindered the formation of reaction products, leading to a more porous structure and reduced mechanical strengths (Barbosa, Mackenzie, \& Thaumaturgo, 2000; Tuyan et al., 2018). Another observation which can be made is about the low compressive strengths at high $\mathrm{Na}_{2} \mathrm{O} / \mathrm{SiO}_{2} \mathrm{ratio}$ or $\mathrm{Na}_{2} \mathrm{O}$ concentration. These results are in agreement with the findings of Robayo-Salazar et al., (2017) who attributed this tendency to the dissociation and de-polymerization of reaction products by excessive $\mathrm{Na}_{2} \mathrm{O}$ content. Also, the excessive $\mathrm{Na}_{2} \mathrm{O}$ concentration, mainly from the addition of $\mathrm{NaOH}$, was shown to generate an excessive amount of $\mathrm{OH}^{-}$. This can result in a faster polycondensation process that does not provide enough time for aluminosilicates to dissolve, resulting in lower compressive strengths (Allahverdi \& Kani, 2013).
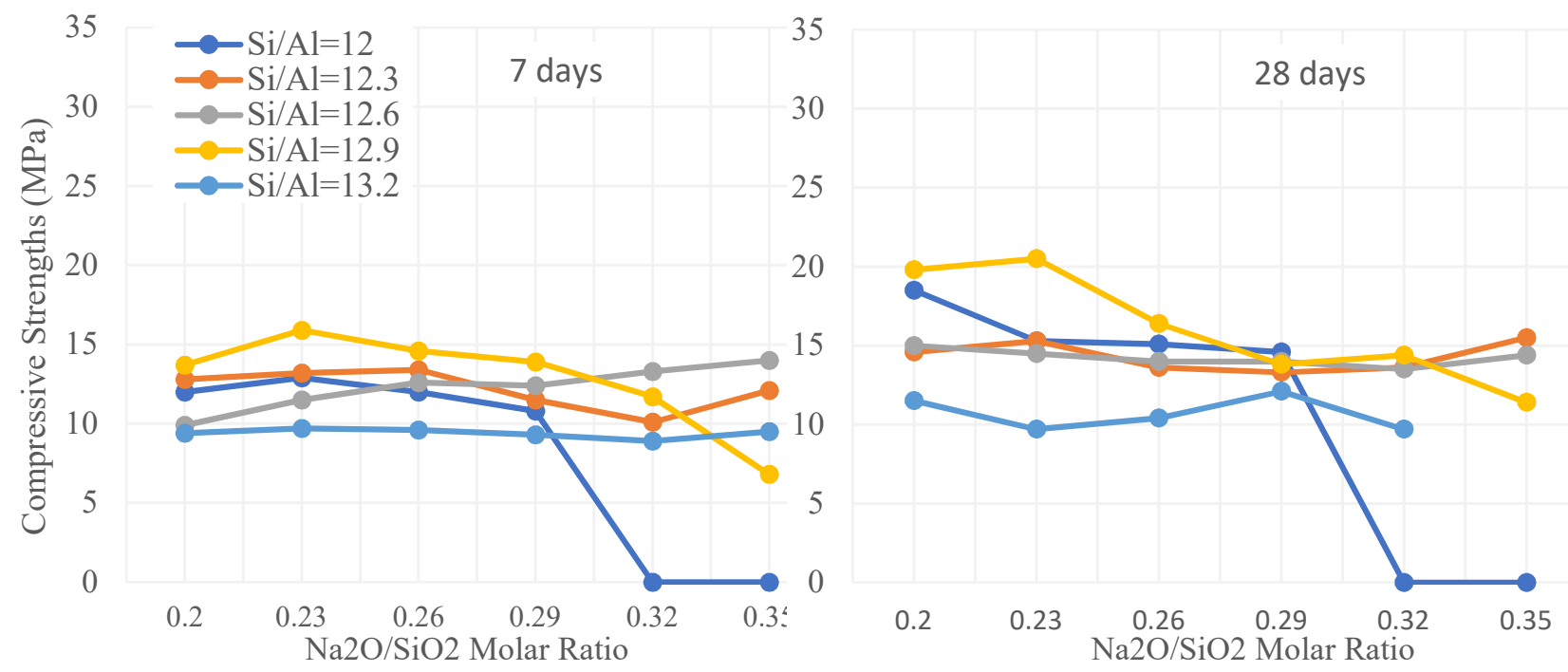

Figure 4.17 Effect of $\mathrm{SiO}_{2} / \mathrm{Al}_{2} \mathrm{O}_{3}$ and $\mathrm{Na}_{2} \mathrm{O} / \mathrm{SiO}_{2}$ ratios on the strengths of mono-system $\mathrm{CW}$ pastes 


\subsubsection{Mechanical Strengths of Binary-system Compositions}

\section{- Mechanical Strengths of Binary-system RCBW+CW Geopolymers}

The compressive strengths of binary RCBW+CW compoistions are presented in Table 4.13. The optimum results were reached for mix BC-8.4-0.18-0.3 with compressive strengths of $18.7 \mathrm{MPa}$ at 7 days and $34.6 \mathrm{MPa}$ at 28 days. This represents an increment of around $85 \%$ between the strength of 7 and 28 days.

Table 4.11 Compressive strengths of binary-system RCBW+CW binders

\begin{tabular}{|c|c|c|c|}
\hline \multirow[b]{2}{*}{ No. } & \multirow[t]{2}{*}{ Composition Code } & \multicolumn{2}{|c|}{ Compressive Strength (MPa) } \\
\hline & & 7 Days & 28 Days \\
\hline 1 & BC-7.7-0.18-0.30 & 10.9 & 21.6 \\
\hline 2 & BC-7.7-0.21-0.30 & 10.3 & 13.2 \\
\hline 3 & BC-7.7-0.24-0.30 & 6.4 & 7.1 \\
\hline 4 & BC-8.4-0.18-0.30 & 18.7 & 34.6 \\
\hline 5 & BC-8.4-0.21-0.30 & 15.4 & 18.5 \\
\hline 6 & BC-8.4-0.24-0.30 & 13.8 & 27.1 \\
\hline 7 & BC-9.0-0.18-0.30 & 13.9 & 13.6 \\
\hline 8 & BC-9.0-0.21-0.30 & 14.2 & 18.9 \\
\hline 9 & BC-9.0-0.24-0.30 & 12.7 & 24.8 \\
\hline 10 & BC-10.5-0.18-0.30 & 10.8 & 24.1 \\
\hline 11 & BC-10.5-0.21-0.30 & 12.3 & 18.1 \\
\hline 12 & BC-10.5-0.24-0.30 & 11.1 & 15.2 \\
\hline
\end{tabular}

The effect of $\mathrm{SiO}_{2} / \mathrm{Al}_{2} \mathrm{O}_{3}$ and $\mathrm{Na}_{2} \mathrm{O} / \mathrm{SiO}_{2}$ molar ratios on the compressive strengths of binary $\mathrm{RCBW}+\mathrm{CW}$ geopolymers is presented in Figure 4.18.
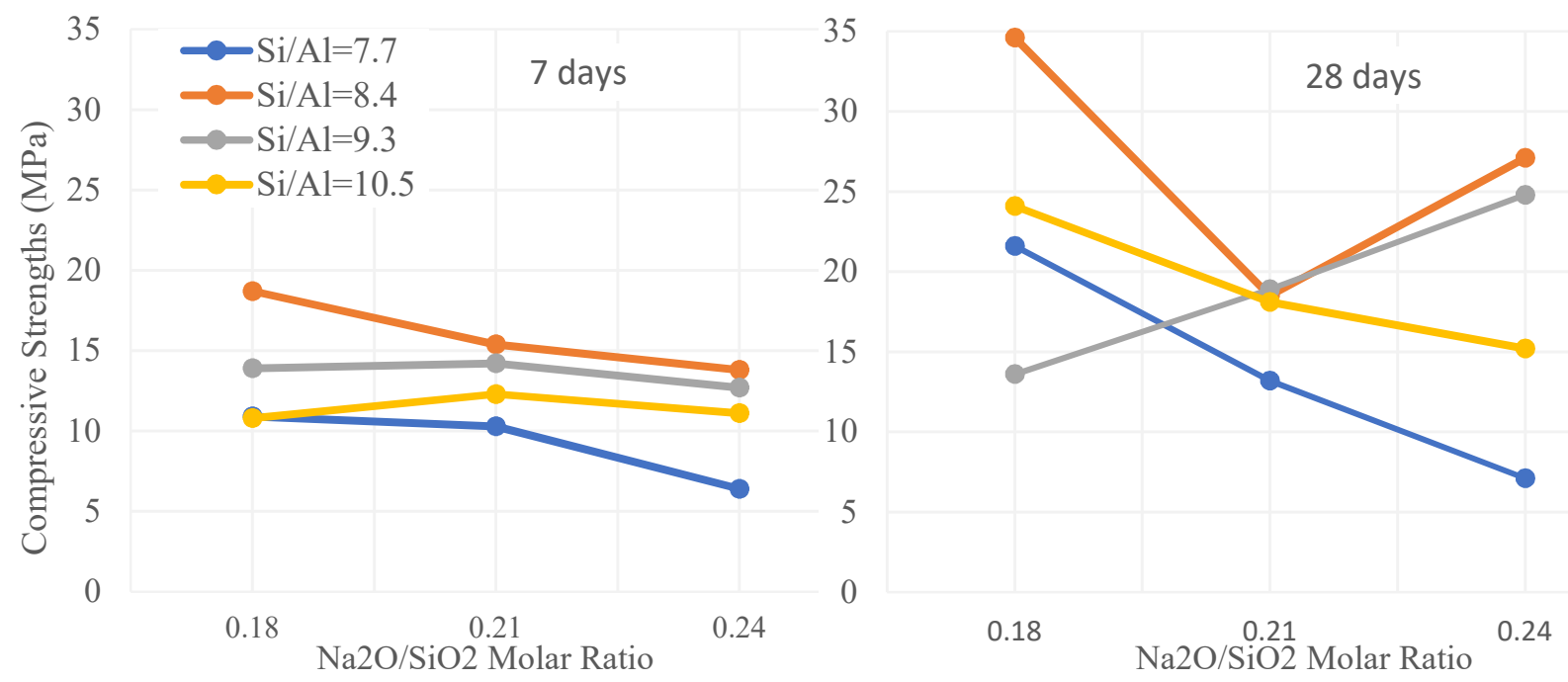

Figure 4.18 Effect of $\mathrm{SiO}_{2} / \mathrm{Al}_{2} \mathrm{O}_{3}$ and $\mathrm{Na}_{2} \mathrm{O} / \mathrm{SiO}_{2}$ ratios on the strengths of binary $\mathrm{RCBW}+\mathrm{CW}$ pastes 
The strong relationship between $\mathrm{SiO}_{2} / \mathrm{Al}_{2} \mathrm{O}_{3}$ and $\mathrm{Na}_{2} \mathrm{O} / \mathrm{SiO}_{2}$ ratios and the change of compressive strengths is clear from this figure. The higher strengths were achieved at $\mathrm{SiO}_{2} / \mathrm{Al}_{2} \mathrm{O}_{3}=8.4$ and $\mathrm{Na}_{2} \mathrm{O} / \mathrm{SiO}_{2}=0.18$ ratios, while the lower strengths were at $\mathrm{SiO}_{2} / \mathrm{Al}_{2} \mathrm{O}_{3}=7.7$ and $\mathrm{Na} 2 \mathrm{O} / \mathrm{SiO}_{2}=0.24$. The results increased as $\mathrm{SiO}_{2} / \mathrm{Al}_{2} \mathrm{O}_{3}$ increased from 7.7 to 8.4, however they reduced beyond the optimum value of 8.4. Also, the higher strengths were attained at $\mathrm{Na}_{2} \mathrm{O} / \mathrm{SiO}_{2}=0.18$, except for compositions with $\mathrm{SiO}_{2} / \mathrm{Al}_{2} \mathrm{O}_{3}$ of 9.3 whose results increased with increased $\mathrm{Na}_{2} \mathrm{O} / \mathrm{SiO}_{2}$. The effect of chemical ratios is in line with the $\mathrm{Na}_{2} \mathrm{O}$ concentration, which was mainly influenced by the percentage of $\mathrm{CW}$ in the system. The reason for this could be the presence of high $\mathrm{CaO}$ content in $\mathrm{CW}$ which resulted in the coexistence of C-S-H and N-A-S-H as geopolymer reaction products. Thus, the need for $\mathrm{Na}_{2} \mathrm{O}$ was reduced because a percentage of silica was bonded to $\mathrm{Ca}$.

\section{- Mechanical Strengths of Binary-system CTW+CW Geopolymers}

The compressive strengths of binary $\mathrm{CTW}+\mathrm{CW}$ compositions are presented in Table 4.14 and the effect of $\mathrm{SiO}_{2} / \mathrm{Al}_{2} \mathrm{O}_{3}$ and $\mathrm{Na}_{2} \mathrm{O} / \mathrm{SiO}_{2}$ ratios on these results is shown in Figure 4.19.

Table 4.12 Compressive strengths of binary-system CTW $+\mathrm{CW}$ binders

\begin{tabular}{|c|c|c|c|}
\hline \multirow[b]{2}{*}{ No. } & \multirow[t]{2}{*}{ Composition Code } & \multicolumn{2}{|c|}{ Compressive Strength (MPa) } \\
\hline & & 7 Days & 28 Days \\
\hline 1 & TC-11.4-0.18-0.30 & 12.9 & 16.3 \\
\hline 2 & TC-11.4-0.21-0.30 & 7.7 & 10.7 \\
\hline 3 & TC-11.4-0.24-0.30 & 7.6 & 8.5 \\
\hline 4 & TC-12-0.18-0.30 & 19.2 & 27.5 \\
\hline 5 & TC-12-0.21-0.30 & 17.2 & 21.8 \\
\hline 6 & TC-12-0.24-0.30 & 12.7 & 22.9 \\
\hline 7 & TC-12.3-0.18-0.30 & 15.3 & 31.7 \\
\hline 8 & TC-12.3-0.21-0.30 & 15.6 & 26.7 \\
\hline 9 & TC-12.3-0.24-0.30 & 11.6 & 20.4 \\
\hline 10 & TC-12.5-0.18-0.30 & 10.8 & 22.4 \\
\hline 11 & TC-12.5-0.21-0.30 & 10.9 & 19.7 \\
\hline 12 & TC-12.5-0.24-0.30 & 11.7 & 18.9 \\
\hline
\end{tabular}

Mixes TC-12-0.18-0.30 and TC-12-0.18-0.3 achieved the higher compressive strengths of 19.2 MPa and 31.7 $\mathrm{MPa}$ at 7 and 28-days respectively. These geopolymer binders showed improvements of $43 \%$ and $107 \%$ respectively, from 7 to 28 days. The results increased as the $\mathrm{SiO}_{2} / \mathrm{Al}_{2} \mathrm{O}_{3}$ molar ratio increased from 11.4 to 12.3 . However, further increases beyond 12.3 caused the strength to reduce. Also, the results generally reduced with increased $\mathrm{Na}_{2} \mathrm{O} / \mathrm{SiO}_{2}$ from 0.18 to 0.24 , except for compositions with a $\mathrm{Na}_{2} \mathrm{O} / \mathrm{SiO}_{2}$ of 11.4 which presented an opposite trend at 7 days. As for binary RCBW+CW, the effects of $\mathrm{Na}_{2} \mathrm{O} / \mathrm{SiO}_{2}$ on $\mathrm{CTW}+\mathrm{CW}$ pastes were mainly related to the $\mathrm{Na}_{2} \mathrm{O}$ concentration that reduced with 
increased CW over CTW in the binary binder in order to achieve better mechanical performance. Therefore, the appropriate contents of $\mathrm{SiO}_{2} / \mathrm{Al}_{2} \mathrm{O}_{3}$ and $\mathrm{Na} 2 \mathrm{O} / \mathrm{SiO}_{2}$ were important, as beyond their optimal values the strengths were significantly affected.
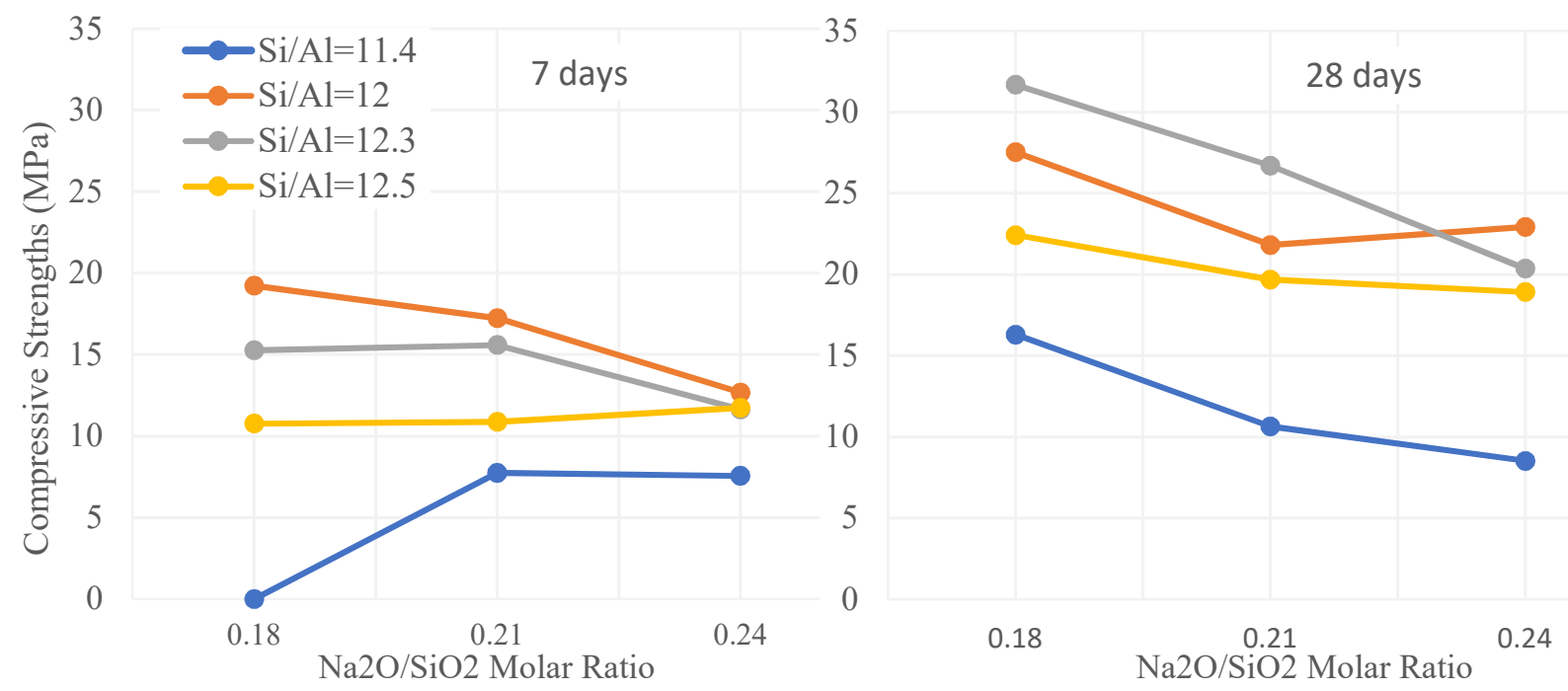

Figure 4.19 Effect of $\mathrm{SiO}_{2} / \mathrm{Al}_{2} \mathrm{O}_{3}$ and $\mathrm{Na}_{2} \mathrm{O} / \mathrm{SiO}_{2}$ ratios on the strengths of binary $\mathrm{CTW}+\mathrm{CW}$ pastes

\section{- Mechanical Strengths of Binary-system RCBW+CTW Geopolymers}

Table 4.15 presents the compressive strength results of binary RCBW+CTW compositions. As can be seen from this table, the higher compressive strengths were reached for mix BT-10-0.24-0.3 with optimal values of $26.6 \mathrm{MPa}$ at 7 days and $30 \mathrm{MPa}$ at 28-days. A strength increment of $12 \%$ was calculated between these two curing times.

Table 4.13 Compressive strengths of binary-system RCBW+CTW binders

\begin{tabular}{|c|c|c|c|}
\hline \multirow[b]{2}{*}{ No. } & \multirow[t]{2}{*}{ Composition Code } & \multicolumn{2}{|c|}{ Compressive Strength (MPa) } \\
\hline & & 7 Days & 28 Days \\
\hline 1 & BT-7.8-0.18-0.30 & 8.4 & 12.1 \\
\hline 2 & BT-7.8-0.21-0.30 & 7.9 & 11.5 \\
\hline 3 & BT-7.8-0.24-0.30 & 17.7 & 21.4 \\
\hline 4 & BT-8.4-0.18-0.30 & 7.0 & 8.8 \\
\hline 5 & BT-8.4-0.21-0.30 & 8.0 & 13.3 \\
\hline 6 & BT-8.4-0.24-0.30 & 25.8 & 27.0 \\
\hline 7 & BT-9.2-0.18-0.30 & 8.0 & 11.8 \\
\hline 8 & BC-9.2-0.22-0.28 & 13.8 & 18.6 \\
\hline 9 & BC-9.2-0.24-0.28 & 17.2 & 21.4 \\
\hline 10 & BT-10-0.18-0.30 & 16.4 & 16.5 \\
\hline 11 & BT-10-0.21-0.30 & 13.5 & 18.3 \\
\hline 12 & BT-10-0.24-0.30 & 26.6 & 30.0 \\
\hline
\end{tabular}


Figure 4.20 shows the effect of $\mathrm{SiO}_{2} / \mathrm{Al}_{2} \mathrm{O}_{3}$ and $\mathrm{Na}_{2} \mathrm{O} / \mathrm{SiO}_{2}$ molar ratios on the compressive strength change of binary RCBW+CTW geopolymers. The optimal results were attained at $\mathrm{SiO}_{2} / \mathrm{Al}_{2} \mathrm{O}_{3}$ of 10 and $\mathrm{Na}_{2} \mathrm{O} / \mathrm{SiO}_{2}$ of 0.24 , while less optimal results were noticed for compositions with $\mathrm{SiO}_{2} / \mathrm{Al}_{2} \mathrm{O}_{3}$ of 8.4 and $\mathrm{Na}_{2} \mathrm{O} / \mathrm{SiO}_{2}$ of 0.18 . Overall, the strengths increased as the $\mathrm{SiO}_{2} / \mathrm{Al}_{2} \mathrm{O}_{3}$ and $\mathrm{Na}_{2} \mathrm{O} / \mathrm{SiO}_{2}$ ratios increased. For example, at similar $\mathrm{SiO}_{2} / \mathrm{Al}_{2} \mathrm{O}_{3}$ of 10 , the results significantly increased from $16.5 \mathrm{MPa}$ to $30 \mathrm{MPa}$ when $\mathrm{Na}_{2} \mathrm{O} / \mathrm{SiO}_{2}$ was enhanced from 0.18 to 0.24 . As previously mentioned, $\mathrm{Na}_{2} \mathrm{O}$ played an important role in stimulating the movement of soluble silicate species ( $\mathrm{Si}-\mathrm{O}-$ ) into the geopolymer gel. This may have improved the inter-particle bonding between the geopolymer gels and unreacted particles, resulting in greater compressive strengths ( Pacheco-Torgal et al., 2008; Robayo-Salazar et al., 2017). Unlike binary $\mathrm{RCBW}+\mathrm{CW}$ and $\mathrm{CTW}+\mathrm{CW}$, the absence of $\mathrm{CW}$ in $\mathrm{RCBW}+\mathrm{CTW}$ binders required high amounts of $\mathrm{Na}_{2} \mathrm{O}\left(\mathrm{Na}^{+}\right)$concentrations to suffice for balancing the high amount of soluble silica species supplied by the sodium silicate.
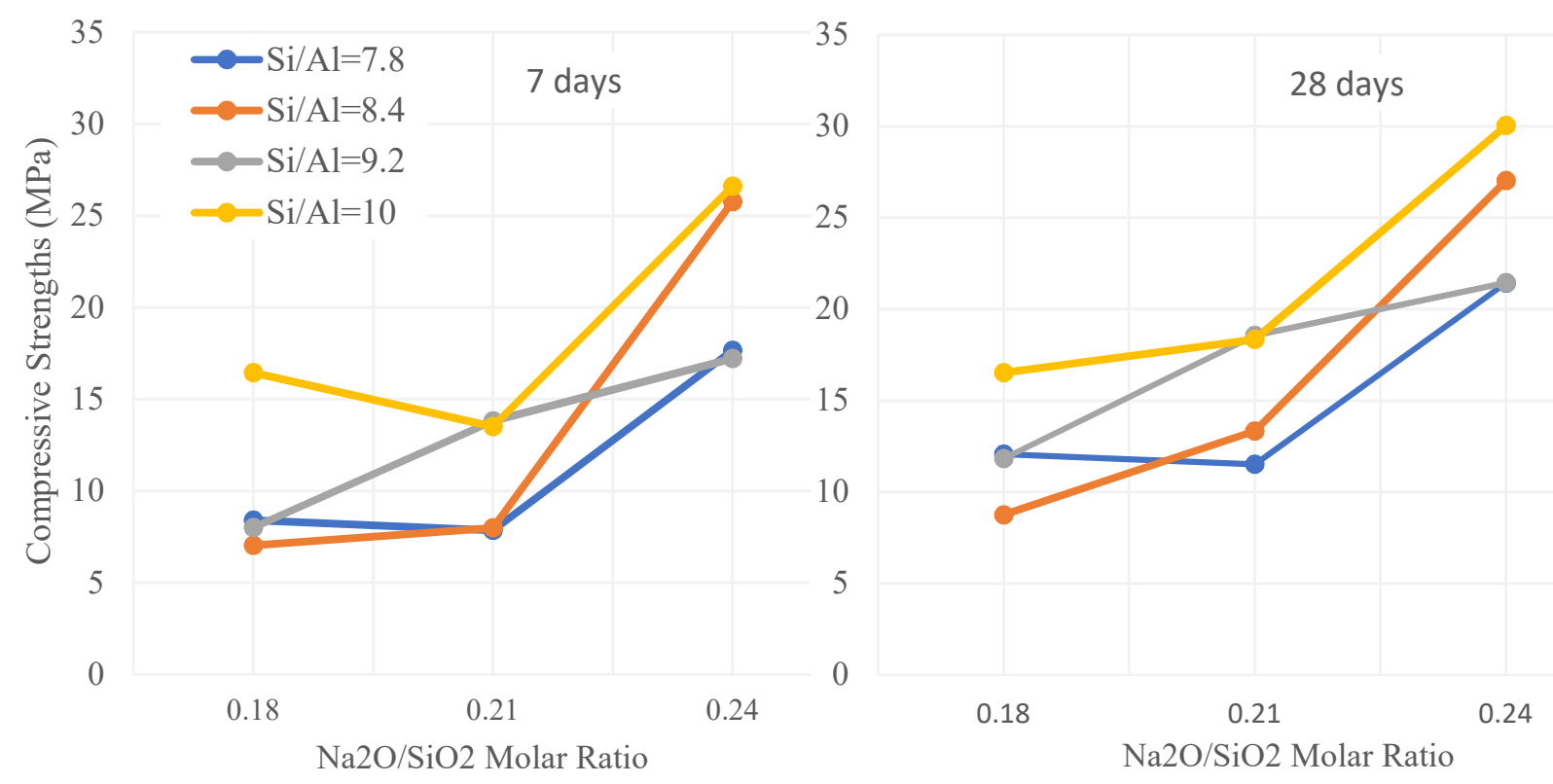

Figure 4.20 Effect of $\mathrm{SiO}_{2} / \mathrm{Al}_{2} \mathrm{O}_{3}$ and $\mathrm{Na}_{2} \mathrm{O} / \mathrm{SiO}_{2}$ ratios on the strengths of binary $\mathrm{RCBW}+\mathrm{CTW}$ pastes

\subsubsection{Mechanical Strengths of Ternary-system Compositions}

The compressive strengths of ternary mixes of $\mathrm{RCBW}+\mathrm{CTW}+\mathrm{CW}$ are presented in Table 4.16. Among all possible combinations, BCT10-10.2-0.18-0.3 with 20\% RCBW, 40\% CTW and 40\% CW presented the higher results of $27.4 \mathrm{MPa}$ and $52.2 \mathrm{MPa}$ at 7 and 28 days respectively. These remarkable results were attained at $\mathrm{SiO}_{2} / \mathrm{Al}_{2} \mathrm{O}_{3}$ and $\mathrm{Na}_{2} \mathrm{O} / \mathrm{SiO}_{2}$ ratios of 10.2 and 0.18 respectively. However, at close 
composition, with the same $\mathrm{SiO}_{2} / \mathrm{Al}_{2} \mathrm{O}_{3}$ of 10.2, BCT11-10.2-0.21-0.3 with $\mathrm{Na}_{2} \mathrm{O} / \mathrm{SiO}_{2}$ of 0.21 presented also the second-best values of $25.2 \mathrm{MPa}$ at 7 days and $38.3 \mathrm{MPa}$ at 28 days of curing. These strengths were the optimum reached for all mono, binary and ternary systems. When considering the percentage of each CDW in the ternary combinations, BCT22- 9.1-0.18-0.30 with 40\% RCBW, 20\% CTW and 40\% CW and BCT29-10.6-0.21-0.30, with 20\% RCBW, 20\% CTW and 60\% CW showed the second and third peak results compared to other mixes with various CDW contents. Interestingly, the amount of CW was $40 \%$ or $60 \%$ in all optimized ternary compositions, which confirms the previous discussions about the strong effect of CW contents on improving the mechanical performance of CDW-based geopolymers. Figure 4.21 shows the effect of $\mathrm{SiO}_{2} / \mathrm{Al}_{2} \mathrm{O}_{3}$ and $\mathrm{Na}_{2} \mathrm{O} / \mathrm{SiO}_{2}$ molar ratios on the strengths of ternary $\mathrm{RCBW}+\mathrm{CTW}+\mathrm{CW}$ geopolymers. In this Figure, the results were divided based on the key material used to design each group, which was RCBW for mixes between BCT1 and BCT12 (Si/Al=7.6, 8.4, 9.2 and 10.2), CTW for BCT13 to BCT24 (Si/Al=10.6, 10, 9.7, and 9.1) and CW for BCT25 to BCT36 ( $\mathrm{Si} / \mathrm{Al}=12$, 10.6, 9.8 and 9). The combinations with the same RCBW, CTW and CW amounts ( $\mathrm{Si} / \mathrm{Al}=9.4)$ were presented with those of CW-key material mixes. Although, in a similar key-material-group of RCBW (between BCT1 and BCT12), the strengths increased as the $\mathrm{SiO}_{2} / \mathrm{Al}_{2} \mathrm{O}_{3}$ molar ratio increased and for CTW-group, between BCT13 and BCT24, and the opposite trend can be reported, there was no general trend of change valid for all ternary combinations. For example, in equivalent $\mathrm{Na}_{2} \mathrm{O} / \mathrm{SiO}_{2}$ ratio of 0.18 , the compressive strength for compositions with $\mathrm{SiO}_{2} / \mathrm{Al}_{2} \mathrm{O}_{3}=7.6,8.4,10.2,10.6$ and 12 were 6.8, 20.3, 52.2, 9.6 and 30.8 MPa respectively. However, in most cases, the results reduced from a $\mathrm{Na}_{2} \mathrm{O} / \mathrm{SiO}_{2}$ ratio of 0.18 to 0.24 . The reason for this phenomenon is related to the percentage of $\mathrm{CW}$ in the ternary geopolymer binders and associated high $\mathrm{CaO}$ content. Thus, the amount of $\mathrm{Na}^{+}$needed to balance the system was reduced with an increased $\mathrm{CW}$ amount because of the probable formation of N-A-S-H and $\mathrm{C}-\mathrm{A}-\mathrm{S}-\mathrm{H}$ as reaction products. Therefore, the results decreased beyond a general threshold of $\mathrm{Na}_{2} \mathrm{O} / \mathrm{SiO}_{2}$ and specified $\mathrm{SiO}_{2} / \mathrm{Al}_{2} \mathrm{O}_{3}$ ratio. Also, at high $\mathrm{Na}_{2} \mathrm{O} / \mathrm{SiO}_{2}$, a faster poly-condensation of reaction products is expected. This may not allow the gels to fully geopolymerize, resulting in reduced compressive strengths (Allahverdi \& Kani, 2013). 
Table 4.14 Compressive strengths of ternary-system RCBW+CTW $+\mathrm{CW}$ binders

\begin{tabular}{|c|c|c|c|}
\hline & \multirow[t]{2}{*}{ Composition Code } & \multicolumn{2}{|c|}{ Compressive Strength (MPa) } \\
\hline No. & & 7 Days & 28 Days \\
\hline 1 & ВСТ1-7.6-0.18-0.30 & 4.0 & 6.8 \\
\hline 2 & ВСТ2-7.6-0.21-0.30 & 8.8 & 5.2 \\
\hline 3 & ВСТ3-7.6-0.24-0.30 & 6.5 & 4.6 \\
\hline 4 & BCT4-8.4-0.18-0.30 & 15.5 & 20.3 \\
\hline 5 & ВСТ5-8.4-0.21-0.30 & 9.8 & 15.7 \\
\hline 6 & ВСТ6-8.4-0.24-0.30 & 8.1 & 10.5 \\
\hline 7 & ВСТ7-9.2-0.18-0.30 & 19.1 & 25.9 \\
\hline 8 & ВСТ8-9.2-0.21-0.30 & 23.2 & 24.9 \\
\hline 9 & ВСТ9-9.2-0.24-0.30 & 13.2 & 21.5 \\
\hline 10 & BCT10-10.2-0.18-0.30 & 27.4 & 52.2 \\
\hline 11 & BCT11-10.2-0.21-0.30 & 25.2 & 38.3 \\
\hline 12 & ВCT12-10.2-0.24-0.30 & 19.3 & 27.9 \\
\hline 13 & BCT13-10.6-0.18-0.30 & 8.6 & 9.6 \\
\hline 14 & BCT14-10.6-0.21-0.30 & 8.8 & 10.2 \\
\hline 15 & ВCT15-10.6-0.24-0.30 & 9.9 & 11.7 \\
\hline 16 & ВCT16-10-0.18-0.30 & 15.3 & 23.4 \\
\hline 17 & ВСТ17-10-0.21-0.30 & 7.6 & 11.1 \\
\hline 18 & BCT18-10-0.24-0.30 & 6.9 & 9.5 \\
\hline 19 & ВСТ19-9.7-0.18-0.30 & 18.6 & 29.7 \\
\hline 20 & ВСТ20-9.7-0.21-0.30 & 17.3 & 25.9 \\
\hline 21 & ВСТ21-9.7-0.24-0.30 & 8.6 & 13.6 \\
\hline 22 & ВСТ22-9.1-0.18-0.30 & 19.5 & 38.1 \\
\hline 23 & ВСТ23-9.1-0.21-0.30 & 18.3 & 27.0 \\
\hline 24 & ВСТ24-9.1-0.24-0.30 & 16.3 & 21.2 \\
\hline 25 & BCT25-12-0.18-0.30 & 11.9 & 30.8 \\
\hline 26 & ВCT26-12-0.21-0.30 & 15.2 & 36.6 \\
\hline 27 & ВСТ27-12-0.24-0.30 & 13.9 & 27.3 \\
\hline 28 & ВСТ28-10.6-0.18-0.30 & 19.5 & 34.4 \\
\hline 29 & ВСТ29-10.6-0.21-0.30 & 22.6 & 37.8 \\
\hline 30 & ВСТ30-10.6-0.24-0.30 & 17.8 & 31.8 \\
\hline 31 & ВСТ31-9.8-0.18-0.30 & 17.7 & 33.9 \\
\hline 32 & ВСТ32-9.8-0.21-0.30 & 17.9 & 23.8 \\
\hline 33 & ВСТ33-9.8-0.24-0.30 & 17.5 & 28.6 \\
\hline 34 & ВСТ34-9-0.18-0.30 & 10.9 & 19.3 \\
\hline 35 & ВСТ35-9-0.21-0.30 & 4.2 & 9.8 \\
\hline 36 & ВСТ36-9-0.24-0.30 & 4.9 & 6.5 \\
\hline 37 & ВСТ37-9.4-0.18-0.30 & 15.8 & 35.4 \\
\hline 38 & ВСТ38-9.4-0.18-0.30 & 17.2 & 24.9 \\
\hline 39 & ВСТ39-9.4-0.18-0.30 & 19.9 & 23.0 \\
\hline
\end{tabular}



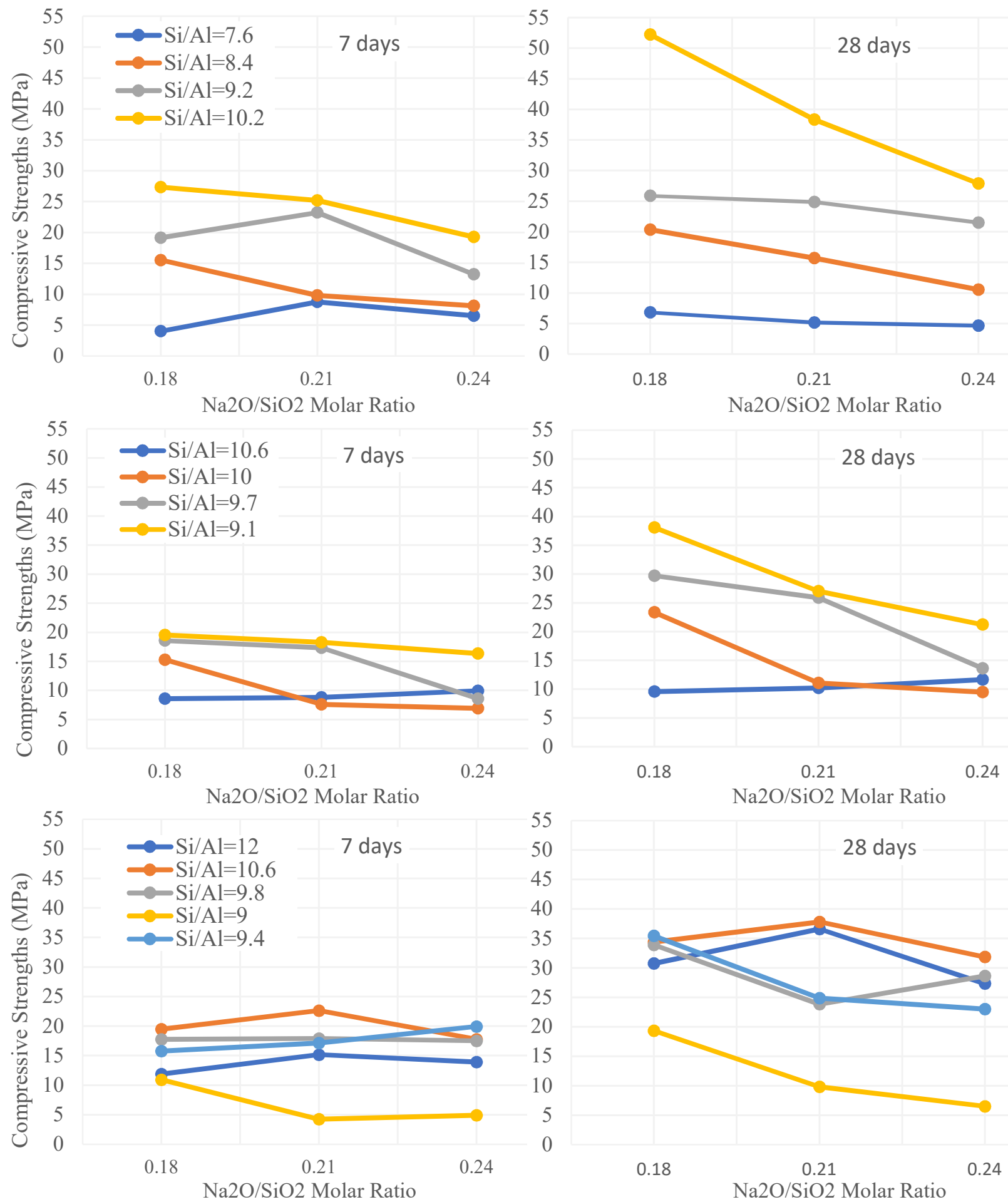

Figure 4.21 Effect of $\mathrm{SiO}_{2} / \mathrm{Al}_{2} \mathrm{O}_{3}$ and $\mathrm{Na}_{2} \mathrm{O} / \mathrm{SiO}_{2}$ on the strengths of ternary $\mathrm{RCBW}+\mathrm{CTW}+\mathrm{CW}$ pastes 


\subsection{Effect of High Temperature Curing on Mechanical Strengths}

Four compositions with optimal strengths at room temperature were selected from each mono, binary and ternary system to study the effect of high temperature curing on the mechanical properties of developed CDW-based geopolymers. These mixes were subjected to different 24-hour temperature curing of $50{ }^{\circ} \mathrm{C}, 75{ }^{\circ} \mathrm{C}$ and $100{ }^{\circ} \mathrm{C}$ directly after molding. Subsequently, they were removed from the controlled temperature chamber and kept at an ambient curing environment until the age of testing. The compressive strengths completed at high temperature curing were compared with those of room curing results presented in the previous section for better understanding of the relationship between curing temperature and developed mechanical strengths.

\subsubsection{Effect of High Temperature Curing on Mono-system Geopolymers}

\section{- Effect of High Temperature Curing on Mono-system RCBW Geopolymers}

The four optimized compositions selected for mono- RCBW system were B-7.1-0.22-0.3, B-7.1-0.240.3, B-7.3-0.22-0.3 and B-7.3-0.24-0.3 which reached strengths of 32.4, 36.5, 24.4 and 30.2 respectively, at ambient temperature curing. Figure 4.22 presents the relation between the high temperature curing and the 7 and 28-day compressive strengths of these mixes.

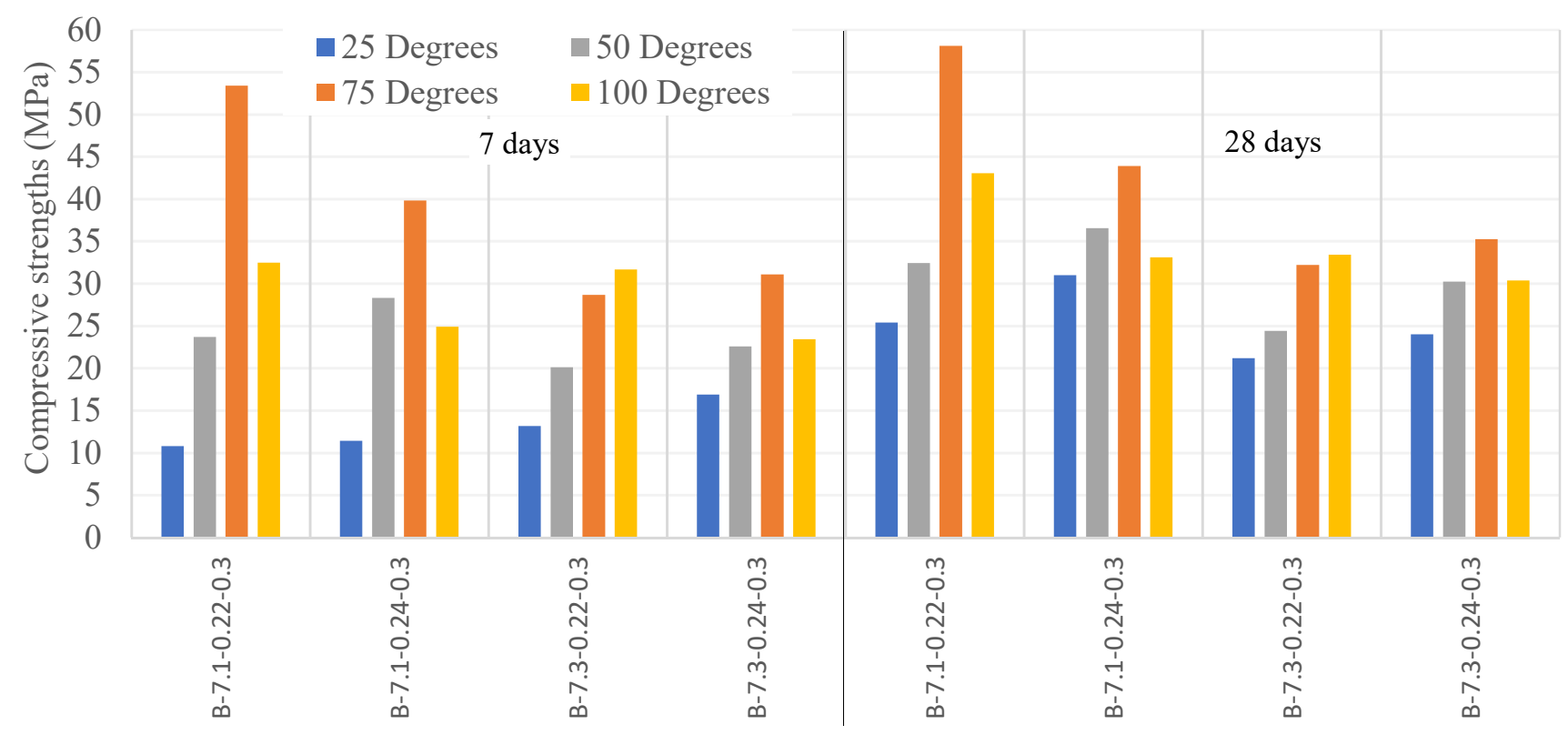

Figure 4.22 Effect of high temperature curing on compressive strengths of mono RCBW geopolymers

From Figure 4.22, except for mix B-7.3-0.22-0.3 in which the result increased up to $100^{\circ} \mathrm{C}$ of curing temperature, the compressive strengths of mono RCBW binders increased as the curing temperature 
increased from $25^{\circ} \mathrm{C}$ to $75^{\circ} \mathrm{C}$ then reduced at $100^{\circ} \mathrm{C}$. The higher strengths were registered for mix B-7.10.22-0.3 with optimum results of 53.4 MPa and 58.1 MPa at 7- and 28-days respectively. At temperature curing of/or higher than $50^{\circ} \mathrm{C}$, mix B-7.1-0.24-0.3, which presented the optimum strengths at room temperature showed lower performance than that of B-7.1-0.22-0.3. This may explain why the optimized strength combinations defined at ambient temperature are not necessarily the same at high temperature curing, though the optimal strength registered at room curing $(31 \mathrm{MPa})$ significantly increased when using a temperature curing of $75^{\circ} \mathrm{C}(43.9 \mathrm{MPa})$. Also, considering the ambient temperature result of 10.8 $\mathrm{MPa}$ at 7 days and $25.4 \mathrm{MPa}$ at 28 days, significant improvements of around $400 \%$ and $129 \%$ can be calculated respectively, for mix B-7.3-0.22-0.3. This important effect of high temperature curing, especially on early age strengths of optimized mono-RCBW geopolymers, was already reported in literature. According to Robayo et al., (2016), the geopolymeric reaction enhances and the geopolymerization processes accelerate with increased temperature curing, mostly because the accelerated kinetics of dissolution and polycondensation stages. However, this statement is not valid for each high temperature curing as the compressive strengths at $100^{\circ} \mathrm{C}$ were lower compared to those of $75^{\circ} \mathrm{C}$ curing. These results agreed with those of Komnitsas et al., (2015) and Robayo et al., (2016) who noticed reduced compressive strengths between $80^{\circ} \mathrm{C}$ and $90^{\circ} \mathrm{C}$ temperature curing. According to these authors, the reason for the reduced performance at temperatures higher than $80^{\circ} \mathrm{C}$ is maybe due to the formation of microcracks, contractions and rapid dihydroxylation in the geopolymer gels.

\section{- Effect of High Temperature Curing on Mono-system CTW Geopolymers}

The effect of high temperature curing on the optimized compositions of mono- CTW system is presented in Figure 4.23. The mixes selected for mono- CTW geopolymers were T-10.9-0.18-0.30, T-10.9-0.200.30, T-11.1-0.20-0.30 and T-11.1-0.22-0.30 which showed strengths of 28.7, 27.6, 31.8 and 29.6 MPa respectively, at 28 days of ambient curing environment. Except for specimens T-10.9-0.18-0.30 at 28 days and those of T-10.9-0.20-0.30 at 7 and 28 days which displayed optimum strength increments at $75^{\circ} \mathrm{C}$ curing, all other results improved with increased curing temperature up to $100^{\circ} \mathrm{C} .50^{\circ} \mathrm{C}$ curing temperature was not able to fully activate the geopolymeric reaction, though results were also improved compared to room temperature curing. The higher strengths at 7 and 28 days were attained for mix T10.9-0.18-0.3 with $38.1 \mathrm{MPa}$ at $100^{\circ} \mathrm{C}$ and $42 \mathrm{MPa}$ at $75^{\circ} \mathrm{C}$ respectively. These represent increments of around $80 \%$ and $46 \%$ compared to its room temperature results of $21.1 \mathrm{MPa}$ and 28.7 respectively. The high enhancement registered for 7-day compared to 28-day results was linked to the rapid and enhanced geopolymerization of reaction products which are expected to be mostly N-A-S-H (Komnitsas et al., 
2015). According to Dadsetan et al. (2019), at high temperature curing, greater amounts of soluble silica can be consumed by aluminosilicate molecules, leading in denser microstructure and better compressive strength. As for mono-RCBW results, the optimum strength at high temperature was achieved for a mono CTW-geopolymer composition different than that of the ambient temperature curing. This confirm that the high curing temperature can affect the pattern of the threshold level of both $\mathrm{SiO}_{2} / \mathrm{Al}_{2} \mathrm{O}_{3}$ and $\mathrm{Na}_{2} \mathrm{O} / \mathrm{SiO}_{2}$ ratios. At high temperature, the optimum strengths were attained at $\mathrm{SiO}_{2} / \mathrm{Al}_{2} \mathrm{O}_{3}$ and $\mathrm{Na}_{2} \mathrm{O} / \mathrm{SiO}_{2}$ values lower than those of ambient curing temperature.

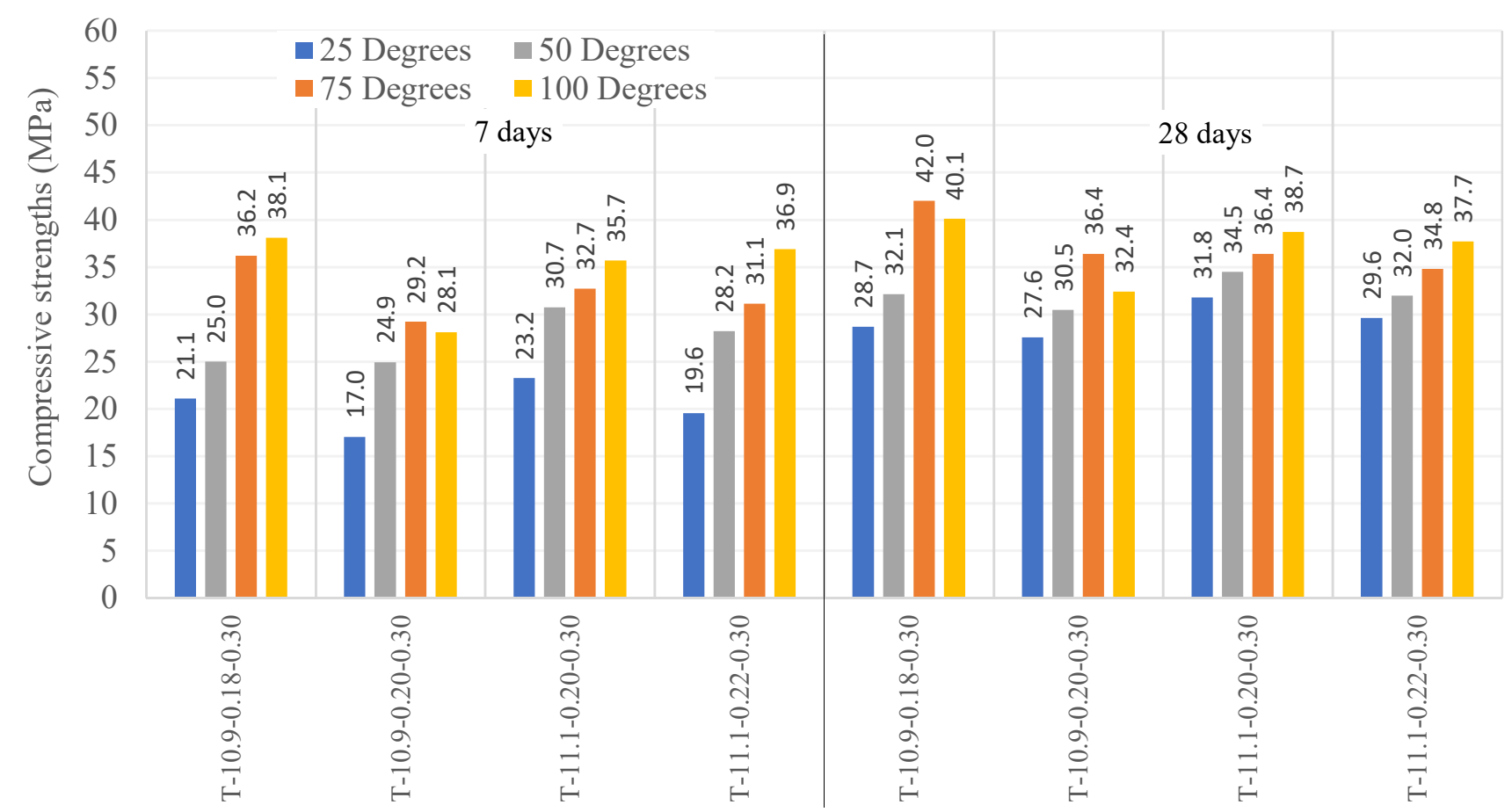

Figure 4.23 Effect of high temperature curing on compressive strengths of mono CTW geopolymers

\section{- Effect of High Temperature Curing on Mono-system CW Geopolymers}

Four compositions of mono $\mathrm{CW}$ geopolymer binders were selected based on the higher compressive strengths of room temperature curing. These mixes were $\mathrm{CW}-12-0.20-0.30, \mathrm{CW}-12-0.23-0.30, \mathrm{CW}-12.9$ 0.2-0.30 and CW-12.9-0.23-0.30 which presented strengths of 20.8, 17.2, 21.1 and 23.4 MPa respectively, at ambient curing environment. Figure 4.24 chows the effect of $24 \mathrm{~h}$ initial curing temperatures of and $50^{\circ} \mathrm{C}, 75^{\circ} \mathrm{C}$ and $100^{\circ} \mathrm{C}$ on the mechanical performance of these optimized compositions. As can be seen in Figure 4.24, the compressive strengths of all compositions increased with enhanced temperature curing up to $100^{\circ} \mathrm{C}$. The optimum strengths were reached for combinations CW-12.9-0.23-0.3 with values of 31.9 at 7 days and 37.1 MPa at 28 days. These represent increments of $100 \%$ and $80.5 \%$ at 7 and 28 days between results obtained at $100^{\circ} \mathrm{C}$ and those of room temperature 
curing. These results are in agreement with (Komnitsas et al., 2015; Robayo-Salazar et al., 2017; Robayo et al., 2016) who achieved the higher compressive strengths for concrete wastes-based geopolymer binders at temperatures of above $90{ }^{\circ} \mathrm{C}$. However, these authors presented results ranging from 20 to $30 \mathrm{MPa}$ which are very low compared to the optimized strengths reached in this study at the same high temperature curing of more $90{ }^{\circ} \mathrm{C}$ (Komnitsas et al., 2015). Unlike the reactions products expected from mono-RCBW and CTW geopolymers which were shown to be mostly N-A-S-H crystals, the presence of high amount of $\mathrm{CaO}$ in $\mathrm{CW}$ maybe resulted in new reaction components tend to have a structure near $\mathrm{C}$ A-S-H rather N-A-S-H (Robayo-Salazar et al., 2017). As N-A-S-H, the reaction kinetics of C-A-S-H seems also influenced by the temperature of curing; however, the optimum temperature for greater C-AS-H formation was higher than that of N-A-S-H.

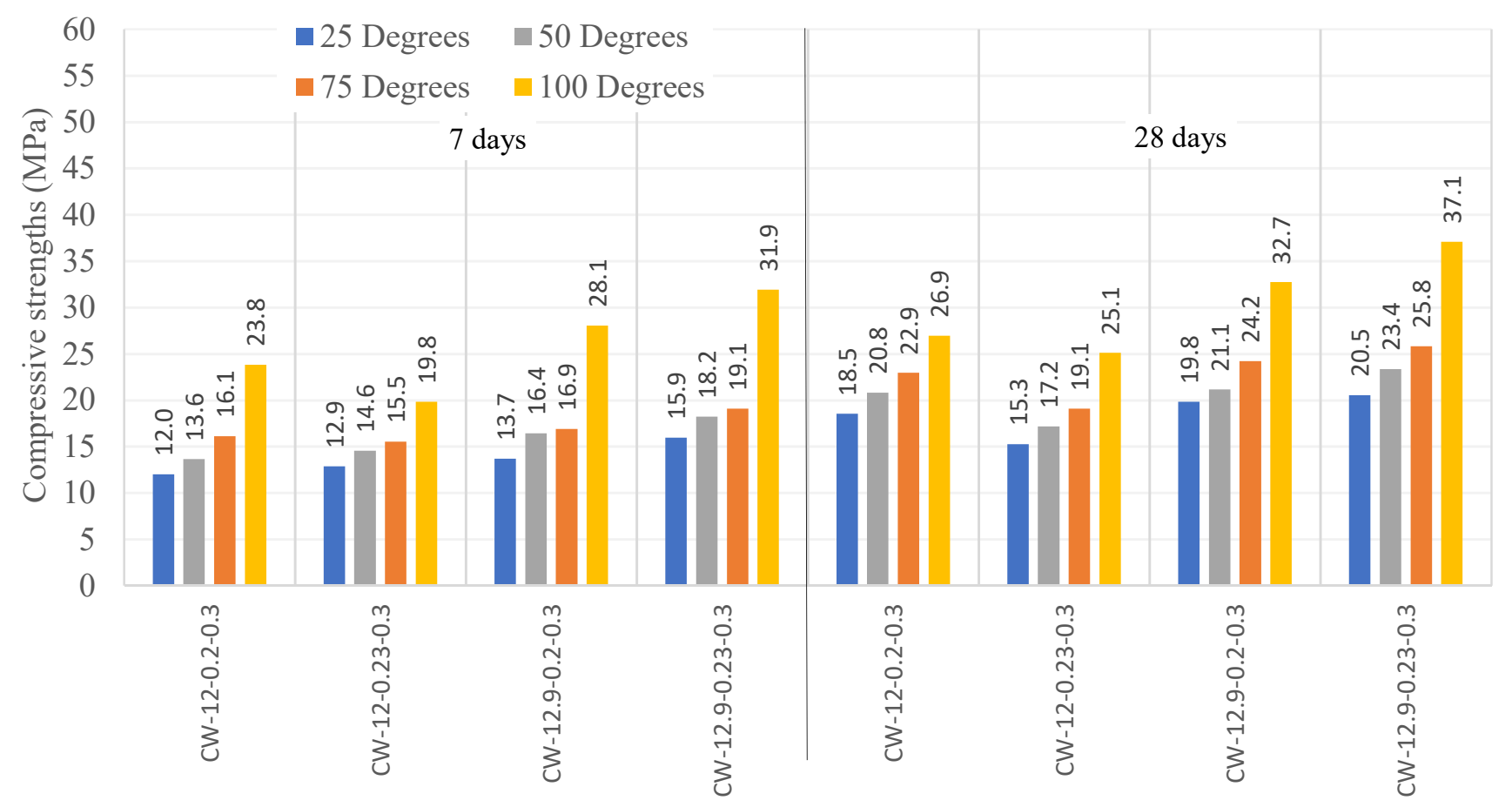

Figure 4.24 Effect of high temperature curing on compressive strengths of mono CW geopolymers

\subsubsection{Effect of High Temperature Curing on Binary-system Geopolymers}

\section{- Effect of High Temperature Curing on Binary-system RCBW+CW Geopolymers}

At room temperature curing, the four compositions of binary-system RCBW $+\mathrm{CW}$ geopolymers which presented the maximum strengths of 43.7, 28.4, 35.4 and 25.9 were BC-8.4-0.18-0.30, BC-8.4-0.24-0.30, BC-9.0-0.24-0.30 and BC-10.5-0.18-0.30 respectively. These mixes were selected to be subjected to an initial high temperature curing of $24 \mathrm{~h}$. The results of $50^{\circ} \mathrm{C}, 75^{\circ} \mathrm{C}$ and $100^{\circ} \mathrm{C}$ curing temperatures of 
binary- RCBW+CW pastes are presented in Figure 4.25.

At all curing ages, the four mixes showed important compressive strength increments with increased curing temperature up to $100^{\circ} \mathrm{C}$. This demonstrates that applying a high temperature curing of up to $100^{\circ} \mathrm{C}$ can improve substantially the optimal binary-system $\mathrm{RCBW}+\mathrm{CW}$ geopolymers without compromising their structural network from developing thermal shrinkage microcracks or losing their bonded water.

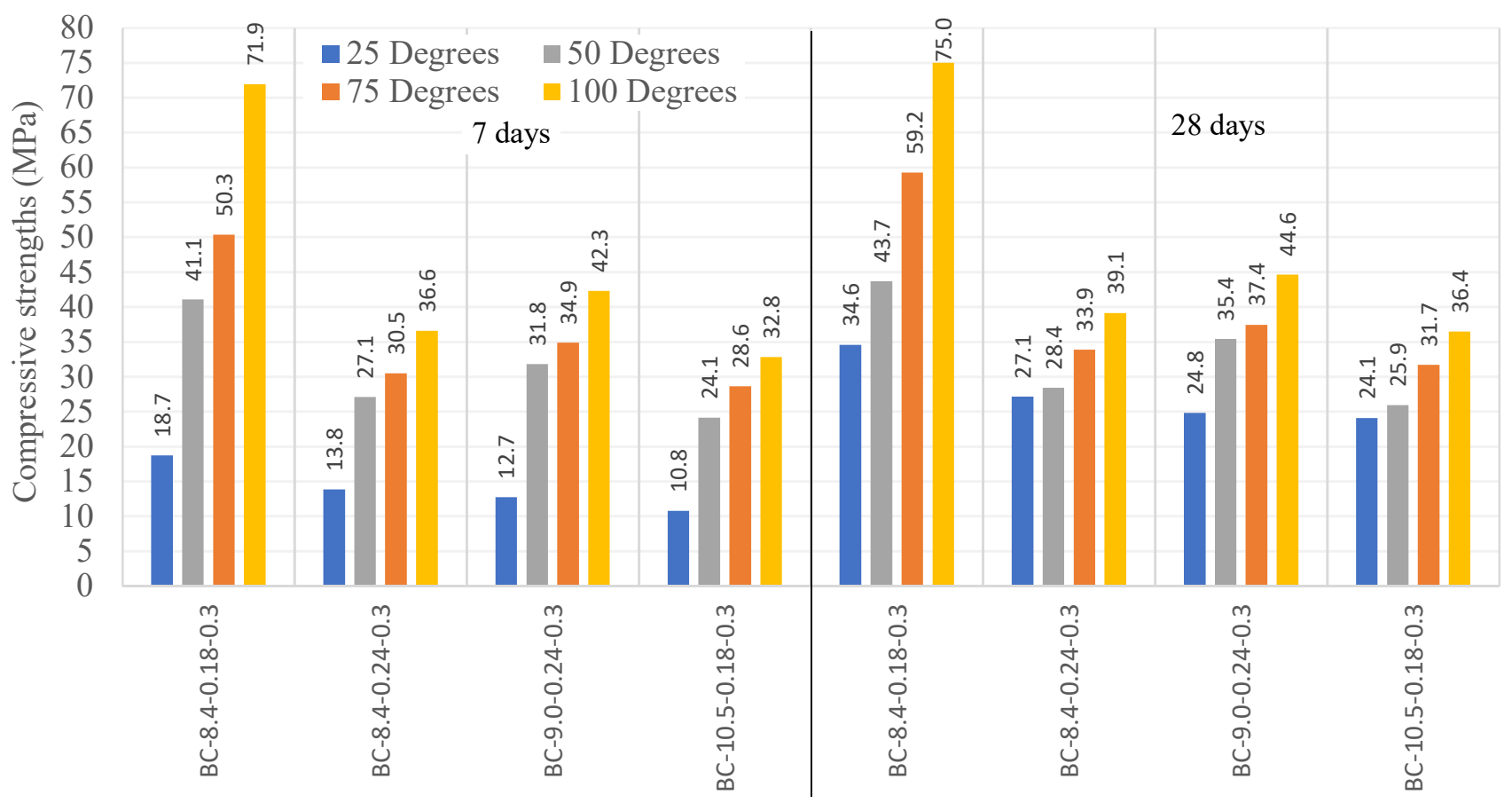

Figure 4.25 Effect of high temperature curing on strengths of binary RCBW+CW geopolymers

The highest strengths were achieved for specimens of BC-8.4-0.18-0.30 with $75 \mathrm{MPa}$ at 7 and 28 days respectively. These represent very significant improvements of almost $285 \%$ and $301 \%$ compared to the optimized strengths achieved at room temperature curing. However, most enhancements were in the first 7 days of curing, with reduced changes between 7 and 28 days. This prove again the high acceleration level of geopolymeric processes at higher temperature curing, which can be attributed to their faster trend of dissolution and polycondensation stages. In addition, in the binary RCBW+CW mixes, the possible simultaneous formation of both N-A-S-H and C-A-S-H in their systems may led to the development of strong three-dimensional (3D) bonds at high temperature curing (Nagral, 2014).

\section{- Effect of High Temperature Curing on Binary-system CTW+CW Geopolymers}

The combinations selected for binary-CTW $+\mathrm{CW}$ geopolymers were TC-12.0-0.18-0.30, TC-12.0-0.240.30, TC-12.3-0.18-0.30 and TC-12.3-0.21-0.30 with compressive strengths of 33.2, 37.6, 50.1 and 31.9 
$\mathrm{MPa}$ at room temperature curing. Figure 4.26 shows the 7 and 28-day compressive strengths of binary $\mathrm{CTW}+\mathrm{CW}$ binders cured initially during $24 \mathrm{~h}$ at $25,50,75$ and $100^{\circ} \mathrm{C}$. At 7 and 28 days, all strengths increased with increased temperature curing up to $100^{\circ} \mathrm{C}$. The optimum compressive strengths reached were 80.9 and $88.8 \mathrm{MPa}$ respectively, developed for the same optimized composition at room temperature curing that is TC-12.3-0.18-0.30. At maximum temperature of $100^{\circ} \mathrm{C}$, the results of mix TC12.3-0.18-0.30 displayed significant enhancements of $431 \%$ and $482 \%$ at 7 and 28 days respectively. Also, remarkable strengths were reached for all other three compositions where values of 62.4, 59.8 and 54.4 were registered for TC-12.0-0.18-0.30, TC-12.0-0.24-0.30 and TC-12.3-0.21-0.30 respectively, at 28 days. Thus, the general trend of enhancements for binary $\mathrm{CTW}+\mathrm{CW}$ compositions was even higher than that of RCBW-CW binders which showed one single composition at a range of strength higher than $50 \mathrm{MPa}$ at the same age and optimal temperature of curing.

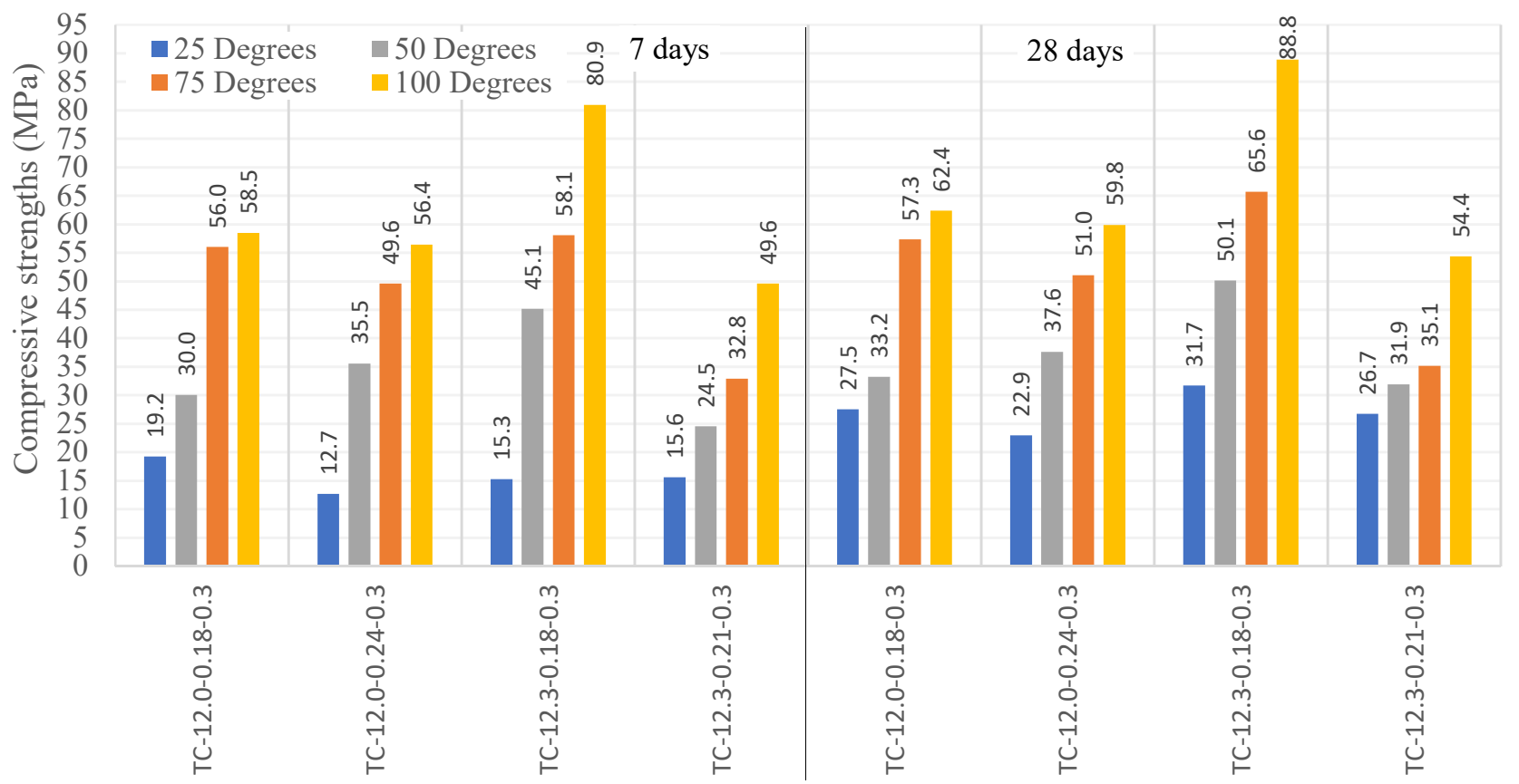

Figure 4.26 Effect of high temperature curing on strengths of binary $\mathrm{CTW}+\mathrm{CW}$ geopolymers

\section{- Effect of High Temperature Curing on Binary-system RCBW+CTW Geopolymers}

The four compositions of binary RCBW+CTW pastes selected based on their higher results at room temperature curing were BT-8.4-0.24-0.30, BT-9.2-0.24-0.28, BT-10.0-0.21-0.30 and BT-10.0-0.240.30 with 28-day strengths of 32.4, 28.8, 24.1 and 36.9 MPa respectively. The effect of an initial 24h curing temperature of $50{ }^{\circ} \mathrm{C}, 75^{\circ} \mathrm{C}$ and $100{ }^{\circ} \mathrm{C}$ on the mechanical performance of these mixes is presented in Figure 4.27. At both 7 and 28-day of age, all binary RCBW+CTW binders presented enhanced 
strengths with increased temperature curing until $100^{\circ} \mathrm{C}$. BT-10-0.24-0.30, which showed the optimal compressive strengths at ambient curing, developed the higher results at 50, 75 and $100^{\circ} \mathrm{C}$. At maximum curing temperature of $100^{\circ} \mathrm{C}$, the results determined for this paste combination were 49.2 and $52.3 \mathrm{MPa}$ at 7 and 28 days, which represent improvements of 84.8 and $96.6 \%$ respectively, compared to room curing strengths. When comparing the binary RCBW $+\mathrm{CTW}$ with that of $\mathrm{RCBW}+\mathrm{CW}$ and $\mathrm{CTW}+\mathrm{CW}$, $\mathrm{RCBW}+\mathrm{CTW}$ system showed different strength increment patterns with a significantly lower trend compared to the two other systems. As mentioned before, geopolymer reaction products of binary binders synthesized without $\mathrm{CW}$ powder are more likely near N-A-S-H composition rather than a consolidated $\mathrm{N}-\mathrm{A}-\mathrm{S}-\mathrm{H} / \mathrm{C}-\mathrm{A}-\mathrm{S}-\mathrm{H}$ formation expected for CW-based binary geopolymers. This may have created an unbalanced geopolymer network with over saturated silica content, resulting in lower amount of reaction products compared to that of binary $\mathrm{RCBW}+\mathrm{CW}$ and $\mathrm{CTW}+\mathrm{CW}$ cured at the same temperature.

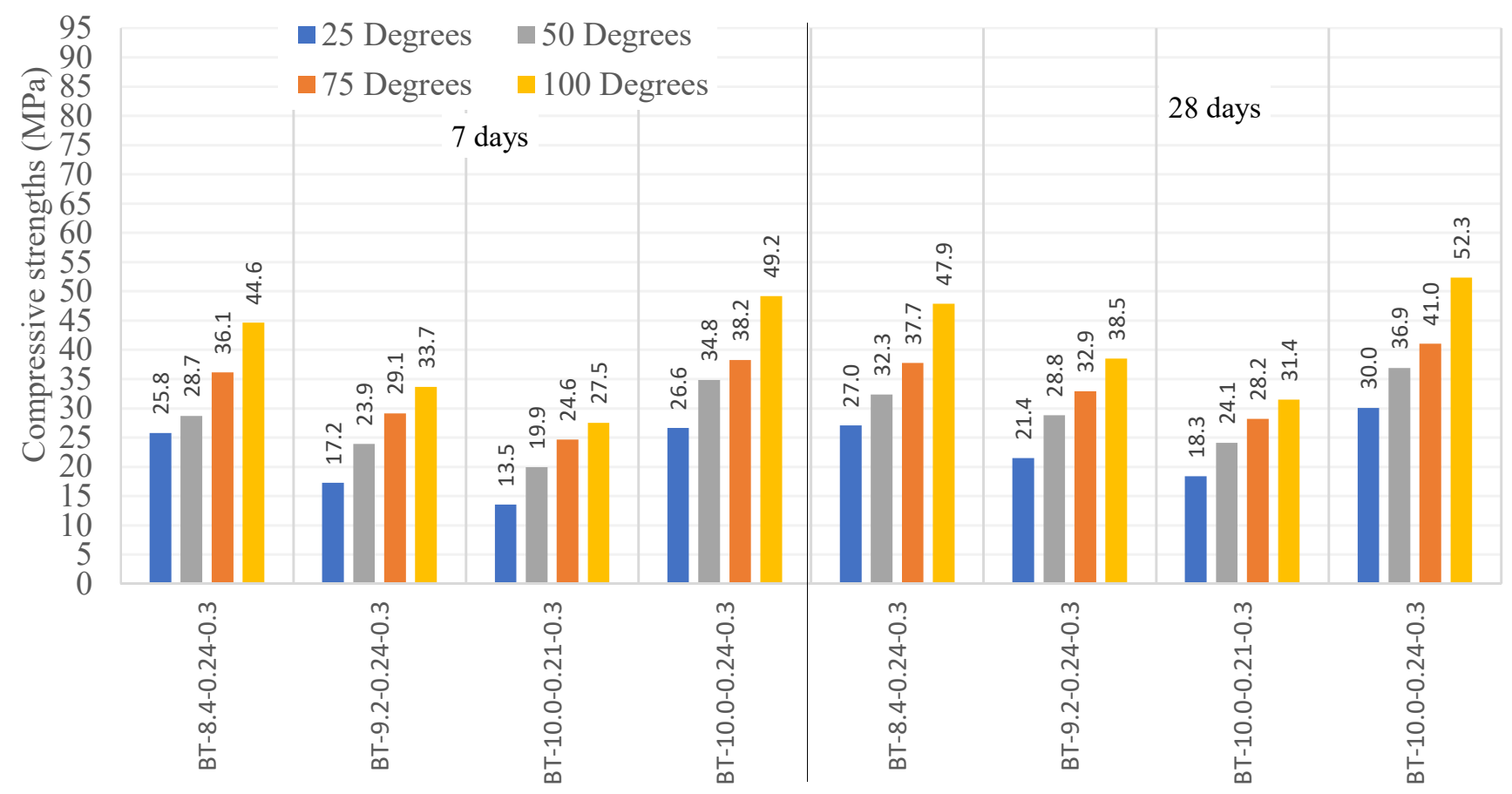

Figure 4.27 Effect of high temperature curing on strengths of binary RCBW+CTW geopolymers

\subsubsection{Effect of High Temperature Curing on Ternary-system Geopolymers}

BCT-10.2-0.18-0.30, ВCT-10.2-0.21-0.30, ВCT-9.2-0.21-0.30 and BCT-10.6-0.21-0.30 with 57.71, 39.9, 35.3 and 38.4 MPa were selected to be subject to elevated 24h initial temperature curing, based on their optimum strengths registered at ambient curing. The results of $25,50,75$ and $100^{\circ} \mathrm{C}$ curing temperatures of these ternary $\mathrm{RCBW}+\mathrm{CTW}+\mathrm{CW}$ mixes are presented in Figure 4.28. From this figure, the 7 and 28-day results increased for all compositions as the curing temperature increased from $25^{\circ} \mathrm{C}$ to 
$100^{\circ} \mathrm{C}$. The optimal compressive strength at 7-day curing age was $62.9 \mathrm{MPa}$ and that at 28-day was 65.1 $\mathrm{MPa}$, attained for BCT-10.2-0.18-0.30 that presented the higher results at room curing. This mix displayed strength increments of $130 \%$ and $25 \%$ at 7 and 28 days respectively, between ambient and 100 ${ }^{\circ} \mathrm{C}$ temperature curing. This explain that the optimized ternary mix attained its most important phase of geopolymerization at early age of curing because the accelerated reaction processes resulted from the high temperature curing. As for room environment results, the strengths at higher temperature curing seem influenced by $\mathrm{SiO}_{2} / \mathrm{Al}_{2} \mathrm{O}_{3}$ and $\mathrm{Na}_{2} \mathrm{O} / \mathrm{SiO}_{2}$ ratios of each composition. However, at high temperature curing, the change in $\mathrm{Na}_{2} \mathrm{O} / \mathrm{SiO}_{2}$ presented greater influence in the trend of results than $\mathrm{SiO}_{2} / \mathrm{Al}_{2} \mathrm{O}_{3}$ ratio. This can be noticed from the high reductions recorded between BCT-10.2-0.18-0.3 and BCT-10.2-0.210.3, with the same $\mathrm{SiO}_{2} / \mathrm{Al}_{2} \mathrm{O}_{3}$ of 10.2, and the equivalent strengths registered BCT-9.2-0.21-0.30 and BCT-10.6-0.21-0.30, with the same $\mathrm{Na}_{2} \mathrm{O} / \mathrm{SiO}_{2}$ ratio. The presence of $\mathrm{CW}$ in ternary mixes provided new supplementary sources for reaction products leading to consuming most of the available silica and sodium contents, especially at high temperature environment where the reaction was shown to accelerate (Dadsetan et al. 2019). However, the over presence of sodium maybe created a porous network by hindering the movement of silica and bonding more internal water. Although, the high curing temperatures are intended to facilitate the contact between the remaining silica and the unreacted precursor powder, they likely also to create higher porosity and shrinkage because the consumed/evaporated water. This statement was supported by the very small differences noticed at 28 days between all the temperature curing results of mix BCT-10.6-0.21-0.3, with $\mathrm{SiO}_{2} / \mathrm{Al}_{2} \mathrm{O}_{3}$ of 10.6. 


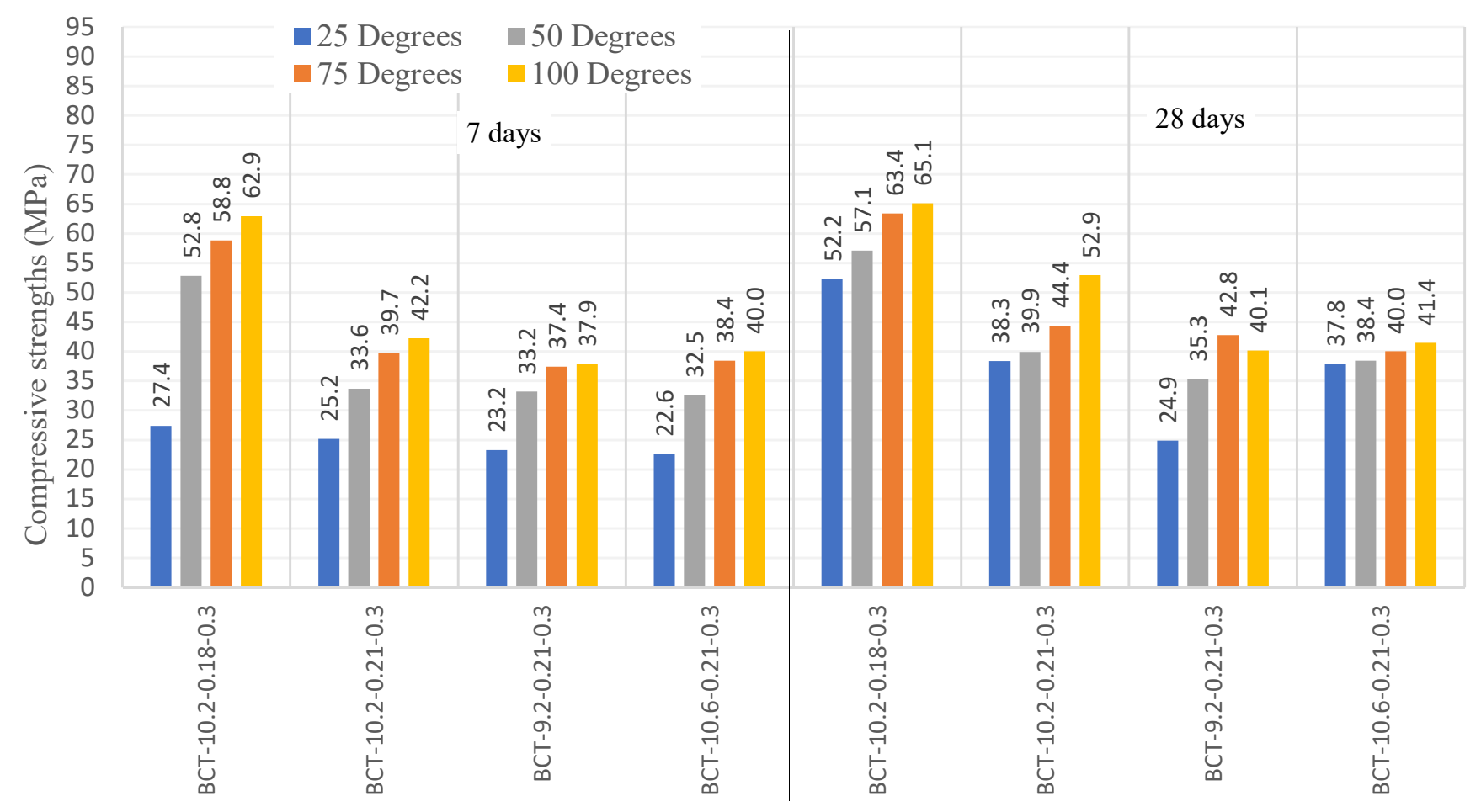

Figure 4.28 Effect of high temperature curing on strengths of ternary RCBW $+\mathrm{CTW}+\mathrm{CW}$ geopolymers

\subsection{Effect of Adding Supplementary Cementitious Materials (SCMs) into CDW-based Geopolymers}

The utilization of industrial by-products as aluminosilicate sources for development of geopolymer materials has two-fold benefits; first, production of recycled geopolymers with low energy consumption and reduced greenhouse gases emission, and second the reutilization of industrial wastes to reduce the consumption of virgin natural materials. Supplementary cementitious materials such as fly ash (class C and F), metakaolin (MK) and granulated blast furnace slag (GBFS) have been widely studied for development of geopolymer binders, mortars and concretes. However, further investigations are warranted to comprehensively investigate the effect of adding some SCMs into different mono, binary and ternary-systems based CDW geopolymers. This section presents the effect of four commonly used SCMs, which are FA-C, FA-F, GBFS and MK, on the compressive strengths of the optimized compositions of mono, binary and ternary CDW- binders developed at room temperature curing. All SCM contents were gradually replaced by CDW amounts at $15 \%, 30 \%$ and $45 \%$ in the maximum strength composition of each system. All specimens were fully cured and ambient temperature curing to separate the effect of SCMs and that of high temperature curing. 


\subsection{1- Effect of the Addition of SCMs on the Strengths of Mono-system Geopolymers}

\section{- Effect of the Addition of SCMs on the Strengths of Mono-system RCBW Geopolymers}

The control combination selected for this investigation was for B-7.1-0.24-0.3, which presented the optimal strengths 11.4 and $31 \mathrm{MPa}$ at 7 and 28 days of room temperature (section 4.4). The new mix proportions and their related compressive strengths resulted from the addition of $15 \%, 30 \%$ and $45 \%$ FA-C, FA-F, MK and GBBS into the optimized mono-RCBW geopolymer mix, presented in Table 4.17. Also, the effect of different SCM content on the strengths of control mono-RCBW mix is presented in Figure 4.29.

Only BFAC-5.7-0.24-0.30-FAC45 with 45\% FA-C replacement by RCBW presented increased strengths compared to the results achieved for control mix B-7.1-0.24-0.30 at both 7 and 28 days. Although the addition of MK in mix BMK-4.2-0.24-0.30-MK45 and that of GGBS in BGBFS-7.45-0.24-0.30-S30 also presented improvements of $13.2 \%$ and $140 \%$ at 7 days, their results at 28 days presented reductions of $11 \%$ and $3.2 \%$ compared to those of the control mix. Increments between BFAC-5.7-0.24-0.30-FAC45 and control composition were $197 \%$ and $13.2 \%$ at 7 and 28 days respectively.

Table 4.15 Compressive strengths of mono-system RCBW binders

\begin{tabular}{|c|c|c|c|c|c|c|c|c|c|c|}
\hline \multicolumn{4}{|c|}{ Mono RCBW+FAC Experiments Matrix } & \multicolumn{5}{|c|}{ Mix Proportions $(\mathrm{kg} / \mathrm{m} 3)$} & \multicolumn{2}{|c|}{$\begin{array}{c}\text { Compressive Strength } \\
(\mathrm{MPa})\end{array}$} \\
\hline No & Composition Code & RCBW & $\% \mathrm{SCM}$ & RCBW & $\mathrm{SCM}$ & $\mathrm{SS}$ & $\mathrm{SH}$ & Water & 7 Days & 28 Days \\
\hline 1 & BFAC-6.65-0.24-0.3-FAC15 & 85 & 15 & 935 & 165 & 244.4 & 432.0 & 0 & 6.52 & 8.83 \\
\hline 2 & BFAC-6.2-0.24-0.3-FAC30 & 70 & 30 & 784 & 336 & 284.1 & 387.4 & 0 & 14.5 & 21.9 \\
\hline 3 & BFAC-5.7-0.24-0.3-FAC45 & 55 & 45 & 649 & 531 & 304.9 & 354.5 & 0 & 33.8 & 35.1 \\
\hline 4 & BFAF-6.55-0.24-0.3-FAF15 & 85 & 15 & 935 & 165 & 224 & 462.7 & 0 & 2.8 & 3.1 \\
\hline 5 & BFAF-6.0-0.24-0.3-FAF30 & 70 & 30 & 781 & 335 & 228.6 & 448.4 & 0 & 2.1 & 3.3 \\
\hline 6 & BFAF-5.55-0.24-0.3-FAF45 & 55 & 45 & 613 & 502 & 251.1 & 426.8 & 0 & 2.4 & 13.7 \\
\hline 7 & BMK-5.8-0.24-0.3-MK15 & 85 & 15 & 935 & 165 & 210 & 480.6 & 0 & 0.7 & 2.0 \\
\hline 8 & BMK-4.85-0.24-0.3-MK30 & 70 & 30 & 777 & 333 & 199.4 & 482.5 & 0 & 6.9 & 24.2 \\
\hline 9 & BMK-4.2-0.24-0.3-MK45 & 55 & 45 & 605 & 495 & 216.1 & 474.1 & 0 & 12.9 & 27.6 \\
\hline 10 & BGBFS-7.3-0.24-0.3-S15 & 85 & 15 & 926.5 & 163.5 & 234.7 & 449.8 & 0 & 7.9 & 10.0 \\
\hline 11 & BGBFS-7.45-0.24-0.3-S30 & 70 & 30 & 777 & 333 & 250 & 429.1 & 0 & 19.9 & 23.6 \\
\hline 12 & BGBFS-7.7-0.24-0.3-S45 & 55 & 45 & 616 & 504 & 286 & 402.4 & 0 & 27.2 & 30.0 \\
\hline
\end{tabular}




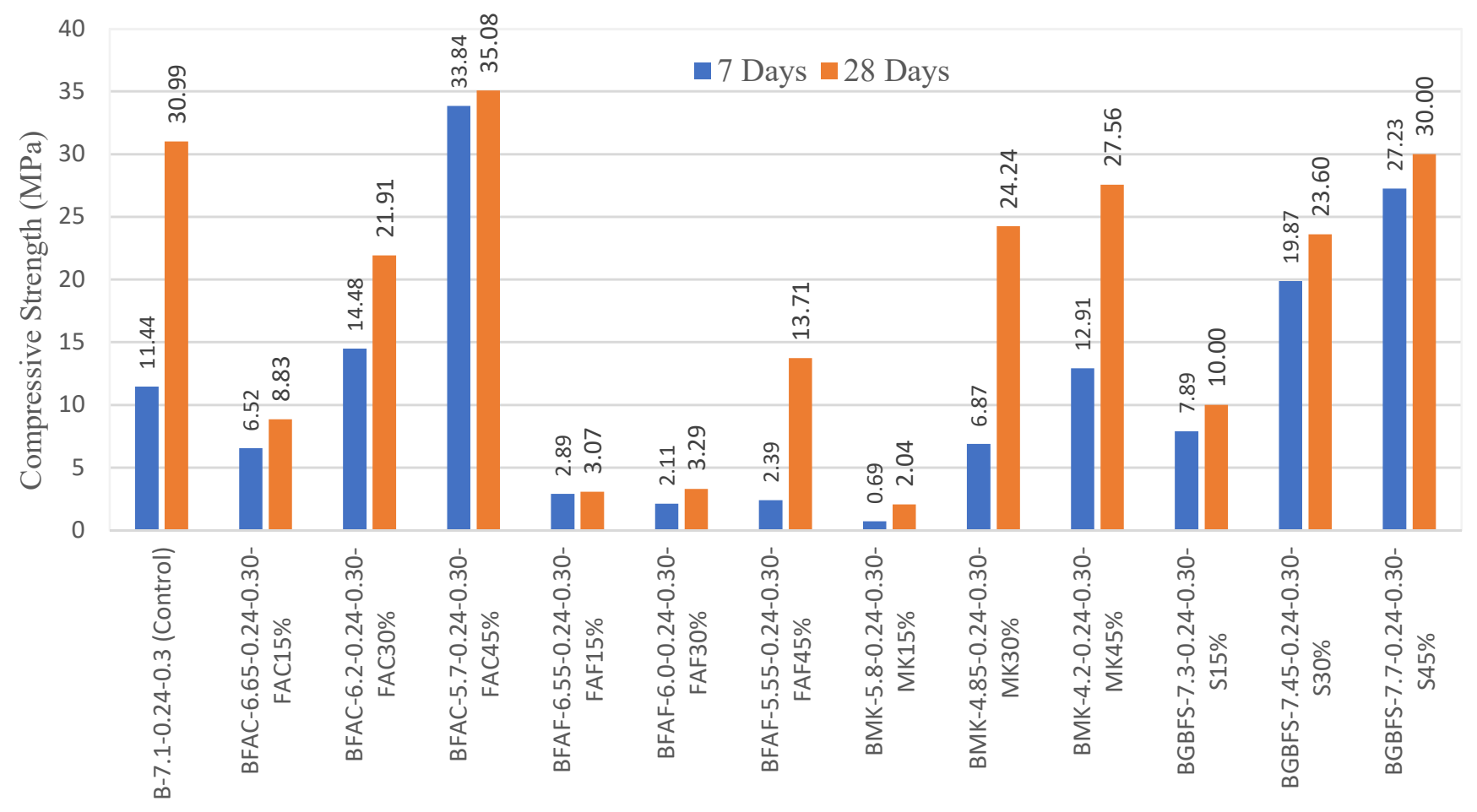

4.29 Effect of SCMs on strength development of mono RCBW geopolymers

The reason for the increased compressive strengths with the addition of FA-C is the possible formation of C-S-H, in addition to N-A-S-H gels, related to the presence of a relatively high CaO content (30.33\%) in FA-C. Furthermore, the strengths were increased as the $\mathrm{SiO}_{2} / \mathrm{Al}_{2} \mathrm{O}_{3}$ ratio decreased from 6.65 to 5.7, indicating that the FA-C content in mono-RCBW system highly influenced the soluble silica amounts in the composition. A good balance between the soluble silica provided from the activator solutions and from FA-C resulted in increased compressive strengths. Unlike FA-C, FA-F-based compositions presented insignificant strengths compared to other SCMs. This may be related to the presence of excessive water content. Thus, the geopolymerization process was not able to fully utilize this existing water. This statement agreed with the results of Kovalchuk et al. (2007) who showed that, with the use of FA-F in the geopolymerization process, moderate water content is required to develop a dense geopolymer with reduced porosity. Also, when the extra water from the initial dissolution stage released, an extended time is required for the condensation stage to form a well-developed and continuous gel (Criado et al., 2010). This is supported by the very low strengths developed at 7 days for FA-F+RCBW geopolymer binders, especially at higher $\mathrm{SiO}_{2} / \mathrm{Al}_{2} \mathrm{O}_{3}$ ratios. The addition of $\mathrm{MK}$ into mono-RCBW geopolymer binders resulted a sharp increase in the results with increased MK percentage from 15 to $45 \%$. However, the maximum strength reached for MK-RCBW compositions was $27.6 \mathrm{MPa}$ at 28 days, 
with $11 \%$ reduction compared to the control mono-RCBW mix. Also, at a constant $\mathrm{Na} 2 \mathrm{O} / \mathrm{SiO}_{2}$ ratio of 0.24, the strengths of $\mathrm{MK}+\mathrm{RCBW}$-binders increased as the $\mathrm{SiO}_{2} / \mathrm{Al}_{2} \mathrm{O}_{3}$ ratio decreased from 5.8 to 4.2. This may indicate that a limited soluble silica content was available during the geopolymerization process, resulting in excessive hydroxyl groups $\left(\mathrm{OH}^{-}\right)$and $\mathrm{Na}^{+}$in the system. This explanation is also valid for GGBS+RCBW-compositions where relatively no strength improvements were seen at 28 days compared to the control mix. According to Komnitsas and Zaharaki, (2009), the addition of sodium silicate can provide additional soluble silicates, thus stronger Si-O-Al bonds can be created, denser microstructure and compressive strengths can be developed.

\section{- Effect of the Addition of SCMs on the Strengths of Mono-system CTW Geopolymers}

The control mix selected from the results of mono-CTW binders cured at room temperature was T-11.1$0.2-0.3$. This control composition showed strengths $23.2 \mathrm{MPa}$ at 7 days and $31.8 \mathrm{MPa}$ at 28 days. The new combinations and their compressive strengths of mono-CTW mixes incorporating FA-C, FA-F, MK and GGBS are presented in Table 4.16. From this table, it was possible to improve the control result by adding $30 \%$ and $45 \% \mathrm{FA}-\mathrm{C}, 45 \% \mathrm{MK}$ or $45 \%$ GGBS into the mix composition. Increments of $25.8 \%$, $89 \%, 3.8 \%$ and $22 \%$ were calculated for TFAC-8.3-0.20-0.30-FAC30, TFAC-7.3-0.20-0.30-FAC45, TMK4.9-0.20-0.30-MK45 and TGBFS-10.4-0.20-0.30-S45 respectively, compared to the control mix. Furthermore, from Figure 4.30 that presents the effect of each SCM on the compressive strength results of CTW-compositions, the general trend of strengths increased with the increased SCMs content from $15 \%$ to $45 \%$, especially when adding FA-C. Interesting strengths were reached for 45\% FA-C-based CTW-binders with 39.3 $\mathrm{MPa}$ and $60.12 \mathrm{MPa}$ at 7 and 28 days respectively. This could be because the possible co-existed formation of C-A-S-H/C-S-H and N-A-S-H gels as geopolymer reaction products.

Table 4.16 Compressive strengths of mono-system CTW binders

\begin{tabular}{|c|c|c|c|c|c|c|c|c|c|c|c|}
\hline \multicolumn{4}{|c|}{ Mono RCBW+FAC Experiments Matrix } & \multicolumn{3}{c|}{ Mix Proportions (kg/m3) } & \multicolumn{3}{c|}{ Compressive Strength (MPa) } \\
\hline No. & Composition Code & RCBW \% & SCM \% & RCBW & SCM & SS & SH & Water & 7 Days & 28 Days \\
\hline 1 & TFAC-9.6-0.20-0.30-FAC15 & 85 & 15 & 1003 & 177 & 337.3 & 375.9 & 0 & 11.6 & 12.8 \\
\hline 2 & TFAC-8.3-0.20-0.30-FAC30 & 70 & 30 & 840 & 360 & 379.0 & 327.6 & 0 & 14.6 & 40.0 \\
\hline 3 & TFAC-7.3-0.20-0.30-FAC45 & 55 & 45 & 665.5 & 544.5 & 444.2 & 272.9 & 0 & 39.3 & 60.1 \\
\hline 4 & TFAF-9.3-0.20-0.30-FAF15 & 85 & 15 & 1003 & 177 & 296.5 & 409.5 & 0 & 2.4 & 5.5 \\
\hline 5 & TFAF-8.0-0.20-0.30-FAF30 & 70 & 30 & 815.5 & 349.5 & 338.3 & 379.8 & 0 & 2.4 & 9.0 \\
\hline 6 & TFAF-6.9-0.20-0.30-FAF45 & 55 & 45 & 646.3 & 528.8 & 356.4 & 361.1 & 0 & 2.5 & 10.5 \\
\hline 7 & TMK-7.9-0.20-0.30-MK15 & 85 & 15 & 981.8 & 173.3 & 296.9 & 415.7 & 0 & 2.8 & 10.9 \\
\hline 8 & TMK-6.05-0.20-0.30-MK30 & 70 & 30 & 805 & 345 & 289.8 & 409.7 & 0 & 12.6 & 27.2 \\
\hline 9 & TMK-4.9-0.20-0.30-MK45 & 55 & 45 & 643.5 & 526.5 & 303.2 & 411.2 & 0 & 22.6 & 33.0 \\
\hline 10 & TGBFS-10.9-0.20-0.30-S15 & 85 & 15 & 1003 & 177 & 310.9 & 401.4 & 0 & 8.4 & 13.2 \\
\hline 11 & TGBFS-10.7-0.20-0.30-S30 & 70 & 30 & 826 & 354 & 351.4 & 370.3 & 0 & 17.2 & 29.2 \\
\hline 12 & TGBFS-10.4-0.20-0.30-S45 & 55 & 45 & 660 & 540 & 376.4 & 347 & 0 & 27.2 & 38.8 \\
\hline
\end{tabular}




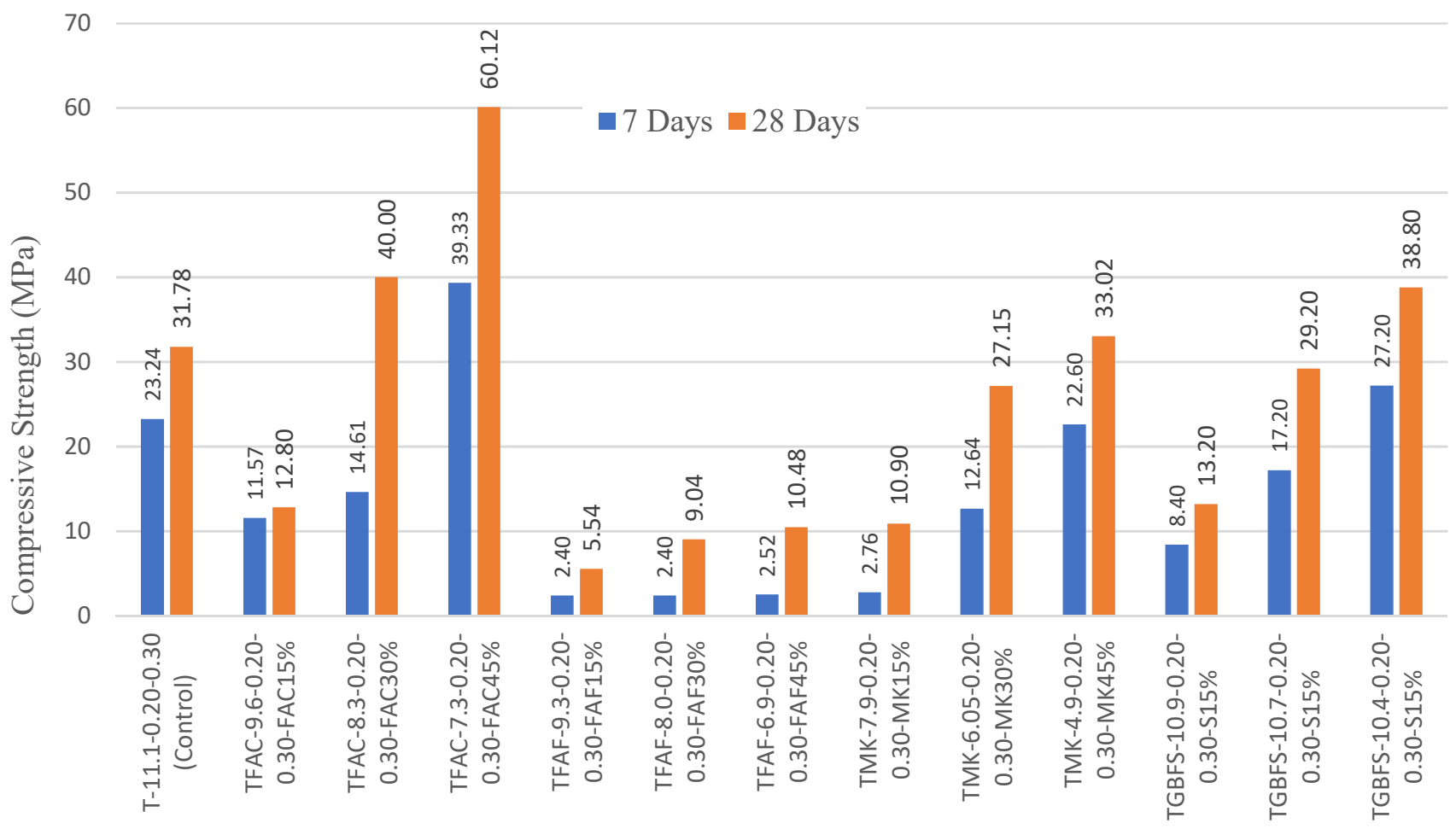

4.30 Effect of SCMs on strength development of mono CTW geopolymers

As for RCBW-based geopolymers, the addition of FA-F in CTW-compositions caused important reductions in their mechanical strengths. This indicates that FA-F is not appropriate for mono-CTW geopolymers, especially at high $\mathrm{SiO}_{2} / \mathrm{Al}_{2} \mathrm{O}_{3}$ ratio. The optimum strengths attained for $\mathrm{MK}$ - and GGBS-based compositions were $33 \mathrm{MPa}$ and $38.8 \mathrm{MPa}$ at $45 \% \mathrm{MK}$ and GGBS contents respectively. $\mathrm{SiO}_{2} / \mathrm{Al}_{2} \mathrm{O}_{3}$ ratio played an important role in the development of their strengths, which increased with decreased $\mathrm{SiO}_{2} / \mathrm{Al}_{2} \mathrm{O}_{3}$ ratio from 7.9 to 4.9 and from 10.9 to 10.4 respectively. At high MK or GGBS contents, high amounts of $\mathrm{Al}_{2} \mathrm{O}_{3}$ or $\mathrm{CaO}$ are expected leading to rich Al-phase or Ca-phase formations when aluminosilicates in precursor powders are being dissolved. These required balanced amounts of soluble silica to form strong N-A-S-H and or C-A-S-H products.

\section{- Effect of the addition of SCMs on the strengths of mono-system CW geopolymers}

The optimized composition used for investigating the effect of SCMs on the mechanical performance of mono-CW mixes was CW-12.9-0.23-0.3 with compressive strengths of 15.9 and $20.5 \mathrm{MPa}$ at 7 and 28 days respectively. The different mix proportions and related strengths of $\mathrm{CW}$-geopolymer mixes incorporating FA-C, FA-F, MK and GGBS are presented in Table 4.17. At 28 days, the addition of SCMs into the control CW-mix resulted in improved strengths for all arranged compositions. The optimal result 
for each SCM was at 45\% FA-C, 45\% FA-F, 30\% MK and 45\% GGBS contents which presented strengths of 46.8 $\mathrm{MPa}, 30.1 \mathrm{MPa}, 47.2 \mathrm{MPa}$, and $82 \mathrm{MPa}$ respectively. These indicate increments of $133 \%, 47 \%, 130 \%$ and $300 \%$ respectively, compared to the result of control mono-CW binder.

Table 4.17 Compressive strengths of mono-system CW binders

\begin{tabular}{|c|c|c|c|c|c|c|c|c|c|c|}
\hline \multicolumn{4}{|c|}{ Experiments Matrix } & \multicolumn{3}{c|}{ Mix Proportions (kg/m3) } & \multicolumn{3}{c|}{ Compressive Strength (MPa) } \\
\hline No & Composition Code & CW \% & SCM \% & CW & SCM & SS & SH & Water & 7 Days & 28 Days \\
\hline 1 & CWFAC-10-0.23-0.3-FAC15 & 85 & 15 & 1063 & 187.5 & 538.7 & 160.1 & 10 & 17.66 & 23.00 \\
\hline 2 & CWFAC-8-0.23-0.3-FAC30 & 70 & 30 & 878.5 & 376.5 & 558.8 & 155.6 & 0 & 22.72 & 34.20 \\
\hline 3 & CWFAC-6.8-0.23-0.3-FAC45 & 55 & 45 & 679.3 & 555.8 & 580.7 & 147.2 & 0 & 26.52 & 47.76 \\
\hline 4 & CWFAF-10-0.23-0.3-FAF15 & 85 & 15 & 1050 & 185.3 & 483.1 & 194 & 30 & 10.80 & 22.72 \\
\hline 5 & CWFAF-8-0.23-0.3-FAF30 & 70 & 30 & 864.5 & 370.5 & 447.9 & 224.9 & 30 & 15.60 & 28.56 \\
\hline 6 & CWFAF-6.8-0.23-0.3-FAF45 & 55 & 45 & 671 & 549 & 422.3 & 251.8 & 30 & 25.60 & 30.12 \\
\hline 7 & CMK-7.4-0.23-0.3-MK15 & 85 & 15 & 1033 & 182.3 & 518.1 & 206.5 & 0 & 15.80 & 35.08 \\
\hline 8 & CMK-5.2-0.23-0.3-MK30 & 70 & 30 & 850.5 & 364.5 & 465.5 & 256.2 & 0 & 29.12 & 47.17 \\
\hline 9 & CMK-4.15-0.23-0.3-MK45 & 55 & 45 & 665.5 & 544.5 & 410 & 304.8 & 0 & 32.56 & 43.76 \\
\hline 10 & CGBFS-13.2-0.23-0.3-S15 & 85 & 15 & 1054 & 186 & 537.4 & 183 & 0 & 12.40 & 26.00 \\
\hline 11 & CGBFS-12-0.23-0.3-S30 & 70 & 30 & 871.5 & 373.5 & 515 & 205.6 & 0 & 35.20 & 40.40 \\
\hline 12 & CGBFS-11.1-0.23-0.3-S45 & 55 & 45 & 682 & 558 & 494.4 & 226.2 & 0 & 76.00 & 82.00 \\
\hline
\end{tabular}

Figure 4.31 presents the effect of the addition of SCMs on the compressive strengths of mono CW-based geopolymer binders. The results increased as the percentage of SCMs increased from 15 to $45 \%$, except for MK-mixes, which demonstrated an optimal strength at 30\%. Unlike, mono-RCBW and mono-CTW geopolymers, the addition of FA-F into mono- $\mathrm{CW}$ mixes resulted in greater strengths compared to the control $\mathrm{CW}$ paste. The improved results of $\mathrm{CW}+\mathrm{FA}-\mathrm{F}$ compared to those of $\mathrm{RCBW}+\mathrm{FA}-\mathrm{F}$ and CTW+FA-F could be attributed to the high Ca content of CW, which caused the formation of (N, C)-AS-H gel by replacing Na by Ca in some N-A-S-H gels. According to Garcia-Lodeiro et al., (2014), a high $\mathrm{pH}$ value and the presence of aluminum species in the aqueous phase play an important role in the process of geopolymerization of $\mathrm{CW}$-geopolymers. These conditions seem to be achieved in CW-FA-F compositions because of the high $\mathrm{NaOH}$ molarity used and the approropriate alumina content from the dissolution of FA-F, which may be the reason for their improved compressive strengths compared to control mono-CW and other geopolymer systems of RCBW+FA-F and CTW+FA-F. 


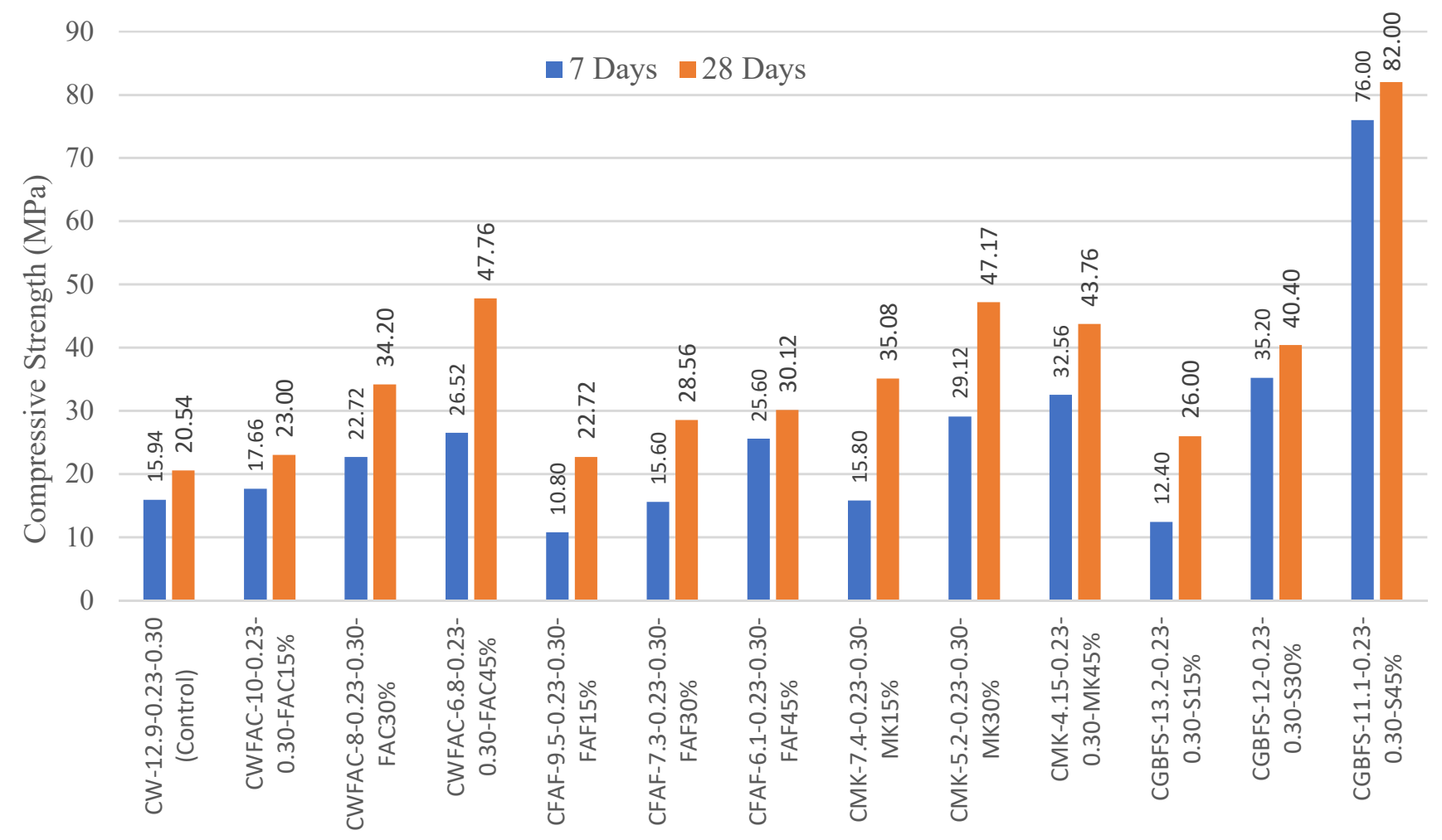

4.31 Effect of SCMs on strength development of mono CW geopolymers

The addition of GBBS into mono-CW geopolymer system resulted in very high enhancements in the compressive strength results. Interesting strengths of 76MPa and $82 \mathrm{MPa}$ were reached at 7 and 28 days respectively, for $45 \%$ GBBS content in mono-CW binder. The high early strength of $\mathrm{CW}+\mathrm{GBBS}$ binders can be related to the balanced amounts and chemical compositions of CW and GGBS in the geopolymer system. $\mathrm{CaO}$, existed in both $\mathrm{CW}$ and GBBS, highly contributed to the improved compressive strengths by developing new amorphous C-A-S-H gel structure during the geopolymerization process. This suggestion agreed with the conclusions made by Najimi, et al. (2018) about the effect of GGBS in geopolymer systems.

\subsection{2- Effect of the addition of SCMs on the strengths of binary-system geopolymers}

\section{- Effect of the addition of SCMs on the strengths of binary-system RCBW+CW geopolymers}

The control composition that was selected for this investigation was BC-8.4-0.18-0.3, which presented 18.7 $\mathrm{MPa}$ and $34.6 \mathrm{MPa}$ at 7 and 28 days respectively, at room environment curing. $\mathrm{SiO}_{2} / \mathrm{Al}_{2} \mathrm{O}_{3}$ ratios were varied based on the combined chemical compositions of SCMs and RCBW+CW, while $\mathrm{Na} 2 \mathrm{O} / \mathrm{SiO}_{2}$ and L/S ratios were kept constant. The mix proportions and compressive strength results of binary-system 
$\mathrm{RCBW}+\mathrm{CW}$ binders incorporated SCMs are presented in Table 4.18. The effect of the addition of $15 \%$, $30 \%$ and $45 \%$ FA-C, FA-F, MK and GGBS on the strength developments is presented in Figure 4.32.

Table 4.18 Compressive strengths of binary-system RCBW $+\mathrm{CW}$ binders

\begin{tabular}{|c|c|c|c|c|c|c|c|c|c|c|c|c|}
\hline \multicolumn{9}{|c|}{ Experiments Matrix } & \multicolumn{5}{c|}{ Mix Proportions (kg/m3) } & \multicolumn{3}{c|}{$\begin{array}{c}\text { Compressive } \\
\text { Strength (MPa) }\end{array}$} \\
\hline $\begin{array}{c}\text { N } \\
\text { o }\end{array}$ & Composition Code & $\begin{array}{c}\text { RCB } \\
\text { W\% }\end{array}$ & $\begin{array}{c}\text { CW } \\
\%\end{array}$ & $\begin{array}{c}\text { SCM } \\
\%\end{array}$ & RCBW & CW & SCM & SS & SH & Water & 7 days & 28 days \\
\hline 1 & BCFAC-8.1-0.18-0.3-FAC15 & 35 & 50 & 15 & 441 & 630 & 189 & 492.7 & 184.3 & 25 & 14.8 & 29.6 \\
\hline 2 & BCFAC-7.1-0.18-0.3-FAC30 & 25 & 45 & 30 & 320 & 576 & 384 & 493.2 & 152.4 & 45 & 19.6 & 41.3 \\
\hline 3 & BCFAC-6.2-0.18-0.3-FAC45 & 20 & 35 & 45 & 260 & 455 & 585 & 486.7 & 134.4 & 60 & 27.2 & 50 \\
\hline 4 & BCFAF-8-0.18-0.3-FAF15 & 35 & 50 & 15 & 434 & 620 & 186 & 492.7 & 211.1 & 10 & 10 & 23.1 \\
\hline 5 & BCFAF-7-0.18-0.3-FAF30 & 25 & 45 & 30 & 311.3 & 560.3 & 373.5 & 498.5 & 207.7 & 10 & 10 & 31.6 \\
\hline 6 & BCFAF-6-0.18-0.3-FAF45 & 20 & 35 & 45 & 250 & 437.5 & 562.5 & 437.1 & 224.7 & 30 & 30 & 45.9 \\
\hline 7 & BCMK-6.7-0.18-0.3-MK15 & 35 & 50 & 15 & 430.5 & 615 & 184.5 & 490.2 & 224.4 & 0 & 17.2 & 40.8 \\
\hline 8 & BCMK-5.3-0.18-0.3-MK30 & 25 & 45 & 30 & 302.5 & 544.5 & 363 & 492.7 & 230.8 & 0 & 38.4 & 47.3 \\
\hline 9 & BCMK-4.35-0.18-0.3-MK45 & 20 & 35 & 45 & 244 & 427 & 549 & 451.5 & 261.8 & 0 & 49.2 & 62.2 \\
\hline 10 & BCS-9.5-0.18-0.3-S15 & 35 & 50 & 15 & 437.5 & 625 & 187.5 & 500.8 & 206.1 & 10 & 17.2 & 52.4 \\
\hline 11 & BCS-9.7-0.18-0.3-S30 & 25 & 45 & 30 & 313.8 & 564.8 & 376.5 & 507.6 & 196.2 & 10 & 22.0 & 58.4 \\
\hline 12 & BCS-9.3-0.18-0.3-S45 & 20 & 35 & 45 & 251 & 439.3 & 564.8 & 439.3 & 206.6 & 40 & 40.4 & 106.5 \\
\hline
\end{tabular}

An optimal very high compressive strength of 106.5 MPa was achieved at 28 days for mix BCS-9.5-0.180.3-S45, which incorporated 45\% GBBS, 35\% CW and 20\% RCBW at $\mathrm{SiO}_{2} / \mathrm{Al}_{2} \mathrm{O}_{3}$ and $\mathrm{Na}_{2} \mathrm{O} / \mathrm{SiO}_{2}$ ratios of 9.5 and 0.18 respectively. This represents an increment of $208 \%$ compared to the control composition of binary RCBW+CW geopolymers. Interesting high strengths of $50 \mathrm{MPa}, 45.9 \mathrm{MPa}$ and $62.2 \mathrm{MPa}$ were also achieved at 28 days for BCFAC-6.2-0.18-0.3-FAC45, BCFAF-6-0.18-0.3-FAF45, BCMK-4.35-0.180.3-MK45 respectively. In these compositions the addition of 45\% FA-C, 45\% FA-F or 45\% MK resulted in improvements of $44 \%, 32 \%$ and $80 \%$ respectively, compared to binary RCBW+CW mix. In general, the strengths increased as the SCM content increased from $15 \%$ to $45 \%$ contents. However, it can be seen that the addition of $15 \%$ and $30 \%$ of MK or GGBS is also suitable to increase the strengths of the control binary composition by percentages between $18 \%$ and $36.7 \%$ and from $51 \%$ to $69 \%$ respectively, at 28-day age. 


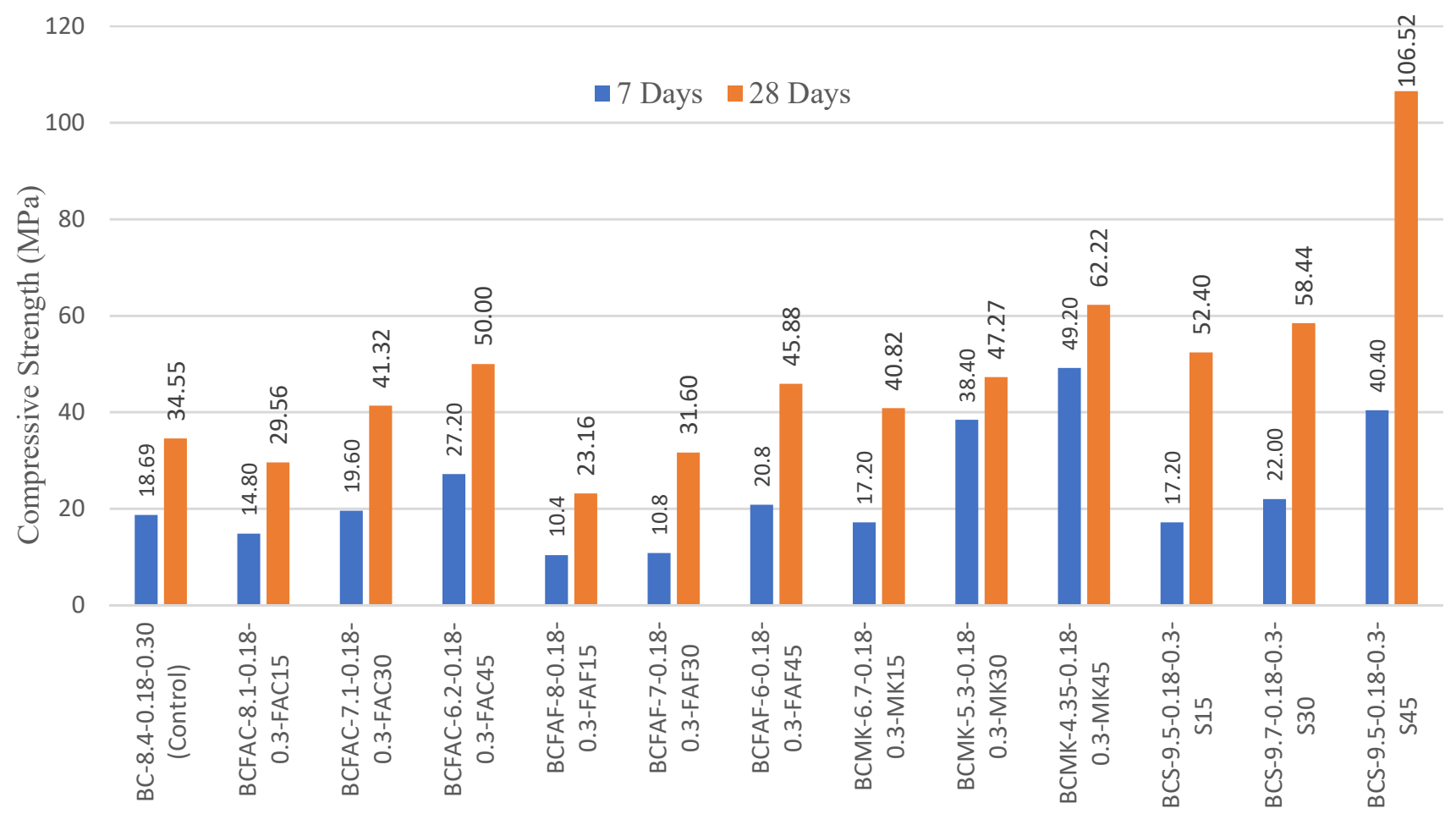

4.32 Effect of SCMs on strength development of binary RCBW+CW geopolymers

The addition of $\mathrm{MK}$ into binary $\mathrm{RCBW}+\mathrm{CW}$ binders caused $\mathrm{SiO}_{2} / \mathrm{Al}_{2} \mathrm{O}_{3}$ ratio to reduce from 6.7 to 4.35 due to the high $\mathrm{Al}_{2} \mathrm{O}_{3}$ content (wt.\% (38.07\%) in $\mathrm{MK}$ powder. This likely resulted in the creation of Alrich geopolymeric system that enhanced the gel formation kinetics by developing highly reactive Si-OAl bonds (Fernández-Jiménez et al., 2006). This explanation is in line with the results of Fernández et al. $(2005,2006)$ who stated that a minimum content of $20 \%$ of reactive alumina in the geopolymer system is necessary for greater compressive strengths. Also, the high early age strengths of MK-based binary $\mathrm{RCBW}+\mathrm{CW}$ geopolymers compared to all other SCMs supports the early formation of dense Si-O-Al bonds when adding MK at appropriate percentages of $30 \%$ and $45 \%$.

The very high strengths registered for GBBS-geopolymers may be related to the high $\mathrm{CaO}$ content in this $\mathrm{SCM}$, leading to a concomitant formation of C-A-S-H and N-A-S-H gels with very dense microstructure. In addition, the optimal $\mathrm{Si} / \mathrm{Al}$ ratio was 9.3, which is the lower ratio for GGBS-based geopolymers, explaining that the silica provided from GGBS required less amounts of sodium silicate and $\mathrm{NaOH}$ solutions to properly balance the chemical ratios and increase the compressive strengths.

\section{- Effect of the addition of SCMs on the strengths of binary-system CTW+CW geopolymers}

Table 4.19 presents the mix proportions and compressive strengths of binary- $(\mathrm{CTW}+\mathrm{CW})$ binders incorporating different SCMs. The effect of replacing 15\%, 30\% and 45\% of FA-C, FA-F, MK and 
GGBS by the binary powders CTW+CW is shown in Figure 4.33. From Table 4.19 and Figure 4.33, for all compositions and curing ages, the results increased as the percentage of SCMs increased from 15 to $45 \%$, except for MK-mixes which presented an optimal value at 30\% addition. As for SCMs and binary $\mathrm{RCBW}+\mathrm{CW}$ binders, significant strength improvements were achieved by the addition of FA-C, FA-F, MK and GGBS into the control mix of binary CTW+CW geopolymers, especially for GGBS-based compositions. The maximum strengths attained for each SCM were 54.6 MPa, 43.2 MPa, 44.6 MPa and 100.8 MPa registered for TCFAC-7-0.18-0.3-FAC45, TCFAF-6.6-0.18-0.3-FAF45, TCMK-5.7-0.18-0.3MK30 and TCS-11-0.18-0.3-S45 respectively. These indicate increments of $71.9 \%, 36.2 \%, 40.6 \%$ and $218 \%$ respectively, compared to the control composition TC-12.3-0.18-0.30 with $31.7 \mathrm{MPa}$ at 28 days.

Table 4.19 Compressive strengths of binary-system CTW+CW binders

\begin{tabular}{|c|c|c|c|c|c|c|c|c|c|c|c|c|}
\hline \multicolumn{4}{|c|}{ Experiments Matrix } & \multicolumn{5}{c|}{ Mix Proportions (kg/m3) } & \multicolumn{3}{c|}{$\begin{array}{c}\text { Compressive } \\
\text { Strength (MPa) }\end{array}$} \\
\hline $\begin{array}{c}\text { N } \\
0\end{array}$ & Composition Code & $\begin{array}{c}\text { CT } \\
\text { W\% }\end{array}$ & $\begin{array}{c}\text { CW } \\
\%\end{array}$ & $\begin{array}{c}\text { SCM } \\
\%\end{array}$ & CTW & CW & SCM & SS & SH & Water & 7 days & 28 days \\
\hline 1 & TCFAC-10-0.18-0.3-FAC15 & 35 & 50 & 15 & 434 & 620 & 186 & 501.1 & 185.9 & 20 & 17.6 & 46.2 \\
\hline 2 & TCFAC-8.2-0.18-0.3-FAC30 & 25 & 45 & 30 & 315 & 567 & 378 & 519.9 & 150.9 & 30 & 22.4 & 46.2 \\
\hline 3 & TCFAC-7-0.18-0.3-FAC45 & 20 & 35 & 45 & 254 & 444.5 & 571.5 & 544.8 & 127.3 & 30 & 24.8 & 54.5 \\
\hline 4 & TCFAF-9.5-0.18-0.3-FAF15 & 35 & 50 & 15 & 437.5 & 625 & 187.5 & 443.4 & 224.8 & 30 & 15.4 & 28.1 \\
\hline 5 & TCFAF-7.8-0.18-0.3-FAF30 & 25 & 45 & 30 & 310 & 558 & 372 & 471.3 & 214 & 20 & 13.3 & 38.9 \\
\hline 6 & TCFAF-6.6-0.18-0.3-FAF45 & 20 & 35 & 45 & 248 & 434 & 558 & 466 & 223 & 15 & 23.2 & 43.2 \\
\hline 7 & TCMK-7.8-0.18-0.3-MK15 & 35 & 50 & 15 & 432.3 & 617.5 & 185.3 & 482.3 & 232.6 & 0 & 32.4 & 43 \\
\hline 8 & TCMK-5.7-0.18-0.3-MK30 & 25 & 45 & 30 & 307.5 & 553.5 & 369 & 473.6 & 242 & 0 & 35.2 & 44.6 \\
\hline 9 & TCMK-4.6-0.18-0.3-MK45 & 20 & 35 & 45 & 246 & 430.5 & 553.5 & 462.1 & 266.8 & 0 & 32.4 & 39.3 \\
\hline 10 & TCS-12-0.18-0.3-S15 & 35 & 50 & 15 & 437.5 & 625 & 187.5 & 485.1 & 214.1 & 15 & 11.2 & 48.6 \\
\hline 11 & TCS-11.5-0.18-0.3-S30 & 25 & 45 & 30 & 313.8 & 564.8 & 376.5 & 495.1 & 202 & 15 & 28 & 67.2 \\
\hline 12 & TCS-11-0.18-0.3-S45 & 20 & 35 & 45 & 250 & 437.5 & 562.5 & 505.3 & 202. & 15 & 47.2 & 100.8 \\
\hline
\end{tabular}




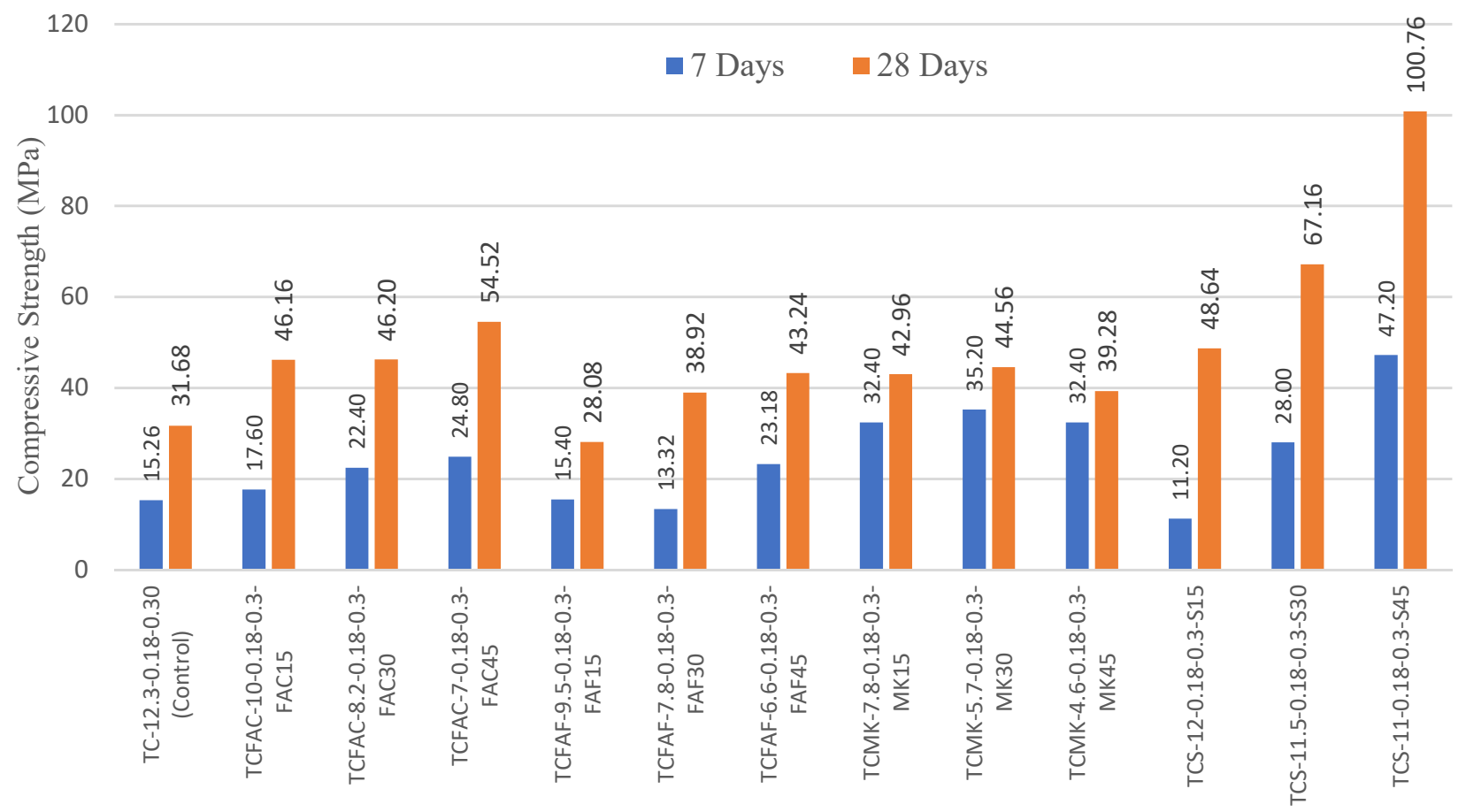

4.33 Effect of SCMs on strength development of binary CTW+CW geopolymers

The higher strengths reached for FA-C mixes at 7 days was $24.8 \mathrm{MPa}$, which also represents a higher increment of $62.5 \%$ than the control mix at the same age. The presence of high $\mathrm{Ca}$ and Si contents in FA$\mathrm{C}$ possibly accelerated the formation of Si-O-Si bonds leading to the creation of stronger geopolymer system and accelerated strength development. Almost the same conditions were reunited for FA-F based binders, with close $\mathrm{SiO}_{2} / \mathrm{Al}_{2} \mathrm{O}_{3}$ ratio and the same $\mathrm{Na}_{2} \mathrm{O} / \mathrm{SiO}_{2}$ and $\mathrm{L} / \mathrm{S}$ ratios. However, the reduced $\mathrm{CaO}$ amount in FA-F resulted in lower improvements compared to FA-C mixes. Unlike other SCMs, the incorporation of $\mathrm{MK}$ in binary $\mathrm{CTW}+\mathrm{CW}$ composition indicated that $30 \% \mathrm{MK}$ was the optimal content for mechanical strengths. The reason for this may be the reduced $\mathrm{SiO}_{2} / \mathrm{Al}_{2} \mathrm{O}_{3}$ ratio that resulted in unbalanced Si and Al system when increasing the percentage of MK beyond $30 \%$. Thus, the addition of more sodium silicate solution can create the equilibrium needed for denser geopolymer network (Fernández-Jiménez et al., 2006; J. Provis \& van Deventer, 2009).

The combination of SCM and CDW precursors played an important role in the development of compressive strengths GGBS-based CTW $+\mathrm{CW}$ mixes. The best combination of precursors was $45 \%$ GBFS $+20 \% \mathrm{CTW}+35 \% \mathrm{CW}$ at a $\mathrm{SiO}_{2} / \mathrm{Al}_{2} \mathrm{O}_{3}$ ratio of 11 . This explains that at low $\mathrm{Si}$ to $\mathrm{Al}$ ratio, $\mathrm{CaO}$ and $\mathrm{Na} 2 \mathrm{O}$ were able to consume greater soluble silica contents from the precursors and alkaline solutions, leading to increased formation of reaction products and greater dissolution activity. Another observation that can be made is about the development of strengths for GGBS-compositions. Previous studies 
performed by Najimi et al.,(2018), Provis and van Deventer, (2009) and Yip, (2004) agreed that the presence of high $\mathrm{CaO}$ content in GGBS can result in high early strengths of geopolymer materials and small gains can be developed at later ages. However, in this study, strengths were highly enhanced between 7 and 28-days, though a high amount of $\mathrm{CaO}$ is expected to be present in the system from both GGBS and $\mathrm{CW}$. This explains that a balanced $\mathrm{SiO}_{2} / \mathrm{Al}_{2} \mathrm{O}_{3}, \mathrm{Na} 2 \mathrm{O} / \mathrm{SiO}_{2}$ and precursor powders may even increase the positive effect of GGBS in developing continuous strength increments.

\section{- Effect of the addition of SCMs on the strengths of binary-system RCBW+CTW geopolymers}

Table 4.20 shows the mix proportions and compressive strength results of binary RCBW+CTW geopolymers prepared with various SCMs. The control mix was BT-10.0-0.24-0.30, which presented strengths of 26.6 and $30 \mathrm{MPa}$ at 7 and 28 days respectively, at ambient curing temperature. Figure 4.34 presents the effect of different SCMs contents on the compressive strengths of binary RCBW $+\mathrm{CTW}$ combinations.

Table 4.20 Compressive strengths of binary-system RCBW+CTW binders

\begin{tabular}{|c|c|c|c|c|c|c|c|c|c|c|c|c|}
\hline \multicolumn{9}{|c|}{ Experiments Matrix } & \multicolumn{5}{c|}{ Mix Proportions (kg/m3) } & \multicolumn{3}{c|}{$\begin{array}{c}\text { Compressive } \\
\text { Strength (MPa) }\end{array}$} \\
\hline $\begin{array}{c}\text { N } \\
\text { o }\end{array}$ & Composition Code & $\begin{array}{c}\text { RCB } \\
\text { W\% }\end{array}$ & $\begin{array}{c}\text { CTW } \\
\%\end{array}$ & $\begin{array}{c}\text { SCM } \\
\%\end{array}$ & RCBW & CTW & SCM & SS & SH & Water & 7 days & 28 days \\
\hline 1 & BTFAC-8.6-0.24-0.3-FAC15 & 20 & 65 & 15 & 228.0 & 741.0 & 171.0 & 253.8 & 459.7 & 0.0 & 5.6 & 8.7 \\
\hline 2 & BTFAC-7.6-0.24-0.3-FAC30 & 15 & 55 & 30 & 175.5 & 643.5 & 351.0 & 288.6 & 415.6 & 0.0 & 12.8 & 20.9 \\
\hline 3 & BTFAC-6.8-0.24-0.3-FAC45 & 10 & 45 & 45 & 117.0 & 526.5 & 526.5 & 339.6 & 358.0 & 0.0 & 30.0 & 56.5 \\
\hline 4 & BTFAF-8.35-0.24-0.3-FAF15 & 20 & 65 & 15 & 228.0 & 741.0 & 171.0 & 213.1 & 492.5 & 0.0 & 3.7 & 4.0 \\
\hline 5 & BTFAF-7.3-0.24-0.3-FAF30 & 15 & 55 & 30 & 172.5 & 632.5 & 345.0 & 235.0 & 472.8 & 0.0 & 10.0 & 5.2 \\
\hline 6 & BTFAF-6.45-0.24-0.3-FAF45 & 10 & 45 & 45 & 115.5 & 519.8 & 519.8 & 261.2 & 450.4 & 0.0 & 9.1 & 14.0 \\
\hline 7 & BTMK-7.1-0.24-0.3-MK15 & 20 & 65 & 15 & 230.0 & 747.5 & 172.5 & 186.6 & 516.2 & 0.0 & 3.6 & 3.8 \\
\hline 8 & BTMK-5.65-0.24-0.3-MK30 & 15 & 55 & 30 & 170.0 & 621.5 & 339.0 & 208.8 & 500.9 & 0.0 & 6.0 & 9.7 \\
\hline 9 & BTMK-5.65-0.24-0.3-MK45 & 10 & 45 & 45 & 113.5 & 510.8 & 510.8 & 213.8 & 497.9 & 0.0 & 17.6 & 26.2 \\
\hline 10 & BTS-9.6-0.24-0.3-S15 & 20 & 65 & 15 & 232.0 & 754.0 & 174.0 & 217.8 & 492.6 & 0.0 & 7.6 & 10.1 \\
\hline 11 & BTS-9.4-0.24-0.3-S30 & 15 & 55 & 30 & 177.0 & 649.0 & 354.0 & 205.8 & 469.8 & 20.0 & 9.6 & 14.1 \\
\hline 12 & BTS-9.2-0.24-0.3-S45 & 10 & 45 & 45 & 120.0 & 540.0 & 540.0 & 198.2 & 445.6 & 45.0 & 11.2 & 27.3 \\
\hline
\end{tabular}

At both 7 and 28 days, the compressive strengths increased with increased SCMs contents from 15 to 45\%. However, only mix BTFAC-6.8-0.24-0.3-FAC45 with 45\% FA-C that resulted in improved strengths compared to the control mix. The optimal strengths of this binder were 30 and $56.5 \mathrm{MPa}$ at 7 and 28 days, which displayed improvements of $13 \%$ and $88 \%$ respectively, compared to the control binary $\mathrm{RCBW}+\mathrm{CTW}$ paste. As mentioned for the addition of FA-C in mono-RCBW and mono-CTW compositions, the $\mathrm{Ca}^{2+}$ cations provided from FA-C amount may have caused the precipitation of N-A- 
S-H/C-A-S-H gels, resulting in denser microstructure. This was possible because of the presence of an appropriate content of soluble silica and alkaline metals, such as $\mathrm{Na}^{+}$and $\mathrm{OH}^{-}$hydroxyl ions, which likely served the formation of $\mathrm{Na}-\mathrm{O}, \mathrm{Si}-\mathrm{O}-\mathrm{Si}, \mathrm{Si}-\mathrm{O}-\mathrm{Al}$ and $\mathrm{Al}-\mathrm{O}-\mathrm{Al}$ bonds in the geopolymeric system.

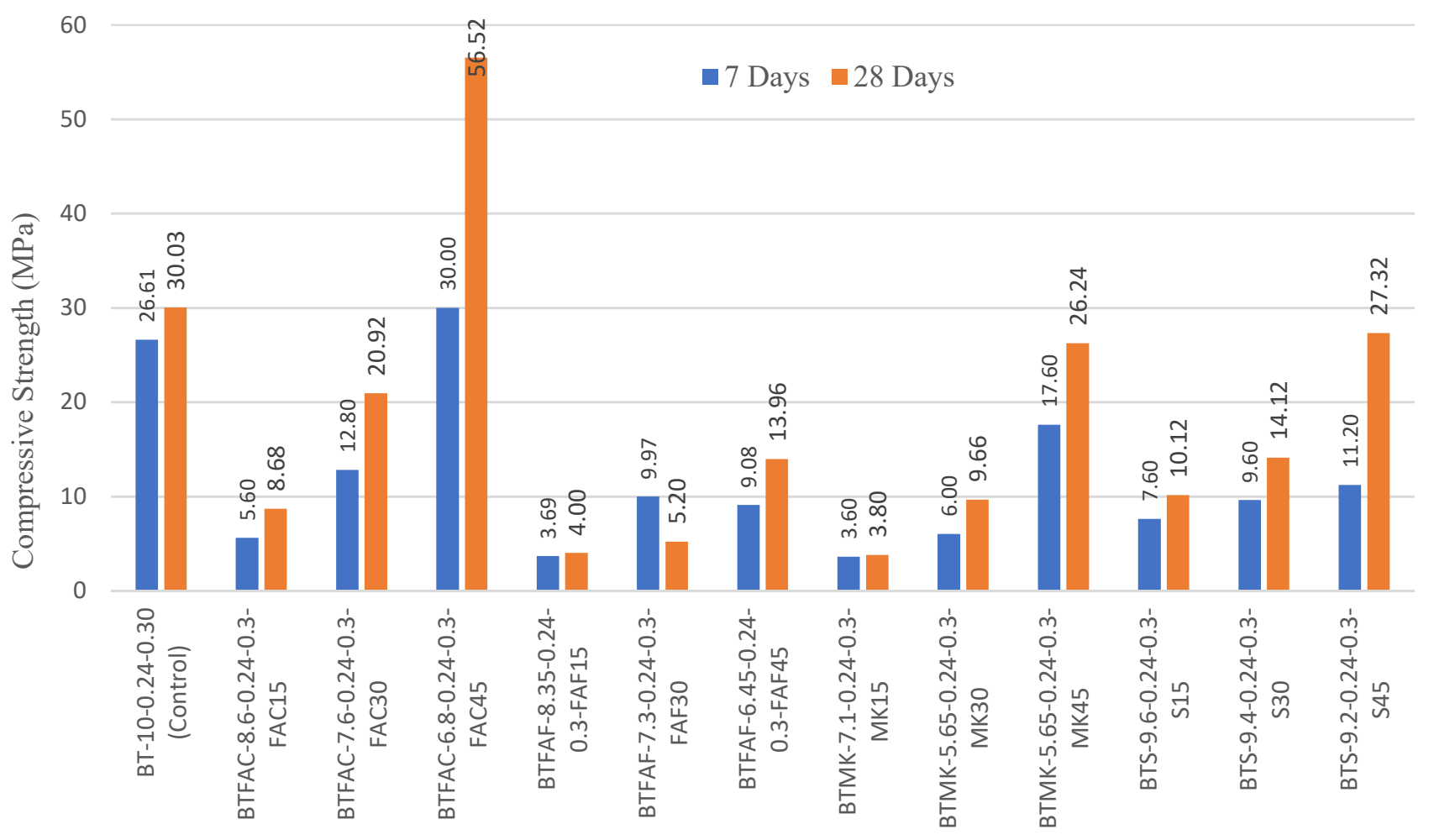

4.34 Effect of SCMs on strength development of binary RCBW+CTW geopolymers

Unlike FA-C pastes, FA-F- based binary RCBW+CTW binders were not well developed. Very low strengths were presented from their compositions, with a maximum value of $14 \mathrm{MPa}$ achieved at 28 days for $45 \%$ content of FA-F. If we compare these performances with the positive effect of FA-F on the strengths of binary $\mathrm{RCBW}+\mathrm{CW}$ and $\mathrm{CTW}+\mathrm{CW}$, the only difference that can be mentioned is the lack of $\mathrm{CW}$ in the combination. This explains that the key reason for the low strengths of FA-F-RCBW+CTW mixes may be the single formation of $\mathrm{N}-\mathrm{A}-\mathrm{S}-\mathrm{H}$ as a reaction product, because of the small $\mathrm{CaO}$ amount in FA-F. The same suggestion is also valid for the addition of MK. However, the results were slightly better than FA-F geopolymers, likely because the presence of Al-rich phase in MK-based geopolymers, resulting in more stable N-A-S-H gel than that of FA-F binders. However, the unbalanced amounts of soluble silica and Al may have caused more interconnected and unreacted particles in the system, thus the compressive strengths were reduced compared to the control mix without MK.

Unlike other binary systems, the addition of GBBS into binary RCBW+CTW composition showed 
reduced strengths compared to the control specimens. An optimal value of 27.3 $\mathrm{MPa}$ was achieved at $45 \%$ GBBS replacement, which represents a reduction of $9 \%$ at 28 -days compared to the control result. It seems that the available $\mathrm{CaO}$ from GGBS was not able to consume the high $\mathrm{Si}$ in the system. This statement is supported by the increased results registered with reduced $\mathrm{SiO}_{2} / \mathrm{Al}_{2} \mathrm{O}_{3}$ ratio.

\subsection{3 - Effect of the addition of SCMs on the strengths of ternary-system RCBW+CTW+CW geopolymers}

The control composition selected to study the combined use of SCMs and ternary system-CDWs was BCT-10.2-0.18-0.30, which gained 27.4 and 52.2 MPa compressive strengths at 7 and 28 days of room temperature curing. The experimental mixes prepared based on 15\%, 30\% and $45 \%$ SCMs substitutions by ternary RCBW+CTW $+\mathrm{CW}$ powders are presented in Table 4.21. The effect of SCM type and content on the compressive strengths of ternary CDW geopolymers is presented in Figure 4.35.

Table 4.21 Compressive strengths of ternary-system RCBW+CTW+CW binders

\begin{tabular}{|c|c|c|c|c|c|c|c|c|c|c|c|c|c|c|}
\hline & \multicolumn{5}{|c|}{ Experiments Matrix } & \multicolumn{7}{|c|}{ Mix Proportions $(\mathrm{kg} / \mathrm{m} 3)$} & \multicolumn{2}{|c|}{$\begin{array}{l}\text { Compressive } \\
\text { Strength } \\
\text { (MPa) }\end{array}$} \\
\hline \begin{tabular}{|l|}
$\mathrm{N}$ \\
$\mathrm{O}$ \\
\end{tabular} & Composition Code & $\begin{array}{l}\mathrm{RCB} \\
\mathrm{W} \% \\
\end{array}$ & \begin{tabular}{|c|}
$\mathrm{CT}$ \\
$\mathrm{W} \%$ \\
\end{tabular} & $\begin{array}{c}\mathrm{CW} \\
\%\end{array}$ & $\begin{array}{c}\text { SCM } \\
\%\end{array}$ & $\begin{array}{c}\text { RCB } \\
\text { W } \\
\end{array}$ & CTW & $\mathrm{CW}$ & SCM & SS & $\mathrm{SH}$ & Water & $\begin{array}{c}7 \\
\text { days } \\
\end{array}$ & $\begin{array}{c}28 \\
\text { days }\end{array}$ \\
\hline 1 & BCTFAC-9.0-0.18-0.3-FAC15 & 15 & 35 & 35 & 15 & 189.8 & 442.8 & 442.8 & 189.8 & 448.4 & 237.0 & 25.0 & 19.1 & 40.3 \\
\hline 2 & BCTFAC-7.6-0.18-0.3-FAC30 & 10 & 30 & 30 & 30 & 129.5 & 388.5 & 388.5 & 388.5 & 413.9 & 210.3 & 60.0 & 22.0 & 46.7 \\
\hline 3 & BCTFAC-6.6-0.18-0.3-FAC45 & 7 & 24 & 24 & 45 & 91.0 & 312.0 & 312.0 & 585.0 & 426.4 & 176.0 & 75.0 & 34.1 & 57.5 \\
\hline 4 & BCTFAF-8.9-0.18-0.3-FAF15 & 15 & 35 & 35 & 15 & 186.0 & 434.0 & 434.0 & 186.0 & 457.4 & 260.8 & 5.0 & 17.8 & 22.9 \\
\hline 5 & BCTS-7.7-0.18-0.3-FAF30 & 10 & 30 & 30 & 30 & 123.0 & 369.0 & 369.0 & 369.0 & 487.0 & 250.5 & 0.0 & 12.3 & 37.1 \\
\hline 6 & BCTS-6.6-0.18-0.3-FAF45 & 7 & 24 & 24 & 45 & 87.5 & 300.0 & 300.0 & 562.5 & 471.0 & 255.0 & 0.0 & 14.4 & 38.2 \\
\hline 7 & BCTMK-7.1-0.18-0.3-MK15 & 15 & 35 & 35 & 15 & 186.0 & 434.0 & 434.0 & 186.0 & 349.3 & 287.6 & 45.0 & 31.2 & 39.0 \\
\hline 8 & ВСТMК-5.6-0.18-0.3-MK30 & 10 & 30 & 30 & 30 & 121.5 & 364.5 & 364.5 & 364.5 & 364.5 & 286.5 & 15.0 & 43.1 & 48.5 \\
\hline 9 & ВСТМK-4.6-0.18-0.3-MK45 & 7 & 24 & 24 & 45 & 83.7 & 286.8 & 286.8 & 537.8 & 396.4 & 293.5 & 5.0 & 43.4 & 53.9 \\
\hline 10 & BCTS-10.2-0.18-0.3-S15 & 15 & 35 & 35 & 15 & 189.0 & 441.0 & 441.0 & 189.0 & 370.8 & 268.6 & 50.0 & 35.2 & 54.2 \\
\hline 11 & BCTS-10.2-0.18-0.3-S30 & 10 & 30 & 30 & 30 & 127.0 & 381.0 & 381.0 & 381.0 & 399.4 & 256.8 & 42.0 & 46.8 & 78.6 \\
\hline 12 & BCTS-10.2-0.18-0.3-S45 & 7 & 24 & 24 & 45 & 88.6 & 303.6 & 303.6 & 570.0 & 453.4 & 242.0 & 20.0 & 70.1 & 85.2 \\
\hline
\end{tabular}

The addition of FA-C or MK at 45\% replacement level and GGBS at 15, 30 and $45 \%$ contents indicated improved results over the control ternary mix. Enhancements were 10.2\%, 3.3\%, 3.8\%, 50.6\% and 63.2\% respectively, explaining optimal improvements at 30\% and 45\% GGBS additions. These interesting results describe an effective way for recycling three different CDW materials in the same geopolymer mix, while developing very high compressive strength binders. However, the incorporation of FA-F at different contents and FA-C or MK at $15 \%$ and $30 \%$ resulted in reduced strengths compared to the control 
mix of ternary RCBW $+\mathrm{CTW}+\mathrm{CW}$. These confirm the relevance aspect from adding GGBS in all CDWbased geopolymers. As discussed earlier, the high $\mathrm{CaO}$ content and the balanced amounts of $\mathrm{Si}$ and $\mathrm{Na}$ in the system are important to create dense intermixed reaction products of C-A-S-H and N-A-S-H. On the other hand, the addition of FA-F seems inappropriate for the mechanical performance of ternary $\mathrm{RCBW}+\mathrm{CTW}+\mathrm{CW}$ geopolymer binder because of its inability to fully utilize the existing water in the polycondensation stage. This indicates that more curing time is required for the formation of a welldeveloped and continuous aluminosilicate gel when FA-F is used in the geopolymer network (Criado et al., 2010).

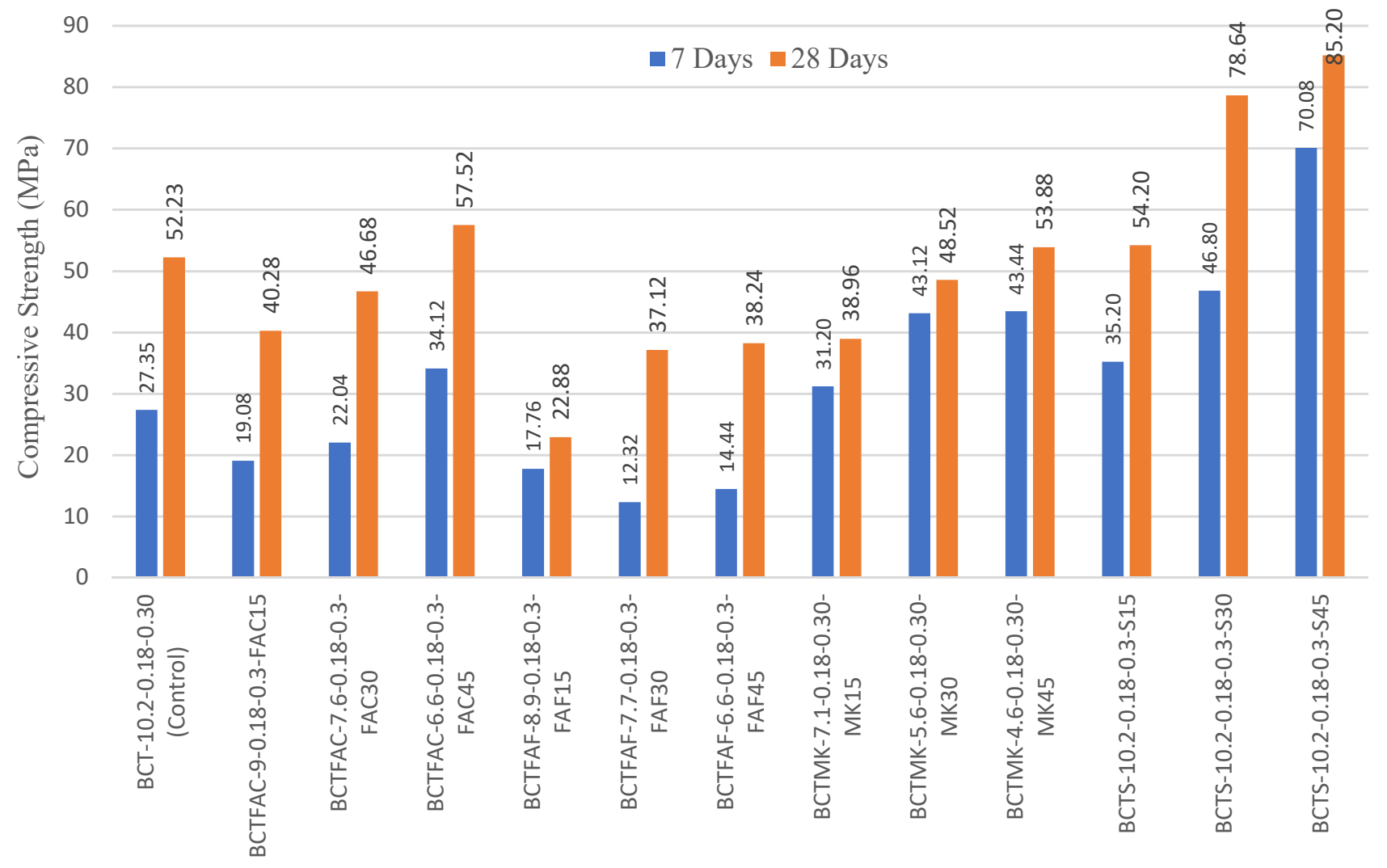

4.35 Effect of SCMs on strength development of ternary RCBW+CTW $+\mathrm{CW}$ geopolymers 


\subsection{Microstructural characterization and discussions}

To study the microstructural properties of developed CDW-based geopolymer binders, extensive investigation utilizing X-ray Diffraction (XRD) and scanning electron microscopy (SEM) was performed on select geopolymer specimens after 28-days of curing age. Samples from the lower and higher strength compositions at ambient temperature curing of each geopolymer system were chosen for comparison. Also, the effect of high temperature curing and the addition of different SCMs on the microstructural changes of each CDW-geopolymer binder was evaluated by analyzing the greater strength composition at optimal high temperature curing and at maximum SCM replacement by CDW powders.

\subsubsection{X-Ray Diffraction (XRD) Analysis}

XRD analysis was used to identify various newly formed crystalline phases and define the level to which the precursor materials have reacted in the geopolymerization process. This is despite the fact that geopolymers were classified as materials having a substantial part of amorphous nature (J. Provis \& van Deventer, 2009).

\section{- XRD Analysis of mono-system CDW pastes}

Figure 4.36, 4.37 and 4.38 show the XRD patterns of RCBW powder and mono-RCBW binders, CTW powder and mono-CTW binders and CW and mono-CW binders respectively. Samples of mono-RCBW pastes were taken from the higher and lower strength compositions of ambient and high temperature curing. From Figure 4.36, the XRD patterns of RCBW materials show the presence of dominant peaks of Montmorillonite (Bentonite) or $\left(\mathrm{AL}_{2} \mathrm{H}_{4} \mathrm{Na}_{0.3} \mathrm{O}_{13} \mathrm{Si}_{4}\right)$, Muscovite $\left(\mathrm{Al}_{3} \mathrm{H}_{2} \mathrm{KO}_{12} \mathrm{Si}_{3}\right)$, Quartz $\left(\mathrm{SiO}_{2}\right)$ in the RCBW powder, and the formation of Albite $\left(\mathrm{NaAlSi}_{3} \mathrm{O}_{8}\right)$, Anorthite $\left(\mathrm{AlCaO}_{8} \mathrm{Si}_{2}\right)$, Pirssonite $\left(\mathrm{Na}_{2} \mathrm{Ca}\left(\mathrm{Co}_{3}\right)_{2 \cdot 2} \mathrm{H}_{2} \mathrm{O}\right)$ and Mullite $\left(\mathrm{Al}_{6} \mathrm{O}_{13} \mathrm{Si}_{2}\right)$ during the geopolymerization process. Albite is an anhydrous alkaline aluminosilicate mineral belonging to Plagioclase mineralogical group, which contributed to the formation of three-dimensional aluminosilicate framework of RCBW-geopolymers. XRD patterns of mono-RCBW paste subjected to $75^{\circ} \mathrm{C}$ of initial curing temperature revealed almost identical spectra compared to those registered at ambient curing. This explains that no new phases were formed at high temperature curing. However, it seems that the intensity of quartz and Muscovite peaks reduced compared to room curing. Also, the peak of anorthite, which is another calcium-based Plagioclase mineral, observed around $31.6^{\circ} 2 \theta$ after geopolymerization process at room and hightemperature curing, was to a lesser extent compared to Albite (sodium-based Plagioclase) registered at 
around $21.9^{\circ}, 33.8^{\circ}, 36.8^{\circ}$ and $41.46^{\circ} 2 \theta$. This shows the presence of sodium-based alkaline reagents in larger quantity in the geopolymer binder. It also reveals the low calcium content in RCBW-geopolymers. Furthermore, the different intensity peaks of crystalline quartz in geopolymer binders indicates a variable degree of geopolymerization. From the XRD spectra of mono RCBW geopolymer derived from the lowest compressive strength composition (RCBW-Lowest), it can be seen that a lower degree of geopolymerization has taken place compared to those of highest compressive strength achieved at room and high temperature curing.

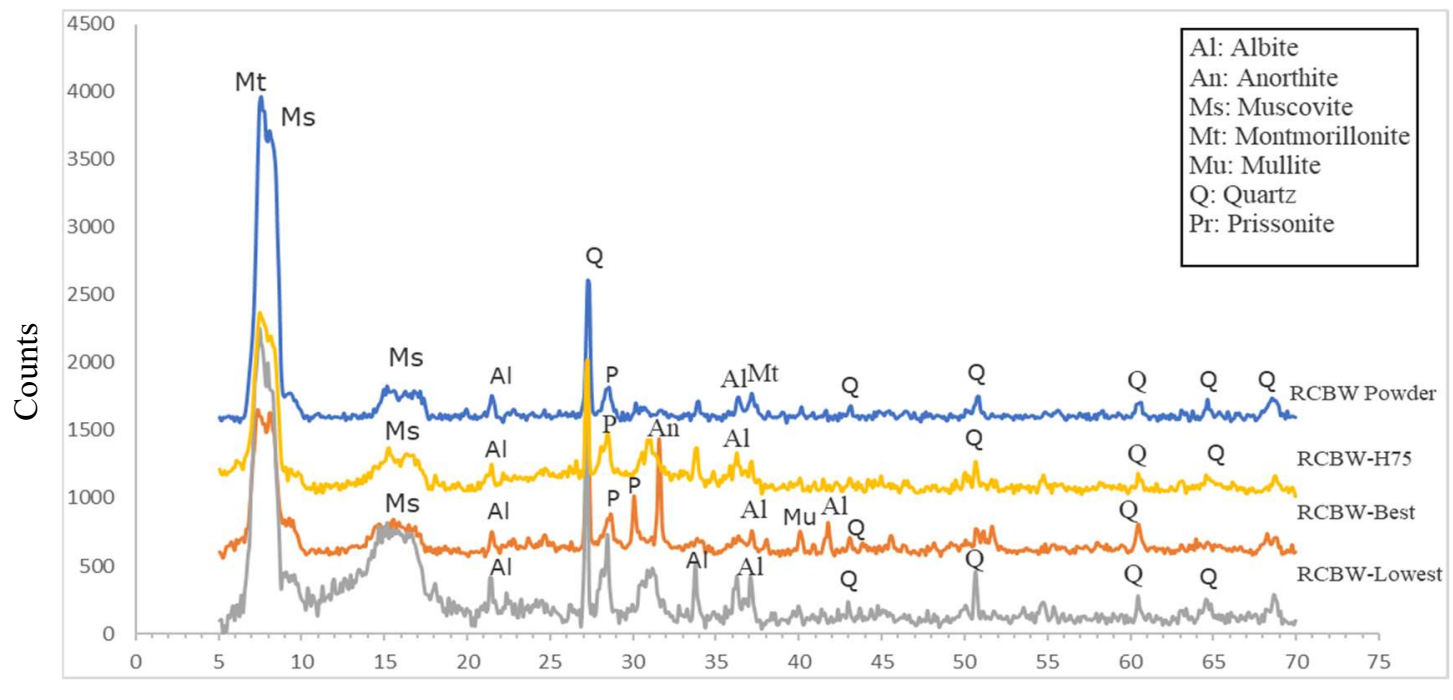

$2 \theta$

Figure 4.36 XRD patterns of RCBW powder (RCBW powder) and mono-RCBW binder at high temperature (RCBW-H75) and room temperature curing (RCBW-Best and RCBW-Lowest with higher and lower strength respectively)

From Figure 4.37, the XRD patterns of CTW powder show the presence of montmorillonite, muscovite, quartz, albite and anorthite. The figure also shows the amorphous nature of mono CTW-based binders. As CTW geopolymer products were developed, the peaks and amounts of crystalline phases reduced. According to Komnitsas et al., (2015), the crystalline phases of anorthite, albite and quartz partially dissolve during the geopolymerization process. This is evident from the reduced intensity peaks of crystalline elements in CTW-geopolymeric pastes compared to those previously present in CTW powder. The same observations stated for RCBW-geopolymers are also valid for CTW-pastes regarding the different intensity peaks of albite, anorthite and muscovite. 


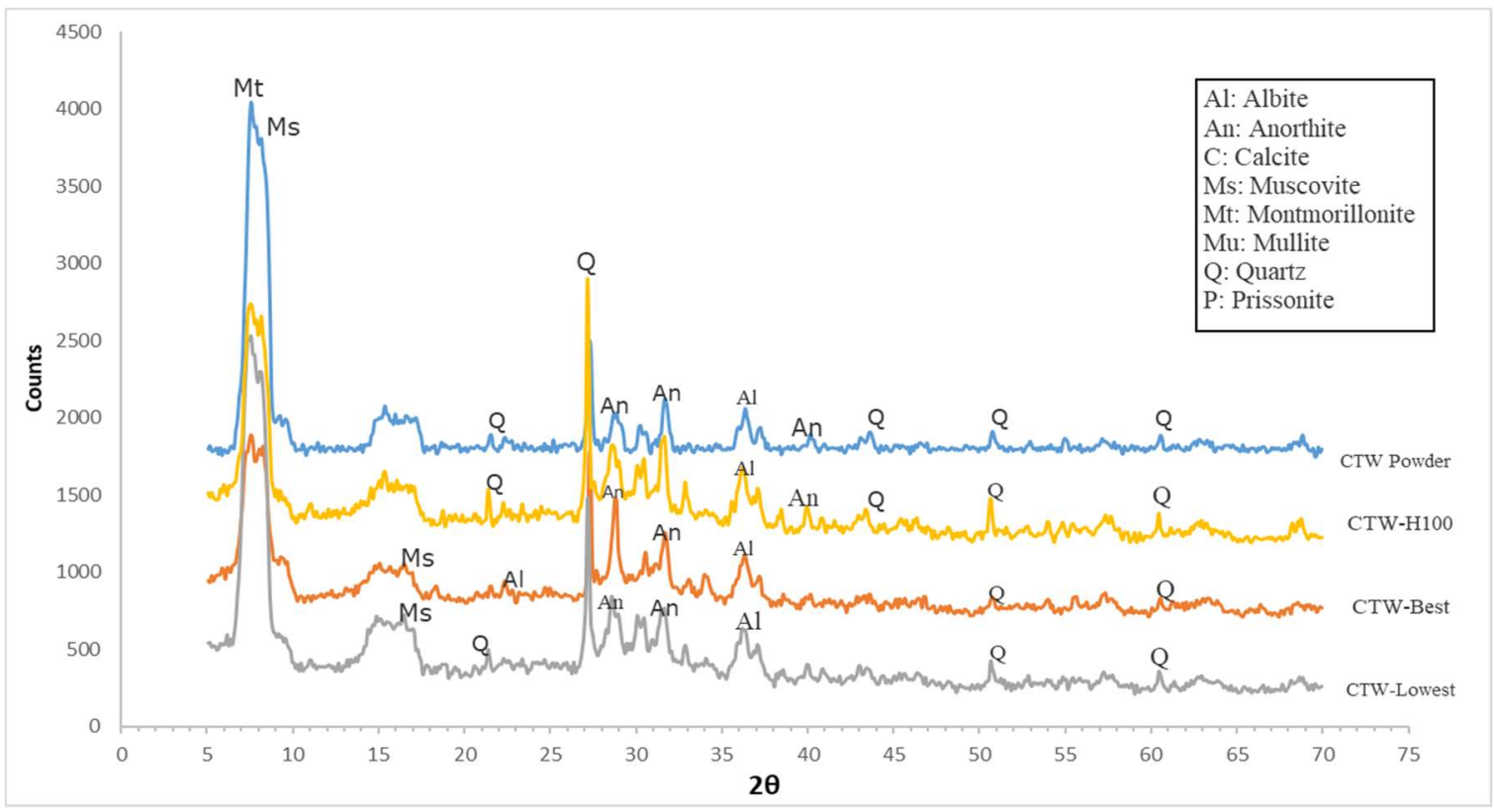

Figure 4.37 XRD patterns of CTW powder (CTW powder) and mono-CTW binder at high temperature (CTW-H100) and room temperature curing (CTW-Best and CTW-Lowest with higher and lower strength respectively)

As can be seen in Figure 4.38, mono-CW geopolymer binders show higher peaks of crystalline phases than mono-RCBW and mono-CTW geopolymers. Also, XRD patterns of raw precursor powder of CW demonstrated the presence of additional crystalline peaks, especially for anorthite at around $30.2^{\circ}$ and $51.6^{\circ} 2 \theta$. Samples derived from the lowest strength composition (CW-12.9-0.35-0.30) showed similar and equally intensive phase peaks compared to the raw powder material, indicating a low geopolymeric reaction in this mix. The decreased crystallinity and increased geopolymerization can be concluded from the reduced intensity of crystalline peaks as the compressive strength enhanced between room and high temperature curing of mono $\mathrm{CW}$ geopolymers. For example, quartz peak at around $26.6^{\circ} 2 \theta$ seems completely absent in CW-paste cured at high temperature (CW-H100) compared to that of ambient curing (CW-Best). A new phase of calcite $\left(\mathrm{CaCO}_{3}\right)$ was detected in $\mathrm{CW}$-based geopolymer binders after which it likely formed when calcium hydroxide reacted with atmospheric carbon dioxide (J. Provis \& van Deventer, 2009). 


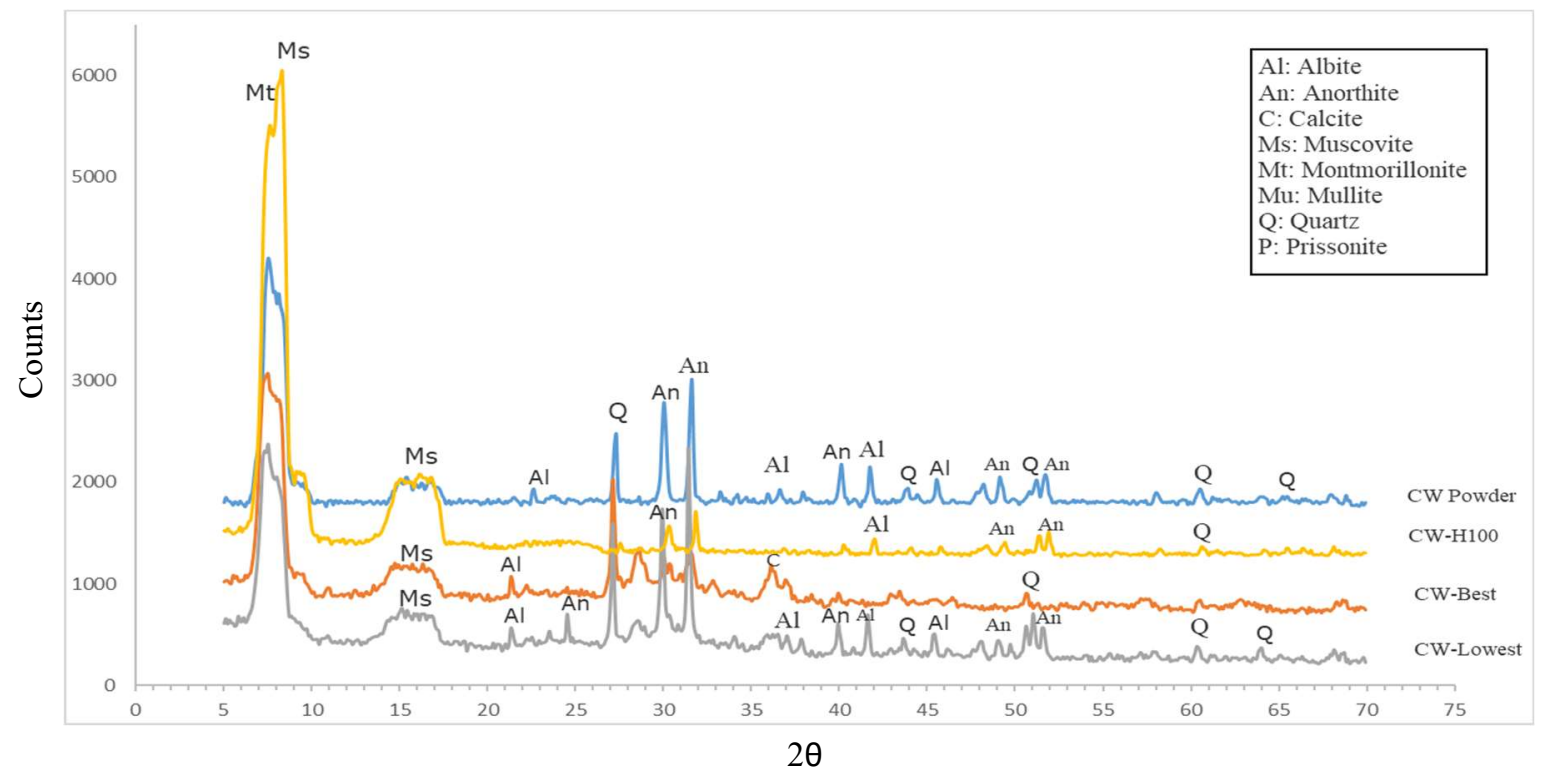

Figure 4.38 XRD patterns of CW powder (CW powder) and mono-CW binder at high temperature (CW-H100) and room temperature curing (CW-Best and CW-Lowest with higher and lower strength respectively)

\section{- XRD Analysis of binary-system CDW pastes}

$\mathrm{XRD}$ patterns of binary combinations of $\mathrm{RCBW}+\mathrm{CW}-, \mathrm{CTW}+\mathrm{CW}-$, and $\mathrm{RCBW}+\mathrm{CTW}$-based geopolymer binders are shown in Figures 4.39, 40 and 4.41 respectively. The selected compositions with lower and higher compressive strengths at ambient temperature were BC-7.7-0.24-0.3 and BC-8.4-0.180.30 respectively; whereas, that at high temperature was the same as the high strength mix at room curing (BC-8.4-0.18-0.30). From Figure 4.39, the presence of high intensity peaks of muscovite, montmorillonite, quartz, anorthite and pirssonite were observed. As for mono-system compositions, the intensity of crystalline phases in $\mathrm{RCBW}+\mathrm{CW}$ pastes reduced with increased strength of the specimens. This was obvious from the reduced quartz patterns between the lower and higher compressive strength mixes cured at the same conditions, and between those of optimal strengths and ambient and high curing temperatures. 


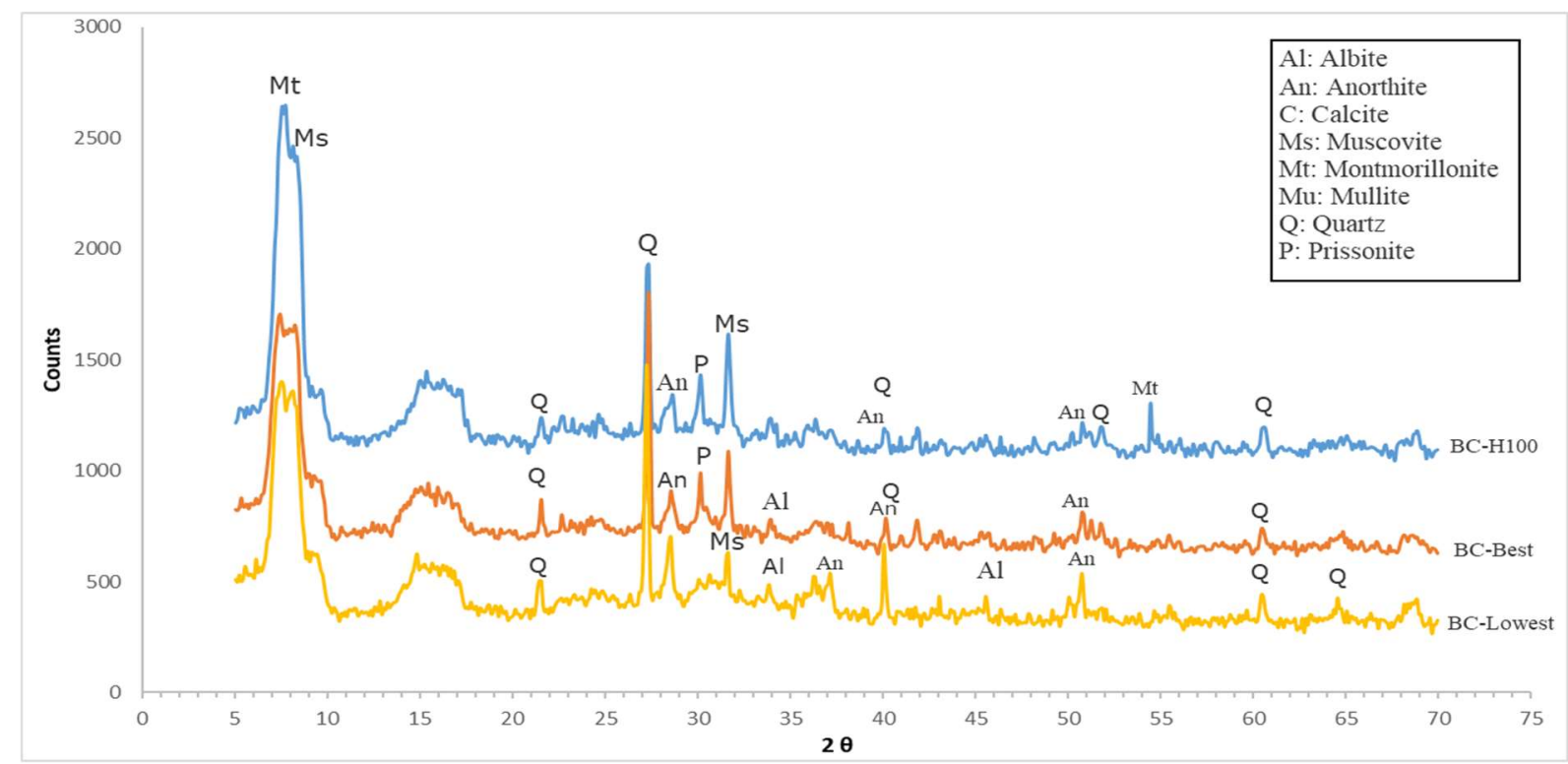

Figure 4.39 XRD patterns of binary RCBW+CW geopolymer binders at high temperature (BC-H100) and room temperature curing (BC-Best and BC-Lowest with higher and lower strength respectively) XRD analysis of binary CTW+CW geopolymer binders shown in Figure 4.40 revealed the presence of intensive peaks of muscovite, montmorillonite, quartz and anorthite in all mixes. However, the intensity of anorthite at around $31.6^{\circ} 2 \theta$ and pirssonite at around $31.03^{\circ} 2 \theta$ was higher in TC-Best and TC-100 with optimal strengths at room and high temperature curing than in TC-Lowest with lower strength at room temperature. This indicates that these elements were mostly formed during the geopolymerization process as a result of the presence of $\mathrm{CW}$ in the binary binder.

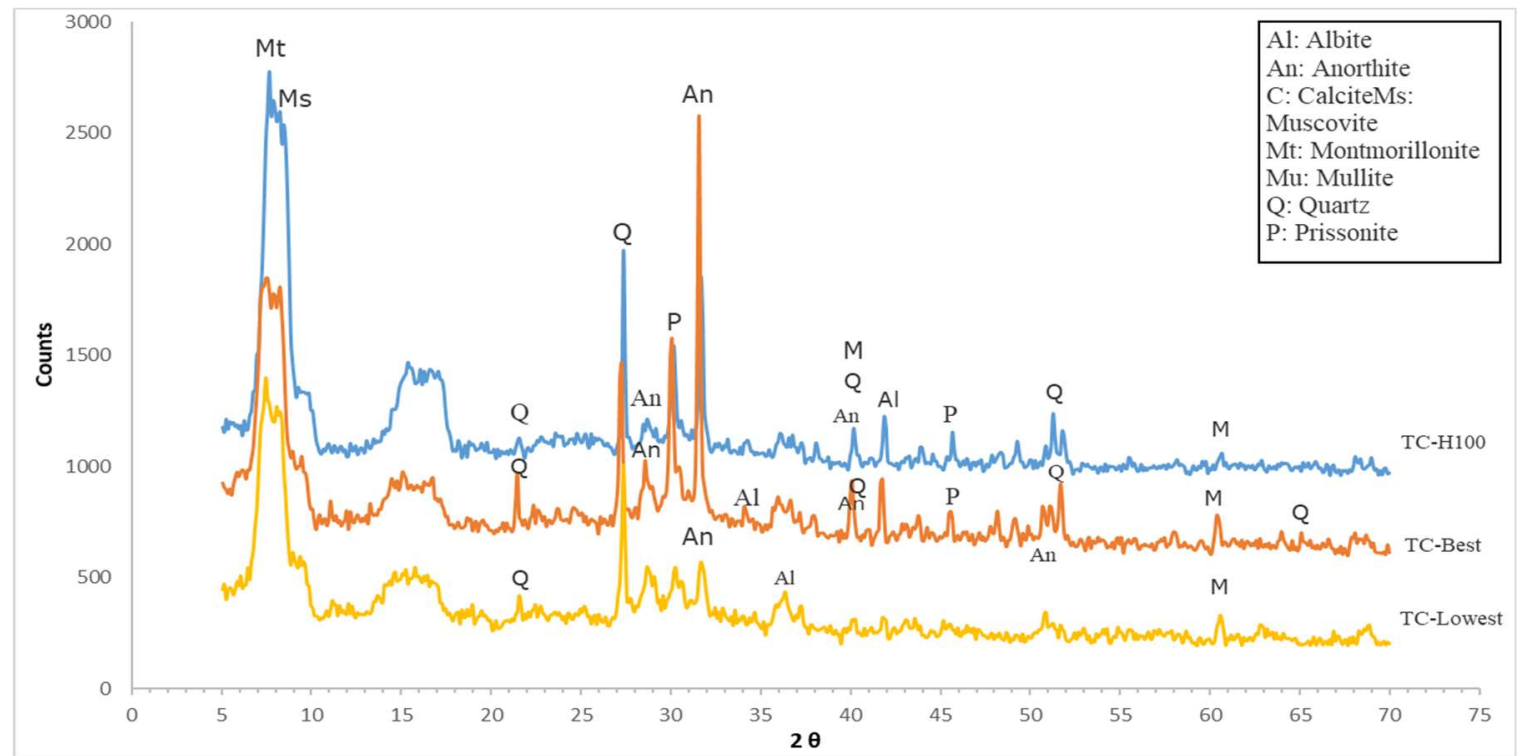

Figure 4.40 XRD patterns of binary CTW+CW geopolymer binders at high temperature (TC-H100) and room temperature curing (TC-Best and TC-Lowest with higher and lower strength respectively) 
XRD analysis of binary RCBW+CTW presented in Figure 4.41 showed lower intensity anorthite peaks compared to those of binary $\mathrm{RCBW}+\mathrm{CW}$, especially for samples derived from high strength composition at room and high-temperature curing. It can be also seen that high intensity pirssonite peak was present in high-temperature curing composition at around $31.03^{\circ} 2 \theta$, which was almost absent in other mixes. This indicates that an extra phase of pirssonite was formed as a result of the higher crystallization of calcium content during the geopolymerization process at high-temperature curing.

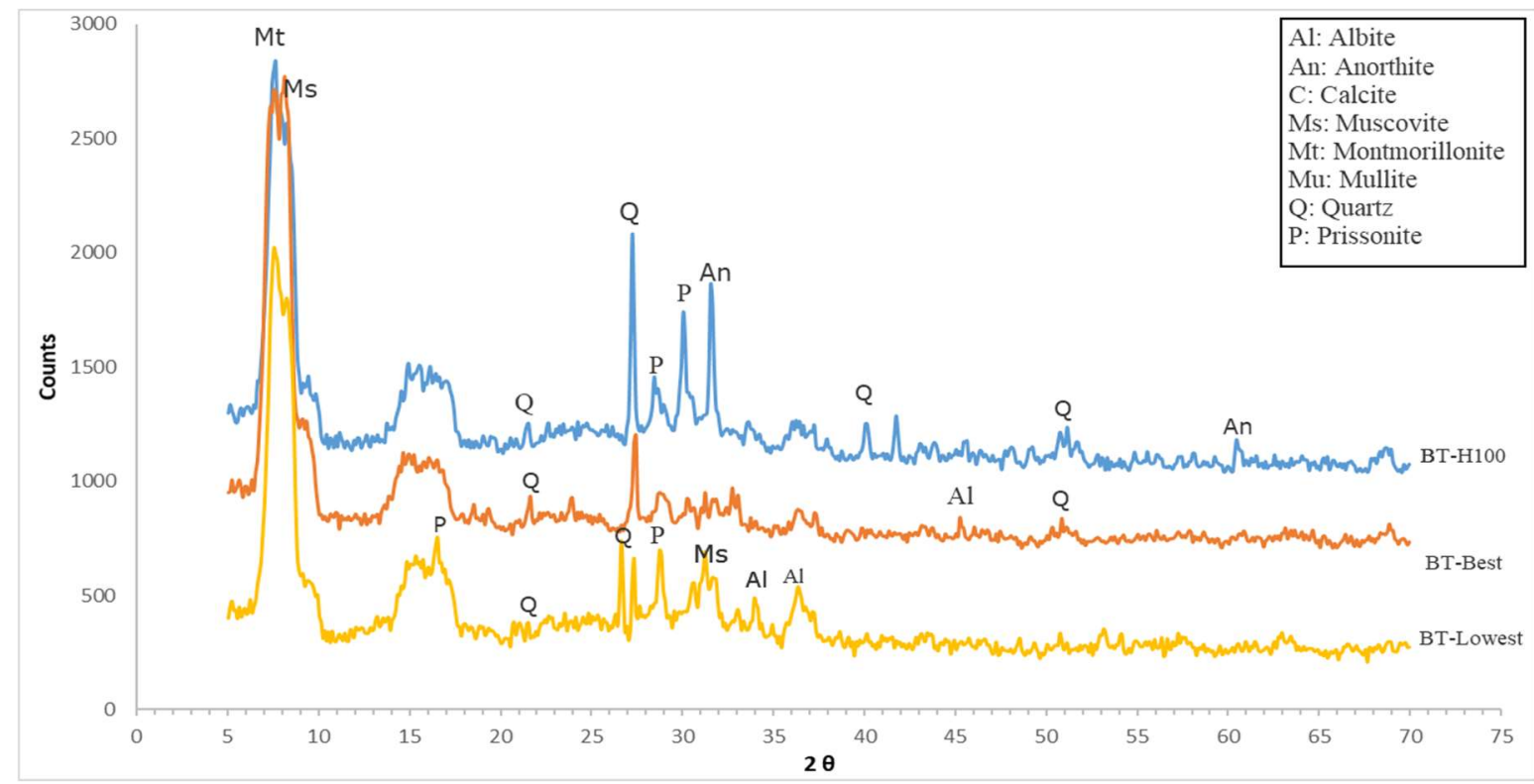

Figure 4.41 XRD patterns of binary RCBW+CTW geopolymer binders at high temperature (BT-H100) and room temperature curing (BT-Best and BT-Lowest with higher and lower strength respectively)

\section{- XRD Analysis of ternary-system CDW pastes}

$\mathrm{XRD}$ analysis of ternary $\mathrm{RCBW}+\mathrm{CTW}+\mathrm{CW}$ geopolymer binders are presented in Figure 4.42. Almost similar XRD patterns can be observed for ternary $\mathrm{RCBW}+\mathrm{CTW}+\mathrm{CW}$ than binary $\mathrm{RCBW}+\mathrm{CW}$ and binary $\mathrm{CTW}+\mathrm{CW}$ binders. The intensity of pirssonite and anorthite phases increased as the compressive strength of specimens increased. This was more evident between 29 and $33^{\circ} 2 \theta$, in which higher intensity peaks were noticed for specimens cured at high-temperature than those cured at ambient environment or issued from low strength composition. 


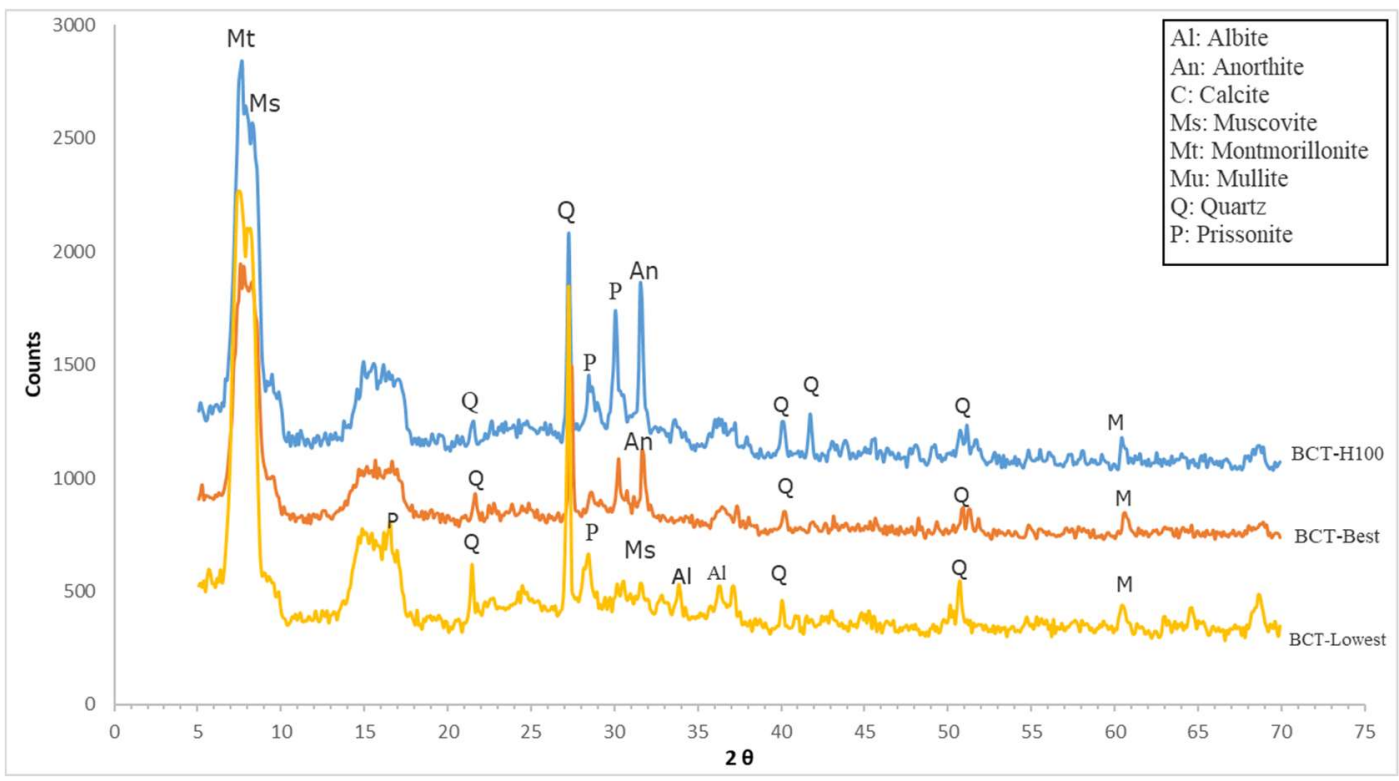

Figure 4. $42 \mathrm{XRD}$ patterns of ternary $\mathrm{RCBW}+\mathrm{CTW}+\mathrm{CW}$ geopolymer binders at high temperature (BCT-H100) and room temperature curing (BCT-Best and BCT-Lowest with higher and lower strength respectively)

\section{- XRD Analysis of mono-system CDW pastes incorporating different SCMs}

XRD patterns of mono RCBW-, mono-CTW- and mono-CW binders incorporating FA-C- FA-F, MK and GGBS are presented in Figure 4.43, 4.44 and 4.45 respectively. From Figure 4.43, intensive peaks of muscovite and montmorillonite can be seen in all SCMs-based mixes. Also, predominant amorphous phases were shown in FA-C, FA-F, MK and GGBS-geopolymers. However, the concentration of the quartz peaks at around $21.6^{\circ}$ and $27.3^{\circ} 2 \theta$ was smaller for GGBS-composition compared to other SCMsmixes, in agreement with the higher geopolymerization reaction and greater compressive strengths of this composition. Almost similar patterns were registered for mono RCBW+SCMs presented in Figure 4.44. Intensive peaks of muscovite and montmorillonite can be seen in all RCBW+SCM binders, with quartz being the third dominant phase. Also, from this figure, the intensity of crystalline phases such as quartz, albite, anorthite in all SCM based RCBW- or CTW-geopolymers reduced significantly compared to that of the raw materials presented earlier for mono compositions without SCMs. These results explain advanced dissolution of RCBW and CTW when SCMs were added, particularly in the case of GGBS addition that seems to have highly stimulated the consumption of Si available in the system. 


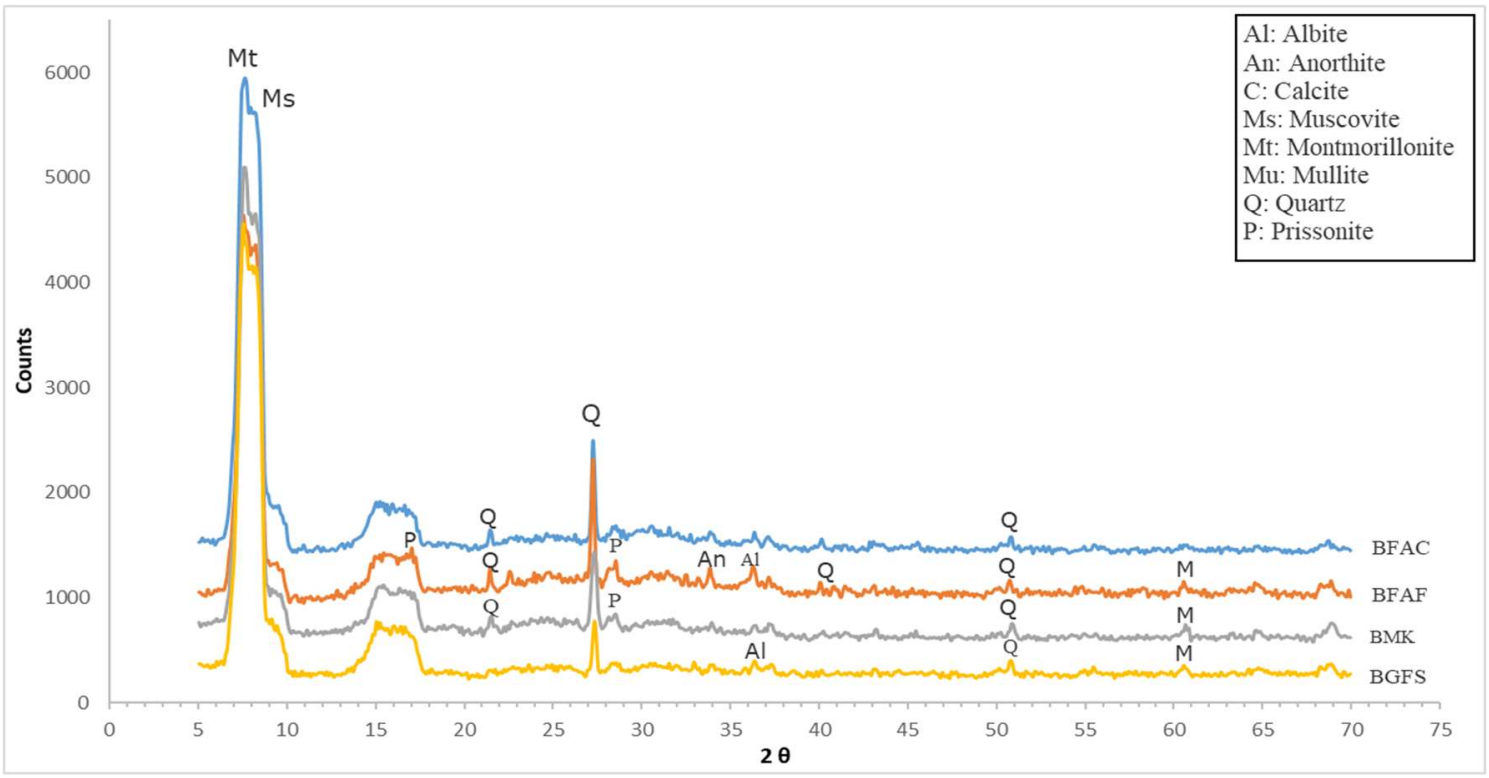

Figure 4.43 XRD patterns of mono-RCBW geopolymer incorporating FA-C (BFAC), FA-F (BFAF), MK (BMK) and GGBS (BGFS)

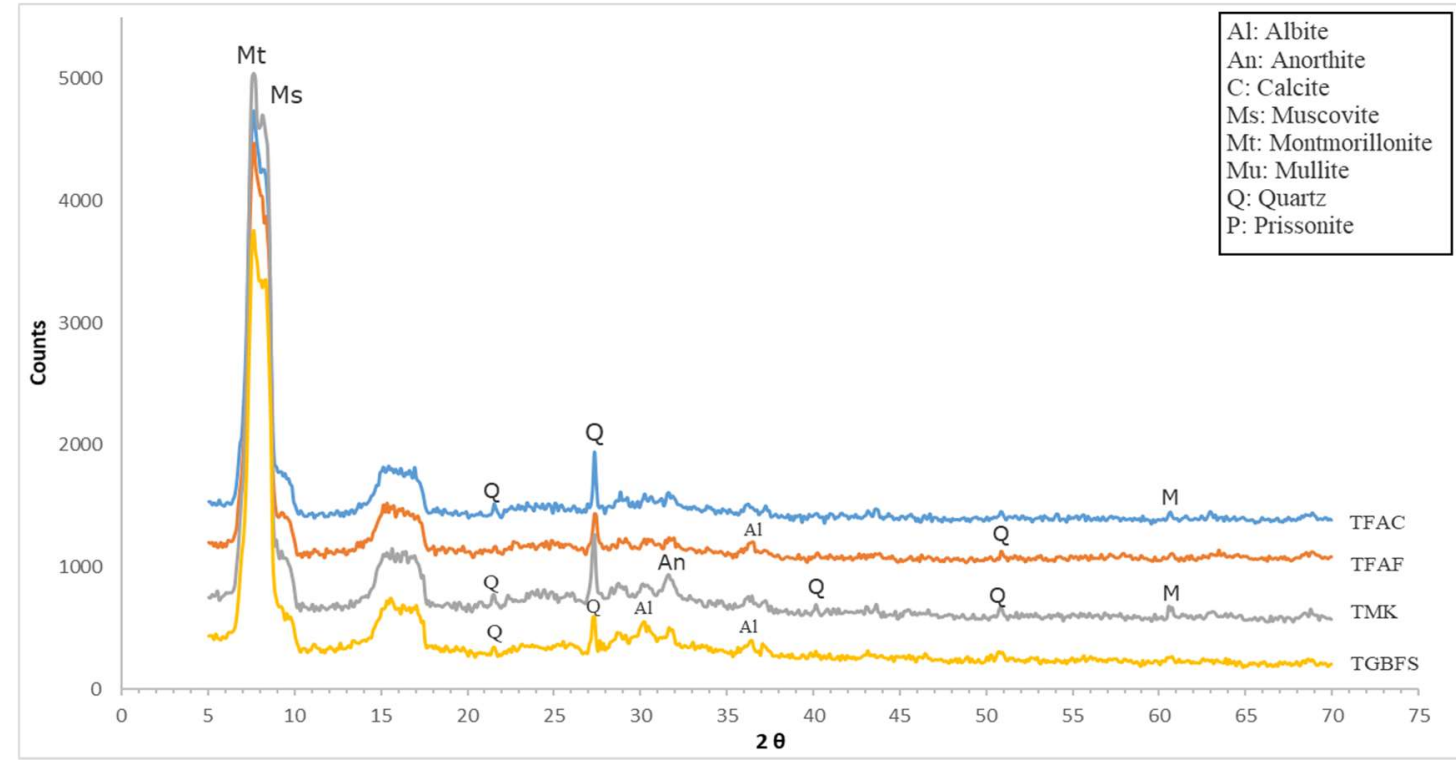

Figure 4. 44 XRD patterns of mono-CTW geopolymer incorporating FA-C (TFAC), FA-F (TFAF), MK (TMK) and GGBS (TGFS)

XRD patterns of mono $\mathrm{CW}+\mathrm{SCMs}$ in Figure 4.45 revealed the presence of anorthite and albite, in addition to intensive peaks of muscovite and montmorillonite. Pirssonite was also present in all compositions; however, with low intensity peak at around $51.5^{\circ} 2 \theta$. The addition of FA-C into mono$\mathrm{CW}$ binder resulted in reduced intensity peaks of quartz, albite and anorthite in CFAC geopolymer paste 
compared to others. These indicate that some crystalline materials were consumed during the geopolymerization process of FA-C binder.

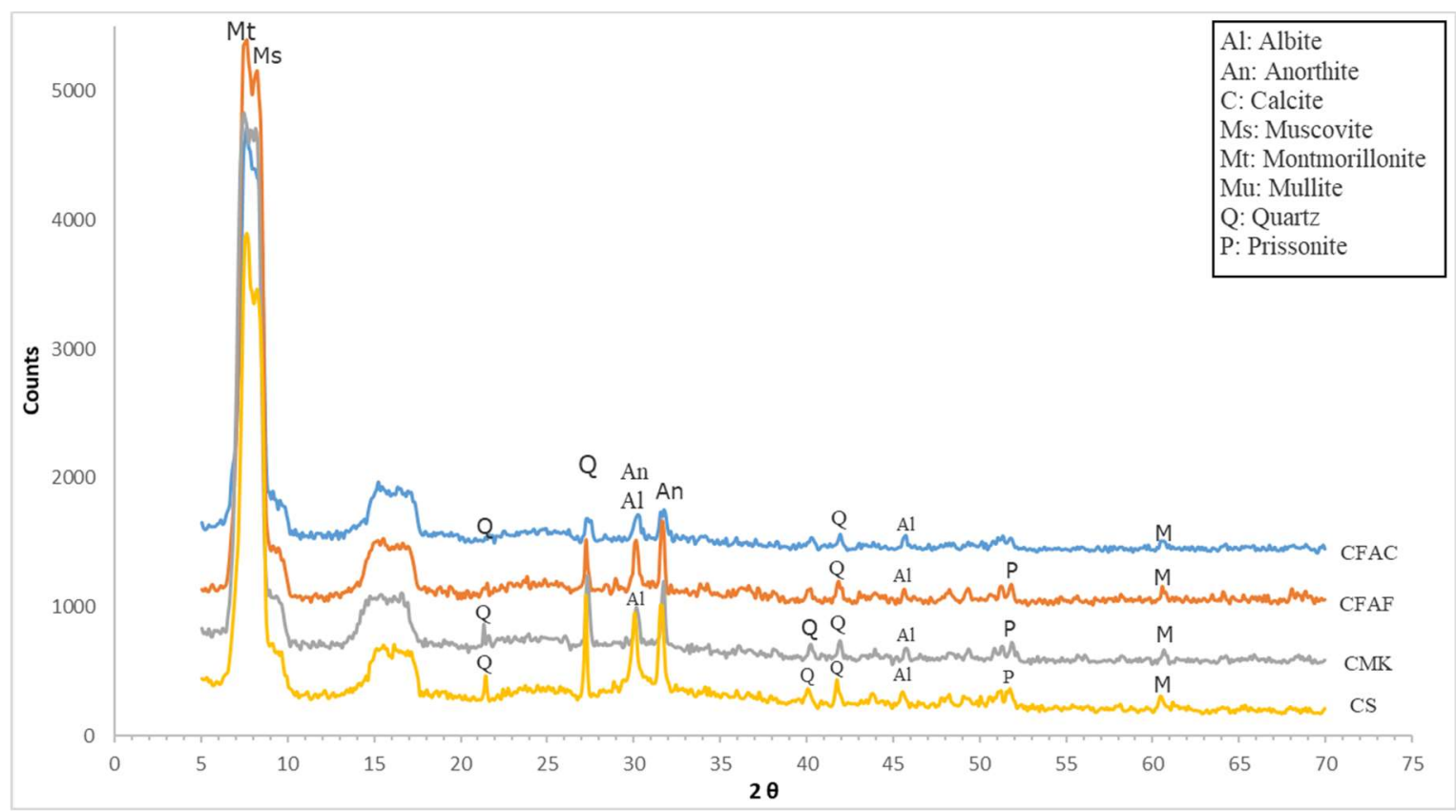

Figure 4.45 XRD patterns of mono-CW geopolymer incorporating FA-C (CFAC), FA-F (CFAF), MK (CMK) and GGBS (CS)

\section{- XRD Analysis of binary-system CDW pastes incorporating different SCMs}

The effect of different SCMs on the microstructure of binary RCBW $+\mathrm{CW}$, binary $\mathrm{CTW}+\mathrm{CW}$ and binary $\mathrm{RCBW}+\mathrm{CTW}$ binders is shown in Figures $4.46,4.47$ and 4.48 respectively. The intensity of quartz peak at around $21.6^{\circ}$ and $27.3^{\circ} 2 \theta$ was lower in GGBS, MK and FA-C-based compositions than in FA-F-mix. This shows that the addition of GGBS, MK and FA-C resulted in a higher degree of geopolymerization and consumption of crystalline phases during their geopolymeric reaction compared to FA-F powder. Interestingly, there is no big difference between the patterns of GGBS-paste, which presented a very high strength of $106 \mathrm{MPa}$, and those of FA-C and MK-binders, with $50 \mathrm{MPa}$ and $62.2 \mathrm{MPa}$ respectively. However, by comparing the humps between $20^{\circ}$ to $40^{\circ} 2 \theta$, which is called by many researchers the finger prints of geopolymerization (Chen et al. 2018, Provis \& van Deventer, 2009), it appears that the peak of albite at around $30.2^{\circ} 2 \theta$ was slightly with higher intensity in GGBS binder compared to other SCMmixes. Also, muscovite and montmorillonite were clearly lower in GGBS- than other SCMcompositions. 


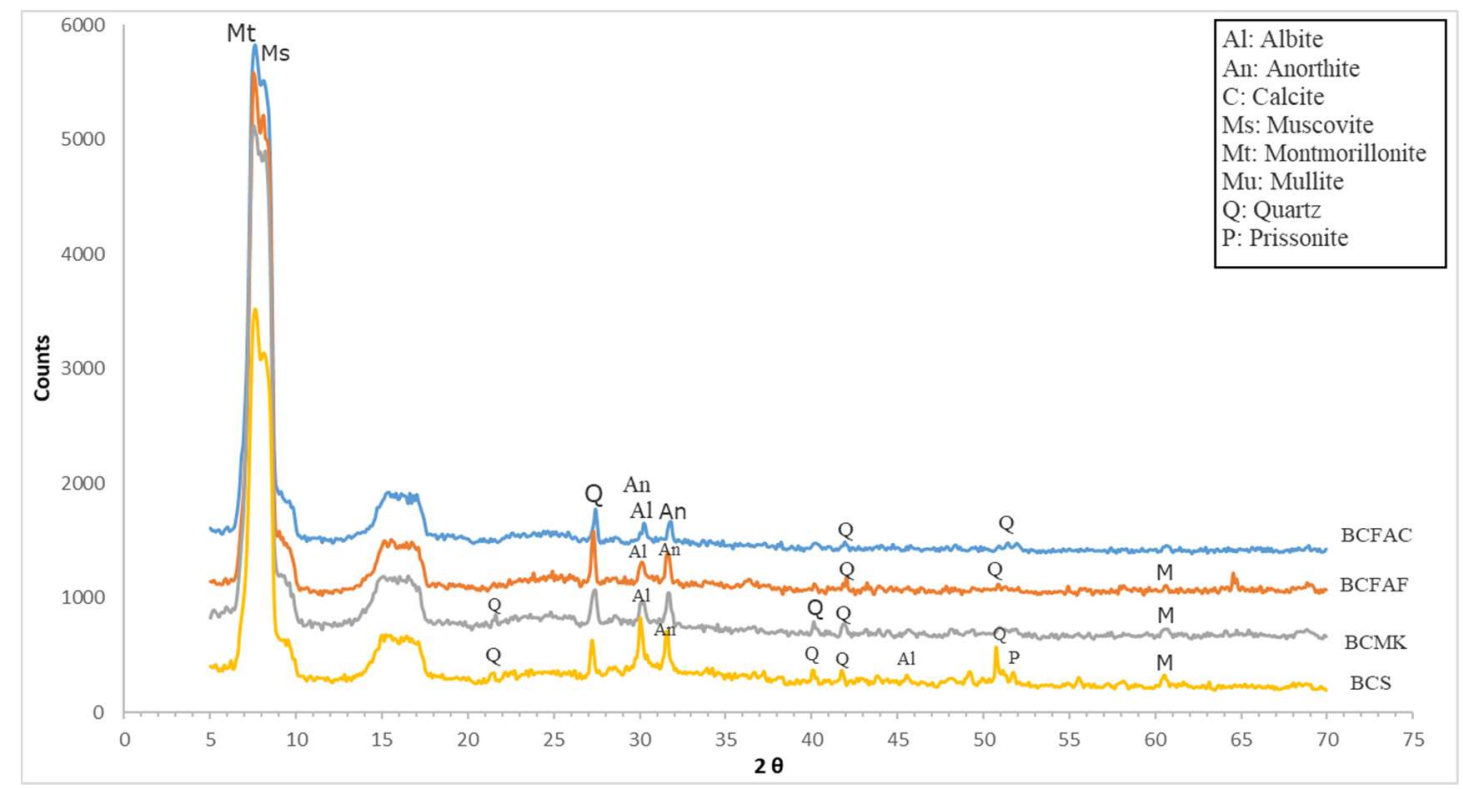

Figure 4.46 XRD patterns of binary-RCBW+CW geopolymer incorporating FA-C (BCFAC), FA-F (BCFAF), MK (BCMK) and GGBS (BCS)

The effect of the addition of SCMs on the XRD patterns of binary CTW+CW binders (Figure 4.53) indicates comparable peaks to those shown for binary $\mathrm{RCBW}+\mathrm{CW}$ incorporated different SCMs. A distinct observation can be made for FA-F-based CTW $+\mathrm{CW}$ paste, which was missing the peak of anorthite at around $32^{\circ} 2 \theta$. This indicates that the microstructure of FA-F binder was mostly dominated by sodium-based plagioclase phases such as albite. However, the dominant peaks for other SCM-mixes was anorthite.

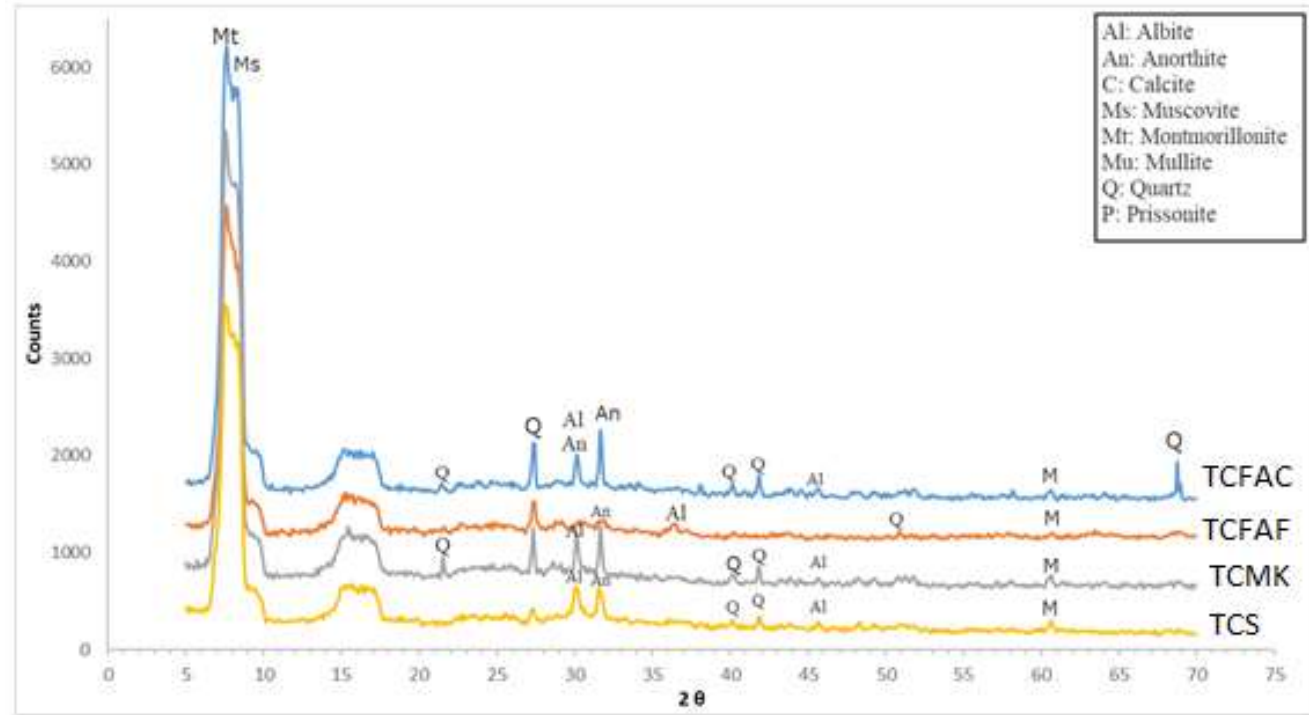

Figure 4.47 XRD patterns of binary-CTW+CW geopolymer incorporating FA-C (TCFAC), FA-F (TCFAF), MK (TCMK) and GGBS (TCS) 
From Figure 4.48, the XRD patterns of binary RCBW+CTW incorporating FA-F showed reduced intensity peaks of albite, anorthite and quartz, while muscovite and montmorillonite presented equivalent intensity peaks compared to other SCM-pastes. This trend indicates that the crystalline phases of montmorillonite and muscovite observed at $7.8^{\circ} 2 \theta$ and $8.9^{\circ} 2 \theta$ respectively, which were also present in the precursor powders, were not consumed during the geopolymeric reaction of BTFAC, BTFAF and BTMK compositions. On the other hand, albite, anorthite, mullite and quartz have been partially or totally consumed during the geopolymerization process, and consequently contributed to the development of mechanical strengths of SCM-based binders.

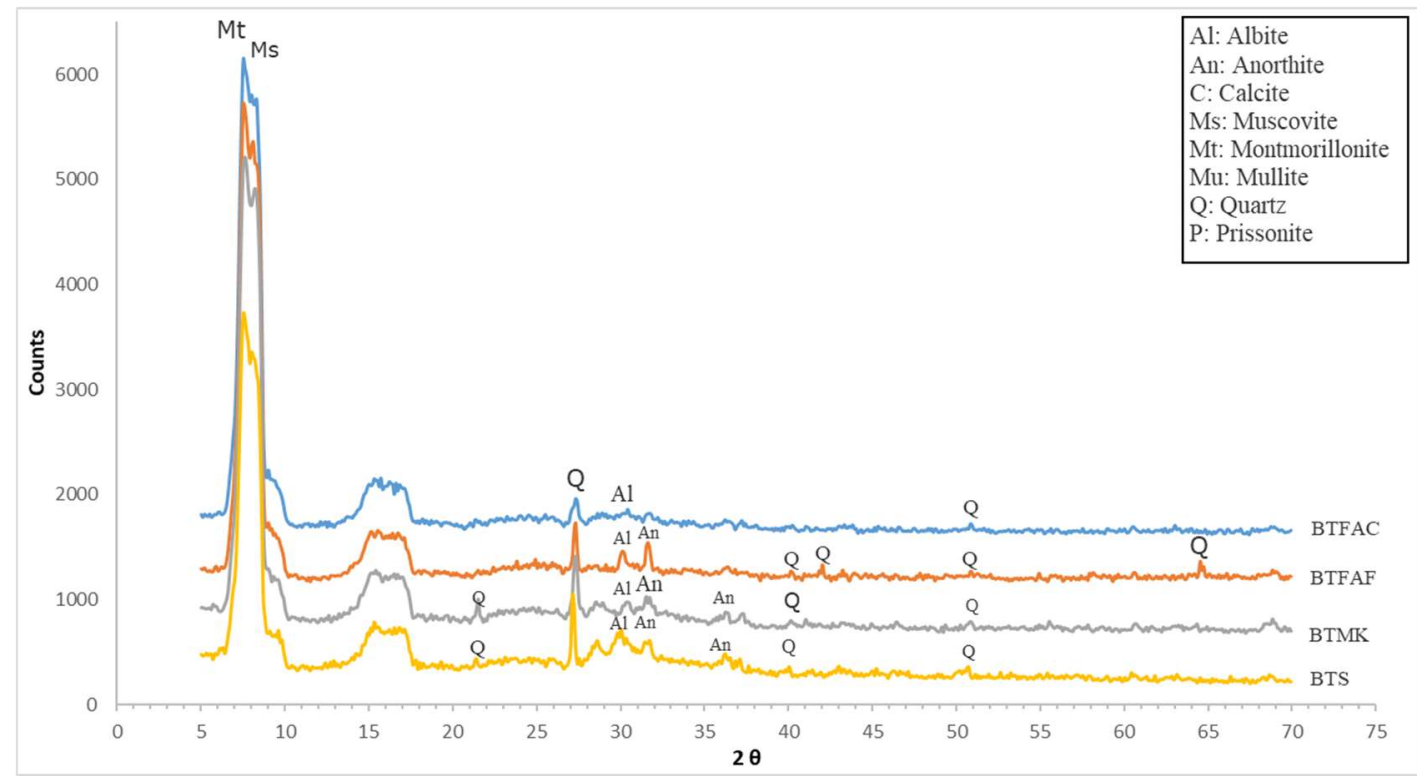

Figure 4. 48 XRD patterns of binary-RCBW+CTW geopolymer incorporating FA-C (BTFAC), FA-F (BTFAF), MK (BTMK) and GGBS (BTS)

\subsubsection{Scanning Electron Microscopy (SEM) and EDS Analysis}

Scanning electron microscopy (SEM) and energy dispersive X-ray spectroscopy (EDS) have been widely used to investigate the microstructural characteristics of geopolymers. According to Fernández-Jiménez et al., (2005), microstructural density, morphology and reaction products of geopolymers can be determined and analyzed through a combined use of SEM and EDS.

Specimens exhibiting the higher and lower compressive strengths at room curing temperature were selected for SEM-EDS analysis. In addition, the effect of high temperature curing and the addition of SCMs on the microstructure of different geopolymer systems was also investigated by analyzing the higher compressive strength composition of these geopolymers. Selected specimens were investigated after 28-days of curing age. 


\section{- SEM-EDS Analysis of mono-system CDW pastes}

The SEM micrographs of mono RCBW geopolymers synthesized at room curing temperature are shown in Figure 4.49. Figure 4.49 (B1) presents the microstructure of the higher compressive strength composition (B-7.1-0.24-0.30) and Figure 4.49 (B2) shows the SEM-EDS of the lower stregth mix (B7.7-0.16-0.3). RCBW granules were largely present in Figure 4.49 (B2) compared to 4.49 (B1) indicating lower dissolution of this powder in higher than in lower strength compositions. Reaction products in SEM micrograph of B-7.1-0.24-0.30 had an irregular shape, as in B-7.7-0.16-0.3. However, greater cohesion, denser microstructure and a more homogeneous geopolymer matrix can be seen in B-7.1-0.240.30 compared to B-7.7-0.16-0.3, which is in line with the strength differences between these compositions. On the other hand, the lower strength composition demonstrated widely open and isolated pores than B-7.1-0.24-0.30. The EDS analysis of these specimens show dominant contents of silica, alumina and sodium in both compositions, indicating the formation of sodium aluminosilicate hydrate (N-A-S-H) gels during the geopolymeric reaction process. However, the higher amount of Na in lower strength composition may indicate that this element created unbalanced N-A-S-H composition in this mix, leading to lower strength development.
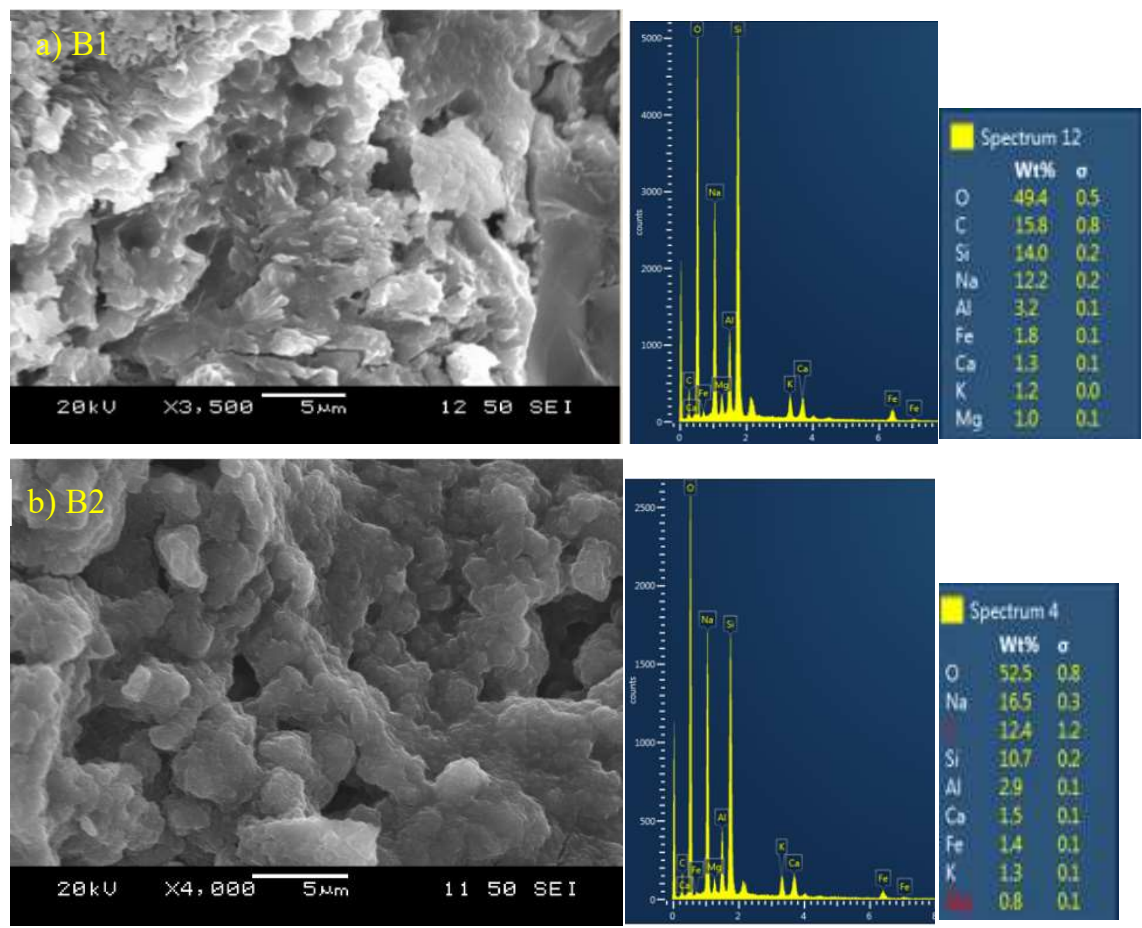

Figure 4. 49 SEM micrograph of mono RCBW geopolymers (B1) highest strength B-7.1-0.24-0.30

(B2) lowest strength B-7.7-0.16-0.3

A very different morphology is shown for mono ceramic tile wastes CTW based binders cured at room temperature (Figure 4.50). The microstructure is highly heterogenous in both higher and lower 128 
compressive strength compositions. However, the morphology of T-11.1-0.20-0.30 sample was dense, with the presence of a very small number of angular shaped unreacted particles and the geopolymeric gel was connecting these particles. It seems that the presence of inter-particle gel in this composition has provided enough microstructural cohesiveness to develop a relatively high compressive strength geopolymer $(31.8 \mathrm{MPa})$. The SEM micrograph of T-11.5-0.14-0.30 showed a highly porous microstructure with spike-like shape, and a considerably lower amount of inter-particle gel. Thus, resulting in lower compressive strength than T-11.1-0.20-0.30. The EDS of both specimens indicate the formation of N-A-S-H gel during the geopolymerization with small Ca content, explaining traces of CA-S-H. However, as with mono RCBW mix, higher $\mathrm{Na}$ amount was present in lower than higher compressive strength compositions.

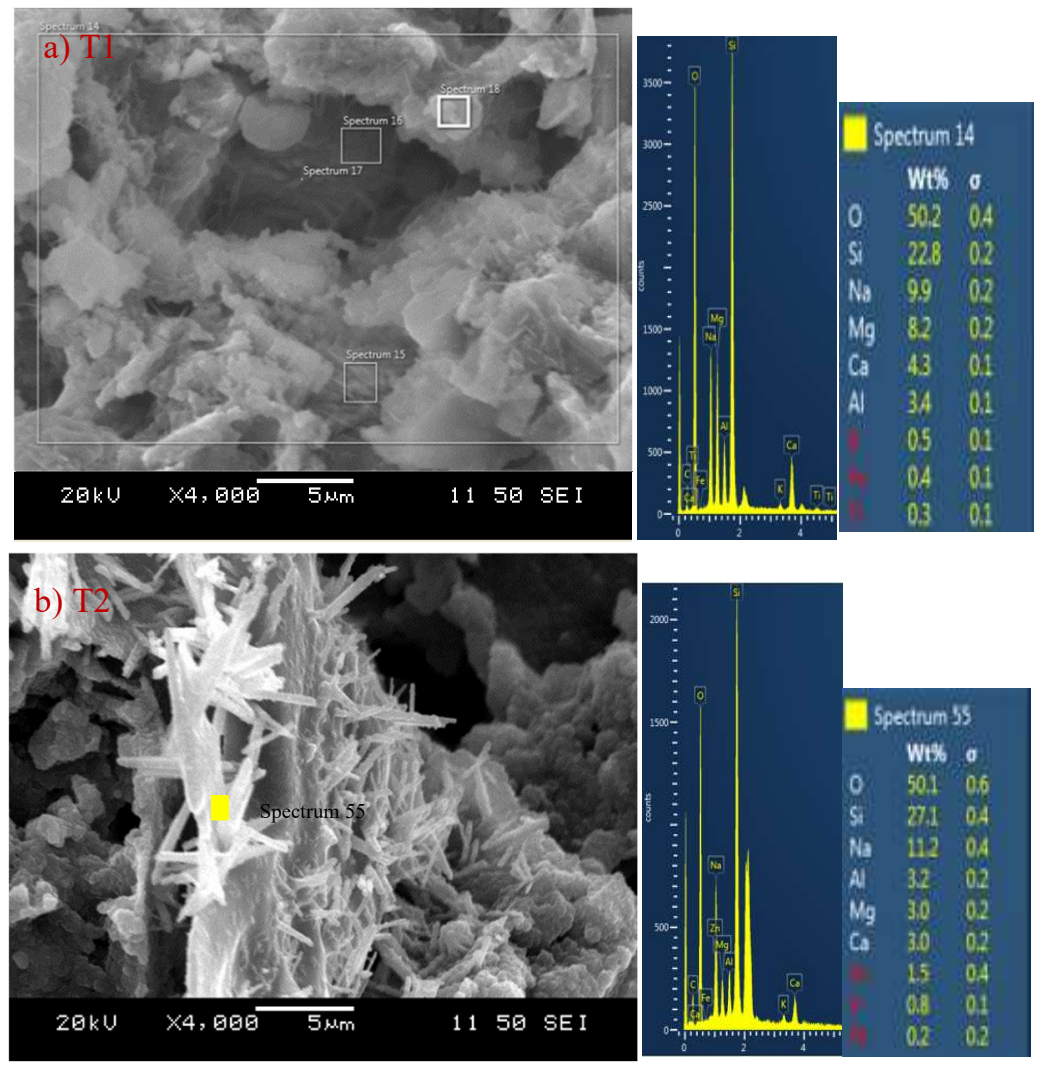

Figure 4.50 SEM micrograph of mono CTW geopolymers (T1) T-11.1-0.20-0.30 with highest strength (T2) T-11.5-0.14-0.30 with lower strength.

The SEM micrographs of mono CW-based geopolymer paste in Figure 4.51 presented quite dense microstructure for higher strength composition (C1), with no visible unreacted grains. Although the SEM micrographs revealed a dense microstructure, the strength achieved was $20.5 \mathrm{MPa}$ for this composition. This was maybe because of the mechanical performance of the reaction products, which were mostly CA-S-H and small amount of N-A-S-H, as indicated in the EDS analysis by the presence of a dominant 
content of $\mathrm{Ca}$, in high strength specimen. The SEM of the lower strength composition showed a heterogeneous matrix, with spike-like shape and a high number of unreacted grains of various sizes, indicating a geopolymer with partial development.
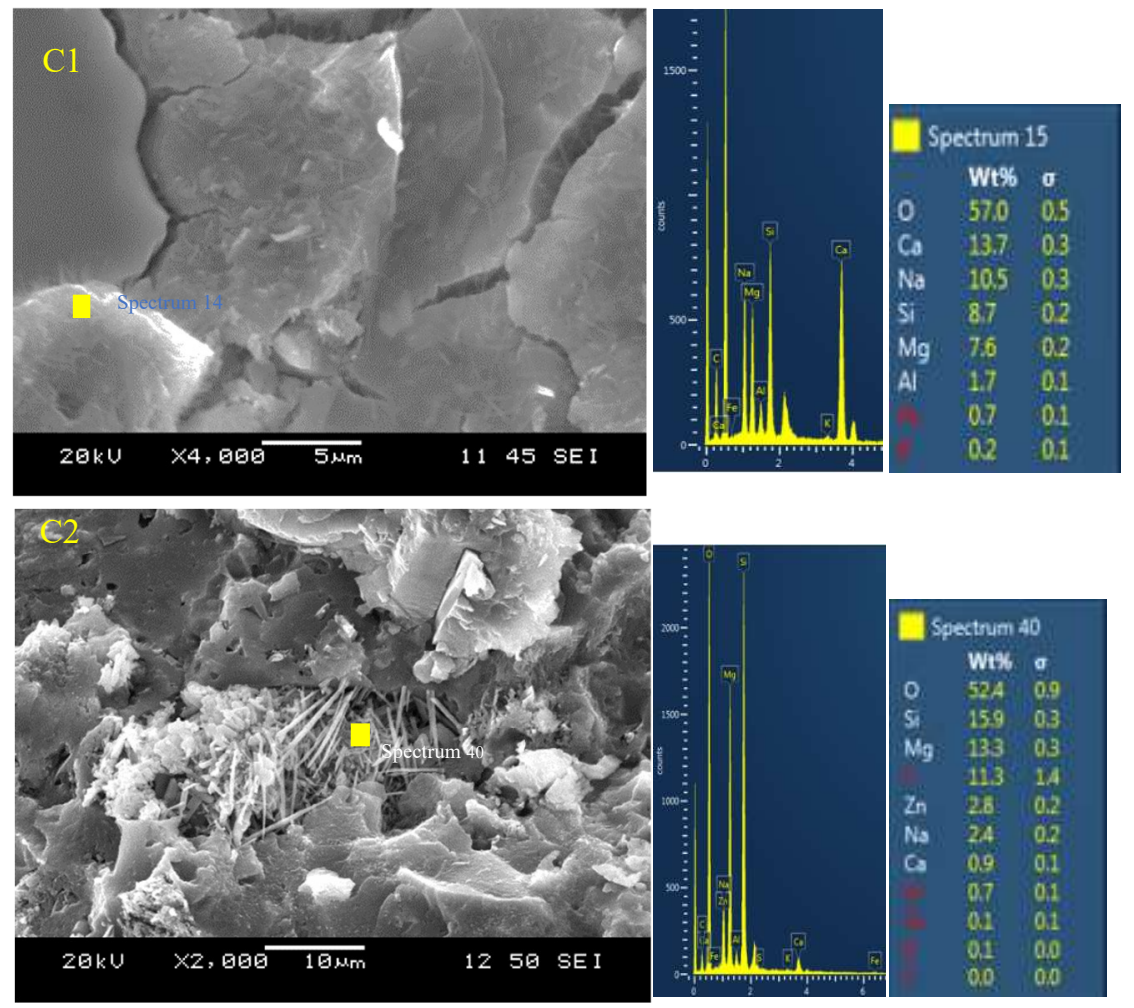

Figure 4.51 SEM micrograph of mono CW geopolymers (C1) CW-12.9-0.23-0.30 with higher strength (C2) CW-13.2-0.35-0.30 with lower strength

\section{- SEM-EDS Analysis of binary-system CDW pastes}

The SEM-EDS analysis of binary RCBW $+\mathrm{CW}$, binary CTW $+\mathrm{CW}$ and binary RCBW $+\mathrm{CTW}$ geopolymer binders is shown in Figures 4.52, 4.53 and 4.54 respectively. The micrographs (BC1) and (BC2) in Figure 4.52 were completed from specimens of mixes BC-8.4-0.18-0.30 and BC-7.7-0.24-0.30, with higher and lower compressive strengths respectively. BC1 micrograpgh presented a highly packed microstructural network with some angular shaped formations in its structure. The related EDS analysis of the darker areas at spectrum 5 location showed a high amount of $\mathrm{Ca}$ indicating a predominant $\mathrm{C}-(\mathrm{A})-\mathrm{S}-\mathrm{H}$ geopolymer product, while the location of spectrum 6 was mostly N-A-S-H gel-based geopolymer. These confirm the previous discussion about the possible presence of intermixed C-A-S-H/N-A-S-H formations as a reason for the high compressive strength reached for this composition (34.6 MPa at 28-days). According to Chen et al. (2018) and Garcia-Lodeiro et al., (2011) the concentration of these two 
geopolymeric products is a good indication of the mechanical strengths of geopolymers. SEM micrograph of the lower strength mix revealed the presence of unreacted particles with irregular shapes and its structure presented relatively porous network compared to the higher strength composition. The EDS analysis of BC2 showed a dominant presence of $\mathrm{Si}$, Na and $\mathrm{Al}$ elements, indicating the formation of $\mathrm{N}-\mathrm{A}-\mathrm{S}-\mathrm{H}$ as the main reaction product of this mix.
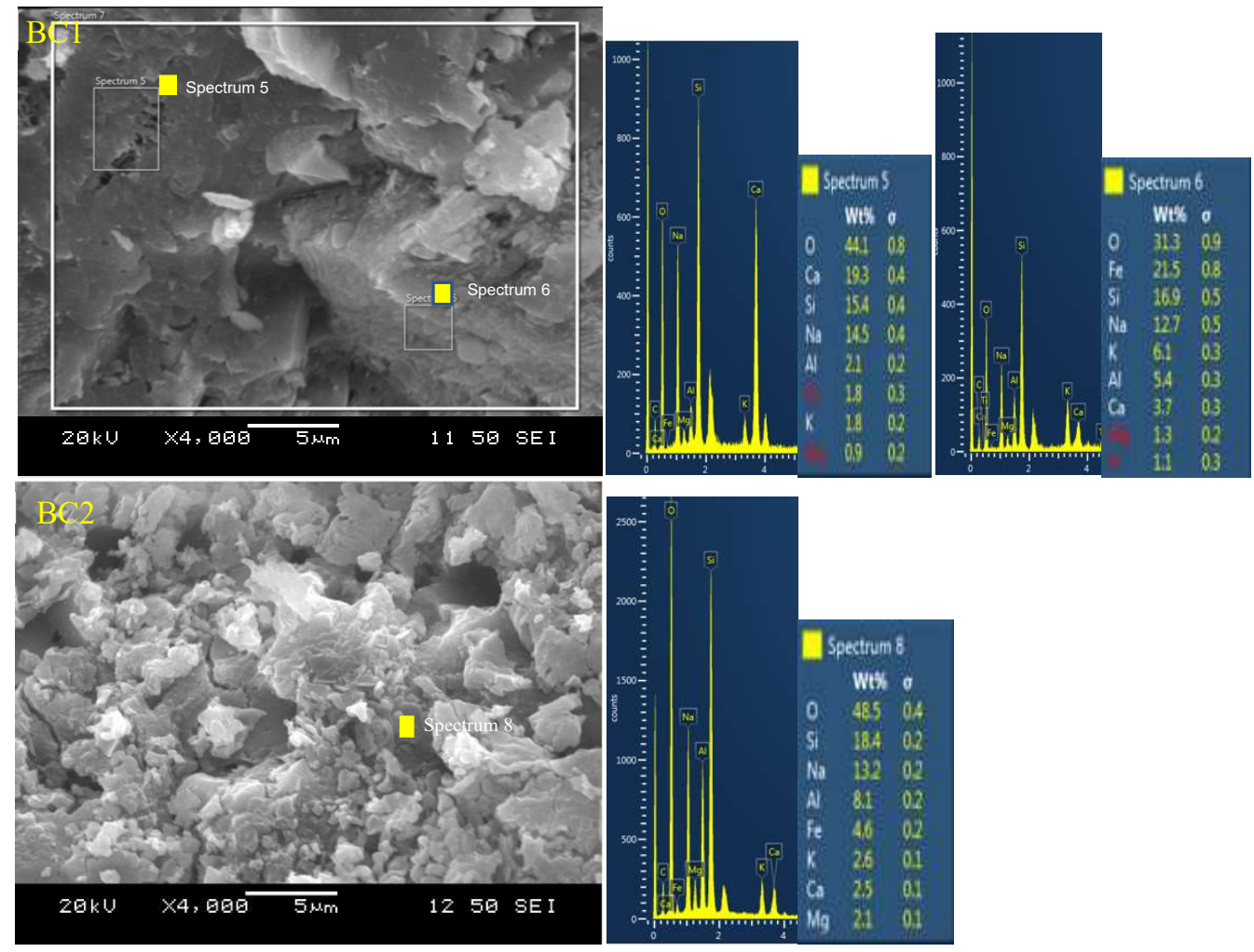

Figure 4. 52 SEM-EDS analysis of binary RCBW+CW geopolymers; (BC1) BC-8.4-0.18-0.30 with higher strength, (BC2) BC-7.7-0.24-0.30 with lower strength

SEM micrographs of binary $\mathrm{CTW}+\mathrm{CW}$ geopolymers presented in Figure 4.53 (TC1) showed the presence of crystalline condensed formations compared to a porous network seen in (TC2). Although the EDS analysis displayed high calcium content in both higher and lower strength compositions, which indicated a major $\mathrm{C}-\mathrm{A}-\mathrm{S}-\mathrm{H}$ formation in their structure, the amount $\mathrm{Na}$ in TC-11.4-0.24-0.30 was higher than that in TC-12.3-0.18-0.30. Also, the presence of high silicon content with lower $\mathrm{Si} / \mathrm{Ca}$ ratio in the high strength composition TC-12.3-0.18-0.30 indicates that the amount of silica provided at appropriate $\mathrm{Si} / \mathrm{Al}$ and $\mathrm{Na} / \mathrm{Si}$ ratios was the main aspect that controlled the compressive strength of binary $\mathrm{CTW}+\mathrm{CW}$ binders. 

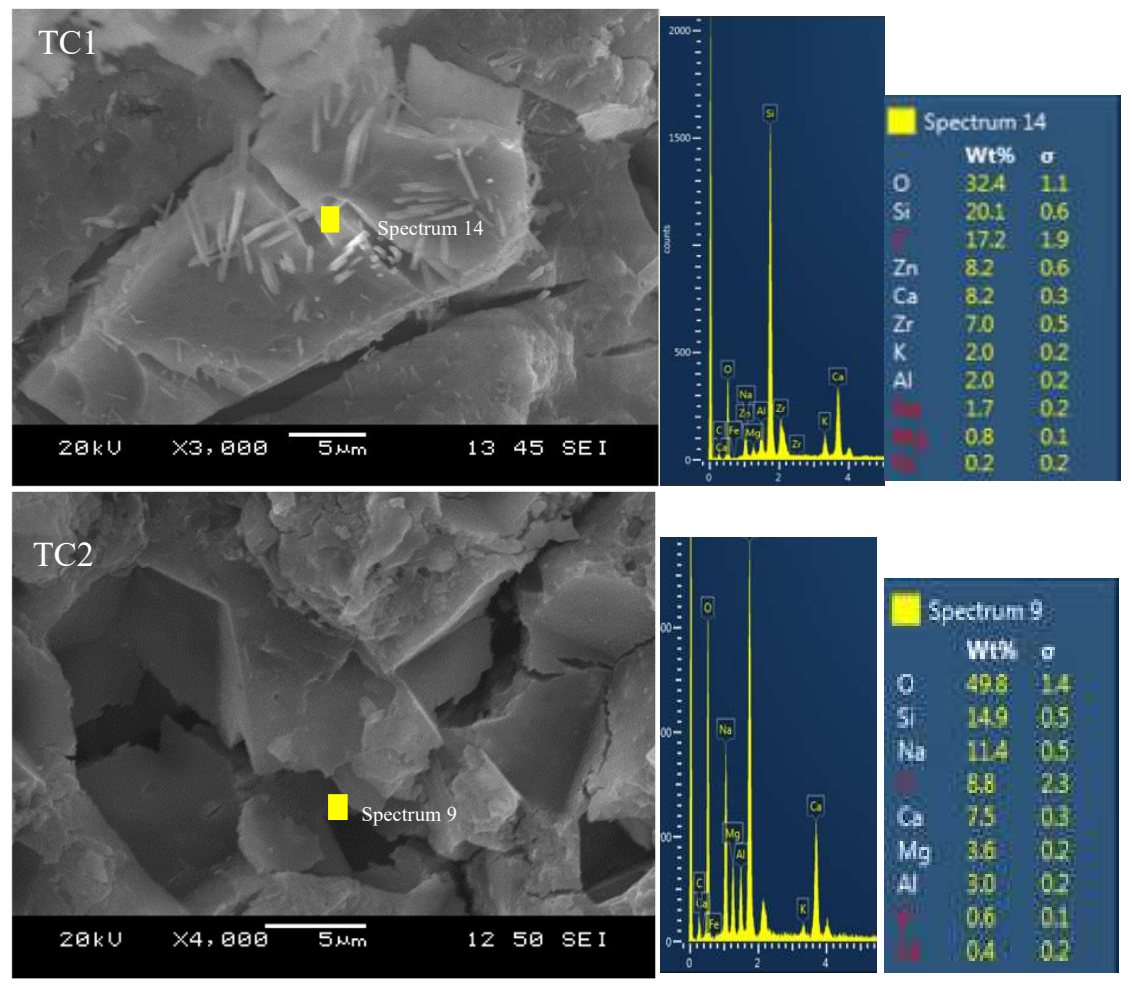

Figure 4.53 SEM-EDS analysis of binary CTW+CW geopolymers; (TC1) TC-12.3-0.18-0.30 with higher strength (TC2) TC-11.4-0.24-0.30 with lower strength

The microstructure of the higher strength binary RCBW+CTW geopolymer presented in Figure 4.54 (BT1) revealed the development of dense crystalline formation surrounded by needle-shaped products. The EDS analysis of the compact area showed a high $\mathrm{Ca}$ and $\mathrm{Na}$ content in its microstructure, indicating the formation of intermixed C-A-S-H/N-A-S-H gels. The SEM of TC2 of the lower strength specimen presented also a crystalline formation and irregularly shaped products; however, with a more looselycompacted aspect than the higher strength sample. The formation of the two distinct reaction products during the geopolymerization process of lower strength composition can be concluded from the dominant peaks of $\mathrm{Si}, \mathrm{Na}, \mathrm{Al}$ and $\mathrm{Ca}$ in its EDS spectra. Nevertheless, N-A-S-H seems to have a higher amount than C-A-S-H and these formations were not fully interconnected and cohesive thus resulting in porous microstructure and low compressive strengths in the case of TC-8.4-0.18-0.30 


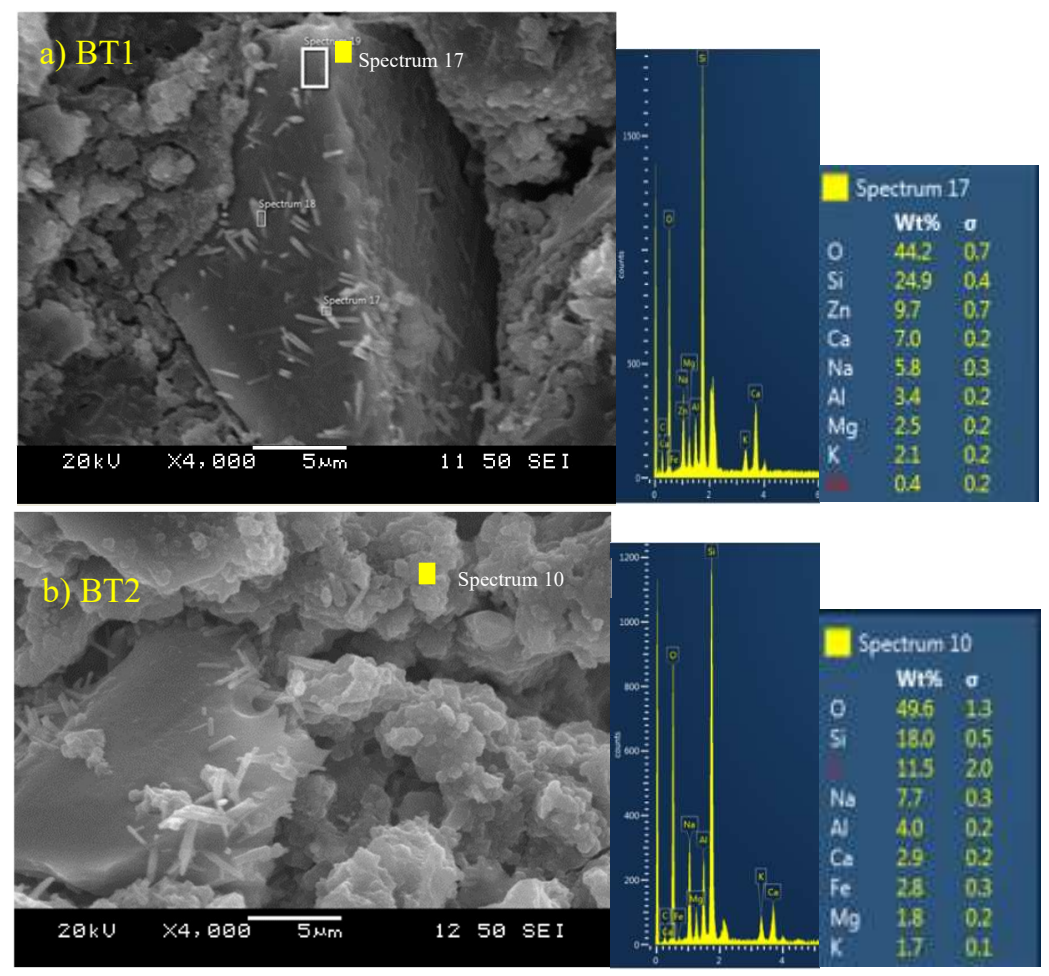

Figure 4. 54 SEM and EDS micrograph of binary RCBW+CTW geopolymers (a) BT-10-0.24-0.30 (highest) (b) TC-8.4-0.18-0.30 (lowest)

\section{- SEM-EDS Analysis of ternary-system CDW pastes}

The SEM micrographs of the higher and lower strength compositions of ternary RCBW+CTW $+\mathrm{CW}$ geopolymer binders are shown in Figure 4.55 (BCT1) and (BCT2) respectively. BCT-10.2-0.18-0.30 (BCT1) presented a strength of $52.2 \mathrm{MPa}$, which is the optimum strength reached for all mono, binary and ternary compositions cured at room temperature. The structure of this compositions showed a highly dense and packed formation, revealing a very high degree of geopolymerization. It can be also seen that the unreacted particles from the three different CDW powders were completely absent, which explains the dissolution of all precursor powders during the geopolymerization process. Also, the EDS analysis of BCT1 presented high amounts of $\mathrm{Si}, \mathrm{Ca}$ and $\mathrm{Na}$ indicating very strong structure due to the complete dissolution of powders and the high consumption of soluble silica and sodium content in the geopolyermic system. This confirms the effectiveness of the targeted $\mathrm{SiO}_{2} / \mathrm{Al}_{2} \mathrm{O}_{3}$ and $\mathrm{Na}_{2} \mathrm{O} / \mathrm{SiO}_{2}$ molar ratios in increasing the strength of CDW binders. Unlike BCT-10.2-0.18-0.30, the SEM micrograph of BCT-7.6-0.24-0.30 with lower strength showed a porous microstructure and some irregularly shaped unreacted granules. Also, a poor interparticle connectivity with less cohesive microstructure can be observed for BCT2. The EDS spectra displayed a main content of $\mathrm{Si}, \mathrm{Ca}, \mathrm{Fe}$ and $\mathrm{Na}$ in its formation. The 
presence of $\mathrm{Fe}$ is maybe related to the unreacted particles of CDW powders.

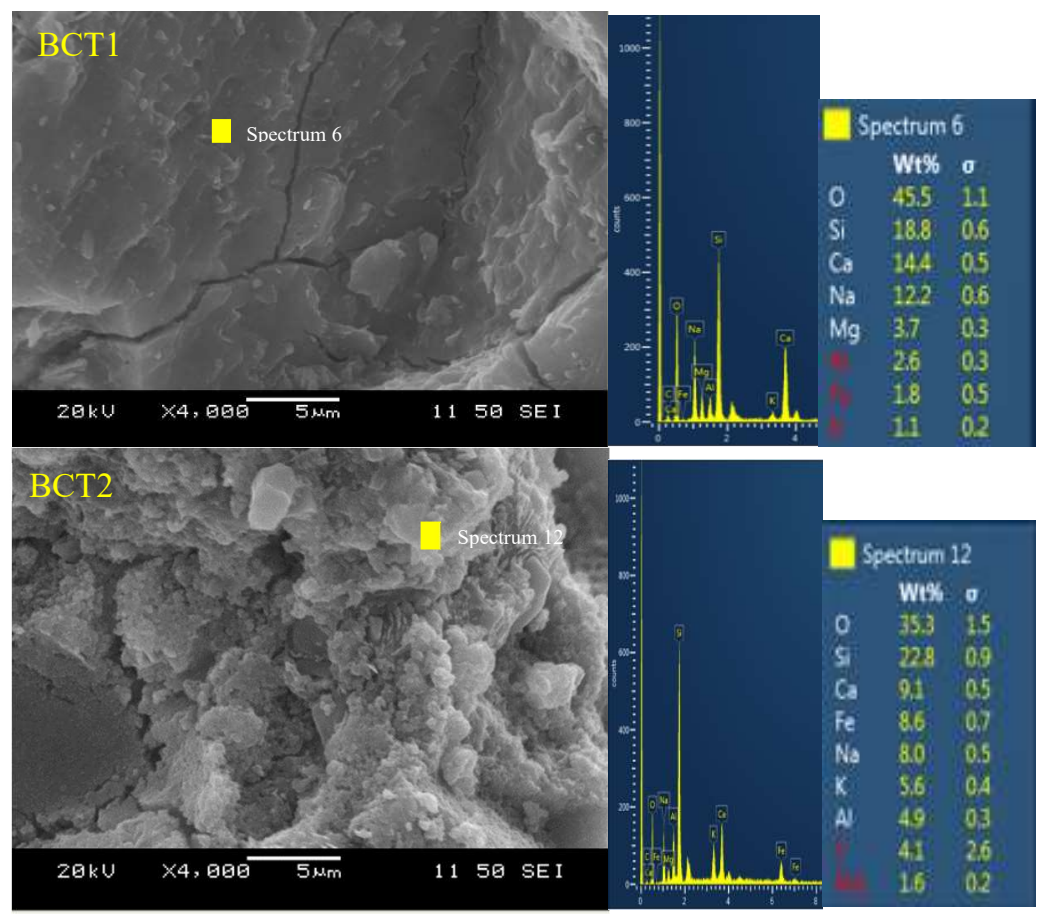

Figure 4.55 SEM-EDS analysis of ternary RCBW+CTW+CW geopolymers; (BCT1) BCT-10.2-0.180.30 with higher strength (BCT2) BCT-7.6-0.24-0.30 with lower strength

\section{- SEM-EDS analysis of mono-system CDW pastes incorporating different SCMs}

The SEM micrographs of mono-RCBW, mono-CTW and mono-CW binders incorporating FA-C, FA-F, MK and GBFS are presented in Figures 4.56, 4.57 and 4.58 respectively. The micrograph of monoRCBW prepared with different SCMs showed that FA-C (Fig. 4.56a) resulted in dense structure with no trace of unreacted particles. This indicates that the aluminosilicates present in FA-C and RCBW precursor powders were totally dissolved during the alkali attack, forming with the silica from sodium silicate solution strong $\mathrm{Si}-\mathrm{O}-\mathrm{Si}$ and $\mathrm{Si}-\mathrm{O}-\mathrm{Al}$ covalent bonds by developing cross-linked $\mathrm{SiO}_{4}$ and $\mathrm{AlO}_{4}$ tetrahedra (Chen et al., 2018). The microstructure of FA-F-based mono-RCBW specimen (Fig. 4.56b) presented some unreacted spherical particles of FA-F. These grains remained inside the geopolymer matrix during the dissolution process. likely because they were not reached by the alkalis present in the system, thus resulting in lower compressive strengths (Fernández-Jiménez et al., 2005; Garcia-Lodeiro et al., 2014; Shi et al., 2011). The micrograph of RCBW+MK sample presented a different crystalline formation of irregular shape; however, with weak cohesiveness. This can explain its reduced strength compared to FA-C-based composition. Figure 4.56d, which presented the SEM analysis of RCBW + slag specimen, indicated some isolated irregularly shaped products with porous structure and weak 
interconnectivity. In addition to $\mathrm{Si}, \mathrm{Na}$ and $\mathrm{Al}$ as the main elements showed in the EDS spectra of all specimens, high amount of $\mathrm{Ca}$ was registered in $\mathrm{RCBW}+\mathrm{FAC}$ binder, indicating a higher concentration of C-A-S-H than N-A-S-H gels in this composition. This also demonstrates the participation of FA-C particles in the dissolution of RCBW by providing appropriate amounts of $\mathrm{Ca}$, silica and alumina into the geopolymer network. The EDS of RCBW+FAF, RCBW+MK and RCBW+GGBS showed almost the same dominated peaks of sodium, silica and alumina, indicating a higher N-A-S-H formation than CA-S-H, especially for MK- and GGBS-based specimens. Also, the presence of unreacted FA-F particles seems related to the inability of alkali cations and $\mathrm{OH}^{-}$hydroxyl groups to fully dissolve the aluminosilicates of FA-F and RCBW.
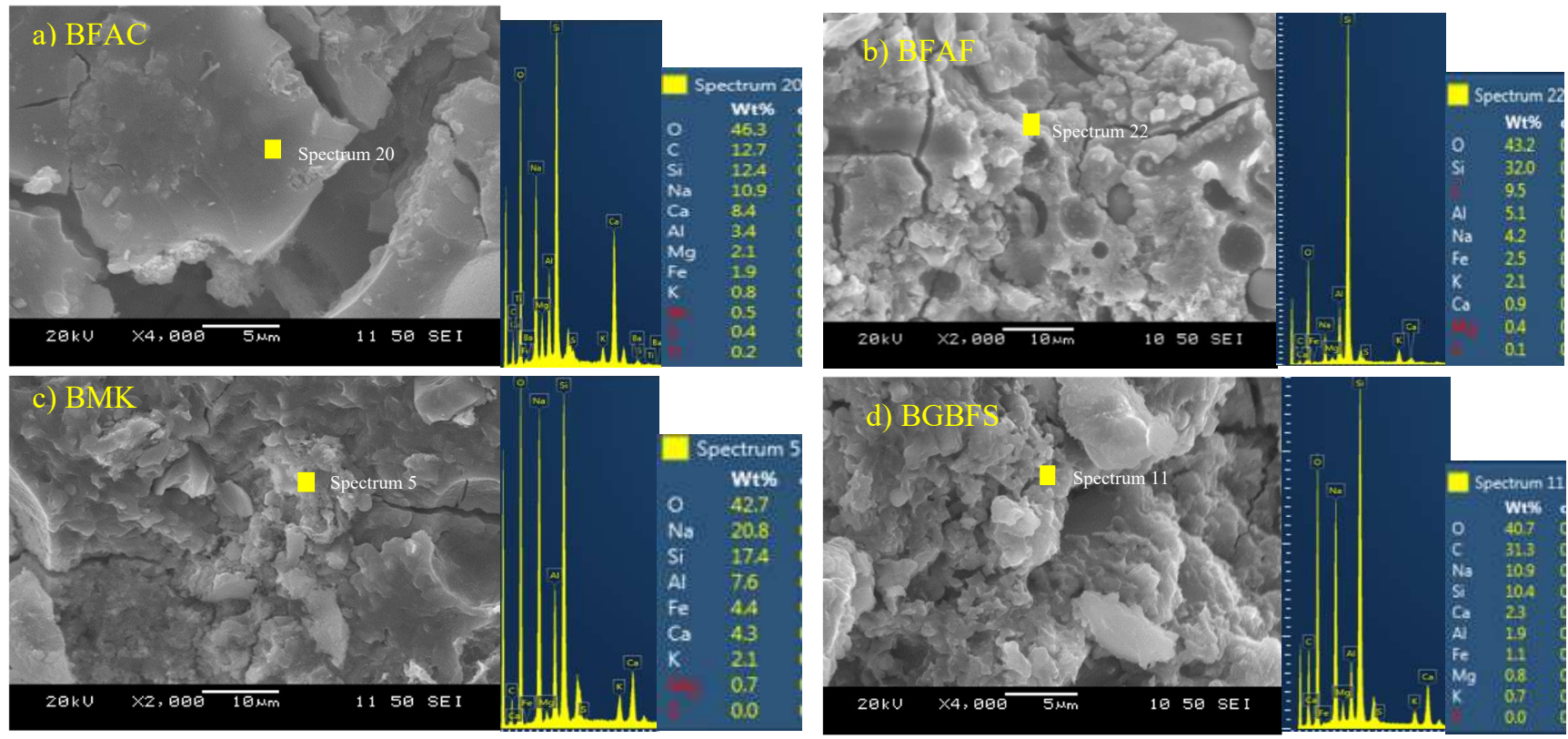

Figure 4.56 SEM-EDS analysis of mono-RCBW incorporating (a) FA-C (b) FAF (c) MK, (d) GBBS

From Figure 4.57(a), the SEM micrograph of CTW-geopolymer prepared with FA-C presented a crystalline microstructure with sharp angular edges. Although some pores were noticed, the geopolymer network looked densely packed, revealing a high degree of geopolymerization, in agreement with the high strength of FA-C-based composition. Its EDS analysis confirmed the co-precipitated formation of N-A-S-H and C-A-S-H gels. However, the elevated Ca content indicates reaction products with higher C-A-S-H amounts than N-A-S-H. Unlike FA-C geopolymer, the SEM of CTW+FA-F (Fig. 4.57(b) showed a very porous structure with a high number of unreacted spherical particles and craters, demonstrating a low degree of geopolymeric reaction. Fig. 4. 57(c) displayed the formation of two distinct reaction products. The area with crystal-like shape and dense structure was analyzed through spectrum 18, showing the presence of $\mathrm{Si}$ and $\mathrm{Ca}$ as the dominant components in its composition. This 
may indicate a C-(A)-S-H formation. The second analyzed area at spectrum 17 showed mostly needlelike structure with high presence of $\mathrm{Na}, \mathrm{Si}$ and $\mathrm{Al}$. This confirms an area reach with N-A-S-H reaction products. The SEM micrograph of CTW + slag in Figure 4.57(d) revealed also two distinct formations, a dense area with some microcracks and a porous area with irregularly shaped crystals. The presence of the low cohesiveness area may be related to the unreacted particles that affected negatively the compressive strength development of this composition.
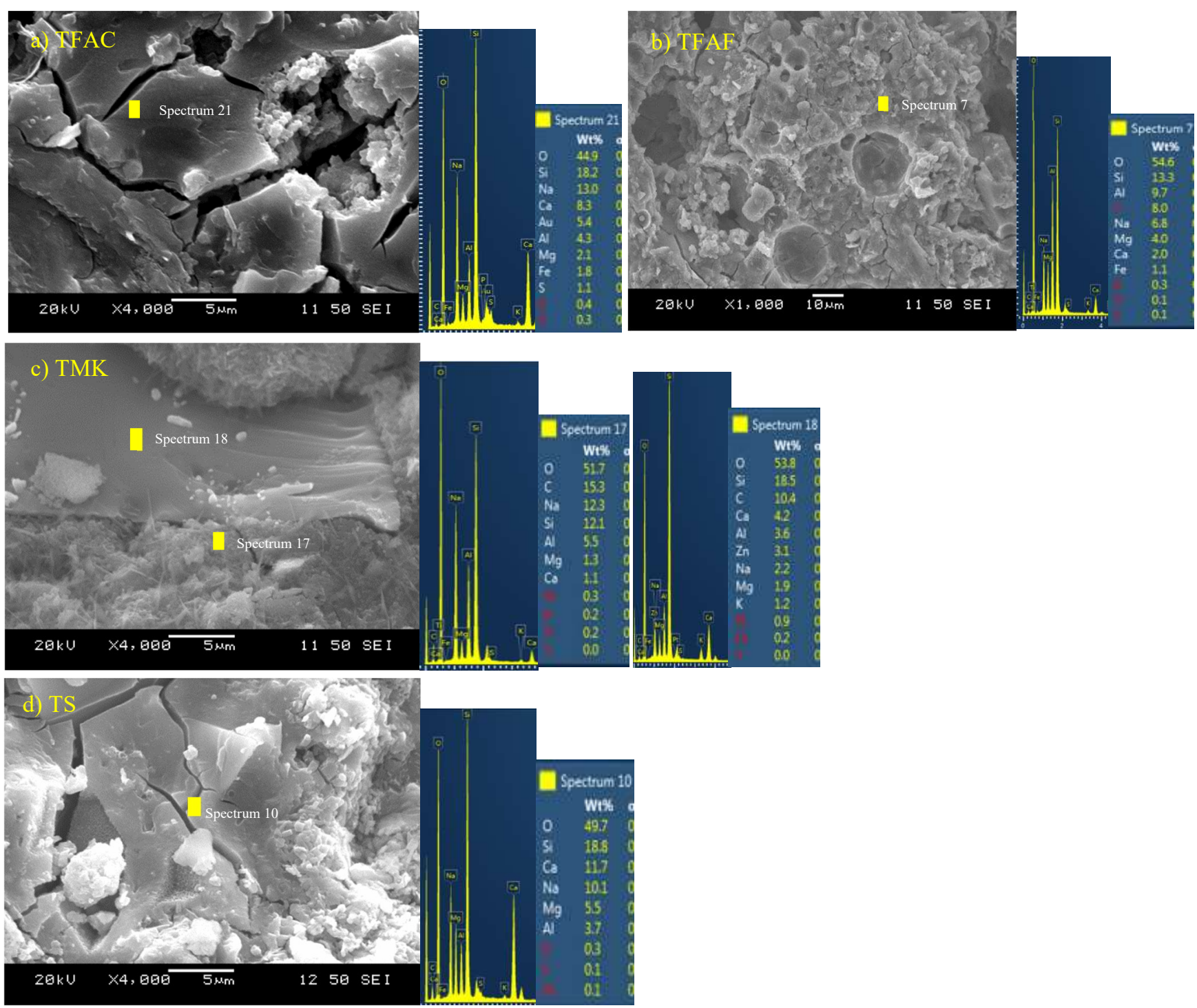

Figure 4.57 SEM-EDS analysis of mono-CTW incorporating (a) FA-C (b) FAF (c) MK, (d) GBBS

The SEM-EDS analysis of the effect FA-C on the microstructure of mono-CW binder (Fig. 4.58(a)) showed a dense formation of crystalline phase. However, some unreacted spherical particles were suspended inside the cracks. Its EDS analysis presented a major content of $\mathrm{Si}, \mathrm{Ca}, \mathrm{Na}$ and $\mathrm{Al}$, explaining an intermixed formation of C-(A)-S-H/N-A-S-H gels. As for RCBW and CTW-geopolymers, the use 
FA-F in CW-compositions resulted in low cohesiveness formations with isolated crystals, indicating the presence of partially unreacted particles of FA-F. In addition, weak porous areas were also present, revealing the formation of $\mathrm{N}-\mathrm{A}-\mathrm{S}-\mathrm{H}$ in addition to the clear structure and EDS of $\mathrm{C}-\mathrm{A}-\mathrm{S}-\mathrm{H}$ in its composition. The presence of pores and unreacted FA-F particles is in line with the reduced strength of FA-F-based mono-CW binders. From Figure 4.58(c) related to $\mathrm{CW}+\mathrm{MK}$, it also presented isolated crystals and sporadic pores with the presence of dense massy areas. The EDS analysis confirms the CA-S-H nature of these areas because of its high $\mathrm{Ca}$ concentration, which revealed that $\mathrm{CW}$ particles were largely dissolved and consumed during the geopolymerization reaction process. The SEM-EDS of CW +GGBS binder showed a very dense and highly-packed microstructure with solid crystalline phase. Its EDS analysis revealed the high formation of intermixed C-A-S-H/N-A-S-H gels, providing a significant increase in the compressive strength of CW-geopolymer compared to other mono-CDW pastes.
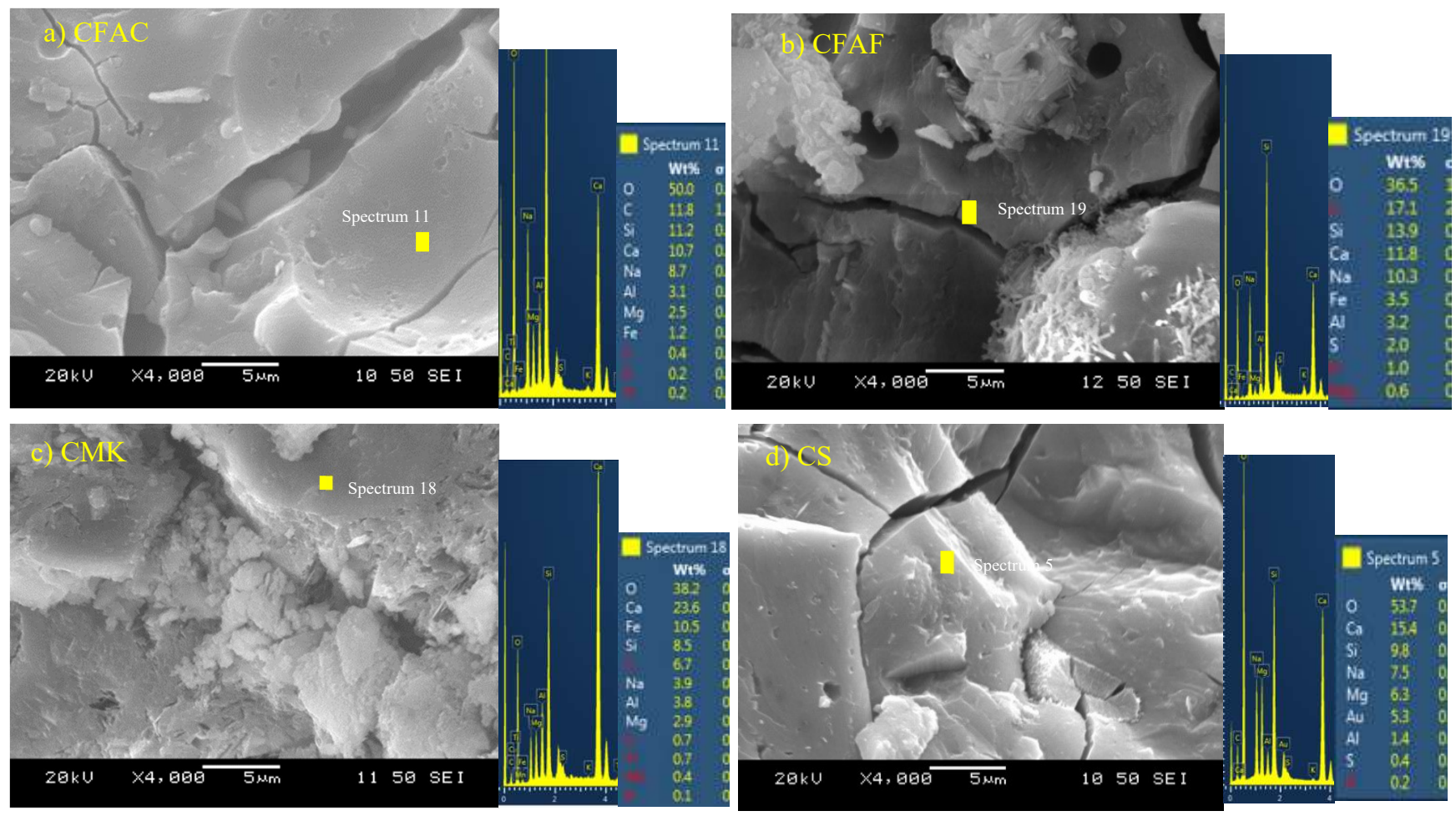

Figure 4.58 SEM-EDS analysis of mono-CW incorporating (a) FA-C (b) FA-F (c) MK, (d) GBBS

\section{- SEM-EDS analysis of binary-system CDW pastes incorporating different SCMs}

Figures 4.59, 4.60 and 4.61 present the SEM-EDS analysis of binary $\mathrm{RCBW}+\mathrm{CW}, \mathrm{CTW}+\mathrm{CW}$ and RCBW+CTW incorporating different SCMs. From Figure 4.59(a), SEM micrograph of binary $\mathrm{RCBW}+\mathrm{CW}$ prepared with MK presented a dense microstructure with angular shape. Its EDS analysis indicated the presence of $\mathrm{Si}, \mathrm{Al}, \mathrm{Na}$ and small $\mathrm{Ca}$ content, indicating the formation of intermixed N-A- 
$\mathrm{S}-\mathrm{H} / \mathrm{C}-\mathrm{A}-\mathrm{S}-\mathrm{H}$ gels during the polymerization reaction; however, with more presence of N-A-S-H than C-A-S-H. The binary RCBW+CW incorporating GGBS indicated an extremely dense and highly-packed microstructure, in agreement with its high compressive strength of $106.5 \mathrm{MPa}$ at 28-days curing age. The EDS analysis of this specimen revealed also the intermixed formation of C-A-S-H/N-A-S-H gels, with higher presence of C-A-S-H compared to N-A-S-H products.

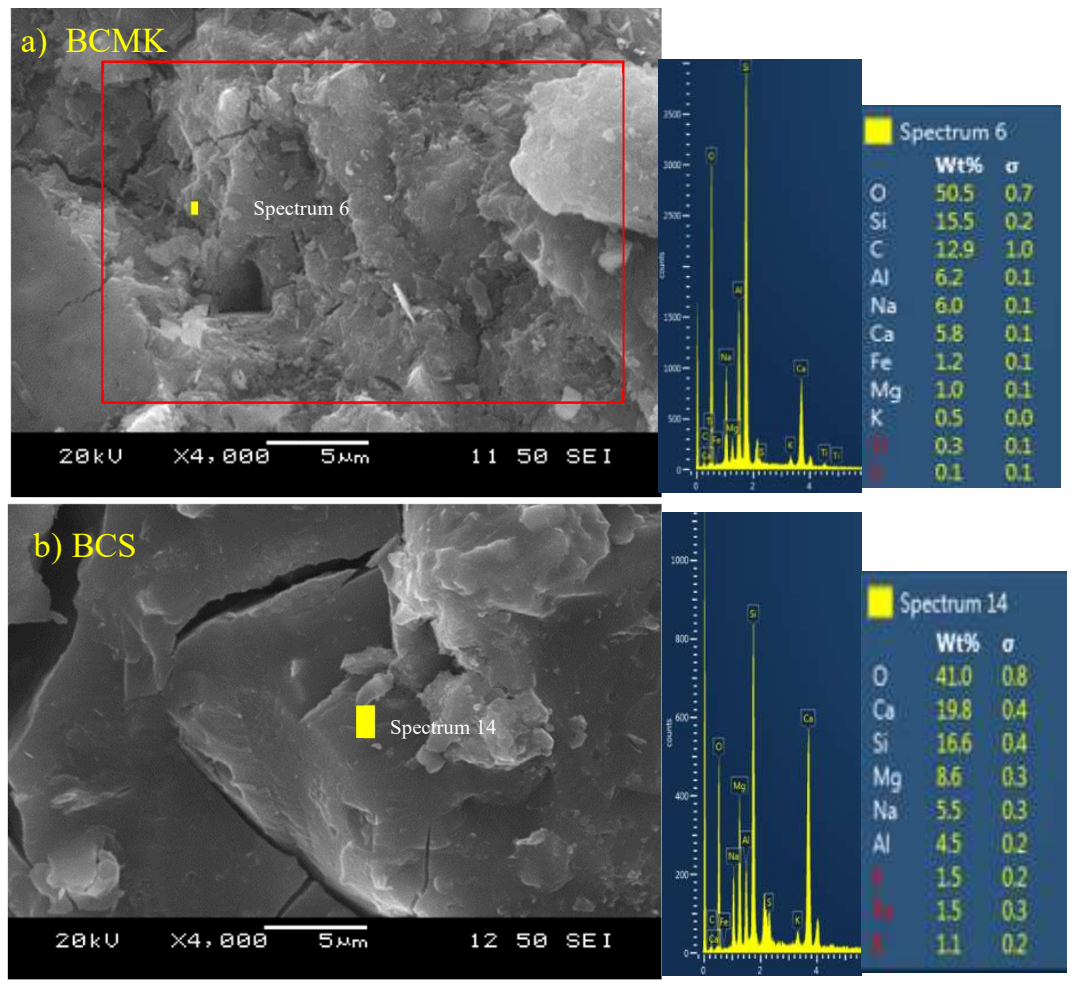

Figure 4.59 SEM-EDS analysis of binary RCBW+CW binder incorporating (a) MK (b) GGBS

From Figure $4.60(\mathrm{a})$, the incorporation of FA-C in binary CTW $+\mathrm{CW}$ composition resulted in the formation of different morphology and extent of reaction products. The crater-like shape presented a partially reacted particle of FA-F. The dense shaped area was characterized by larger amounts of Si, Al and $\mathrm{Na}$, with a Ca content, confirming a pure $\mathrm{N}-\mathrm{A}-\mathrm{S}-\mathrm{H}$ formation. As for binary $\mathrm{RCBW}+\mathrm{CW}, \mathrm{MK}$ in $\mathrm{CTW}+\mathrm{CW}$ binder showed isolated crystalline phases with low cohesiveness. Its EDS analysis explained that the angular crystalline formations are mostly coexisted N-A-S-H and C-(A)-S-H products. Figure 4.60(c) presented also a close morphology and structure as GGBS- based RCBW+CW binder presented in Figure 4.59(b). 

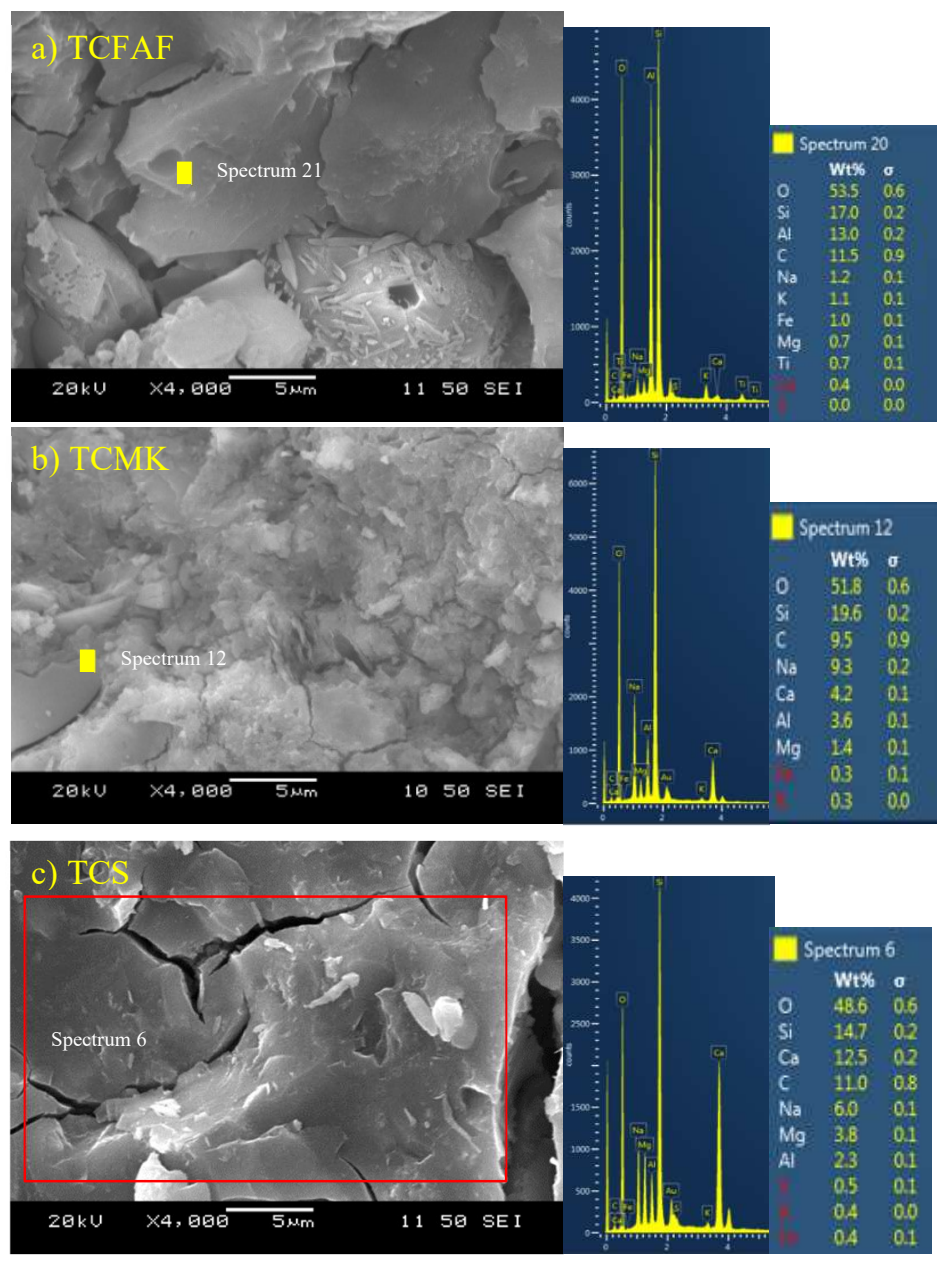

Figure 4. 60 SEM-EDS analysis of binary CTW+CW binder incorporating (a) FA-F, (b) MK, (c) GGBS

Binary RCBW+CTW composition incorporated FA-C (Fig. 4.60(a)) showed a high-density microstructure. Its EDS analysis revealed the formation of intermixed C-A-S-H and N-A-S-H formations, indicating a high dissolution degree of FA-C during the geopolymer reaction. The SEM micrograph of MK-based RCBW+CTW specimen showed a loosely packed microstructure with isolated pores and some crystalline phases. The porous structure and low inter-product connectivity may be the reason for the low compressive strength registered for this composition. Figure 4.60(c) related to the microstructure of GGBS-based RCBW+CTW binder presented different angular and irregularly shaped formations, which may be the unreacted GGBS particles (Chen et al., 2018). This explains that GGBS amount was not dissolved completely, which may have resulted in lower strengths compared to those of binary $\mathrm{RCBW}+\mathrm{CW}$ and $\mathrm{CTW}+\mathrm{CW}$ incorporated GGBS. 

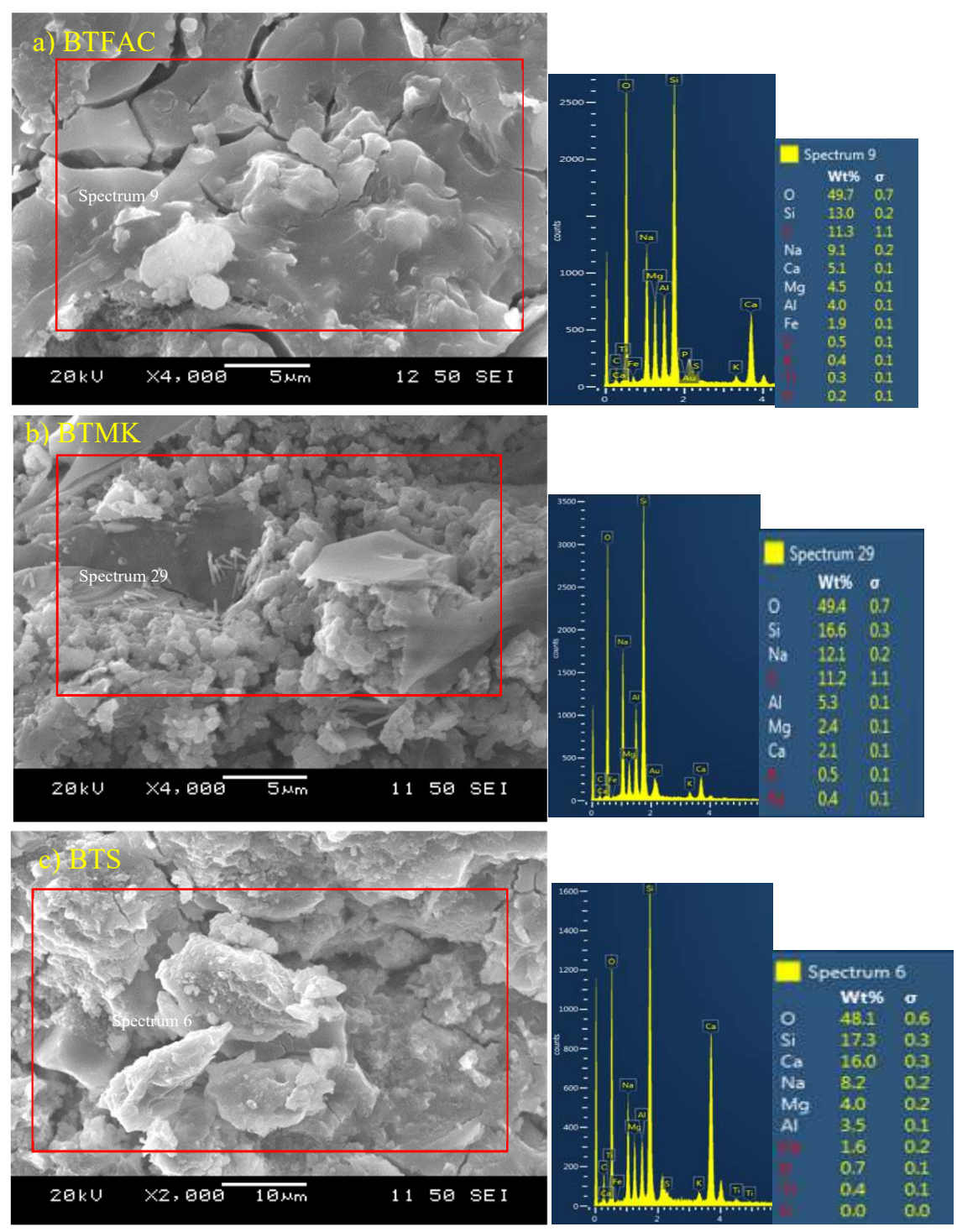

Figure 4. 61 SEM and EDS micrograph of binary CTW with SCMs (a) CTW+FAF (b) CTW+MK and (c) CTW+ Slag 


\section{CHAPTER FIVE}

\section{CONCLUSIONS AND RECOMMENDATIONS}

\subsection{General Conclusions}

This research investigated the reutilization of construction and demolition wastes (CDWs) for the development of green geopolymer binders. CDW materials were classified into three categories of red clay brick waste $(\mathrm{RCBW})$, ceramic tile waste $(\mathrm{CTW})$ and concrete waste $(\mathrm{CW})$. Geopolymer binders were developed incorporating mono-precursor powder of RCBW, CTW and CW, binary-precursors of $\mathrm{RCBW}+\mathrm{CW}, \mathrm{CTW}+\mathrm{CW}$ and $\mathrm{RCBW}+\mathrm{CTW}$, and ternary compositions of $\mathrm{RCBW}+\mathrm{CTW}+\mathrm{CW}$. The main goal was to optimize the mechanical properties of CDW-geopolymers, while using an ambient temperature curing. To achieve this objective, a new method of composition was explored based on targeted ratios of $\mathrm{SiO}_{2} / \mathrm{Al}_{2} \mathrm{O}_{3}, \mathrm{Na}_{2} \mathrm{O} / \mathrm{SiO}_{2}$ and liquid/solid. Flowability and setting time were measured and compressive strengths and microstructural characterizations were assessed at fresh and hardened states of all CDW-based geopolymer combinations. The effect of high-temperature curing on the mechanical strengths of the optimized mixes was also considered by subjecting the optimal strength compositions to a $24 \mathrm{~h}$ initial temperature curing of $50{ }^{\circ} \mathrm{C}, 75^{\circ} \mathrm{C}$ and $100{ }^{\circ} \mathrm{C}$. Furthermore, the effect of incorporating supplementary cementitious materials (SCMs) into the higher strength composition of each CDW-based geopolymer system was studied. Class C fly ash (FA-C), class F fly ash (FA-F), metakaolin (MK) and granulated blast furnace slag (GGBS) were added at 15, 30 and 45\% of each mono, binary and ternary CDW precursor powder. Sodium hydroxide and sodium silicate were used as alkaline reagents (activators) combined at different concentration to achieve targeted chemical and physical ratios of $\mathrm{SiO}_{2} / \mathrm{Al}_{2} \mathrm{O}_{3}$ and $\mathrm{Na}_{2} \mathrm{O} / \mathrm{SiO}_{2}$ and liquid/solid. The following conclusions can be drawn from this study:

- The important relationship between the amount of $\mathrm{SiO}_{2} / \mathrm{Al}_{2} \mathrm{O}_{3}$ and $\mathrm{Na}_{2} \mathrm{O} / \mathrm{SiO}_{2}$ molar ratios and the flowability and setting time of mono, binary and ternary geopolymers was confirmed. However, $\mathrm{Si} / \mathrm{Al}$ molar ratio seemed more influential than $\mathrm{Na} / \mathrm{Si}$ on the flow of the prepared geopolymer pastes. In general, increasing $\mathrm{Na}_{2} \mathrm{O}$ concentration resulted in increased flowability of all the developed compositions. Also, the percentage of precursor powders in binary and ternary systems highly affected the flowability of these mixes. As the percentage of RCBW increased the flow increased, whereas with increased CW content, the flowability decreased. 
- The initial and final setting times of CDW-based geopolymer binders were significantly affected by $\mathrm{SiO}_{2} / \mathrm{Al}_{2} \mathrm{O}_{3}$ and $\mathrm{Na}_{2} \mathrm{O} / \mathrm{SiO}_{2}$ molar ratios. In most cases the setting times increased as the $\mathrm{Si} / \mathrm{Al}$ increased indicating increased content of soluble silica in the mix. The increment of $\mathrm{Na}_{2} \mathrm{O} / \mathrm{SiO}_{2}$ molar ratio and its related $\mathrm{Na}_{2} \mathrm{O}$ concentration resulted in reduced setting times due to the accelerated geopolymerization processes with increased content of $\mathrm{Na}^{+}$cations in the system. It is worth mentioning that all compositions that achieved setting state complied with the maximum setting time required for OPC pastes $(375 \mathrm{~min}$ ) as per ASTM C150/150M specifications. However, a small number of compositions satisfied the initial setting time specified in this standard, which is $45 \mathrm{~min}$.

- The results of mechanical strengths of all the arranged geopolymer binders at room temperature curing were related to the type of CDW precursor powder and also to the combinations of $\mathrm{SiO}_{2} / \mathrm{Al}_{2} \mathrm{O}_{3}, \mathrm{Na}_{2} \mathrm{O} / \mathrm{SiO}_{2}$ and liquid/solid ratios of all mono, binary and ternary geopolymer systems. Although, $\mathrm{Si} / \mathrm{Al}$ ratio was more influential than $\mathrm{Na}_{2} \mathrm{O} / \mathrm{SiO}_{2}$, a balanced amount of $\mathrm{SiO}_{2} / \mathrm{Al}_{2} \mathrm{O}_{3}$ and $\mathrm{Na}_{2} \mathrm{O} / \mathrm{SiO}_{2}$ ratios was important to reach mixes with optimal strengths. The effect of Si/Al did not follow a single trend for all CDW-geopolymer binders. The optimal Si/Al molar ratio varied depending on the type of precursor materials. For example, for mono RCBW the higher compressive strength was achieved at $\mathrm{SiO}_{2} / \mathrm{Al}_{2} \mathrm{O}_{3}$ of 7.1 , while for mono CTW geopolymers it was attained at $\mathrm{SiO}_{2} / \mathrm{Al}_{2} \mathrm{O}_{3}$ of 11.1. The effect of $\mathrm{Na}_{2} \mathrm{O} / \mathrm{SiO}_{2}$ was also dependent on the type of material and its related $\mathrm{Na}_{2} \mathrm{O}$ oxides, and on the concentration of $\mathrm{Si} / \mathrm{Al}$ in the geopolymer network. The presence of $\mathrm{CW}$ in the system required lower $\mathrm{Na}_{2} \mathrm{O} / \mathrm{SiO}_{2}$ concentration to reach greater strengths. For instance, for mono-RCBW geopolymer, the higher compressive strength was achieved at $\mathrm{Na}_{2} \mathrm{O} / \mathrm{SiO}_{2}$ of 0.24 , while for binary RCBW+CW, $\mathrm{Na}_{2} \mathrm{O} / \mathrm{SiO}_{2}$ of 0.18 was the optimal molar ratio. At room temperature curing, maximum compressive strengths attained at 28 days for mono-RCBW, mono-CTW, mono-CW, binary-RCBW+CW, binary$\mathrm{CTW}+\mathrm{CW}$ and binary RCBW+CTW were $31 \mathrm{MPa}, 31.8 \mathrm{MPa}, 20.5 \mathrm{MPa}, 34.6 \mathrm{MPa}, 31.7 \mathrm{MPa}$ and $30 \mathrm{MPa}$ respectively. However, the optimal result achieved was for ternary$\mathrm{RCBW}+\mathrm{CTW}+\mathrm{CW}$ with $20 \% \mathrm{RCBW}, 40 \mathrm{CTW}$ and $40 \% \mathrm{CW}$ prepared at $\mathrm{SiO}_{2} / \mathrm{Al}_{2} \mathrm{O}_{3}$ of 10.2 , $\mathrm{Na}_{2} \mathrm{O} / \mathrm{SiO}_{2}$ of 0.18 and liquid/solid ratio of 0.3 . An interesting compressive strength of $52.2 \mathrm{MPa}$ was determined for this mix at 28 days of ambient temperature curing.

- To study the effect of high temperature curing on the strengths developed at ambient environment curing, the top four optimal strength compositions from mono, binary and ternary CDW geopolymer systems were subjected to a $24 \mathrm{~h}$ initial curing at $50{ }^{\circ} \mathrm{C}, 75{ }^{\circ} \mathrm{C}$ and $100{ }^{\circ} \mathrm{C}$ 
temperature. This resulted in high compressive strength improvements, especially at early curing age. Optimal strengths achieved for both mono-RCBW and mono-CTW geopolymers were at $75^{\circ} \mathrm{C}$ curing temperature, while those of mono- $\mathrm{CW}$ and all binary and ternary-CDW geopolymers were reached at $100^{\circ} \mathrm{C}$. The acceleration of the kinetics of dissolution and polycondensation stages and the geopolymerization process was the reason for high compressive strength increments at early age of elevated temperature curing. A compressive strength of $88.8 \mathrm{MPa}$ was reached when a $24 \mathrm{~h}$ initial curing temperature of $100^{\circ} \mathrm{C}$ was applied for binary-CTW+CW composition, with $40 \% \mathrm{CTW}$ and $60 \% \mathrm{CW}$ and $\mathrm{SiO}_{2} / \mathrm{Al}_{2} \mathrm{O}_{3}, \mathrm{Na}_{2} \mathrm{O} / \mathrm{SiO}_{2}$ and liquid/solid ratios of $12.3,0.18$ and respectively.

- The addition of FA-C, FA-F, MK and GGBS into CDW based geopolymers resulted in significant compressive strength increment with an optimal strength of more than $106 \mathrm{MPa}$. The addition of GGBS resulted in the higher compressive strength gains followed by MK, FA-C and FA- F. Both GBFS and FA-C additions into CDW materials led to the formation of predominant C-(A)-S-H geopolymeric gel. Interestingly, co-existing N-A-S-H and C-(A)-S-H gels were observed in some cases when high amorphous precursor such as RCBW was combined with FA-C or GBFS. The addition of MK and FA-F resulted in clear precipitated N-A-S-H formation.

- Microstructural and mineralogical analysis of CDW and CDW+SCMs based geopolymers showed the presence of different morphologies of diverse crystalline minerals. X-ray diffraction (XRD) investigation of CDW-based geopolymers presented high intensity peaks of muscovite and montmorillonite in all geopolymer binders, which was explained by the unconsumed amounts of these crystalline minerals during the geopolymerization process. Medium intensity peaks of quartz and low intensity peaks of albite, anorthite, pirssonite and mullite were also observed, indicating that these elements were partially or completely consumed during the geopolymerization process. Scanning electron microscopy (SEM) of CDW and CDW+SCMs geopolymers showed various morphological and microstructural formations. Specimens synthesized from CDW+GBFS showed very dense microstructure indicating densely packed geopolymers, in agreement with their very high compressive strengths, whereas the specimens synthesized from CDW+FAF showed porous microstructure, which was the reason for their insignificant compressive strengths. Addition of MK and FA-C resulted in moderately highdensity microstructure systems compared to the compositions prepared with GGBS.

To conclude, interesting mechanical strengths were achieved from the use of various CDW materials as 
the main precursor powders in the geopolymerization processes. Thus, it can be stated that moderate, high and very high compressive strength binders with $100 \%$ green compositions were developed based on mono, binary and ternary-CDW materials, and on curing at ambient and high temperatures of 75 or $100^{\circ} \mathrm{C}$. The addition of different SCMs, and especially GGBS, can significantly increase the mechanical properties of CDW-based binders developed at ambient curing temperature. High compressive strength CDW geopolymers indicate that most types of CDW wastes can be successfully recycled into very useful and sustainable aluminosilicate binders. This represents a unique opportunity for engineers and researchers to develop construction standards and design for the use of CDW-based binders in different structural and non-structural elements.

\subsection{Recommendations for future research}

As Provis and Deventer (2009) mentioned in their book "Geopolymers, structure, processing, properties and industrial applications", "a material that is well characterized but not used in the real world is in effect useless". It is recommended for researchers on geopolymeric materials to work on promoting the commercial use of these products in structural and nonstructural elements. Also, the following recommendations can be considered:

- When sodium and soluble silicate are not fully consumed in the geopolymerization process, it may result in efflorescence, high permeability and water absorption due to the movement of alkali with water (Zheng et al., 2007). These are important durability issues that geopolymeric pastes may face in the construction industry. Therefore, it is important to further research these issues to find solutions.

- Further research on recycled concrete geopolymers is necessary. A thorough investigation of geopolymeric concrete including its compressive strength, durability characteristics, resistance to sulfate and acidic environments, freeze-thaw cycles, water immersion, water absorption and electrical resistivity is recommended.

- Application of geopolymers in ECC and UHPC is also worth studying, as ECC and UHPC have been areas of interest by many researchers across the world.

- A unified code development is necessary for geopolymer to be recognized as a future green construction material, compared to OPC. 


\section{References}

Adak, D., Sarkar, M., \& Mandal, S. (2014). Effect of nano-silica on strength and durability of fly ash based geopolymer mortar. Construction and Building Materials, 70, 453-459. https://doi.org/10.1016/j.conbuildmat.2014.07.093

Ahmari, S., Ren, X., Toufigh, V., \& Zhang, L. (2012). Production of geopolymeric binder from blended waste concrete powder and fly ash. Construction and Building Materials, 35, 718-729. https://doi.org/10.1016/j.conbuildmat.2012.04.044

Allahverdi, A., \& Kani, E. N. (2013). Use of construction and demolition waste (CDW) for alkaliactivated or geopolymer cements. Handbook of Recycled Concrete and Demolition Waste. https://doi.org/10.1533/9780857096906.3.439

Allahverdi, A., \& Najafi Kani, E. (2009). Construction wastes as raw materials for geopolymer binders. International Journal of Civil Engineering, 7(3), 154-160.

Alonso, S., \& Palomo, A. (2001). Calorimetric study of alkaline activation of calcium hydroxidemetakaolin solid mixtures. Cement and Concrete Research, 31(1), 25-30. https://doi.org/10.1016/S0008-8846(00)00435-X

Ariffin, M. A. M., Bhutta, M. A. R., Hussin, M. W., Mohd Tahir, M., \& Aziah, N. (2013). Sulfuric acid resistance of blended ash geopolymer concrete. Construction and Building Materials, 43, 80-86. https://doi.org/10.1016/j.conbuildmat.2013.01.018

Barbosa, V. F. F., Mackenzie, K. J. D., \& Thaumaturgo, C. (2000). Barbosa, Int J Inorg Mat. (2000) Geopol.pdf, 2, 309-317.

Chen, Z., Li, J. S., Zhan, B. J., Sharma, U., \& Poon, C. S. (2018). Compressive strength and microstructural properties of dry-mixed geopolymer pastes synthesized from GGBS and sewage sludge ash. Construction and Building Materials, 182, 597-607. https://doi.org/10.1016/j.conbuildmat.2018.06.159

Criado, M., Fernández-Jiménez, A., \& Palomo, A. (2010). Alkali activation of fly ash. Part III: Effect of curing conditions on reaction and its graphical description. Fuel, 89(11), 3185-3192. 
https://doi.org/10.1016/j.fuel.2010.03.051

Davidovits, J. (1991). Geopolymers - Inorganic polymeric new materials. Journal of Thermal Analysis, 37(8), 1633-1656. https://doi.org/10.1007/BF01912193

Davidovits, J. (2015). Geopolymer Chemistry and Application.

Duan, P., Yan, C., \& Zhou, W. (2017). Compressive strength and microstructure of fly ash based geopolymer blended with silica fume under thermal cycle. Cement and Concrete Composites, 78, 108-119. https://doi.org/10.1016/j.cemconcomp.2017.01.009

Duxson, P., Fernández-Jiménez, A., Provis, J. L., Lukey, G. C., Palomo, A., \& Van Deventer, J. S. J. (2007). Geopolymer technology: The current state of the art. Journal of Materials Science, 42(9), 2917-2933. https://doi.org/10.1007/s10853-006-0637-z

Fernández-Jiménez, A., Palomo, A., \& Criado, M. (2005). Microstructure development of alkaliactivated fly ash cement: A descriptive model. Cement and Concrete Research, 35(6), 1204-1209. https://doi.org/10.1016/j.cemconres.2004.08.021

Fernández-Jiménez, A., Palomo, A., Sobrados, I., \& Sanz, J. (2006). The role played by the reactive alumina content in the alkaline activation of fly ashes. Microporous and Mesoporous Materials, 91(1-3), 111-119. https://doi.org/10.1016/j.micromeso.2005.11.015

Garcia-Lodeiro, I., Palomo, A., \& Fernández-Jiménez, A. (2014). An overview of the chemistry of alkali-activated cement-based binders. Handbook of Alkali-Activated Cements, Mortars and Concretes. Woodhead Publishing Limited. https://doi.org/10.1533/9781782422884.1.19

Garcia-Lodeiro, I., Palomo, A., Fernández-Jiménez, A., \& MacPhee, D. E. (2011). Compatibility studies between N-A-S-H and C-A-S-H gels. Study in the ternary diagram Na2O-CaO-A12O3-SiO 2-H2O. Cement and Concrete Research, 41(9), 923-931.

https://doi.org/10.1016/j.cemconres.2011.05.006

He, J., Zhang, J., Yu, Y., \& Zhang, G. (2012). The strength and microstructure of two geopolymers derived from metakaolin and red mud-fly ash admixture: A comparative study. Construction and Building Materials, 30, 80-91. https://doi.org/10.1016/j.conbuildmat.2011.12.011 
Kani, E. N., \& Allahverdi, A. (2009). Effect of chemical composition on basic engineering properties of inorganic polymeric binder based on natural pozzolan. Ceramics - Silikaty, 53(3), 195-204.

Karthik, A., Sudalaimani, K., \& Vijaya Kumar, C. T. (2017). Investigation on mechanical properties of fly ash-ground granulated blast furnace slag based self curing bio-geopolymer concrete. Construction and Building Materials, 149, 338-349. https://doi.org/10.1016/j.conbuildmat.2017.05.139

Khale, D., \& Chaudhary, R. (2007). Mechanism of geopolymerization and factors influencing its development: A review. Journal of Materials Science, 42(3), 729-746. https://doi.org/10.1007/s10853-006-0401-4

Komnitsas, K., Zaharaki, D., Vlachou, A., Bartzas, G., \& Galetakis, M. (2015). Effect of synthesis parameters on the quality of construction and demolition wastes (CDW) geopolymers. Advanced Powder Technology, 26(2), 368-376. https://doi.org/10.1016/j.apt.2014.11.012

Kouamo, H. T., Elimbi, A., Mbey, J. A., Sabouang, C. J. N., \& Njopwouo, D. (2012). The effect of adding alumina-oxide to metakaolin and volcanic ash on geopolymer products: A comparative study. Construction and Building Materials, 35, 960-969. https://doi.org/10.1016/j.conbuildmat.2012.04.023

Kovalchuk, G., Fernández-Jiménez, A., \& Palomo, A. (2007). Alkali-activated fly ash: Effect of thermal curing conditions on mechanical and microstructural development - Part II. Fuel, 86(3), 315-322. https://doi.org/10.1016/j.fuel.2006.07.010

Lahoti, M., Narang, P., Tan, K. H., \& Yang, E.-H. (2017). Mix design factors and strength prediction of metakaolin-based geopolymer. Ceramics International, 43, 11433-11441. https://doi.org/10.1016/j.ceramint.2017.06.006

Law, D. W., Adam, A. A., Molyneaux, T. K., Patnaikuni, I., \& Wardhono, A. (2014). Long term durability properties of class F fly ash geopolymer concrete. Materials and Structures/Materiaux et Constructions, 48(3), 721-731. https://doi.org/10.1617/s11527-014-0268-9

Lee, N. K., \& Lee, H. K. (2013). Setting and mechanical properties of alkali-activated fly ash/slag concrete manufactured at room temperature. Construction and Building Materials, 47, 1201-1209. 
https://doi.org/10.1016/j.conbuildmat.2013.05.107

Lloyd, R. R., Provis, J. L., \& Van Deventer, J. S. J. (2009). Microscopy and microanalysis of inorganic polymer cements. 1: Remnant fly ash particles. Journal of Materials Science, 44(2), 608-619. https://doi.org/10.1007/s10853-008-3077-0

Najimi, M., Ghafoori, N., \& Sharbaf, M. (2018). Alkali-activated natural pozzolan/slag mortars: A parametric study. Construction and Building Materials, 164, 625-643.

https://doi.org/10.1016/j.conbuildmat.2017.12.222

Nath, P., \& Sarker, P. K. (2014). Effect of GGBFS on setting, workability and early strength properties of fly ash geopolymer concrete cured in ambient condition. Construction and Building Materials, 66, 163-171. https://doi.org/10.1016/j.conbuildmat.2014.05.080

Okoye, F. N., Prakash, S., \& Singh, N. B. (2017). Durability of fly ash based geopolymer concrete in the presence of silica fume. Journal of Cleaner Production, 149, 1062-1067. https://doi.org/10.1016/j.jclepro.2017.02.176

Pacheco-Torgal, F., Castro-Gomes, J., \& Jalali, S. (2008). Alkali-activated binders: A review. Part 1. Historical background, terminology, reaction mechanisms and hydration products. Construction and Building Materials, 22(7), 1305-1314. https://doi.org/10.1016/j.conbuildmat.2007.10.015

Palomo, A., M. Grutzeck, and M. B. (1999). Alkali-activated fly ashes: a cement for the future. Cement and concrete research. Cement and Concrete Research, 29(8):, 1323-1329.

Provis, J. L. (2014). Geopolymers and other alkali activated materials : why, how , and what? Materials and Structures, 11-25. https://doi.org/10.1617/s11527-013-0211-5

Provis, J. L., Lukey, G. C., \& Van Deventer, J. S. J. (2005). Do geopolymers actually contain nanocrystalline zeolites? a reexamination of existing results. Chemistry of Materials, 17(12), 3075-3085. https://doi.org/10.1021/cm050230i

Provis, J., \& van Deventer, J. S. J. (2009). Geopolymers Structure, processing, properties and industrial applications.

Puertas, F., Torres-Carrasco, M., \& Alonso, M. M. (2014). Reuse of urban and industrial waste glass 
as a novel activator for alkali-activated slag cement pastes: A case study. Handbook of AlkaliActivated Cements, Mortars and Concretes. Woodhead Publishing Limited.

https://doi.org/10.1533/9781782422884.1.75

Rakhimova, N. R., \& Rakhimov, R. Z. (2015). Alkali-activated cements and mortars based on blast furnace slag and red clay brick waste. Materials and Design, 85, 324-331. https://doi.org/10.1016/j.matdes.2015.06.182

Reig, L., Tashima, M. M., Borrachero, M. V., Monzó, J., Cheeseman, C. R., \& Payá, J. (2013). Properties and microstructure of alkali-activated red clay brick waste. Construction and Building Materials, 43, 98-106. https://doi.org/10.1016/j.conbuildmat.2013.01.031

Robayo-Salazar, R. A., Rivera, J. F., \& Mejía de Gutiérrez, R. (2017). Alkali-activated building materials made with recycled construction and demolition wastes. Construction and Building Materials, 149, 130-138. https://doi.org/10.1016/j.conbuildmat.2017.05.122

Robayo, R. A., Mulford, A., Munera, J., \& Mejía de Gutiérrez, R. (2016). Alternative cements based on alkali-activated red clay brick waste. Construction and Building Materials, 128, 163-169. https://doi.org/10.1016/j.conbuildmat.2016.10.023

Saha, S., \& Rajasekaran, C. (2017). Enhancement of the properties of fly ash based geopolymer paste by incorporating ground granulated blast furnace slag. Construction and Building Materials, 146, 615-620. https://doi.org/10.1016/j.conbuildmat.2017.04.139

Shi, C., He, F., Fernández-Jiménez, A., Krivenko, P., \& Palomo, A. (2012). Classificaion and Characteristics of Alkali-Activated Cements. Journal of the Chinese Ceramic Society, (October 2015). https://doi.org/CNKI: 11-2310/TQ.20111229.1907.011

Shi, C., Jiménez, A. F., \& Palomo, A. (2011). New cements for the 21st century: The pursuit of an alternative to Portland cement. Cement and Concrete Research, 41(7), 750-763. https://doi.org/10.1016/j.cemconres.2011.03.016

Siyal, A. A., Azizli, K. A., Man, Z., \& Ullah, H. (2016). Effects of Parameters on the Setting Time of Fly Ash Based Geopolymers Using Taguchi Method. Procedia Engineering, 148, 302-307. https://doi.org/10.1016/j.proeng.2016.06.624 
Tuyan, M., Andiç-Çakir, Ö., \& Ramyar, K. (2018). Effect of alkali activator concentration and curing condition on strength and microstructure of waste clay brick powder-based geopolymer.

Composites Part B: Engineering, 135(September 2017), 242-252.

https://doi.org/10.1016/j.compositesb.2017.10.013

Yip, C. (2004). The Role of Calcium in Geopolymerization.

Zaharaki, D., Galetakis, M., \& Komnitsas, K. (2016). Valorization of construction and demolition (C\&D) and industrial wastes through alkali activation. Construction and Building Materials, 121, 686-693. https://doi.org/10.1016/j.conbuildmat.2016.06.051

Zawrah, M. F., Gado, R. A., Feltin, N., Ducourtieux, S., \& Devoille, L. (2016). Recycling and utilization assessment of waste fired clay bricks (Grog) with granulated blast-furnace slag for geopolymer production. Process Safety and Environmental Protection, 103, 237-251.

https://doi.org/10.1016/j.psep.2016.08.001 